\title{
OUTDOOR LEARNING ENVIRONMENTS
}

Elizabeth Farin

Department of City \& Regional Planning

California Polytechnic State University, San Luis Obispo

June 2020 


\section{APPROVAL PAGE}

TITLE: Outdoor Learning Environments

AUTHOR: Elizabeth Farin

DATE SUBMITTED: June 12, 2020

Amir Hajrasouliha, Ph.D.

Signature

Date

Senior Project Advisor

Michael Boswell, Ph.D., ACIP

Signature

Date

Department Head 


\section{ACKNOWLEDGMENTS}

I would like to express my gratitude to my advisor, Dr. Amir Hajrasouliha for the continuous support throughout my senior research and design project.

His insightful guidance and consistent direction helped me create a project of which I am very proud.

Dr. Hajrasouliha, thank you for not only being my advisor but also for allowing me to discover my passion for campus design. This project would not have been successful without your experience, expertise, commitment, valuable feedback, and enthusiasm throughout this process. I could not have imagined having a better advisor and mentor for my senior project.

To my friends and family, thank you for constantly encouraging and motivating me to perform at my best. I am truly grateful for your support both in times of stress and in joyous moments of laughter and success. During these past 6 months I was able to learn and grow as a designer, more than I ever would have imagined.

I'm delighted to share this project with you.

Elizabeth Farin 


\section{TABLE OF CONTENTS}

1 INTRODUCTION pg 5

Project Overview

2 THE 'WHY' pg 6

Benefits of Outdoor Learning

The 'Why Not' - Drawbacks
3 THE 'WHAT' pg 16

Factors

Typologies - Types of Outdoor Learning Environments

Figures \& Diagrams
4 THE 'HOW' pg 25

Case Study

Activities

Design Principles

Design Guidelines

\section{DESIGN CASES pg 57}

3D Visualization

Site Plans

Sections

\section{CONCLUSION pg 89}

Final Remarks

\section{REFERENCES pg 90}

Resource Bibliography 


\section{INTRODUCTION}

Project Overview

Outdoor Learning Environments have the ability to enhance the campus socially, educationally, psychologically, and environmentally. They can provide a defined, outdoor environment that students feel comfortable using and learning in. Outdoor Learning Environments create the space and opportunity to bring individuals and professors together to work on an interdisciplinary project. These spaces provide an area for students to relax and rewind during a stressful day. Outdoor Learning Environments have an enormous potential to achieve University-wide social and learning objectives.

This project examines the potential for Outdoor Learning on University campuses. It explores the benefits and drawbacks of Outdoor Learning Environments, considers two factors of Outdoor Learning Environments, and describes four typologies of Outdoor Learning Environments. This project introduces two case studies for each typology and creates design principles and guidelines based on the typologies and case studies. Existing potential Outdoor Learning Environments at Cal Poly are mapped to provide examples for each of the four typologies. This project identifies methods to enhance each of these mapped spaces. Various site plans, sections, and perspectives have been created to visualize each of the spaces.

Interestingly, the COVID-19 pandemic occurred during the completion of this senior project, thus making this project even more apropos. During the COVID-19 pandemic, students are isolated indoors and long for the days when groups of peers will be able to meet together and attend in-person classes at a university campus. Although this dream might not be occurring in the near future, we should consider solutions to achieve the goal of reuniting students and faculty on campus. Outdoor Learning Environments are an extremely viable solution to the introduction of in-person classes on university campuses during this pandemic. 


\section{THE 'WHY'}

\section{BENEFITS OF OUTDOOR LEARNING}

\section{Introduction}

Outdoor learning or outdoor education can be defined as organized learning taking place outdoors, helping people of all ages, backgrounds, and abilities to reflect and learn while being surrounded by a natural environment. In general, outdoor spaces on a university campus are flexible, providing an opportunity to play sports, meet with friends, practice yoga, or a place to relax in between classes. These spaces are adaptable and have the opportunity for various educational uses such as an individual study space, a defined space to complete online learning, meeting with a small group for a project, or a space to gather as a class. While it is traditional for a classroom to have four walls and multiple rows of desks, that doesn't mean it is mandatory to learn or study in this environment. Many studies encourage the use of outdoor spaces specifically as learning environments and are using these environments to redefine what it means to be a 'classroom'.

Rethinking the way we define a learning environment is predominantly important in higher education institutions because of the constant need for on-campus study spaces outside of the formal classrooms. Additionally universities consider the financial implications to physically construct buildings for students to learn and study in, the visitor's perspectives on the overall appeal of the campus, and the promotion of social interactions on a university campus. When using educational outdoor spaces, positive memories and lasting benefits can occur, including impacting academic achievement, learning new skills, personal and social development, career and professional development, and positive wellbeing and mental health (Institute for Outdoor Learning, 2018). There are many benefits associated with the use of outdoor learning environments and, as a result, this new way of learning has become increasingly popular.

Ellen Kollie outlines the reasons for the sudden interest in outdoor learning spaces in her article 'How to Design Outdoor Learning Environments'. She explains three reasons, the first reason being sustainability or the use of sustainable materials to construct these smaller, more defined outdoor environments instead of constructing an entire building. Traditional classroom structures use more energy and electricity and are much less sustainable than the naturally lit, modest outdoor learning spaces. The second reason is financial implications as educational facilities have become increasing expensive to build. Lastly, the third reason is to enhance campus aesthetic 
and increase initial attraction to a university by prospective students (Kollie, 2015). Improving the overall look and feel of the campus will increase the number of prospective students enjoying their time visiting the university and possibly committing to spend four or more years at that place they will call 'home'.

This section will highlight the 'Why' of why consider outdoor learning environments. Building upon Ellen Kollie's three reasons for the increased popularity of outdoor learning environments, l've categorized the benefits of these spaces into 6 sections: Social Aspects, Active Learning in Nature, Interdisciplinary Learning, Restorative Benefits, Appealing to Prospective Students, and Environmental and Financial Sustainability.

\section{Social Aspects}

Outdoor learning spaces increase the possibility of formal and informal social interaction among students and instructors. They serve as a fluid social space for students and professors to converse when walking to class or meet in a plaza for a quick discussion. "Public spaces create a 'self-organizing public service' by providing a shared resource that aims to facilitate the generation of memories and experiences" (Worpole, 2007). An outdoor public space has the opportunity to serve as the "in between space of the college experience" and has the ability to be defined by the students. Public spaces are the "social glue" needed in urban centers (Worpole, 2007).

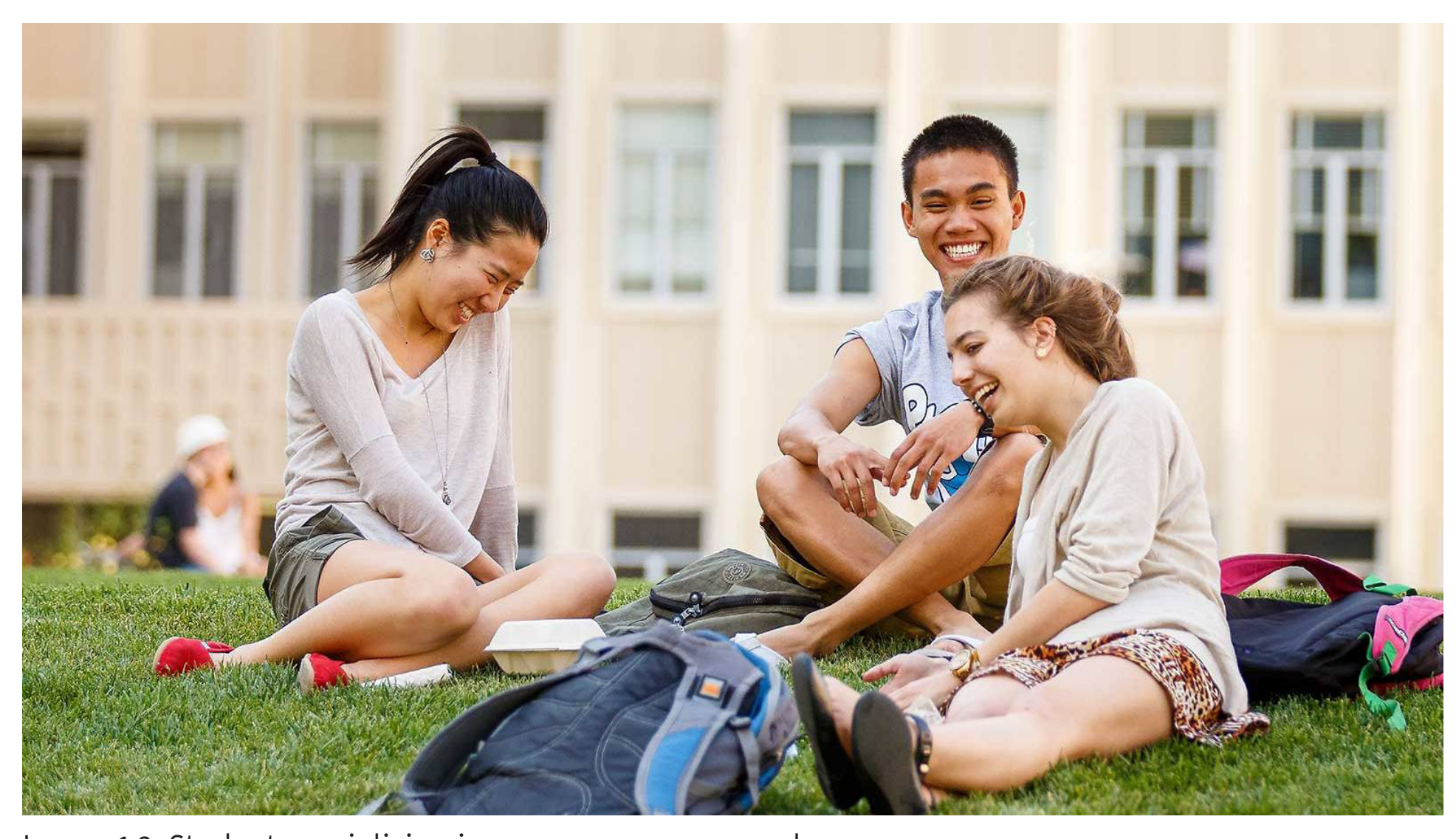

Image 1.0: Students socializing in a group on a campus lawn.

Kollie argues that outdoor learning spaces should be defined as flexible use and these uses should be led directly by the students themselves (Kollie, 2015). They should be both adaptable and foster communication, as Sucher mentions that this is the primary purpose of designing a public space. Dexter Lawn, located at California Polytechnic State University, San Luis obispo, serves as a perfect example of an adaptable open space. Dexter is an open lawn with a few shade trees and walkways surrounding, but also dividing the space. Groups gather on the lawn, clubs hold events, students meet their friends for a quick game of Frisbee, and study briefly in between classes. This space serves many uses directly defined by students. When 
deserted, this space is simply an open lawn, but when populated, the students define the use and, as a result, create a social community.

Rouse, author of College Struggles with Social Space, concluded that social spaces are missing from campus design. While the definition of social spaces varies, the administrators at Harvard recognize that students have a "broad range of needs in terms of social spaces" and the current University Union type spaces are falling short (Rouse, 2011). Limiting the physical space students feel comfortable socializing in limits the college experience (Rouse, 2011). Outdoor learning environments on college campuses would allow students to gain the essential skill of collaboration and show “creativity in education” (Goertz, 2015). Implementing Goertz's 21st Century Classroom principles would not only improve the existing social spaces, allowing for additional collaboration, it would also improve the college experience.

One of Goertz's 21st Century Classroom principles, 'people attract people', is important when designing an adaptable, collaborative outdoor learning environment. Creating a defined space for individuals to socialize in and feel comfortable doing so is imperative. William Whyte describes the term 'Triangulation' in Social Life of Small Urban Spaces as, "the process by which some external stimulus provides a common link between people and prompts socialization between strangers, as if they were not”. The stimulus, for example, can could be a physical object. Applying triangulation in the design of an outdoor learning environment is important when defining the space as a potential collaborative or social space and determining the use.

Redefining the classroom as a whole must address the needs of the students, professors, and campus visitors. Flexible design follows the idea that "people make places more than places make people" (Banning and Strange, 2001). These spaces must meet the needs of the general public and university community to succeed but also remain versatile, adapting to a variety of uses. The public must assess the function and use of that space, officially defining the gathering space as a collaborative space used for social interaction.

\section{Active Learning in Nature}

Why stop at the physical walls of an education building when you can expand that educational space into outdoor environments? Campus design should promote collaboration between people and the environment such as interactions of students with "people made objects and artifacts of material culture"' (Banning and Strange, 2001). Classrooms are beginning to bleed out into the natural spaces around them, "effectively bringing the classroom outdoors, forming a holistic learning experience" (Banning and Strange, 2001). These new outdoor spaces are more active and create a greater opportunity to achieve the purpose of learning for higher education (Banning and Strange, 2001). 


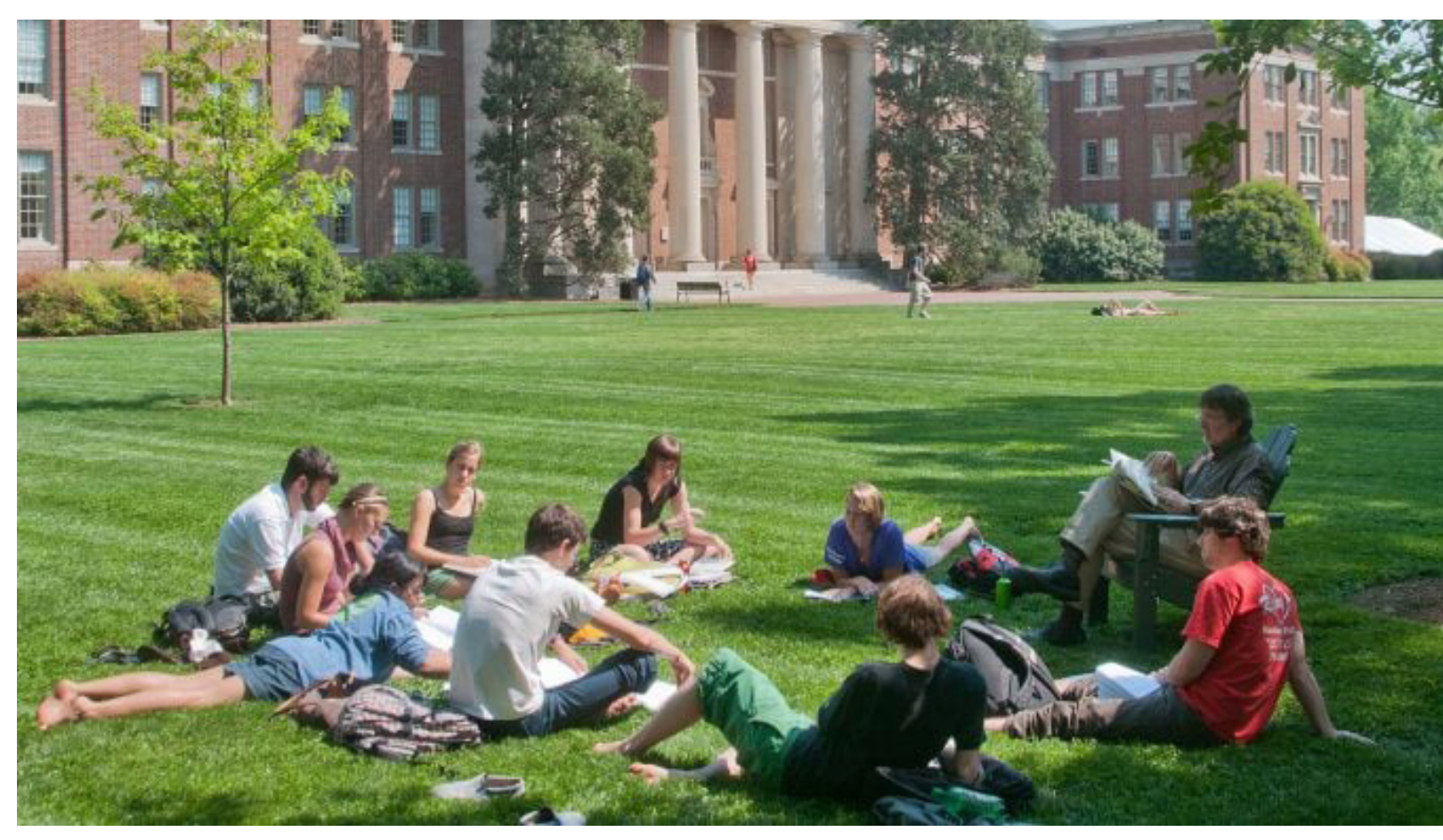

Image 1.1: Students learning in a group on a campus lawn.

Students respond and relate to memories of a specific place, these memories in turn nourish their intellectual growth (Gaines, 1991). Gaines' 21st Century Classroom proposal highlights qualities of these new learning environments, including fewer memorization, more brainstorming, encouraging new perspectives, increasing student choice, improving creative writing, and allowing room for reflection. These qualities should be considered when designing outdoor environments specifically used for learning. The 21st Century Classroom proposal reflects ideas of Banning and Strange's 'Designing for Learning', with the addition of the accessibility to technology and the opportunity to participate in co-curricular activities. Banning and Strange believe this is a pivotal factor of achieving the educational purpose in a well-designed space. When achieved, the space is truly bringing "creativity in education” (Goertz, 2015).
Banning and Strange argue that using alternative learning environments, such as the outdoors, helps students learn to adapt in their environment much like they would in any nonacademic setting (Wilson, page 7, 2018). It's important that the design of these outdoor learning environments offer "features that will challenge students toward active learning, growth, and development" (Banning and Strange, 2001). These unconventional spaces offer restorative effects while creating a collaborative space for students to learn and grow academically.

\section{Interdisciplinary Learning}

As these outdoor learning spaces become a common place for social interaction and an active learning space, students from various disciplines will have the ability to collaborate and learn from each other. Students will begin to be exposed to new disciplines and learning styles through social interaction.

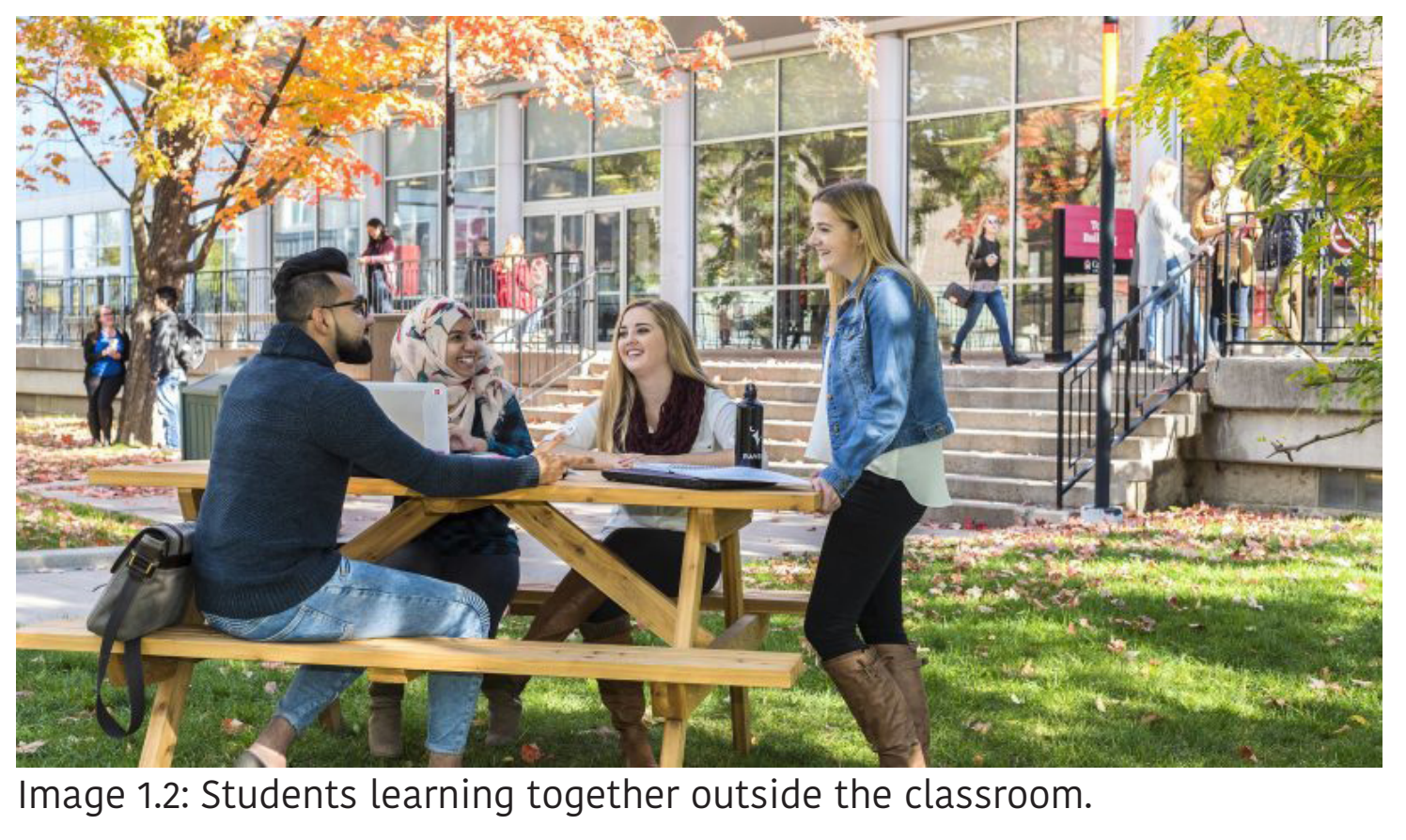


An outdoor educational environment has the ability serve as a space for students to not only enhance their own experience through their current disciplinary track, but also allows undergraduate students to discover other majors or colleges within the university, potentially expanding their interests and knowledge. Expanding the student's academic and social circles promotes the overall engagement of the campus community, in turn increasing the potential for interdisciplinary learning. These outdoor learning spaces can serve as interdisciplinary educational spaces for group studying, class projects, and informal interdisciplinary learning to occur, benefiting both the students and professors.

Common spaces on campus can serve many functions, one function being a place for campus activities to occur or a space to hold outdoor exhibitions. The American Planning Association considers great public spaces to "promote social activities and human contact". These spaces must be "safe, welcoming, and accommodating to all potential users as well as having a visually interesting design and amenities" (APA, 2019). Outdoor learning spaces do not have to be exclusively used for educational learning, they can also serve as a community space that promotes campus activities and human contact across the entire campus. Many university campuses have one or sometimes a couple student union spaces that hold campus events and activities, serving as a social hub. The implementation of the outdoor learning environments can serve as a second, third, or fourth smaller social hub for similar activities. Creating a smaller, more defined space for events and activities to occur allows the university to have multiple centers for collaboration, extending the boundaries of social interaction.

\section{Restorative Benefits}

Designing outdoor learning spaces in conjunction with elements of the environment such as trees, water features, or green vegetation, establishes trust and provides restorative benefits (Whyte, 2001). Being surrounded by these natural elements allows the users to feel at ease, reducing their mental fatigue. Implementing overlapping foliage, green vegetation, and comfortable seating helps establish an environment that is both compelling for students to study and one that is a sheltered, restful space to accommodate spending long periods of time.

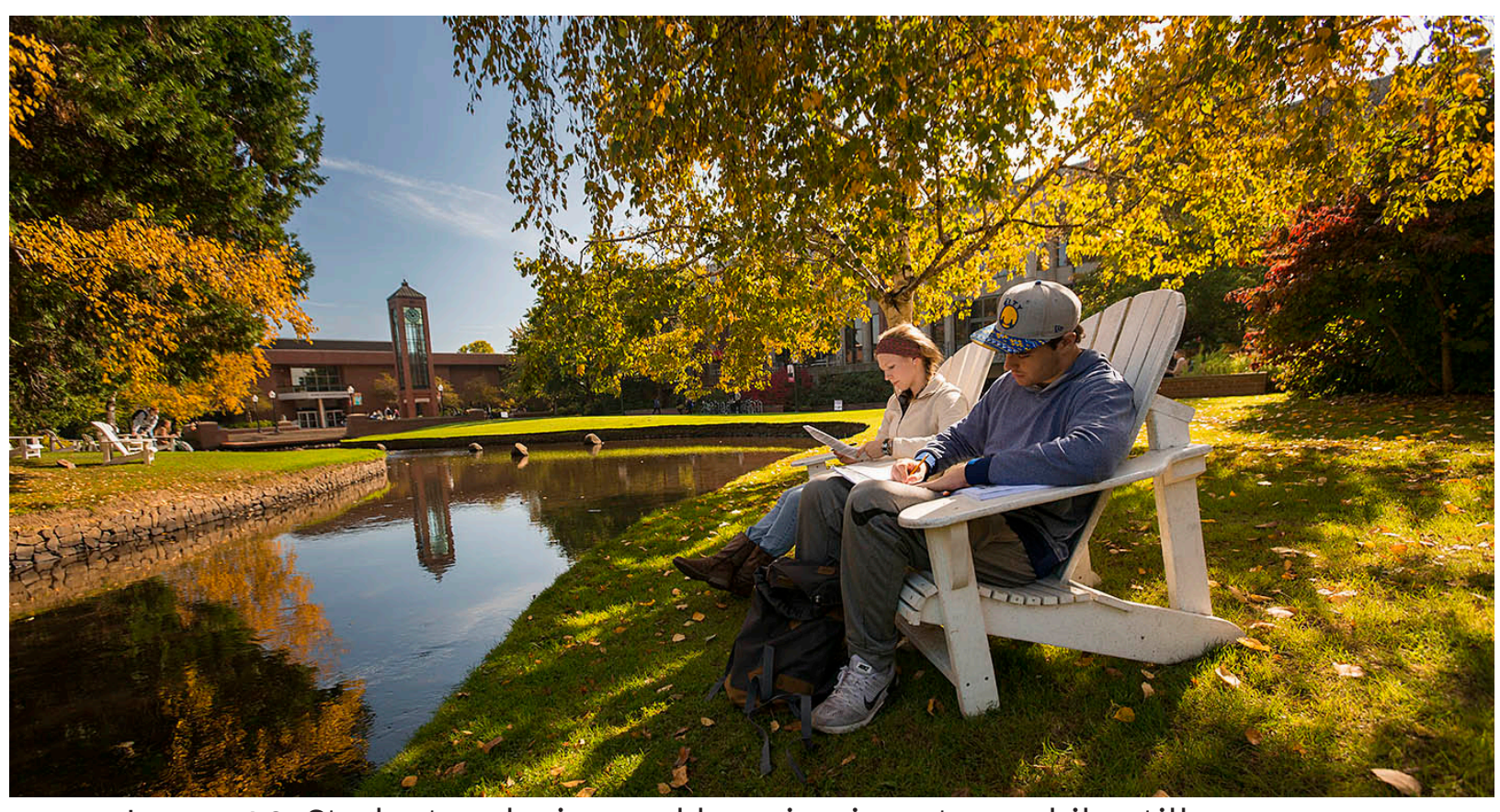

Image 1.3: Students relaxing and learning in nature while still on campus. 
Spending time outdoors for recreational and academic purposes can reduce stress, increase concentration, and promote a healthy and active lifestyle (Goertz, 2015). Similarly, outdoor learning has comparable health and well-being benefits. New, immersive outdoor learning environments allows students to adapt to their surroundings, relax, and focus on the task at hand. Not only are outdoor learning environments improving the student experience, they are also expanding the way teachers teach. Banning and Strange argue that the "physical design of a space is what ultimately creates a successful learning environment”. A successful space can be defined as spaces that: 1) have features within the physical environment that encourage learning and development; and 2) features that promote the acquisition of skills that in turn foster learning and development" (Banning and Strange, 2001). Creating a well-designed space is imperative to increasing student's potential to learn and grow within an outdoor environment.

Speake highlights major factors, for example, vegetation and trees, as a way to help "contextualize the campus as relaxing, protective, and healthy". Speake argues that in order to engage with people around you and be fully focused, it is important to be surrounded by naturally green spaces. For instance, implementing green vegetation, trees, and neutral colors within the design of the defined space in order to mimic being fully surrounded by a naturally green, open space. This increases the potential of establishing a continuous connection to the outdoor learning environment spaces, in turn allowing users to feel comfortable and relaxed while interacting with an outdoor learning environment.

\section{Appealing to Prospective Students}

Creating a distinct space or placemaker is crucial when designing an outdoor educational space. The design of this space needs to form a lasting connection between the students or visitor and the physical environment. This connection "builds loyalty among students, expanding on the restorative qualities of incorporating green spaces through the fabric of the campus" (Speake, 2013). Additionally, it is important that this space is unique, significant, and memorable in order for students and visitors to associate this living, learning environment with an attractive and lively campus. In doing so, prospective students, and their parents, will be impressed with the university, notice these progressive transition away from traditional learning environments, and hopefully establish an emotional connection to the university's campus as a whole.

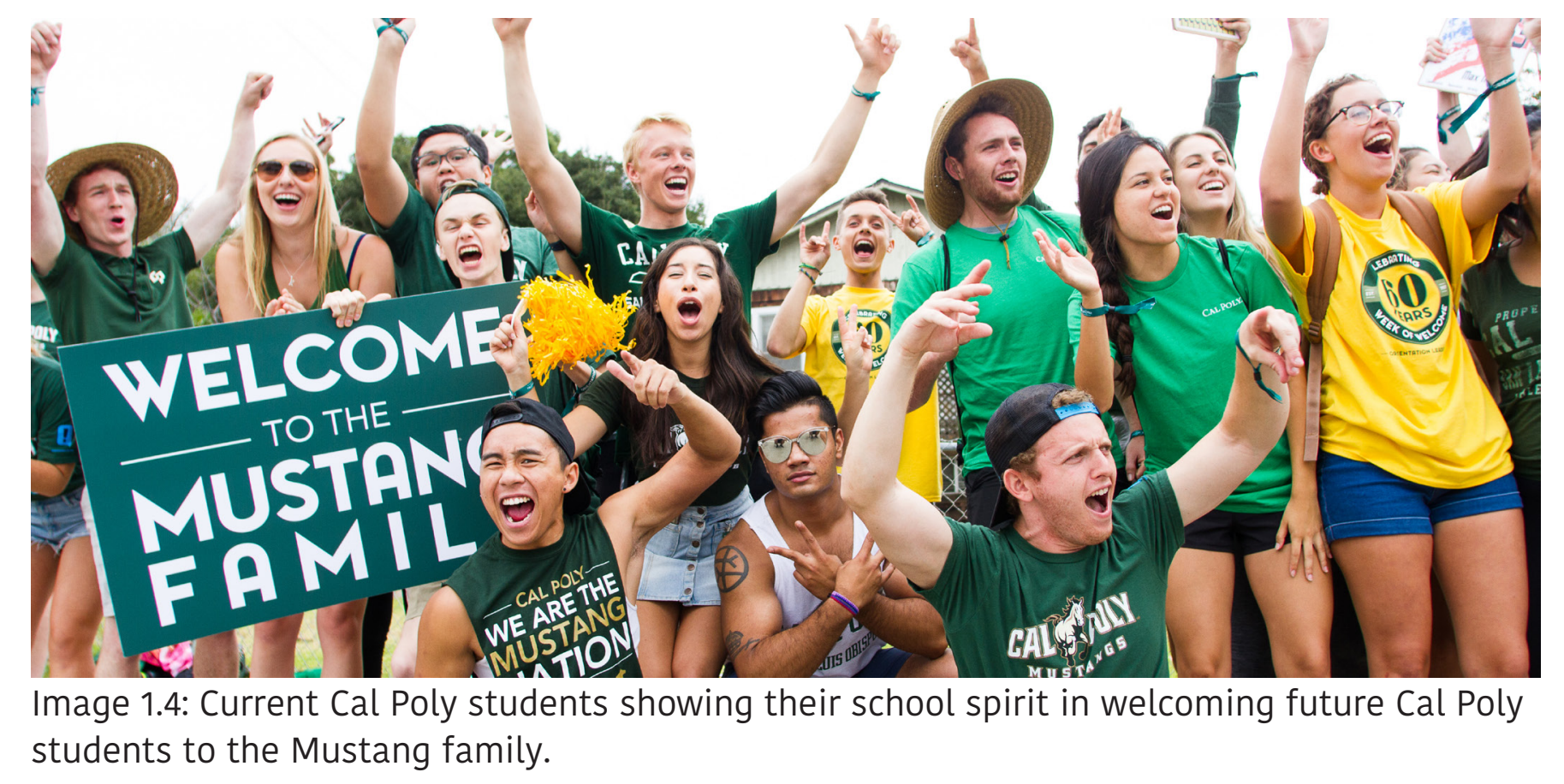


Going away to college is a huge step for high school seniors. They hope to gain independence, study what they are truly interested in, and, as a result, grow as a person. Prospective students visit university and college campuses to confidently determine if that place is the right fit for them to spend the next four years. According to the Carnegie Foundation, " $60 \%$ of prospective students consider visual environment as an important factor when choosing a college" (Gaines, 1991). The built environment on a college campus is extremely important when determining if that college is the right fit. Outdoor learning environments have the opportunity to create an environment that is aesthetically pleasing, present an additional placemaking space, and offers a connection to nature or includes "outdoor value" (Gaines, 1991).

Fostering that emotional connection to a new space is difficult to complete when in the design phases of a project. The designer of an outdoor learning space needs to consider the needs and desires of a prospective student in order to design a space that is appealing both to the students and professors of various ages and abilities. The space needs to durable and designed to be frequently used. Students are attracted to outdoor spaces because these spaces allow for freedom of uses (Kollie, 2015). Giving students the freedom to make that choice allows prospective students to imagine themselves using that space for years to come. Outdoor learning environments will benefit both the students, professors, and visitors frequently using or enjoying these spaces, as well as the university as these space have the potential to appeal to prospective students.

\section{Environmental and Financial Sustainability}

In addition to social, educational, and aesthetic benefits, there are sustainable benefits, both environmentally and financially, associated with the implementation of outdoor learning spaces. These spaces are less expensive to build and have a lesser impact on the natural environment when compared to the construction of a traditional classroom on a university campus. The overall design, use of materials, construction, and implementation of the outdoor learning environments considers the financial sustainability of an institution as well as the environmental effects.

Environmentally sustainable benefits can occur when considering the use of eco-revelatory design or "a design strategy that attempts to enhance site ecosystems as well as engage users by revealing ecological and cultural phenomena, processes and relationships affecting a site" (Kollie, 2015). Kollie describes this type of design as "a partnership between nature and people”. Applying these principles to outdoor learning environments will link social aspects and benefits of outdoor learning environments with the restorative benefits of nature. Additionally, these ecosystems "reveal ecological processes, thus engaging users in the site" (Kollie, 2015). Establishing this connection between the user and the natural environment is imperative when attempting to create a collaborative, frequently used space. 


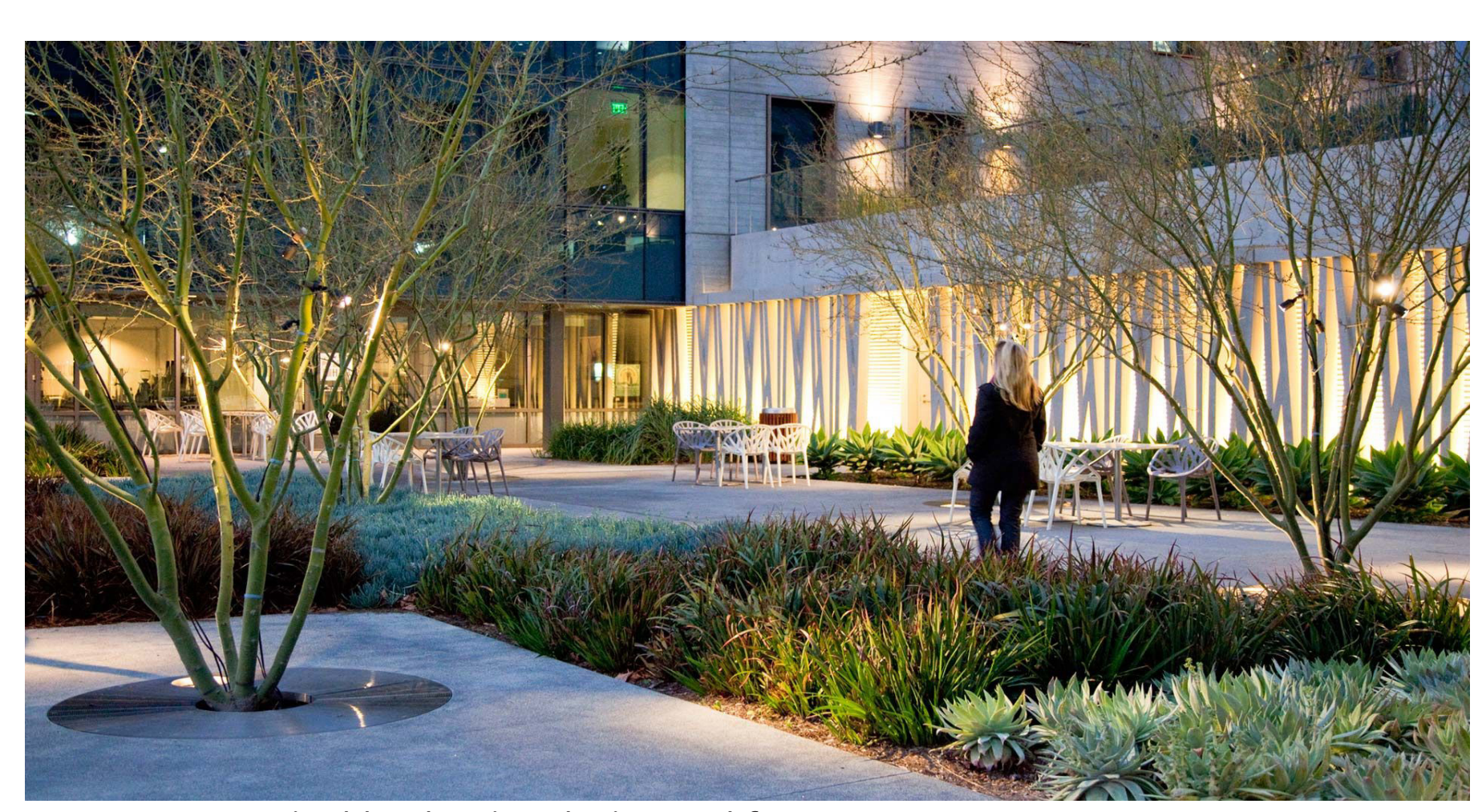

Image 1.5: Sustainable planting design and features on campus.

Similar to Kollie, Speake would agree with using green vegetation as a way of connecting the individual to the built environment while using sustainable materials in the construction. Applying this idea, while implementing eco-revelatory design principles, will engage students and establish a lasting connection between the user and the natural environment. As a result, students will be able to spend an increased amount of time occupying the outdoor learning environment. When implementing environmental and financial sustainable practices, these outdoor learning structures will be long-lasting and ecologically friendly. 


\section{THE 'WHY NOT'}

\section{DRAWBACKS OF OUTDOOR LEARNING}

\section{Unpredictability of Climate}

When studying, speaking with a group, or attending a small class outside, the weather can be unpredictable. The weather can change throughout the day and within a moment's notice. Wind, rain, sun, and shade, can inhibit your ability to learn and effect your desire to stay in that place to fully complete your work. When studying or working with a group the space needs to not only be protected from the weather elements, but also the structure needs to adapt to sudden changes such as strong winds or heavy rain. The design of the outdoor learning environments needs to minimize the weather-related effects that the user or group learning outdoors might experience.

\section{Distractions}

When studying outdoors, there can be many distractions such as sounds of students passing by or rustling of the trees nearby. Changes in temperature or wind speed can distract the user or cause papers to fly. Attempting to learn in a space that is frequently traveled by walkers or groups of people speaking loudly as they walk by can be distracting while typing on a computer or trying to study for a test. Designing the outdoor learning environments in a way that both protects the user and allows the user to feel comfortable while learning is important when attempting to reduce common distractions such as noises and frequent travelers passing by. The user needs to be protected but not secluded, able to interact with the outdoor environment while staying focused. It is important to create a design that allows for minimal distractions while also allowing the user to feel secure and comfortable working and learning in that environment.

\section{Difficult to Schedule Spaces}

Typically indoor, traditional classrooms are scheduled using a computerized system with the list of meetings or classes is listed next to the door of the room to reduce any scheduling conflicts and informing people passing by who is occupying the space. With the outdoor learning environment or structure being in nature and existing as both a formal and informal space, it might be difficult to schedule the environment to be used by a larger group or challenging to inform students currently occupying the space that a group has "booked" the space for a certain time of day. It will be important to consider this when designing the typology of spaces. Possibly including both a space that can be feely used by students without scheduling an appointment and a space specifically used to hold larger groups or a few 
smaller groups of students that schedule their time in advance. While the outdoor, flexible space should be free to all users, the difficultly with class or event scheduling should be considered.

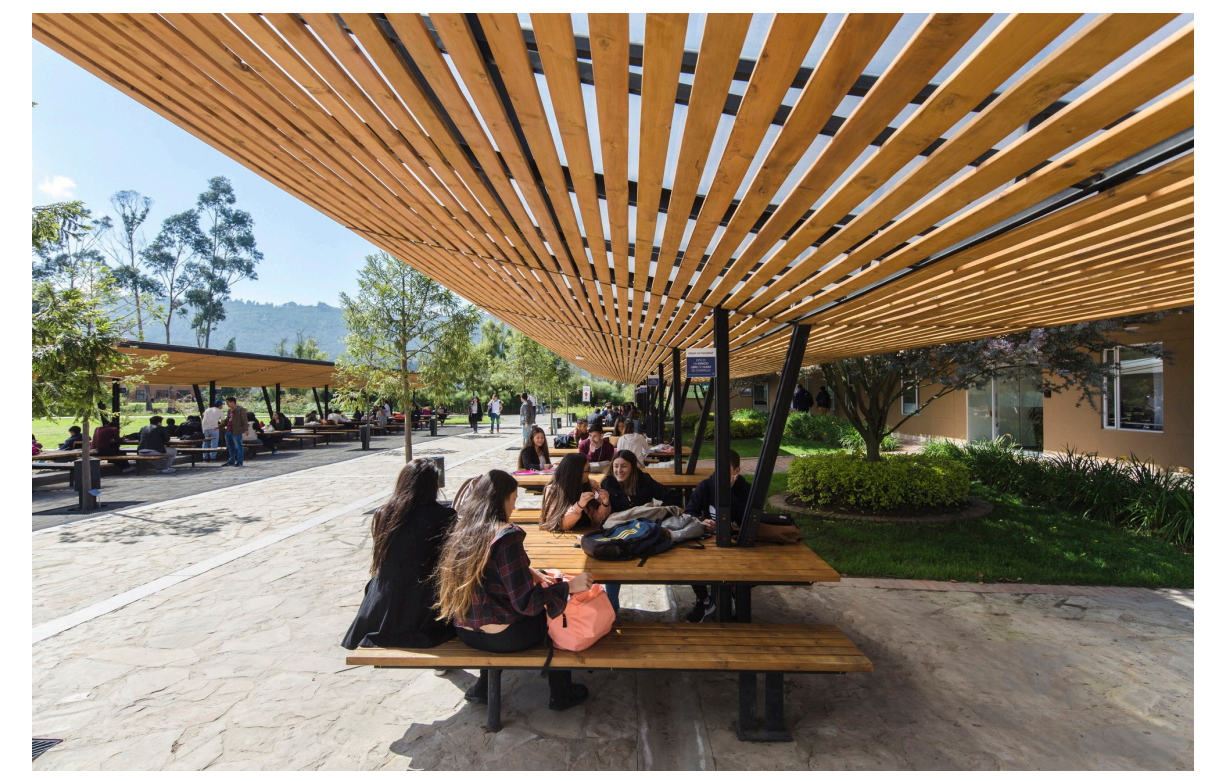

Image 1.6: Students gathering under a shade structure on campus. Appropriate Locations on Campus

Locating exactly where these spaces should be placed will be a challenge and possibly be a limitation. The outdoor learning environment needs to foster communication and be used frequently. While the space needs to be a place that will encourage frequent use, it can't be placed in a space that is traveled too frequently or the user will be distracted often, leading to students staying for short periods of time. Positioning the structure and locating the structure in a way that is both inviting and protected is a challenge. Serving as a second social hub, the space needs to be in an area of campus that fosters collaboration and social interaction but not placed in a location that is too secluded from common paths of pedestrian circulation. Placing these structures near academic buildings, visible distance from a commonly used path, or near on-campus residential communities would allow for maximum use of the outdoor learning environment.

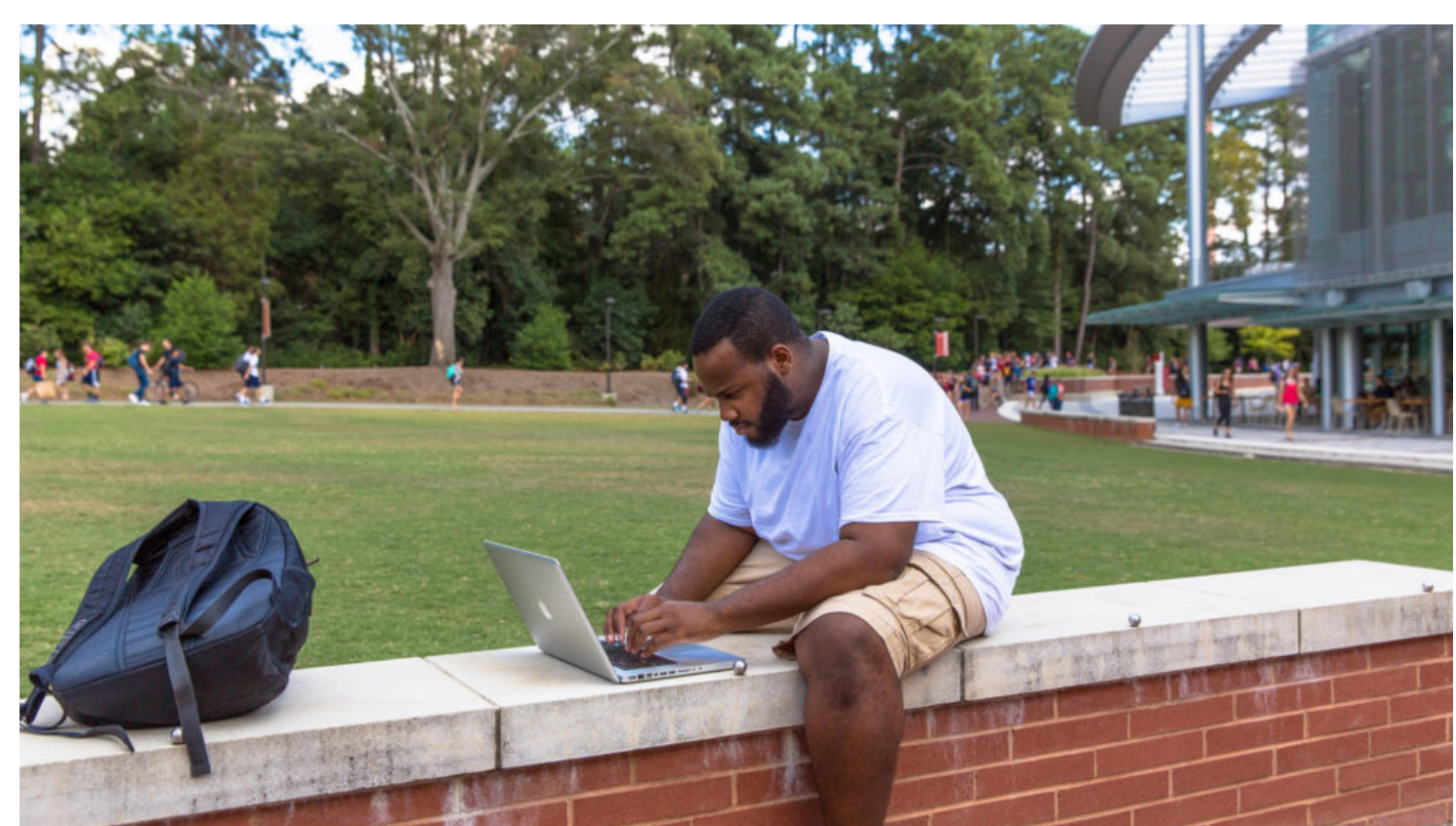

Image 1.7: A student attempting to study outside the Student Union. 


\section{THE 'WHAT'}

\section{DEFINING FACTORS \& TYPOLOGIES OF OUTDOOR LEARNING}

\section{Factors}

These typologies are defined in terms of two specific factors:
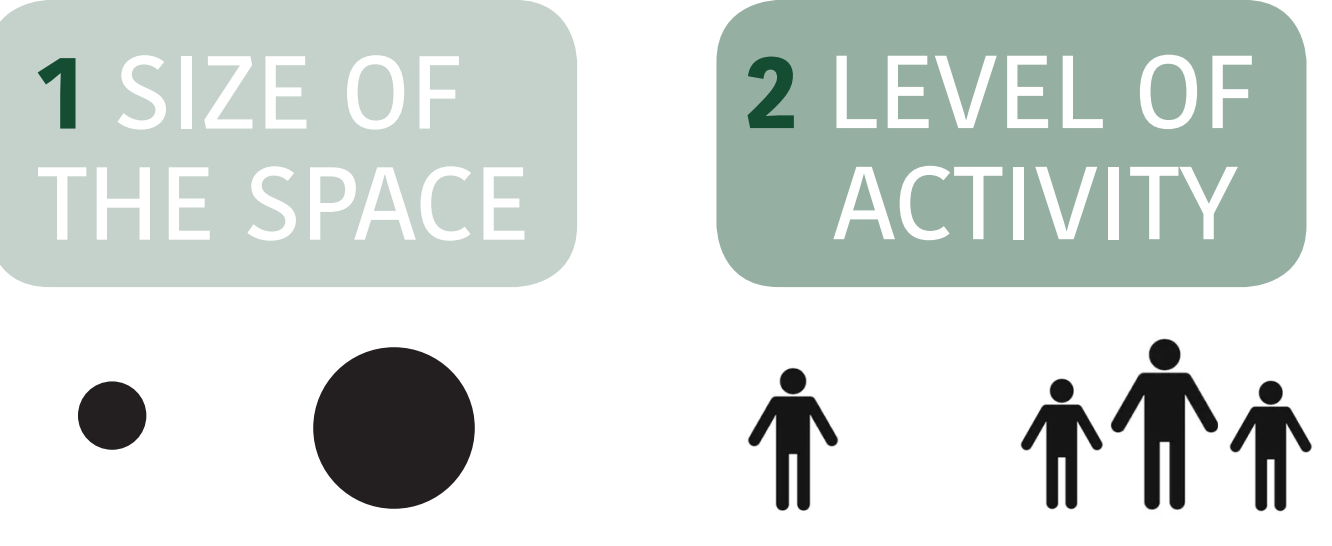

The Size of the outdoor learning environment is divided into large and small spaces. The large spaces could be a large, single space or a collection of smaller or medium sized structures, acting as one space when placed adjacent to one another. Small spaces are scaled down and accommodate for fewer numbers of people occupying the space. The second factor, Level of Activity, is describing if the outdoor learning environment is off or on the main, frequently traveled pathway. A space could be on the main pathway and near buildings or on the main pathway and not surrounded by buildings, allowing for a variety of uses and types. Being surrounded by buildings or forecourts can provide a sense of comfort and security.
Natural elements are added to each outdoor learning environment, whether the space is located in an active section of campus or not or if the space is small or large. These natural element additions can create a restorative space that has the ability to connect the user to the learning space. Additionally, these elements can break up the larger, more active spaces into a more pleasant study space. Therefore, making each learning space more comfortable and calming, and less distracting.

\begin{tabular}{|c|l|c|c|c|c|}
\cline { 3 - 6 } \multicolumn{2}{c|}{} & \multicolumn{4}{c|}{ FACTORS } \\
\hline \multicolumn{2}{|c|}{ TYPOLOGY } & \multicolumn{2}{c|}{ SIZE } & \multicolumn{2}{c|}{$\begin{array}{c}\text { LEVEL OF } \\
\text { ACTIVITY }\end{array}$} \\
\hline 1 & & LARGE & SMALL & ON & OFF \\
\hline 2 & Large Discovered & $X$ & & $X$ & \\
\hline 3 & Small Discovered & $X$ & & & $X$ \\
\hline 4 & Small Active & & $X$ & $X$ & \\
\hline
\end{tabular}

Table 1.0: Factors \& Typology 


\section{Typology}

The four space types, or typologies, are: Large Active, Large Discovered,

Small Discovered, and Small Active. These four learning space types can be placed on a quadrant diagram that accounts for both learning space types and factors.

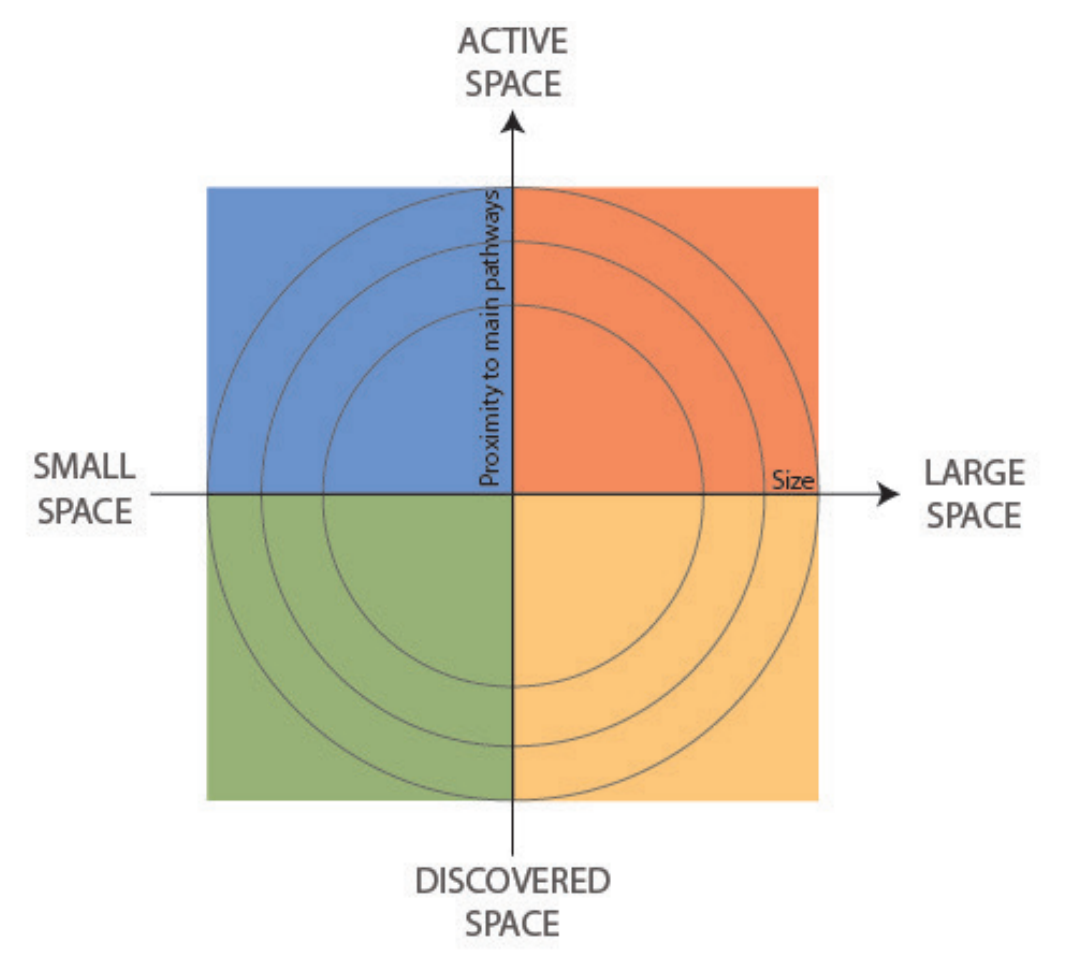

TYPOLOGY LEGEND

Large Active

Large Discovered

Small Discovered

Small Active

Diagram 1.0: Typology Diagram

As the scale moves from left to right, the size of the space increases. As the scale moved from the lowest point to the highest point, the level of activity increases. For example, the Large Active space is located at the top right of the quadrant diagram, meaning this learning space is a large space that is located near a section of campus that has a high level of activity. This quadrant diagram is used to identify and categorize potential, current, and future outdoor learning environments. Potential and existing outdoor learning environments on Cal Poly campuses are categorized and mapped using this quadrant diagram, shown below.

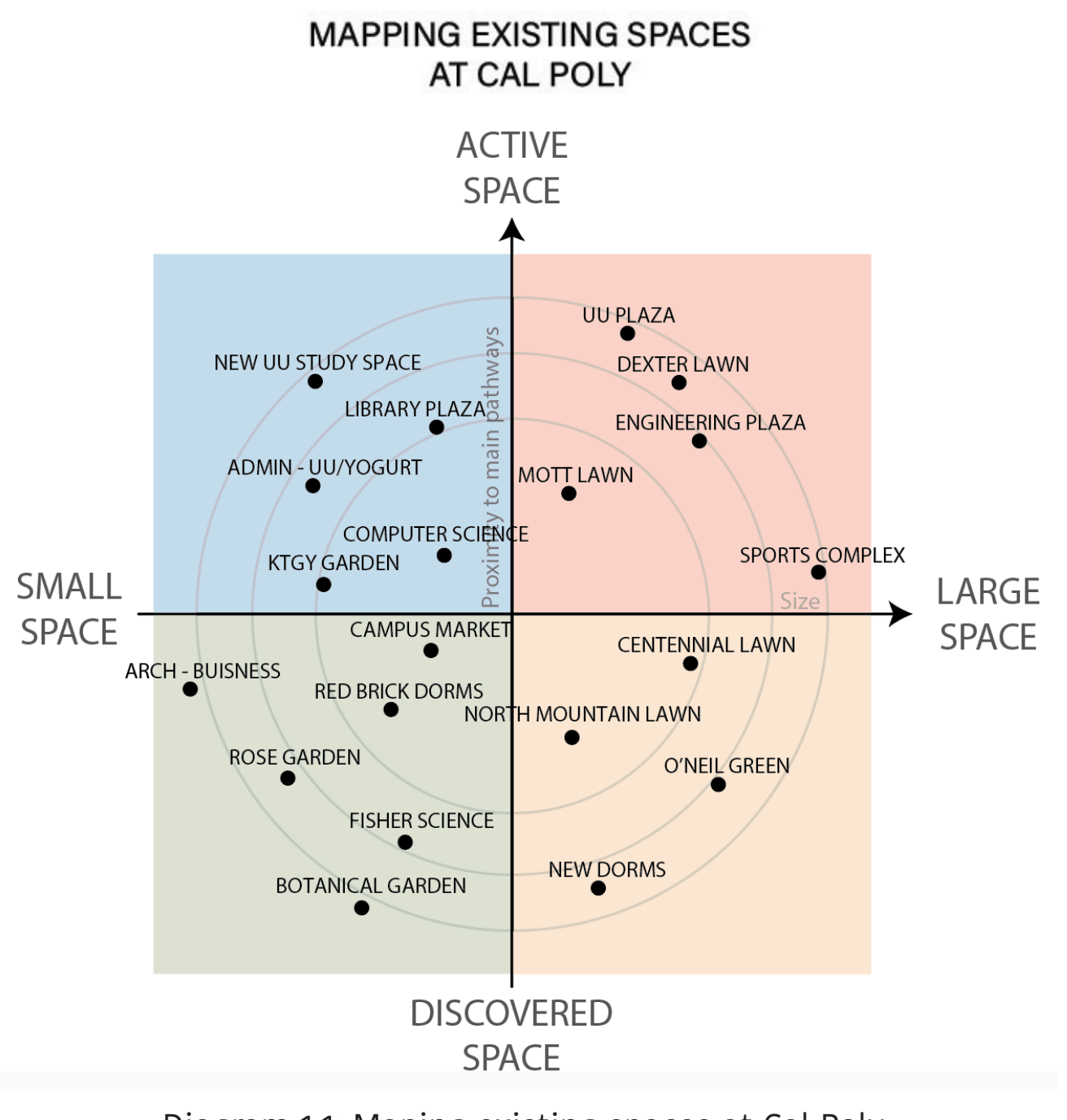

Diagram 1.1: Maping existing spaces at Cal Poly

Through mapping each potential and existing outdoor learning environment at Cal Poly, it is evident that active learning spaces are almost always located in the academic and social cores of campus. Discovered spaces, both large and small, are typically located around the academic and social core of campus. Although, sometimes they are placed between buildings and fourcourts within the campus core. 


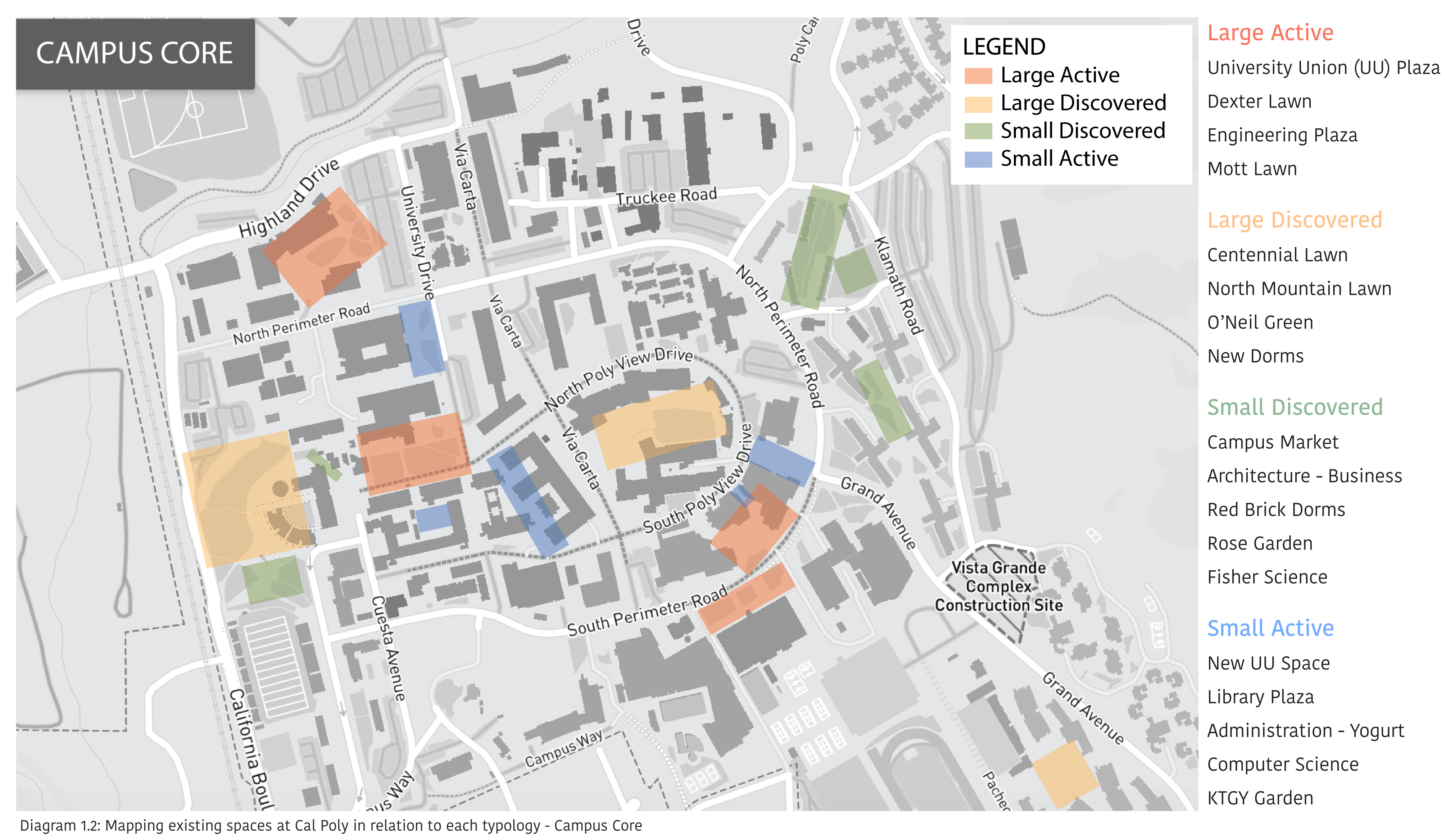




\section{NORTH CAMPUS}

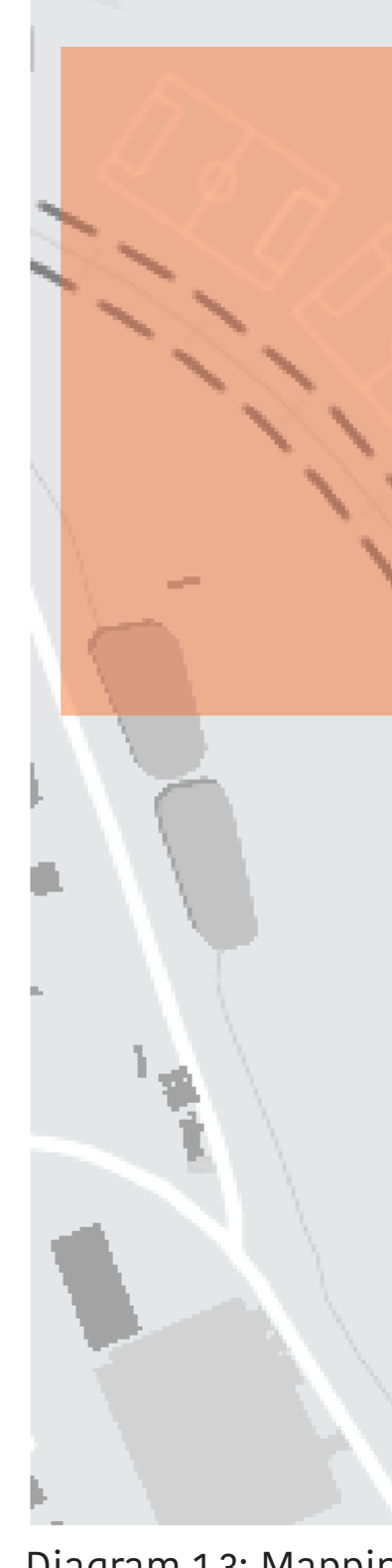

Diagram 1.3: Mapping existing spaces at Cal Poly in relation to each typology - North Campus

\section{ti}

$1+2$

(1)

\section{LEGEND}

Large Active Large Discovered Small Discovered Small Active
Large Active Sports Complex Small Discovered Botanical Garden

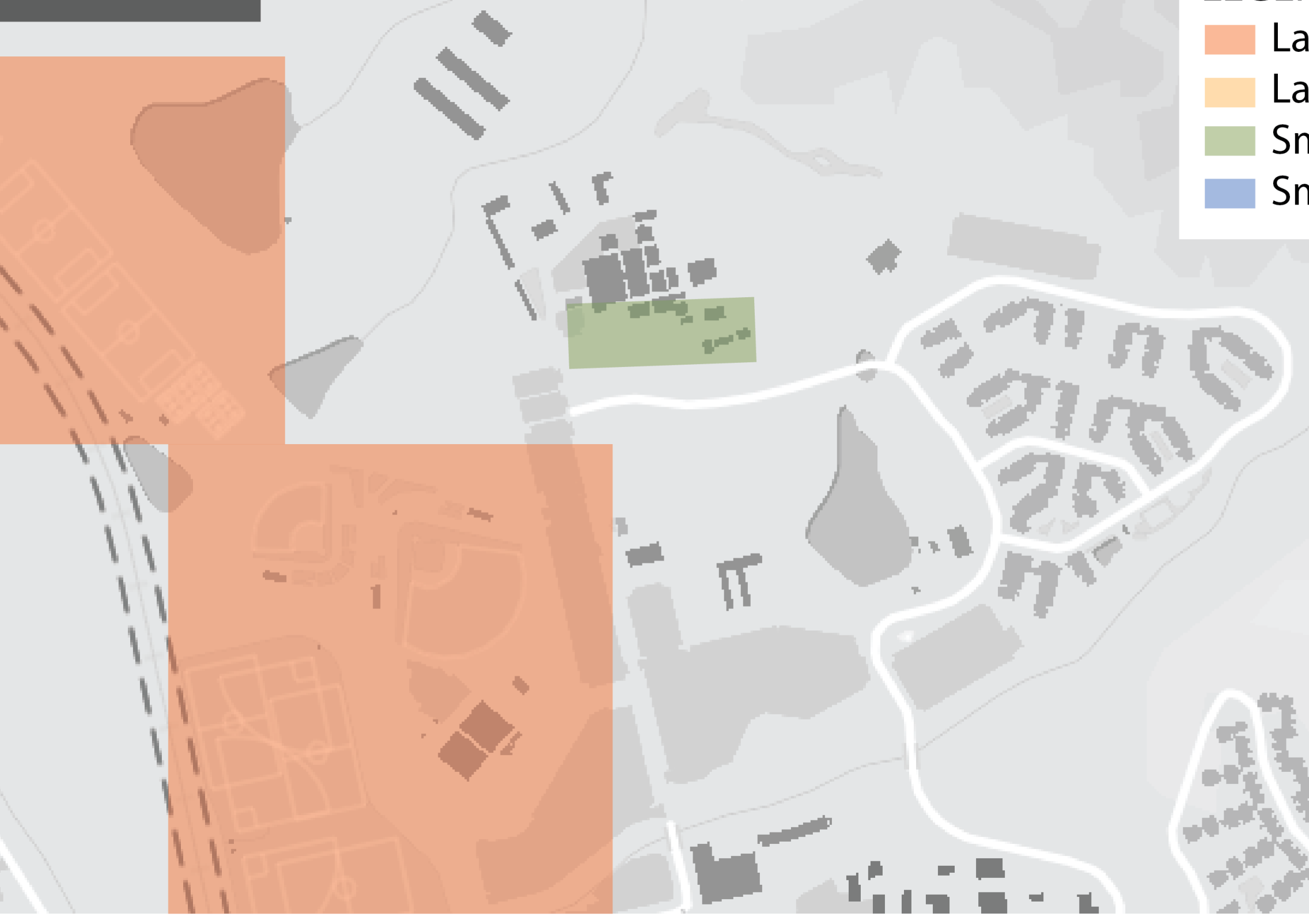

4

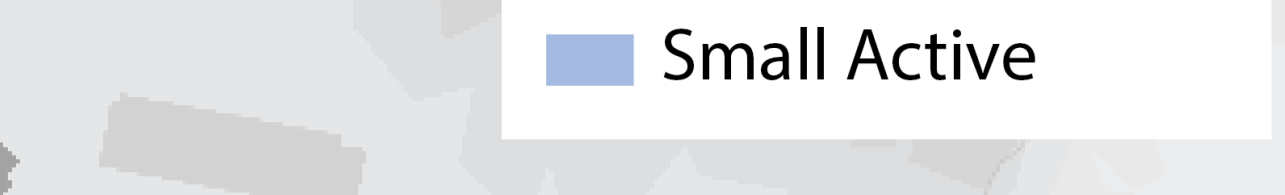

$4+11+1$

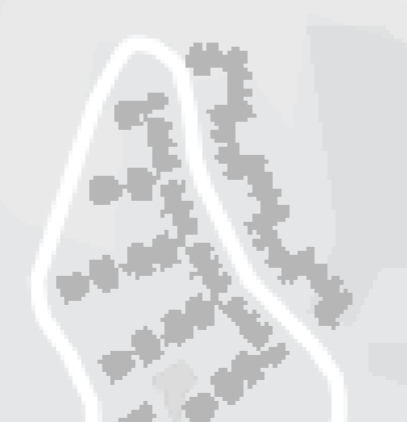




\section{Typology Diagrams}

The Level of Activity factor directly relates to the location of the outdoor learning environment. Each space can be located either directly on or off the main pathway. In the diagram below, each space type is placed near the main pathway if it is an active space, or off of the main pathway if it is considered discovered.

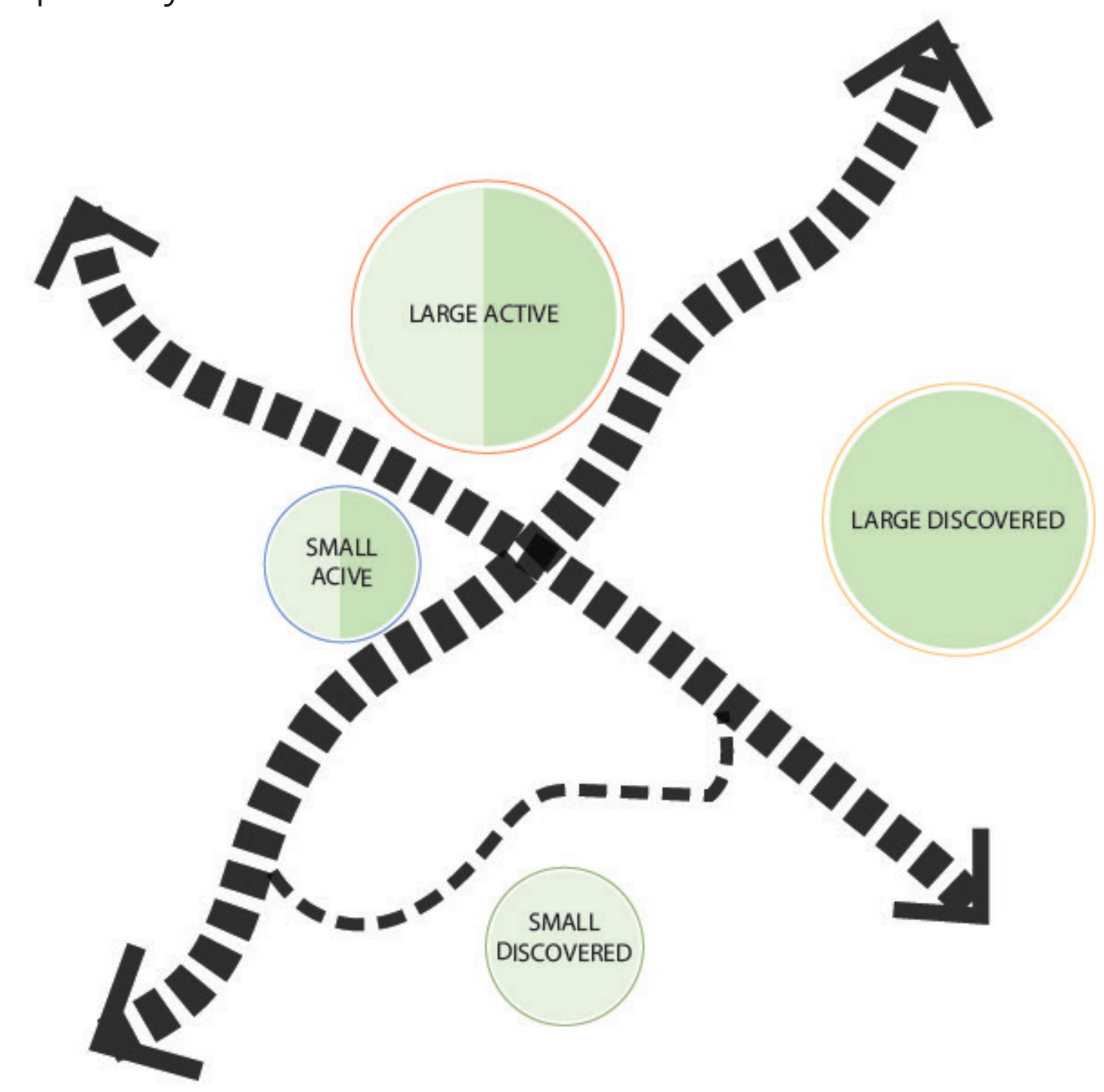

Diagram 1.4: Each typology showing relationship to the pathway and if they are natural or not
Additionally, this diagram considers the recommendation the amount of natural elements included in each outdoor learning space design. Each space type can include a minimal or a large amount of natural elements. The Large Discovered space types always includes natural elements, whereas the Small Discovered doesn't need to include a large amount of natural elements. Both the Large Active and Small Active spaces can either have little to no natural elements or have a large amount of natural elements.

\begin{tabular}{|l|l|l|}
\hline$\#$ & Type & Activities \\
\hline 1 & Large Active & $\begin{array}{l}\text { Large events, campus gatherings, class meetings, small group study, } \\
\text { interdisciplinary study/project space }\end{array}$ \\
\hline 2 & Large Discovered & $\begin{array}{l}\text { Small group study, quiet and secluded individual or partner study, } \\
\text { reading or reflecting space that feels more interactive and } \\
\text { comfortable }\end{array}$ \\
\hline 3 & Small Discovered & $\begin{array}{l}\text { Collaborative and interdisciplinary learning, small group studying, } \\
\text { partner or individual study space in between classes }\end{array}$ \\
\hline 4 & Small Active & $\begin{array}{l}\text { Secluded and more quiet individual, partner, or small group study } \\
\text { space, small class or studio group meeting space, place to present a } \\
\text { project }\end{array}$ \\
\hline
\end{tabular}

Table 1.5: Typology \& Activities

Each space typology includes a list of activities that can occur in each space type. Theses activities should be considered when designing each outdoor learning environment. While some activities may overlap, there are certain activities that are specific to each space type. For example, the Large Active space type has the ability to hold campus events and administrative gatherings. This space should be specifically designed for temporary occasions that hold a large amount of people. 
Space Types

(1) Large Active

Large active areas use the surrounding structures and the landscape to define the campus and create a collaborative environment. These spaces are commonly referred to as a Quadrangle, Yard, or Lawn and provide an open space for large gatherings or campus events. Located in the academic core or near academic or student union spaces, large active areas include elements such as grass, public art, and seating. Framed by academic buildings, these areas have the opportunity to bring the classroom outside and enhance student's learning through group or class learning outdoors. These

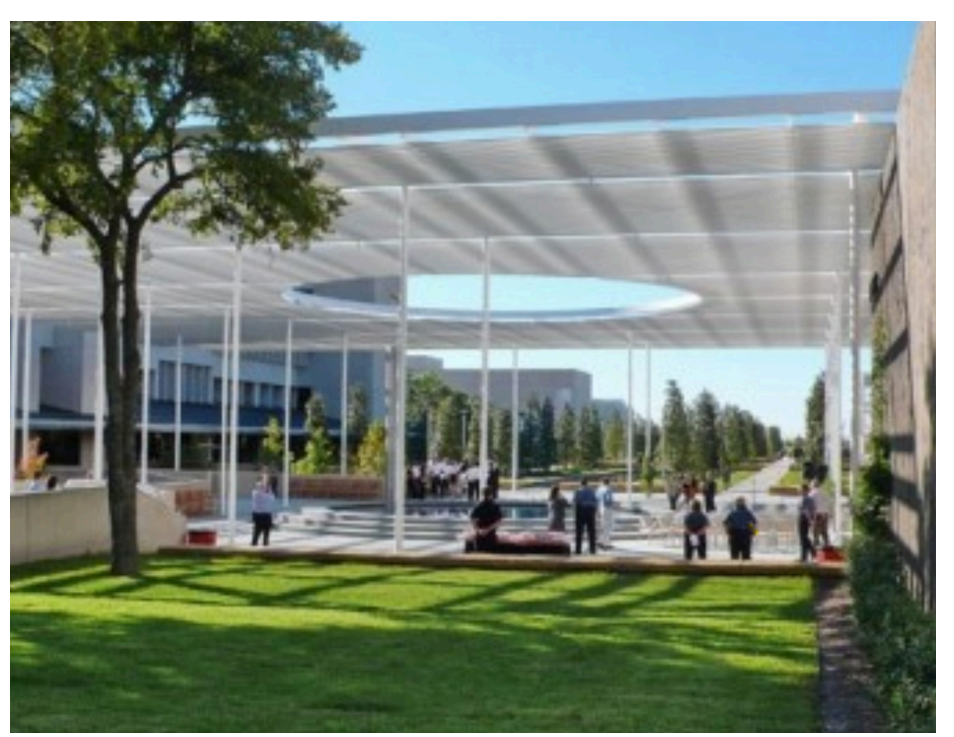
spaces are typically large and on the main pathway or creates a pathway within or around the gathering area. Prospective students could visit this space while on a tour, seeing students collaborating on a class project and envision themselves learning in this outdoor environment.

Figure 1.0: University of Texas at Dallas landscape plaza enhancement plaza

Activities: Large events, campus gatherings, class meetings, small group study, interdisciplinary study/project space, individual reflection

Examples at Cal Poly: Dexter Lawn, UU Plaza, Engineering Plaza, Sports Complex, Mott Lawn

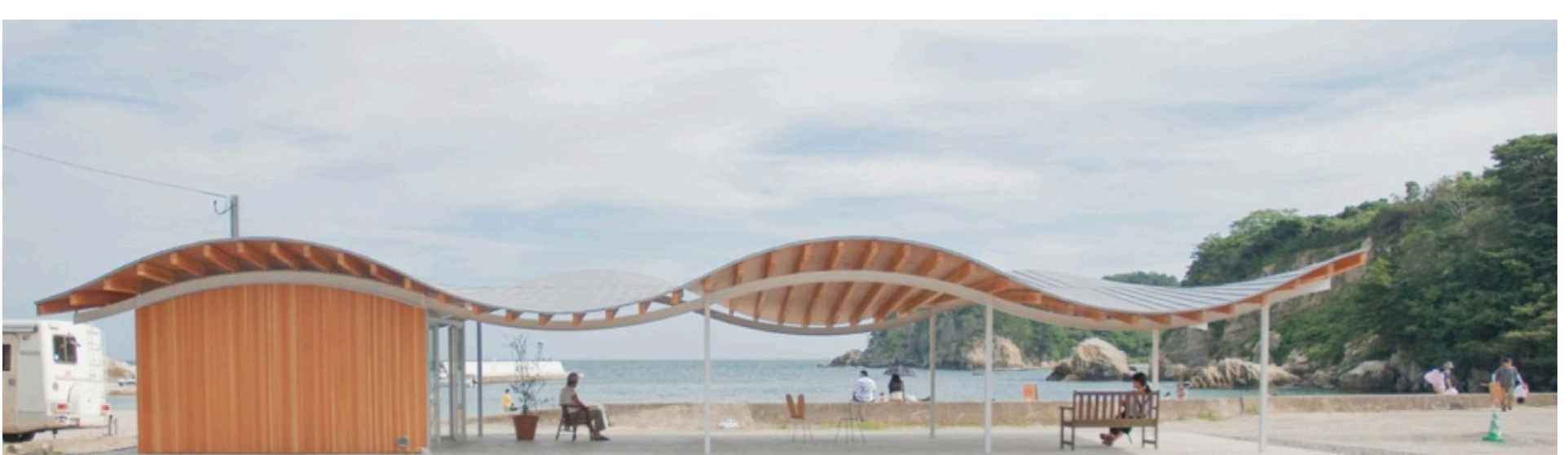

Figure 1.2: Home-for-All in Tsukihama, Miyatojima

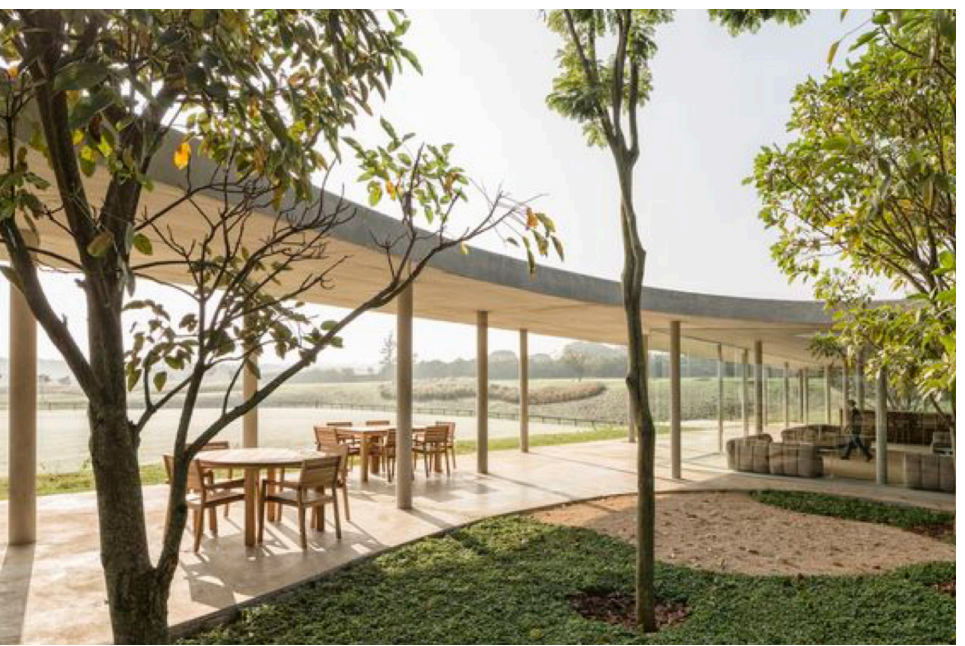

Figure 1.3: Clubhouse gathering space

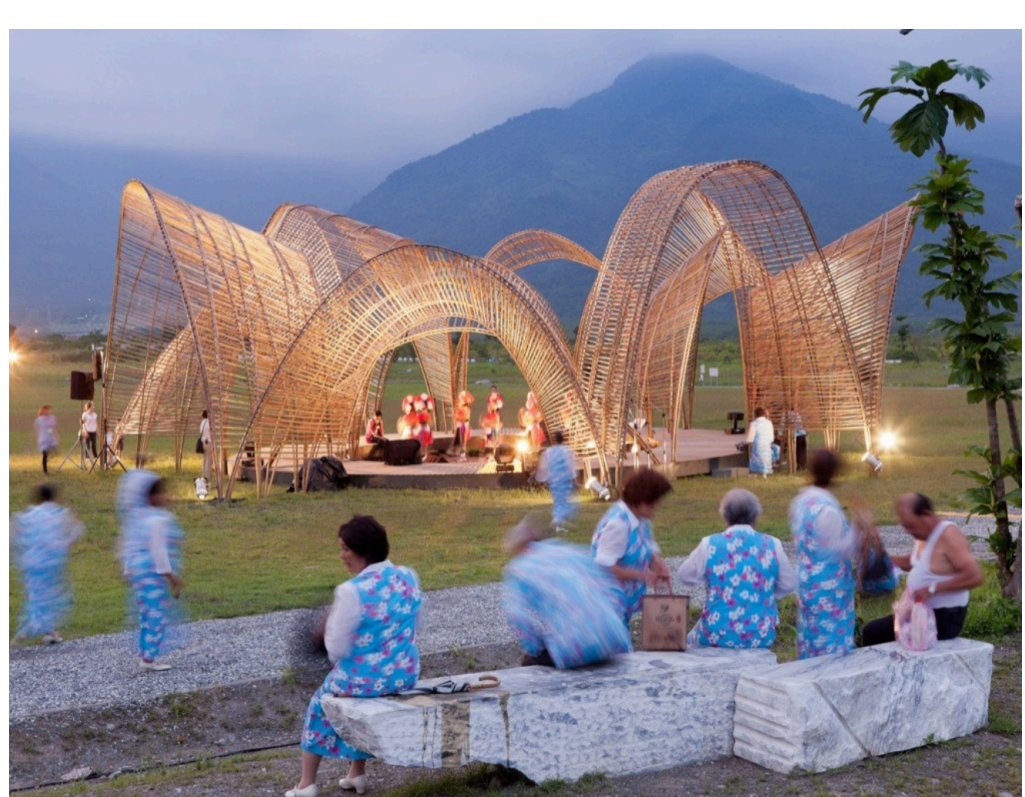

Figure 1.5: Forest Pavillion, Taiwan

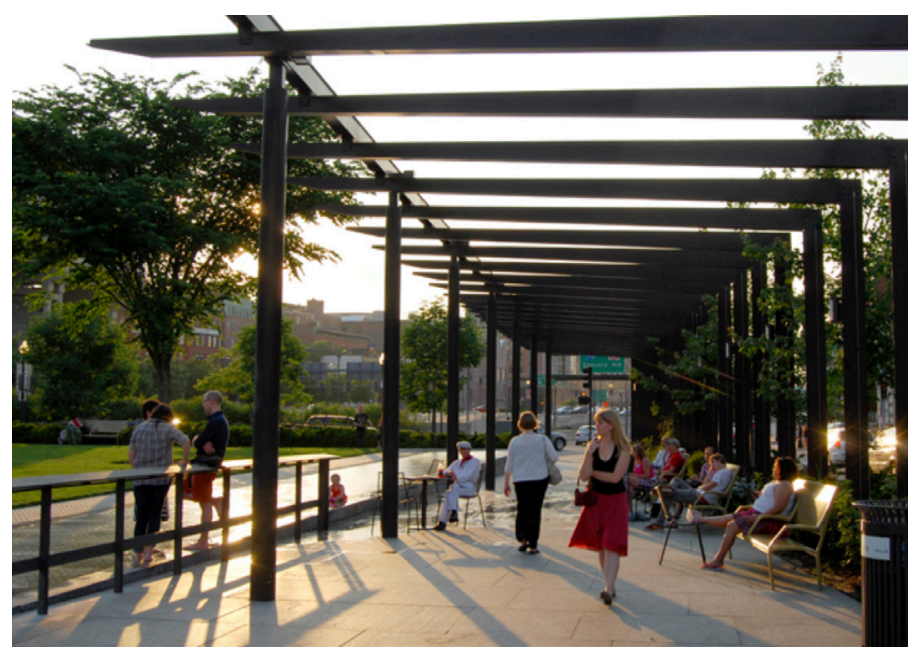

Figure 1.4: North End Parks, Boston, MA

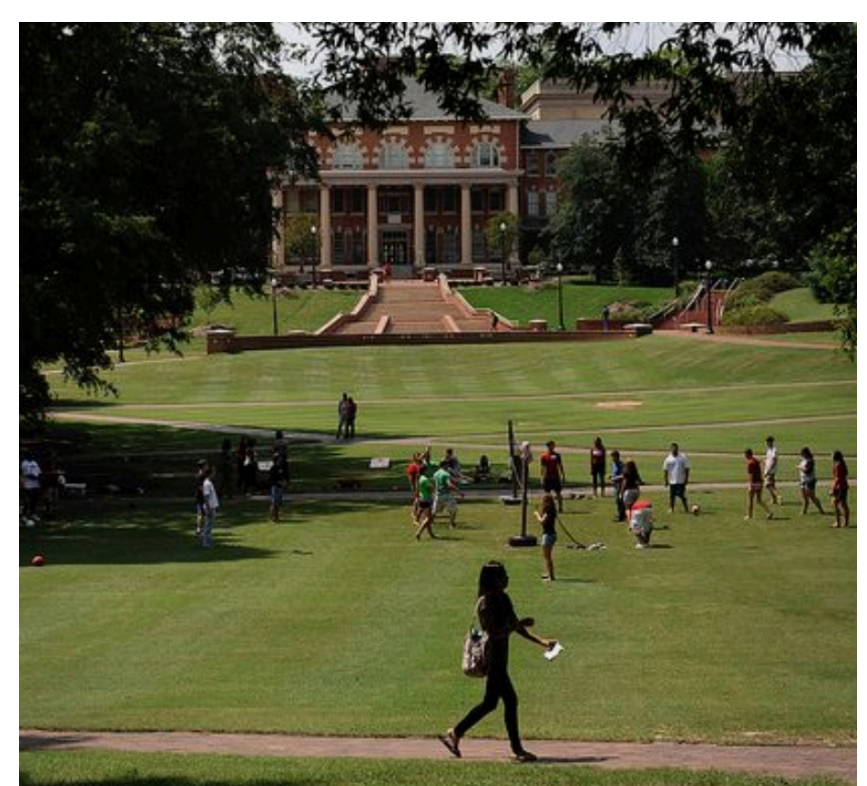

Figure 1.6: Court of the Carolinas, Raleigh, NC 


\section{(2) Large Discovered}

Large discovered spaces encourage restoration and reflection, providing a quiet space to study or relax in between classes. Natural landscape elements such as large canopy trees, native shrubs, leafy vines, water falling, or a small pond, defines the space. Screened from noise and distractions, these spaces are hidden and off the main pathway. These spaces may be located in various spots around campus and are considered placemakers. Utilizing and enhancing the current landscape topography through the implementation of these spaces will keep the character of the space and landscape while providing an additional learning environment. Garden

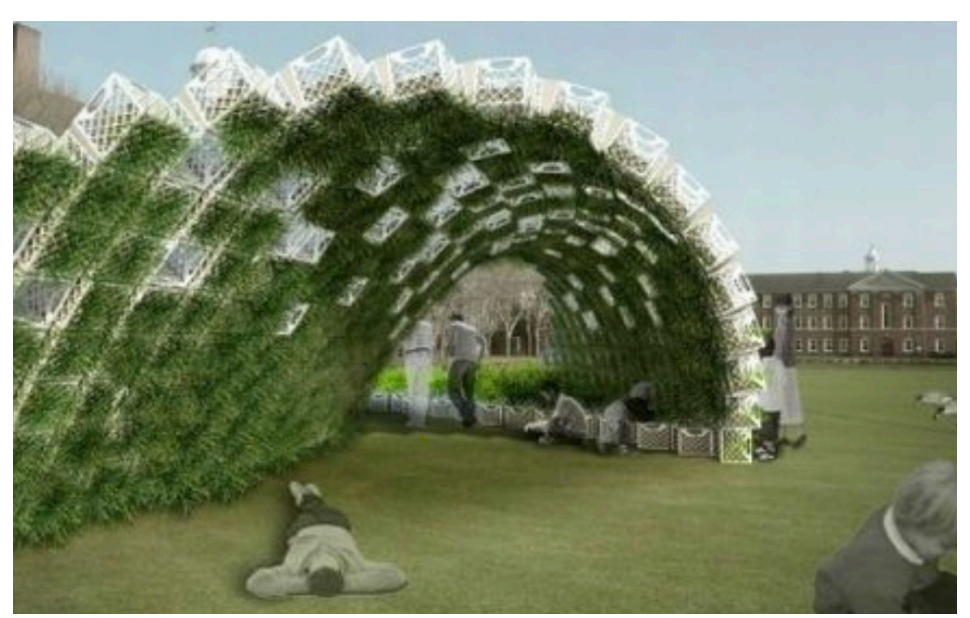

learning spaces are unique but reflect the surrounding built environment and create an inclusive learning environment for an individual, partner, or small group.

Figure 1.7: Students relaxing under a green shade structure

Activities: Small group study, quiet and secluded individual or partner study, reading or reflecting space that feels more interactive and comfortable

Examples at Cal Poly: Centennial Lawn, North Mountain Lawn, New Dorms,

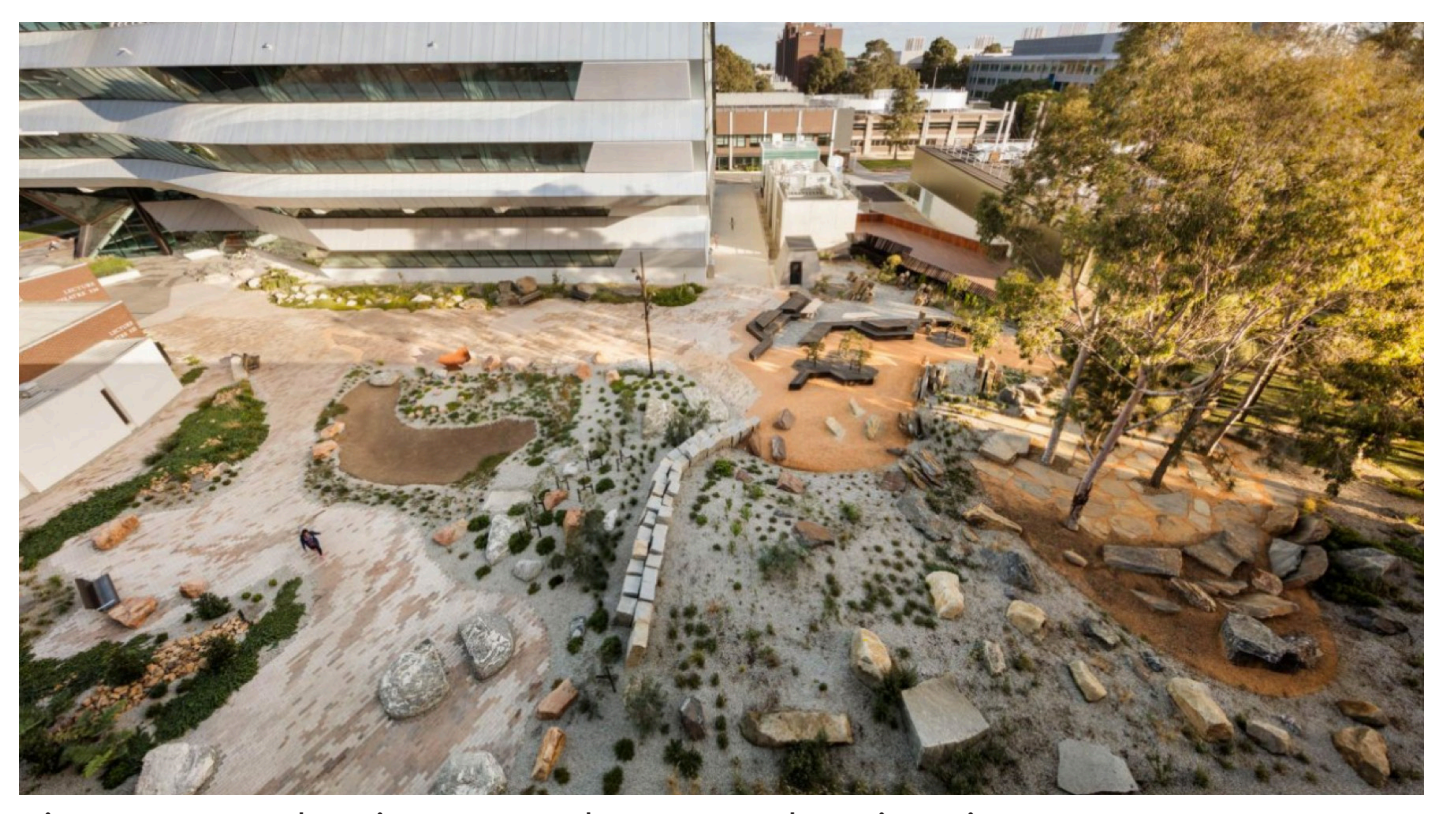

Figure 1.8: Earth Sciences Garden, Monash University

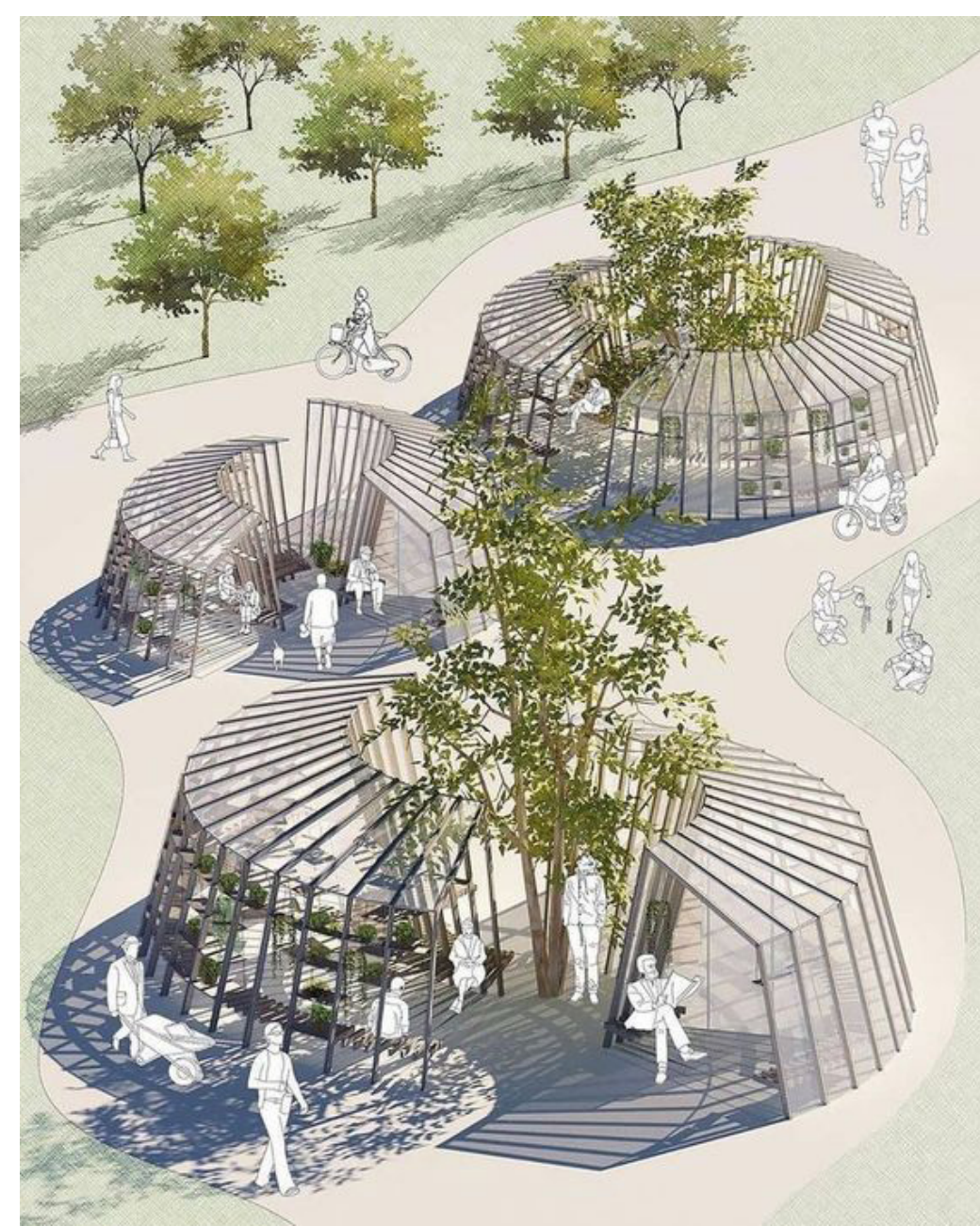

Figure 1.9: Shade structures surrounded by lawn space

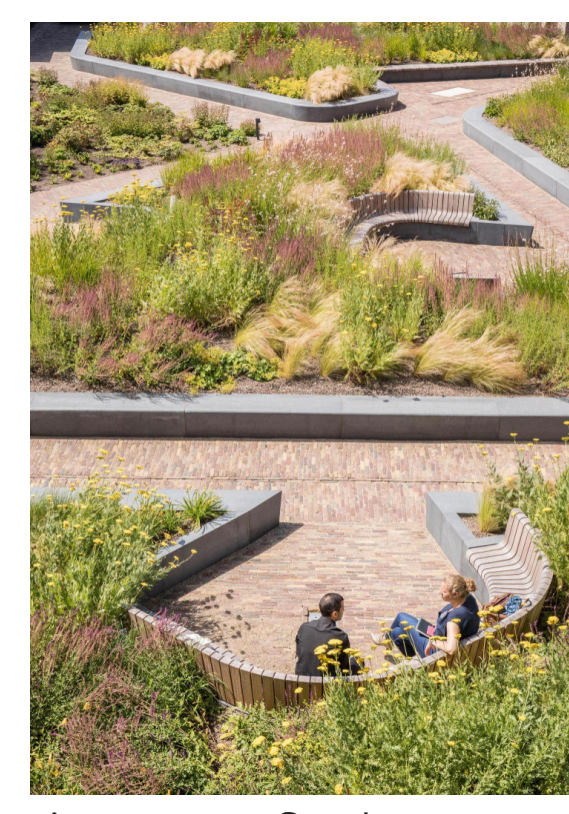

Figure 1.9: Defland Waterway

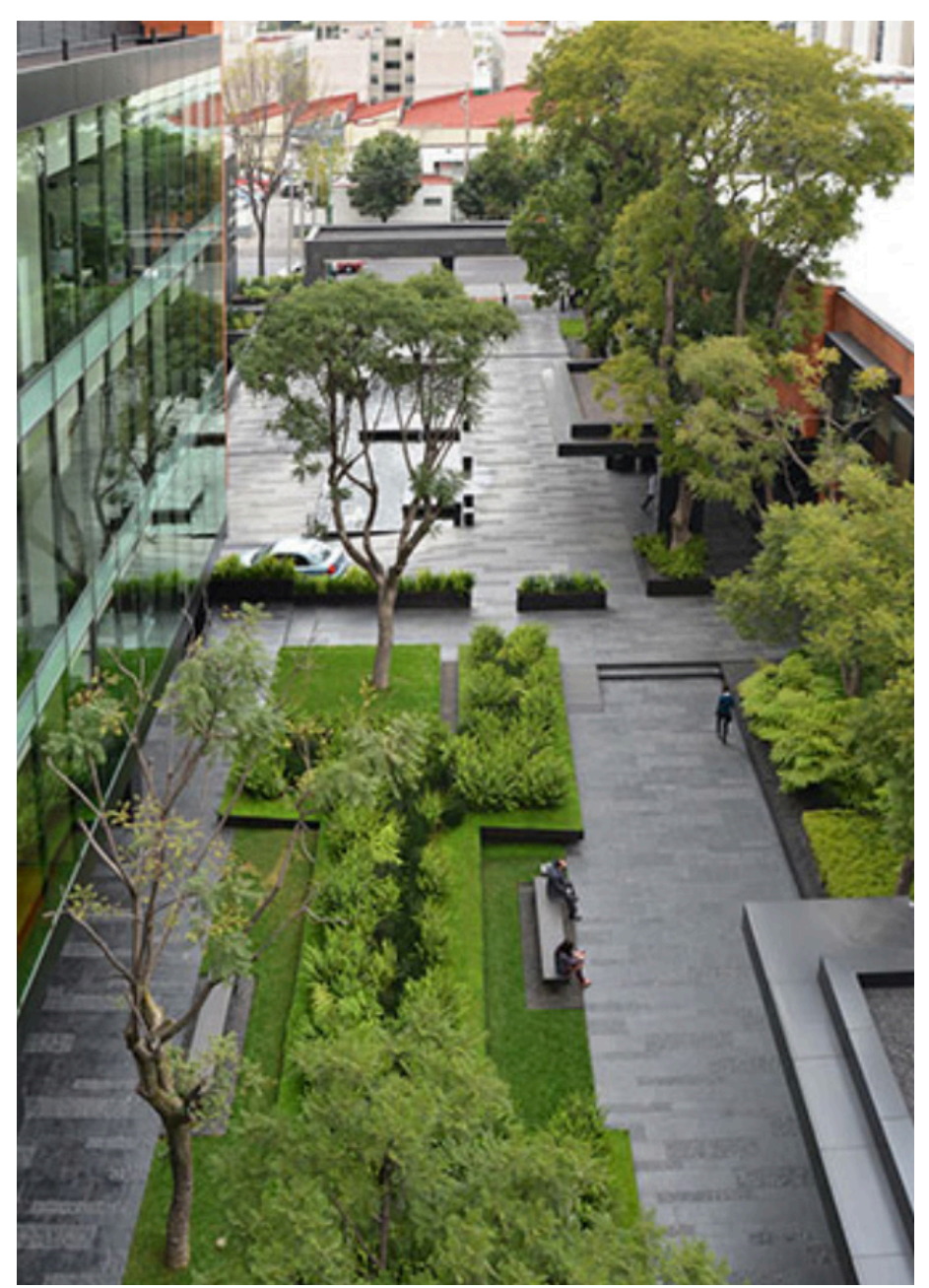

Figure 2.0: Coyoacán Corporate Campus Landscape 


\section{(3) Small Discovered}

Small outdoor learning environments located off the main pathway are intended to accommodate individuals or small groups in a more removed area on campus. While being tucked away and close to or partially surrounded by nature, these spaces are a quiet and intimate. These spaces utilize the landscape and natural elements to create a social but personal space, allowing the user to connect with the environment and feel comfortable using and learning in that space. The small, discovered gathering space serves as a designated space for a brief meeting, to complete a small group assignment, or to complete an assignment individually. Low-traffic walkways lead up to, around, or near these spaces, allowing the visitor to discover this out
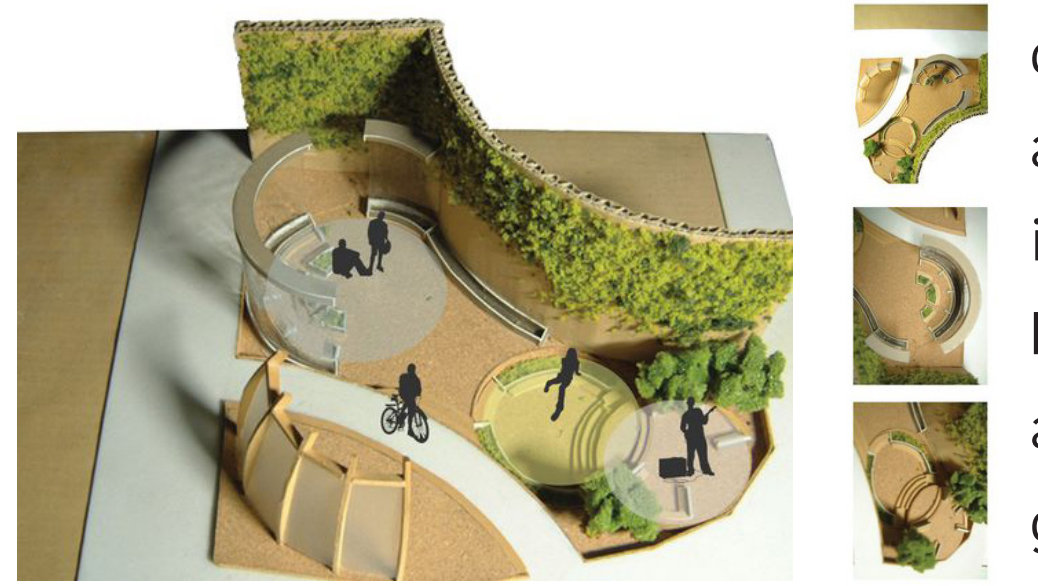
door learning environment. While also serving cultural and administrative functions, these spaces have the opportunity to provide for a variety of uses and collaborative gatherings.

Figure 2.1: Pocket Park Concept

Activities: Secluded and more quiet individual, partner, or small group study space, small class or studio group meeting space, place to present a project or studio charrette

Examples at Cal Poly: Cal Poly botanical garden, Rose Garden, Fisher Science, Red Brick Dorms, Arch-Buisness, Campus Market

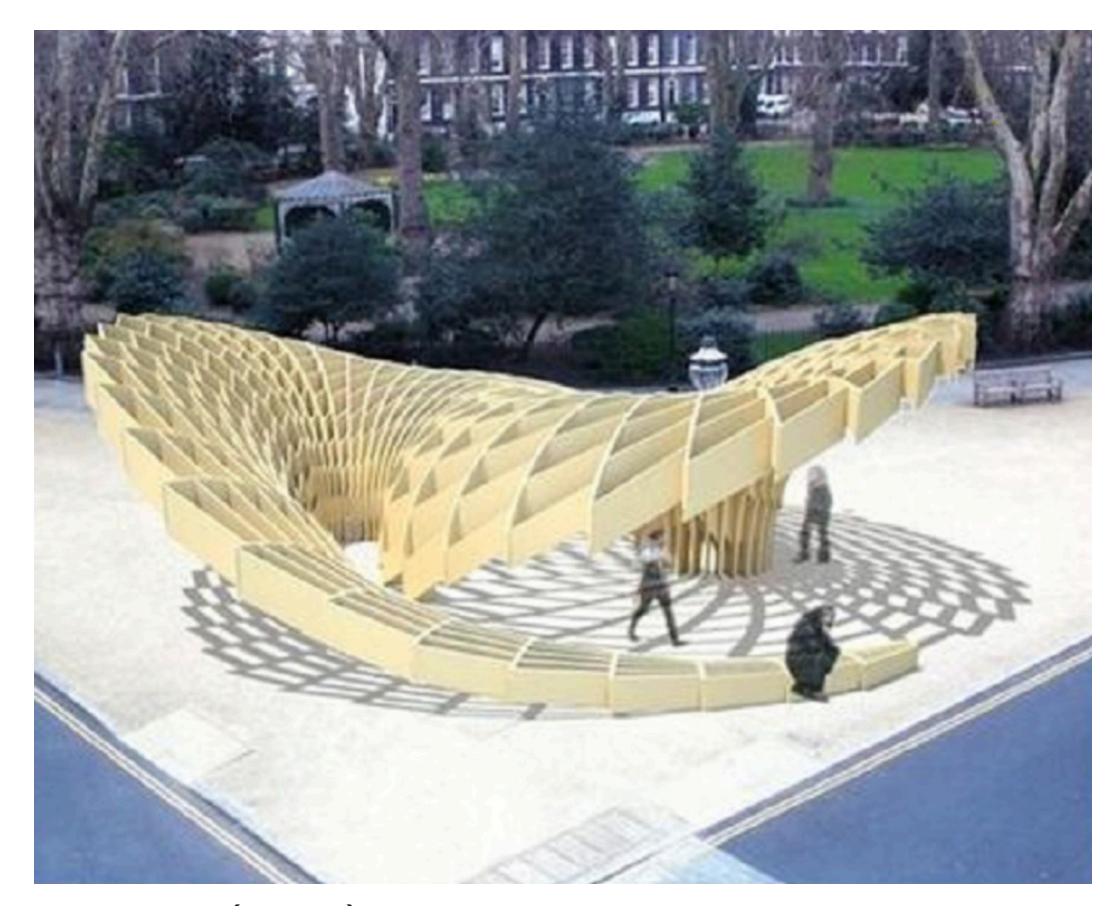

Figure 2.2 (above): Shade structure off of a quiet pathway

Figure 2.3 (right): Small gathering spaces with vines and shade trees. Each gathering space is natural and together, they create a cohesive environment.
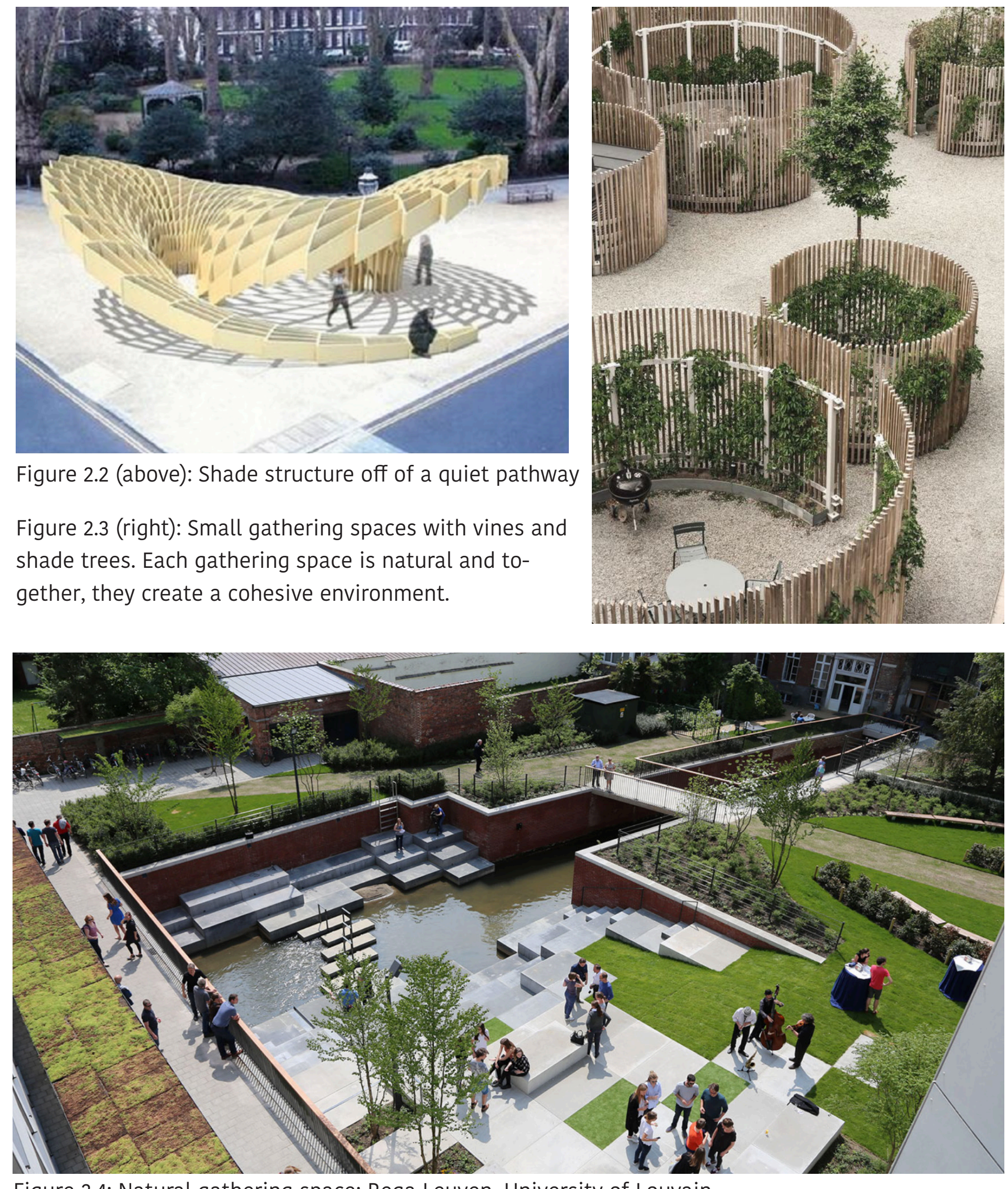

Figure 2.4: Natural gathering space; Rega Leuven, University of Louvain 


\section{(4) Small Active}

These small learning spaces are designed to activate, develop, and enhance courtyards or building forecourts. Located on main pathways and integrated among student circulation in and around buildings, these small spaces are scattered throughout campus and placed in areas next to academic buildings or student unions. Current unused spaces defined by buildings provide an opportunity to shape and develop them into a collaborative learning environment. Natural elements could be incorporated in the design of these outdoor learning environments or the space could strictly be designed as an extension of the current building, without the use of natural elements and features. Features such as seating walls, shade structures, and desk-like attachments help students relax and feel comfortable while learning but also adopts necessary traditional classroom features that allow students to be able to learn. As a space used for collaborative learning, it can be a place where students or professors can discuss, a small group or partner can meet to complete an assignment, or for individual study space.

Activities: Collaborative and interdisciplinary learning, small group studying, partner or individual study space in between classes

Examples at Cal Poly: Space in-between computer science and Engineering East, Admin-UU/Yogurt, Library Plaza, New UU Study Space, KTGY Garden

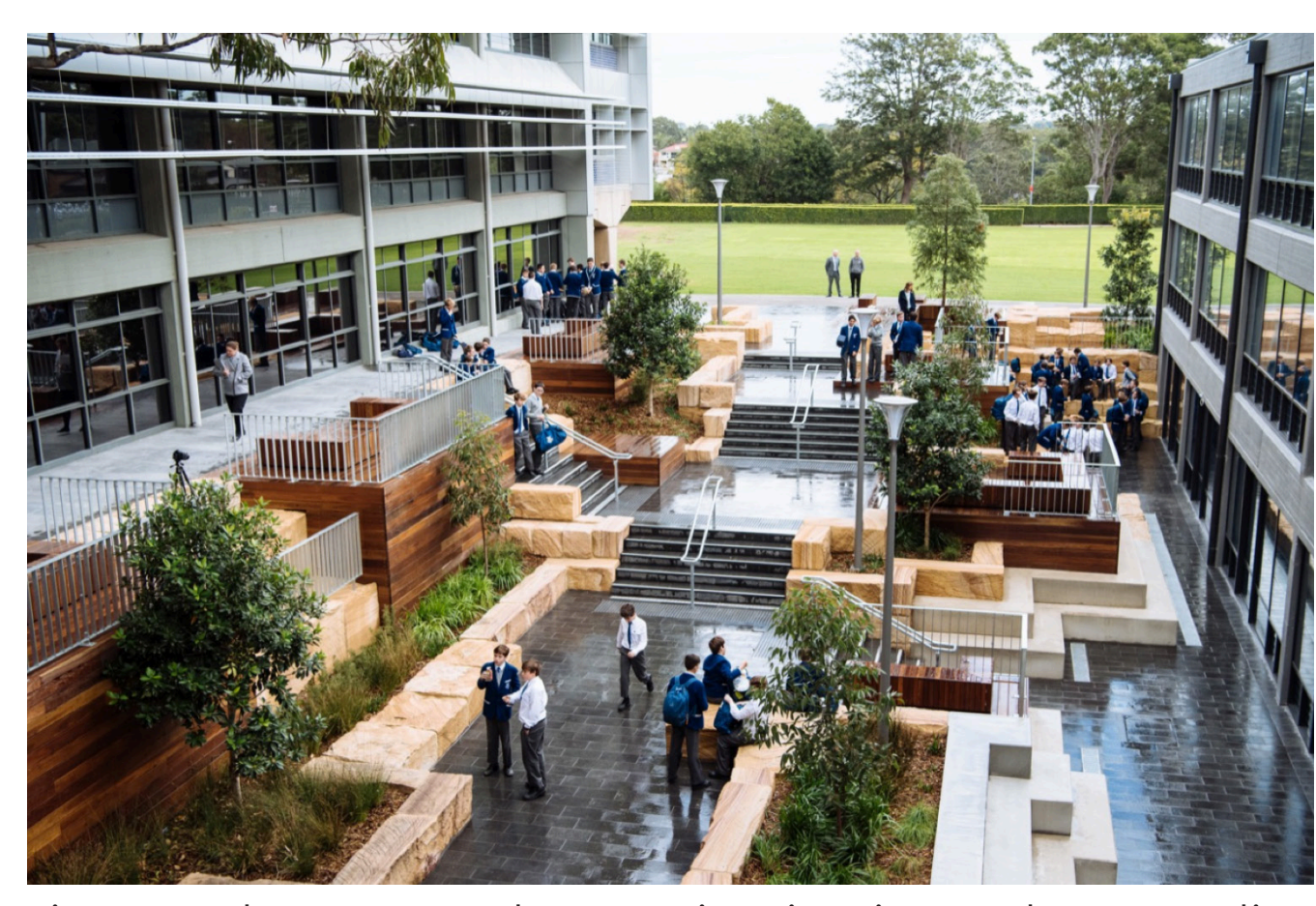

Figure 2.4: Therry Courtyard, St. Ignatius Riverview - Sydney, Australia

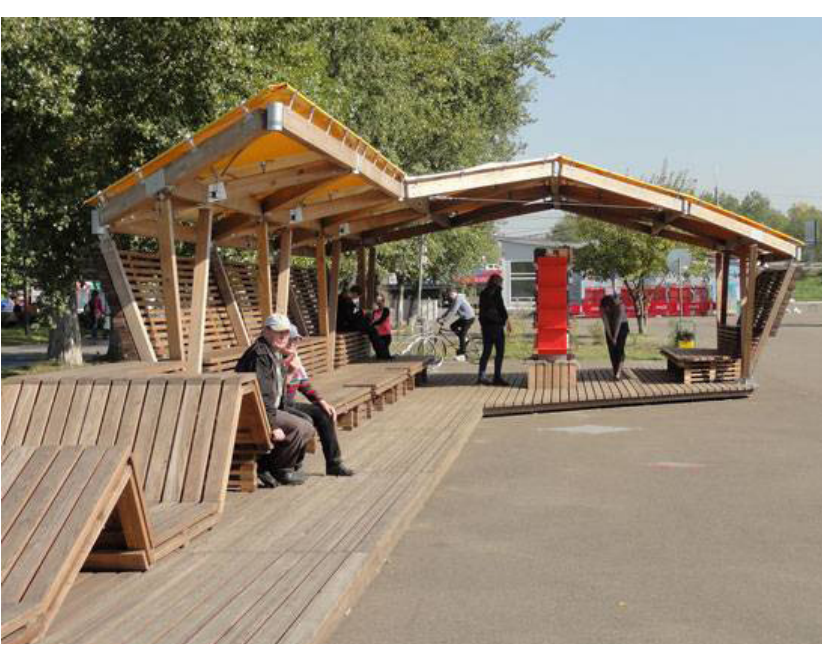

Figure 2.6: Riverside Terrace, Russia

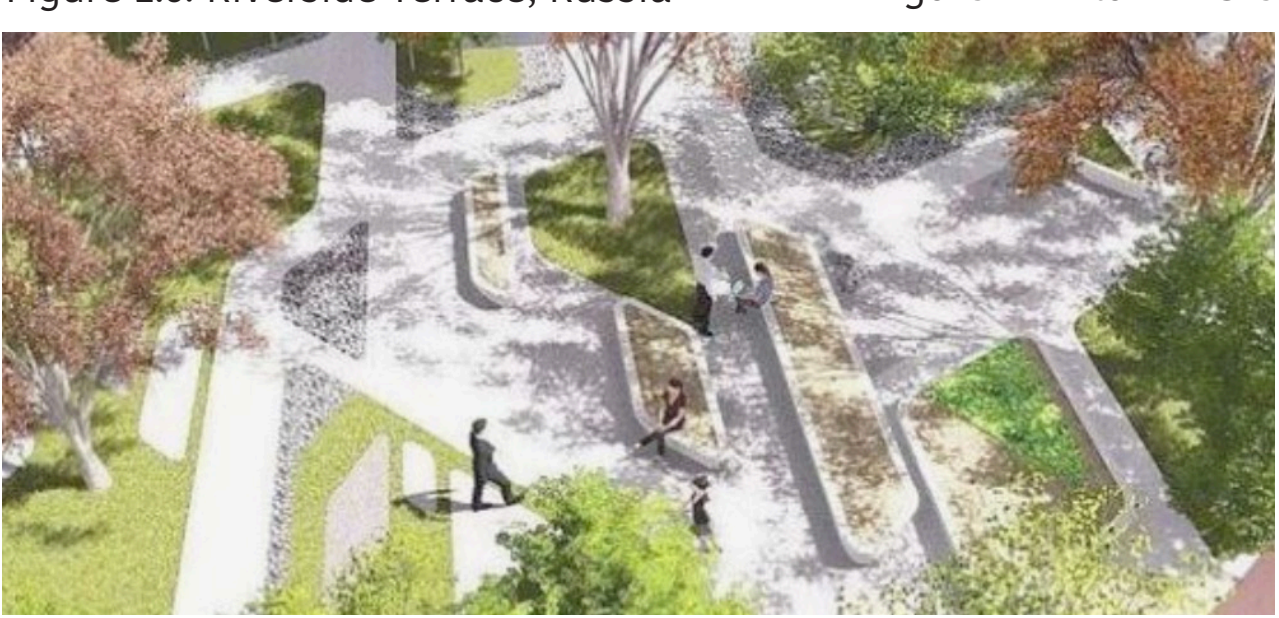

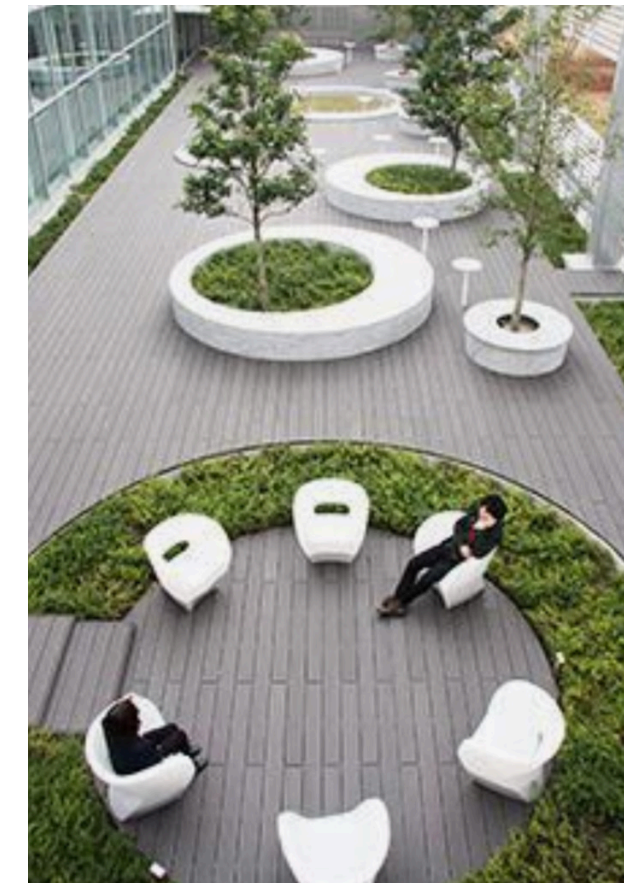

Figure 2.5: Small gathering space

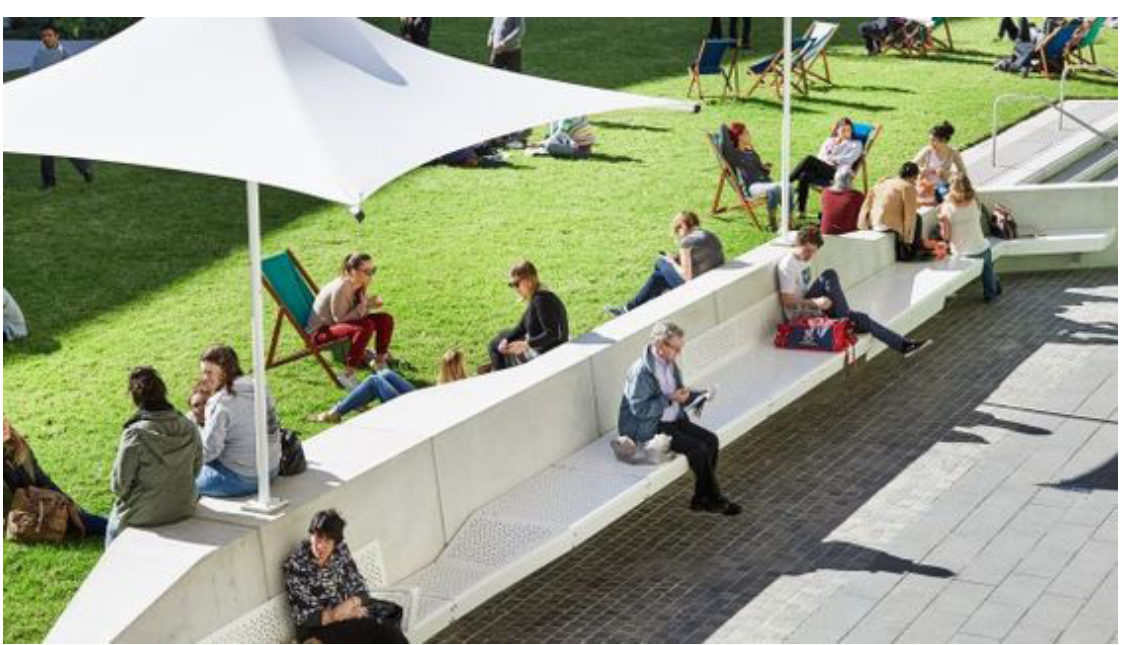

Figure 2.7: Alumni Green - Sydney, Australia

Figure 2.8 (left): Landscape planting and walkway concept design. Focusing on integrating comfortable seating and smaller, gathering spaces within the design of the pedestrian circulation. 


\section{THE 'HOW'}

\section{CASE STUDIES, ACTIVITIES, DESIGN PRINCIPLES, \& DESIGN RECOMMENDATIONS}

\section{LARGE ACTIVE}

University of Texas at Dallas - Landscape Enhancement

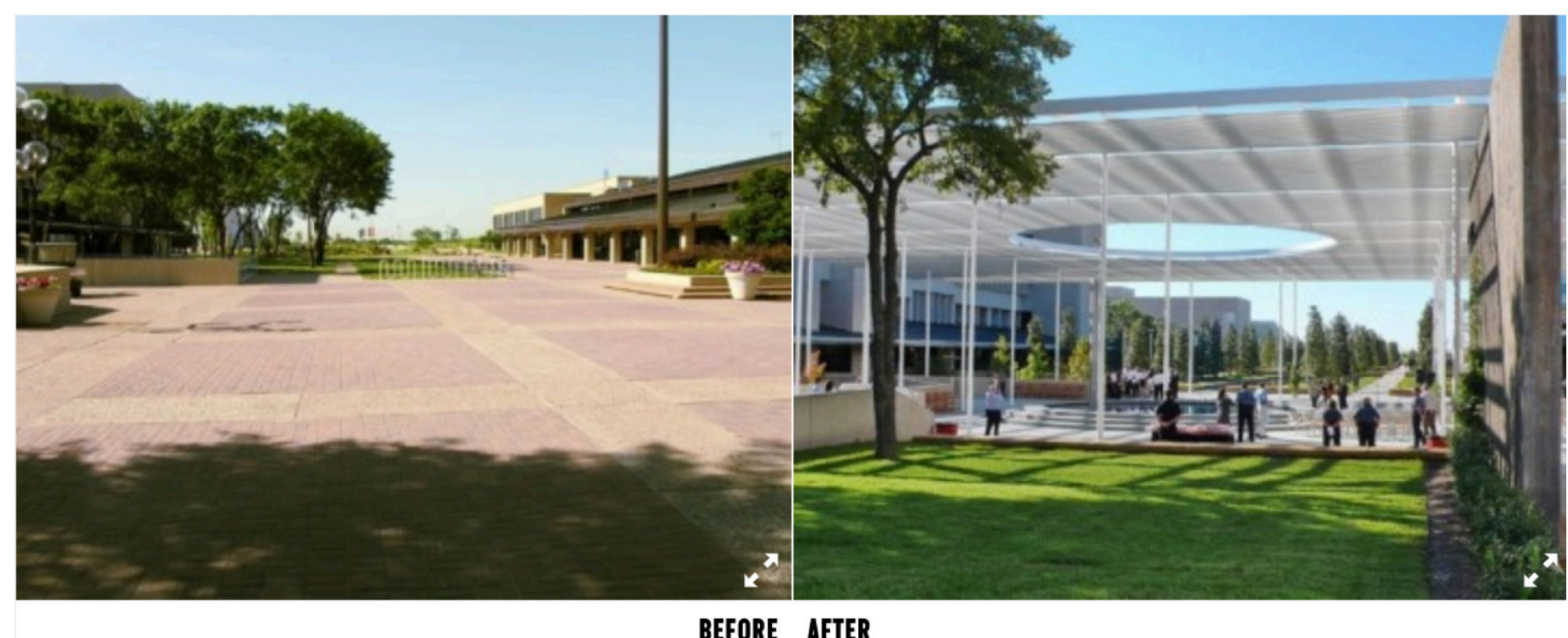

Figure 2.9: University of Texas at Dallas before and after image showing how the landscape enhanced space was transformed into an active, learning environment.

The University of Texas at Dallas transformed a once largely-asphalt courtyard into a social and livable environment. The central courtyard transformation project is one of the many that are included in the 33-acre campus landscape enhancement plan. With a larger goal of creating a comprehensive campus master plan, this project was one of many intended to "commit to landscape-led development and site planning, a pedestrian-based hierarchy of circulation, and the activation of outdoor spaces for social activities" (Landscape Architecture Foundation, 2018, p. 1). Phase 1 was completed in 2010 with a project budget of $\$ 30$ million. Upon completion, this project transformed various sections of campus into a space that reflected the University's identity and radically changed the perception of campus. As a result, students, faculty, and staff take pride in the University's campus community.

The central courtyard transformation project stands out as an extremely successful project for environmental, social, and economic reasons. The main goal of the central courtyard transformation project was to "foster social connections between current and future students, faculty, and staff" (Landscape Architecture Foundation, 2018, p. 1). The designers at PWP Landscape Architecture, used specific design details in order to achieve this overarching goal. The space is semi-shaded with a white structure that is around 25 feet tall. This shade structure is lined with bright green vines that creep up the columns. Large, wooden, stage facing stairs lead directly into to the Student Union and act as temporary seating for both individuals and groups who would like to eat a quick bite or socialize with friends. While the space is mostly hardscape, there is a small green lawn about 30 feet by 50 feet that students can use to throw a Frisbee or relax in the grass in between classes. 
With the addition of movable tables and chairs, and a small platform that acts as a stage, this space can also be converted into an event or gathering space. The space includes native plantings and water features that enhance the overall look of the entry-way to campus. Therefore, transforming the way prospective students view the University and their learning environments.

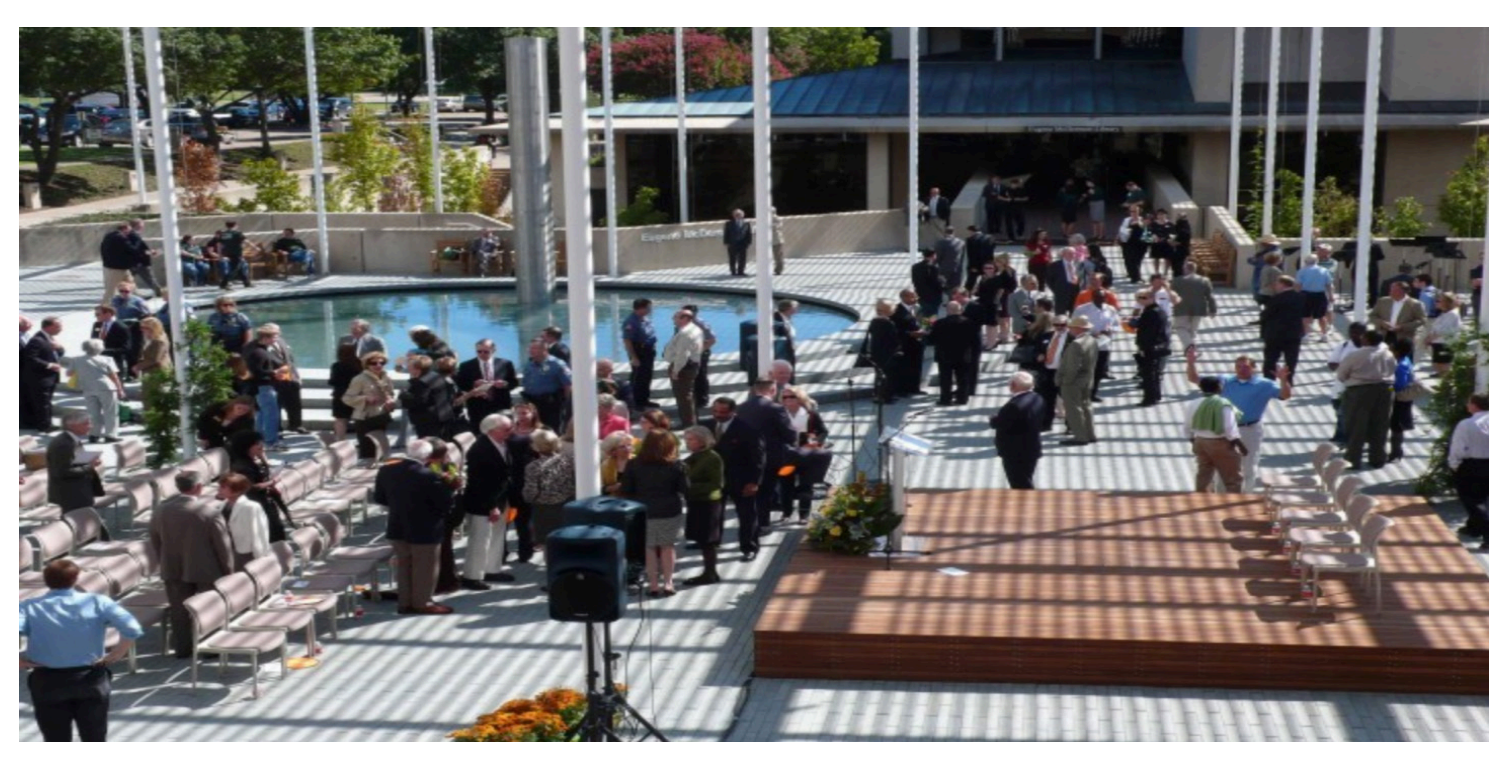

Figure 3.0: The newly enhanced landscape is commonly used as a campus event or meeting space.

Since the completion of this project in 2010, the University has seen increased enrollment by 13\% from 2010 to 2012 (Landscape Architecture Foundation, 2018). A challenge of this project was to create an "enduring campus identity" because the campus lacks unique architectural character (Landscape Architecture Foundation, 2018, p. 2).

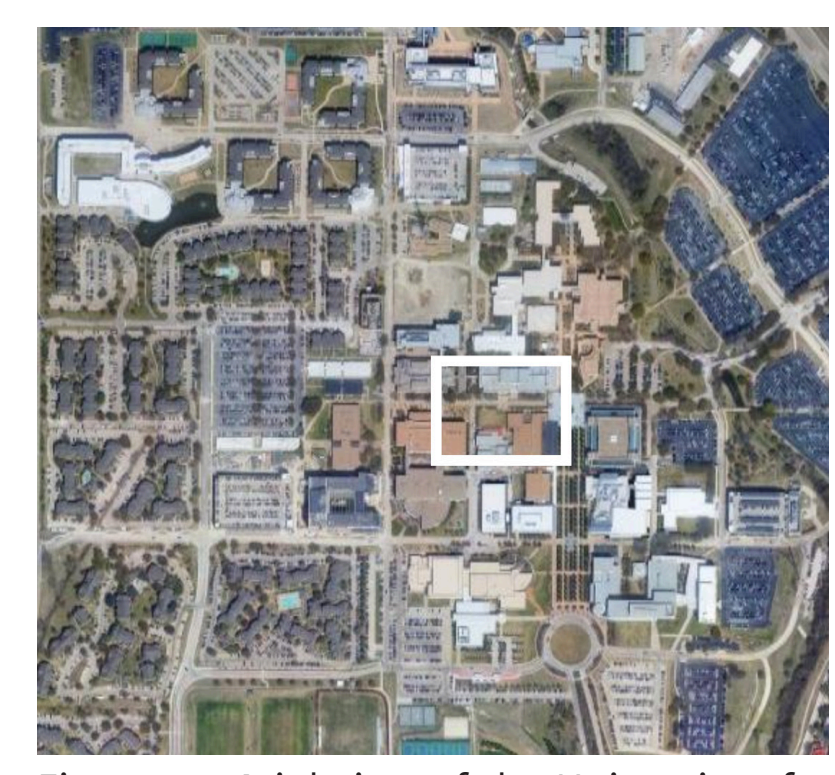

Figure 3.1: Ariel view of the University of Texas at Dallas landscape enhancement plan location.
Located in the central portion of campus, this active learning environment is a memorable and engaging public space. Additionally, it has a feel of an urban park-like environment. The overall project design exceeded the original sustainability goals in areas of stormwater management, locally sourced materials, and native planting and restoration. This project was very successful as $70 \%$ of the students surveyed claimed the central courtyard transformation project improved the quality of life on campus (Landscape Architecture Foundation, 2018). The University of Texas at Dallas' landscape enhancement projects created a new, more vibrant campus environment for students to both socialize and learn.

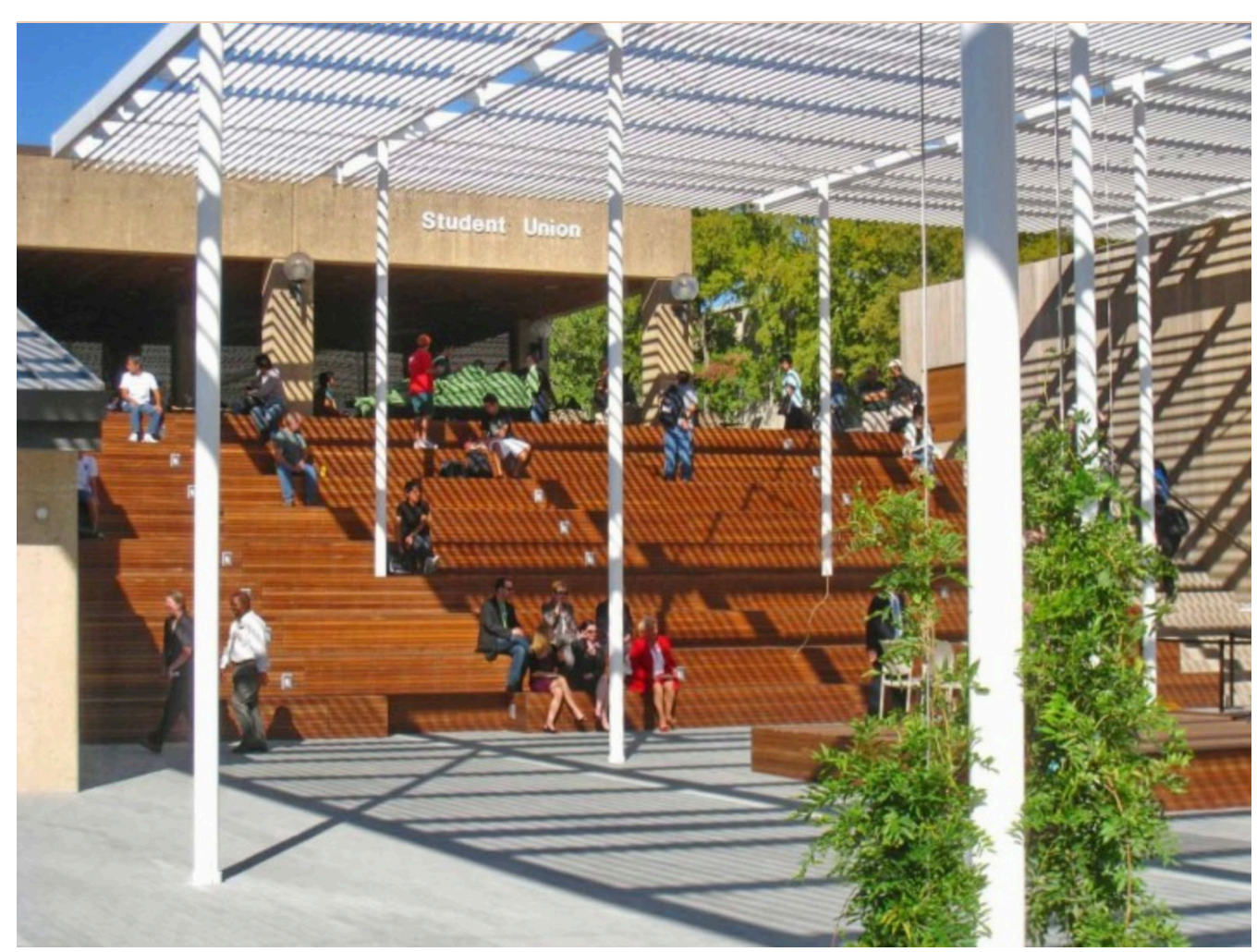

Figure 3.2: The series of steps leading up to the University of Texas at Dallas' student union building is frequently used by students. Features such as a large shade structure with vegetation enhance the space and allow students to spend long periods of time studying. 
The University of Birmingham - The Green Heart

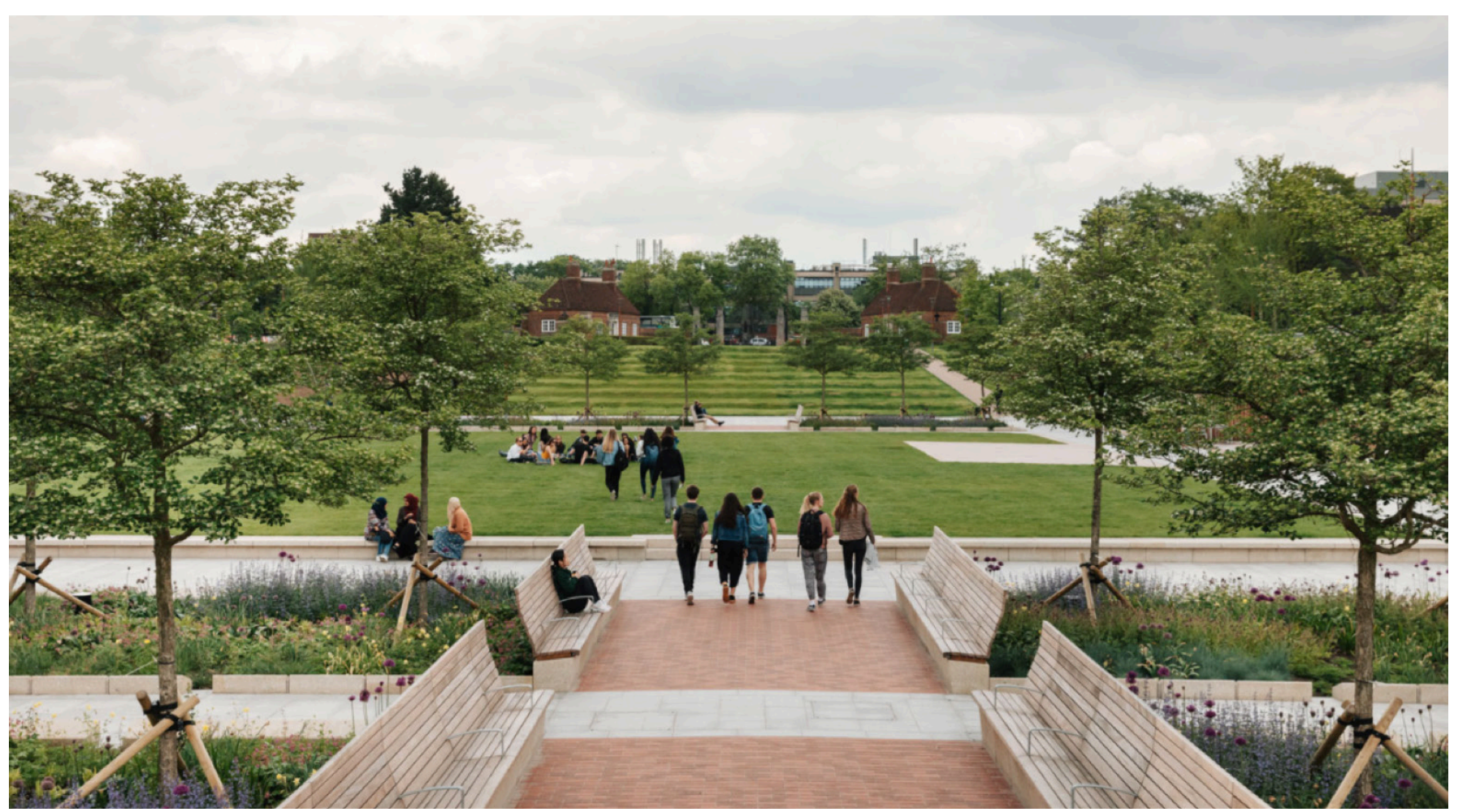

Figure 3.3: University of Birmingham students walking on a pathway in the Green Heart.

The Green Heart, designed by Landscape Architect Churchman Thornhill Finch, is a central gathering lawn on the University of Birmingham's campus. The removal of the 1950's Verner O’Rees Library building created a large open space that can be adapted and transformed. The Green Heart project was completed in 2019 and is designed to enhance the 360-degree view and experience of campus. A student or visitor is able see the clock tower and campus landmark from any section of the lawn, both unifying the space and orientating the user. It was very important to the designer to keep the landmark central to the design, as many pathways direct towards the structure.
Pathways divide the lawn space into about 6 to 8 smaller, more manageable sections. These pathways are well lit and include many benches and seating options, as well as planting boxes and shade trees. As a result of this project, 160 new trees were planted (Landezine, 2019). This park-like environment combines "meet, work, and play" through elements such as a lawn space, an outdoor café, a small amphitheater, and unique art sculptures (Landezine, 2019, p. 1). The Green Heart allows for many uses and activities, therefore creating a diverse space. The active environment allows students to walk through when going to classes, stop on a bench to do homework, gather with friends, and meet with a larger group of people for a club meeting or class project. The lawn space includes many 6 to 8 feet wide pathways, resting benches, both under seating and overhead lighting, colorful garden boxes, and a delicious outdoor café. This lawn space is unique to a campus and creates a campus quadrant or four-quart. The Green Heart lawn reflects ideals and design features of the Drillfield lawn

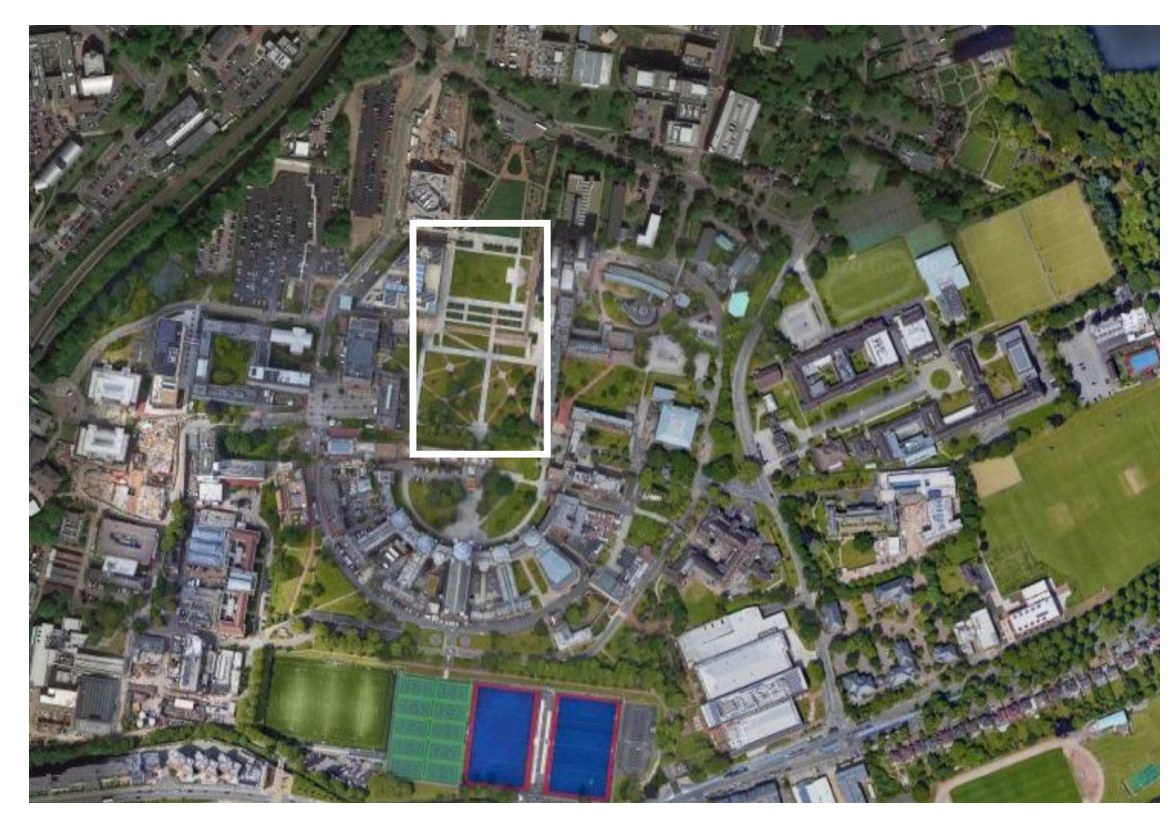
at Virginia Polytechnic Institute. While the Green Heart is more a vibrant space and includes modern features, they both portray the feeling of a united and strong University.

Figure 3.4 (left): Map of the University of Birmingham's campus, showing the location of the Green Heart. 


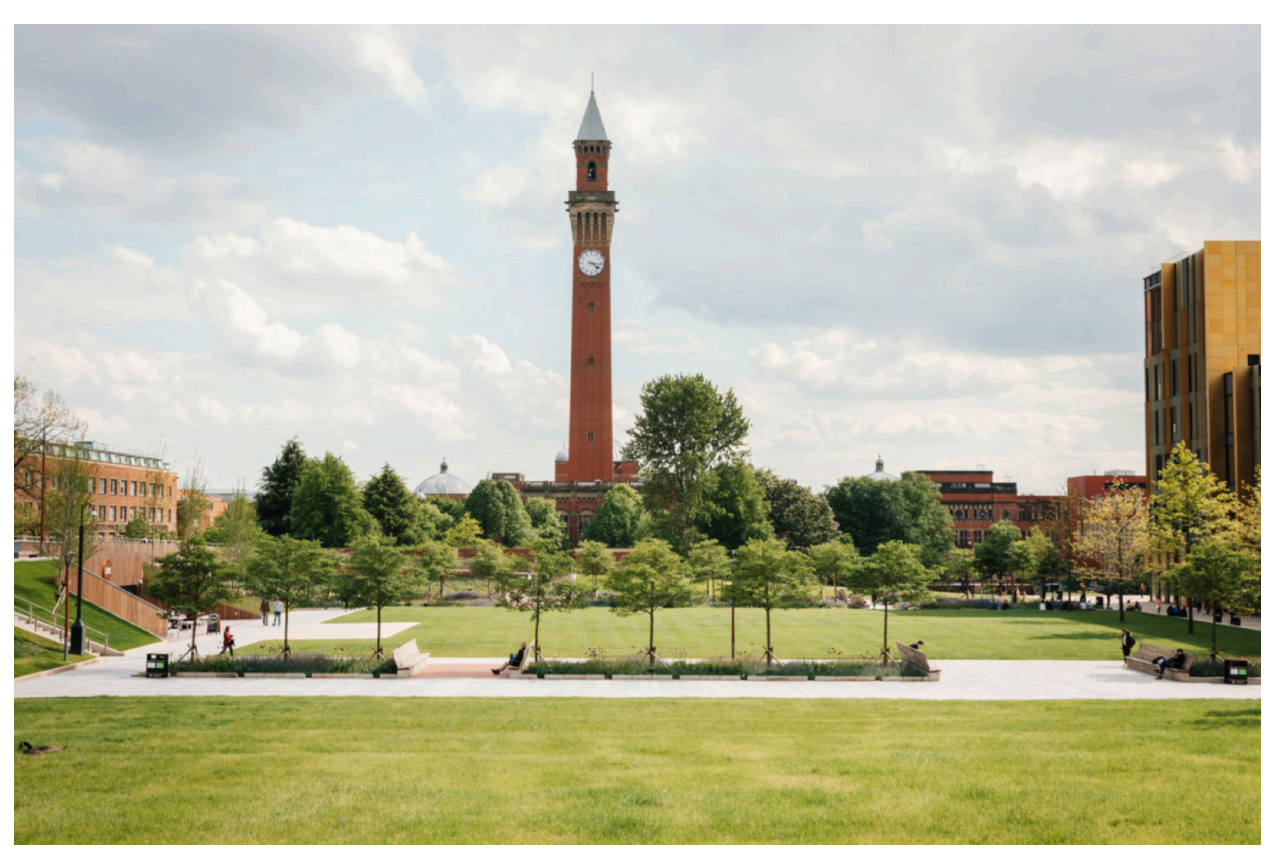

Figure 3.5: Image of the Green Heart lawn that provides views of a campus landmark and clock tower.

Safety and security should be considered in order for the students to feel comfortable using the space. Lighting specialist Speirs and Major assisted the designer of The Green Heart in creating a space that has many lighted pathways and lighting over benches and gathering spaces, making this a

“24/7 environment" (Landezine, 2019). Additionally, this space is inclusive in terms of accessibility and incorporates $\mathrm{Wi}-\mathrm{Fi}$ and outlets.

Figure 3.6 (right): Groups of students studying on the Green Heart lawn.

The Green Heart lawn space serves as a designated area for university wide events and festivals, bringing the campus community together. Lighting is a key component to this space, especially when designing a wide open lawn.

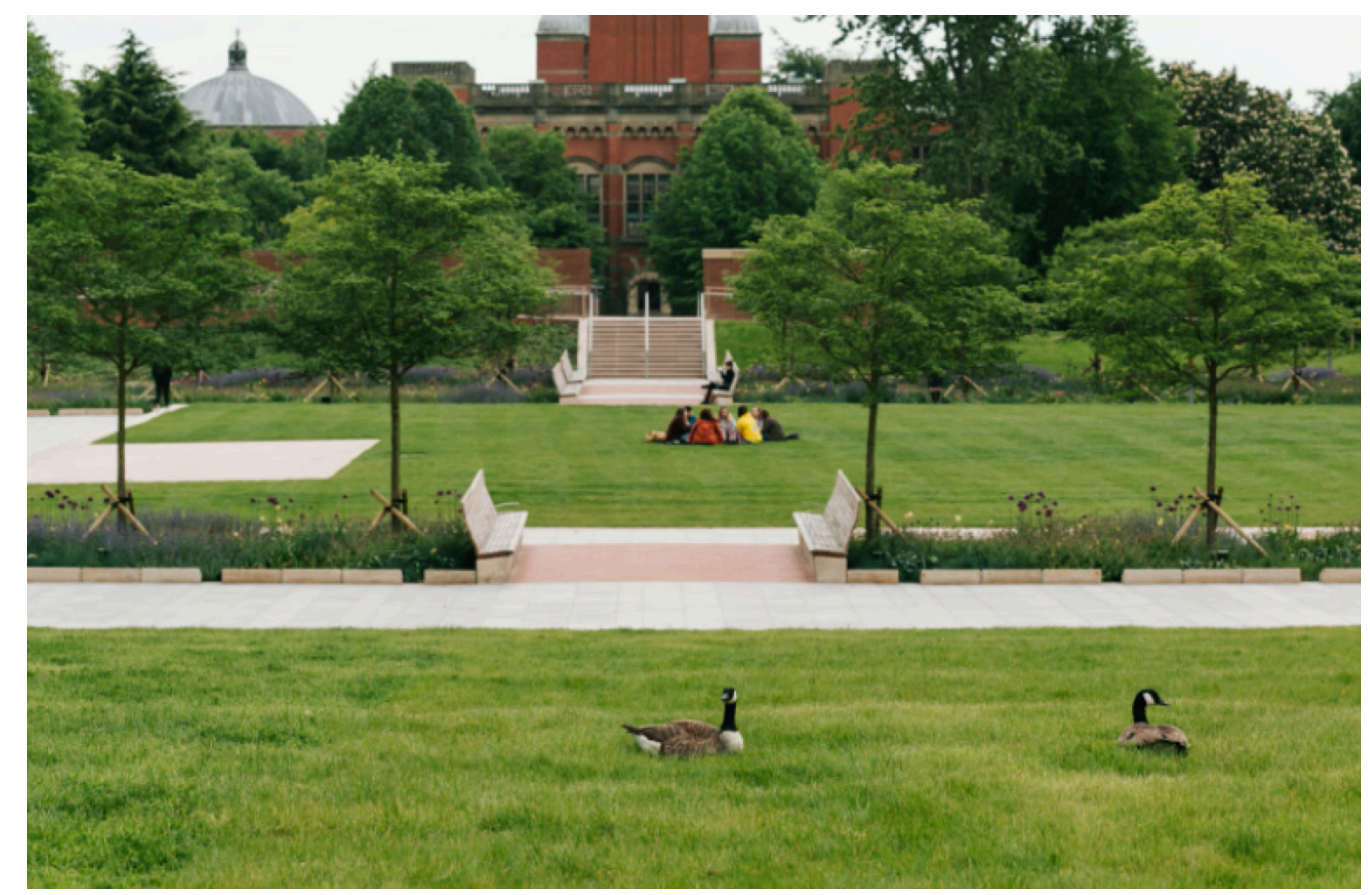

This project is very successful and serves as a precedent for many University fourcourts. The Green Heart project even has its own twitter account and t-shirts made to show the student's pride in their University. The Green Heart is truly an active gathering lawn for the campus community to learn, socialize, and relax.

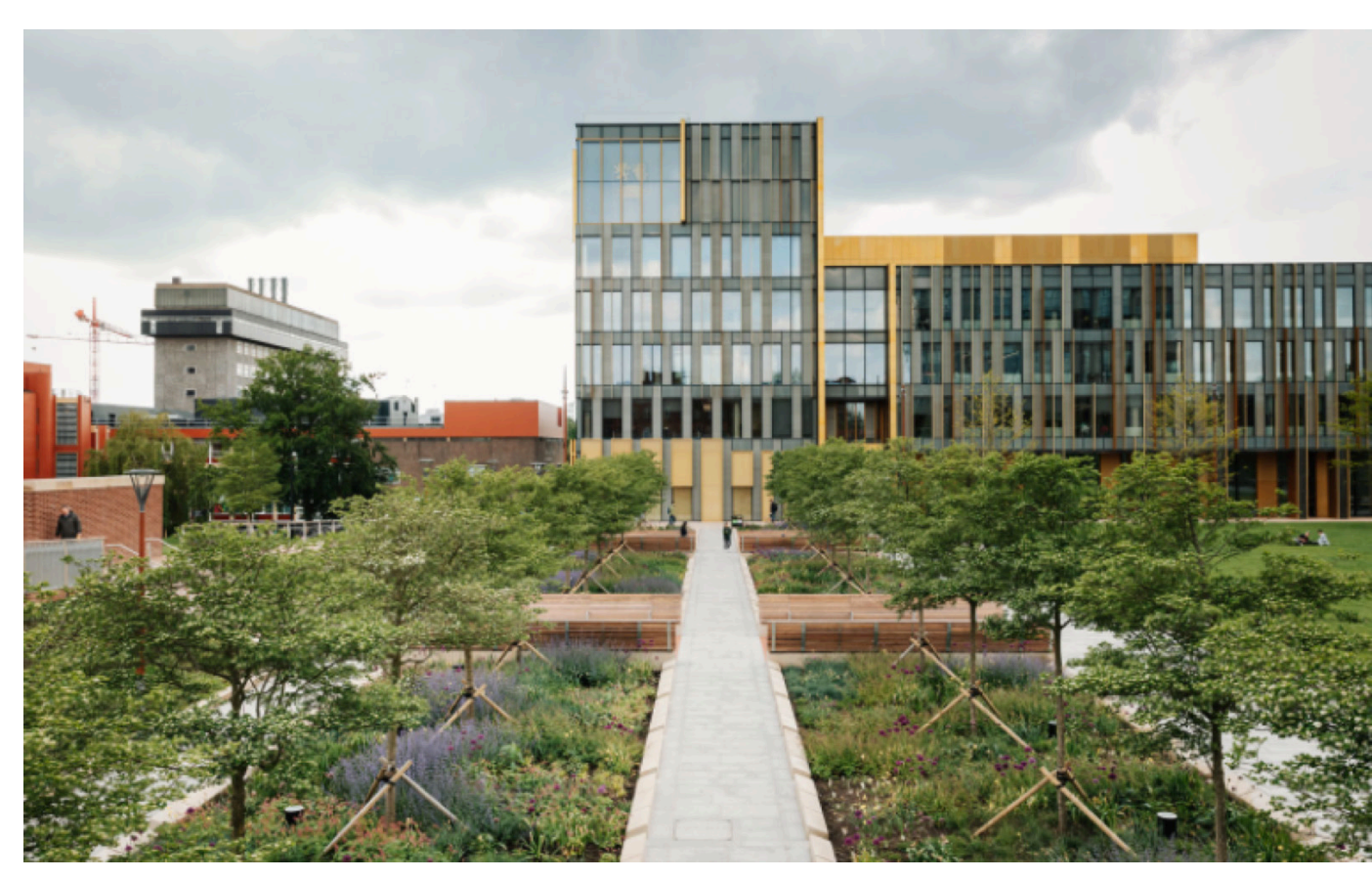

Figure 3.6 (left): Image showing garden boxes located adjacent to the Green Heart lawn.

Figure 3.6 (right): Pathway lighting 7 ines the walkways allowing University of Birmingham students and faculty to feel safe when on the Green Heart lawn at dusk.

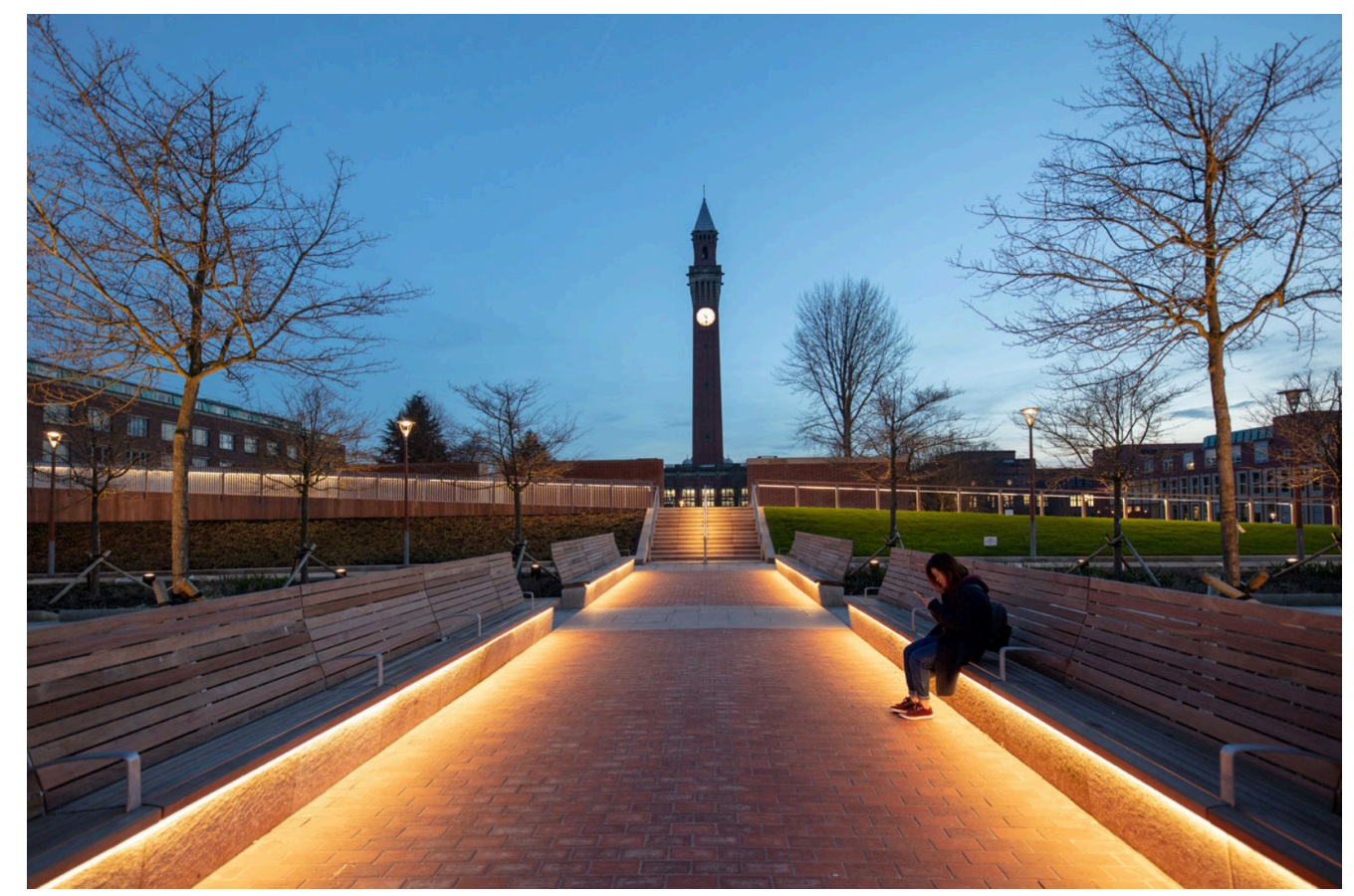



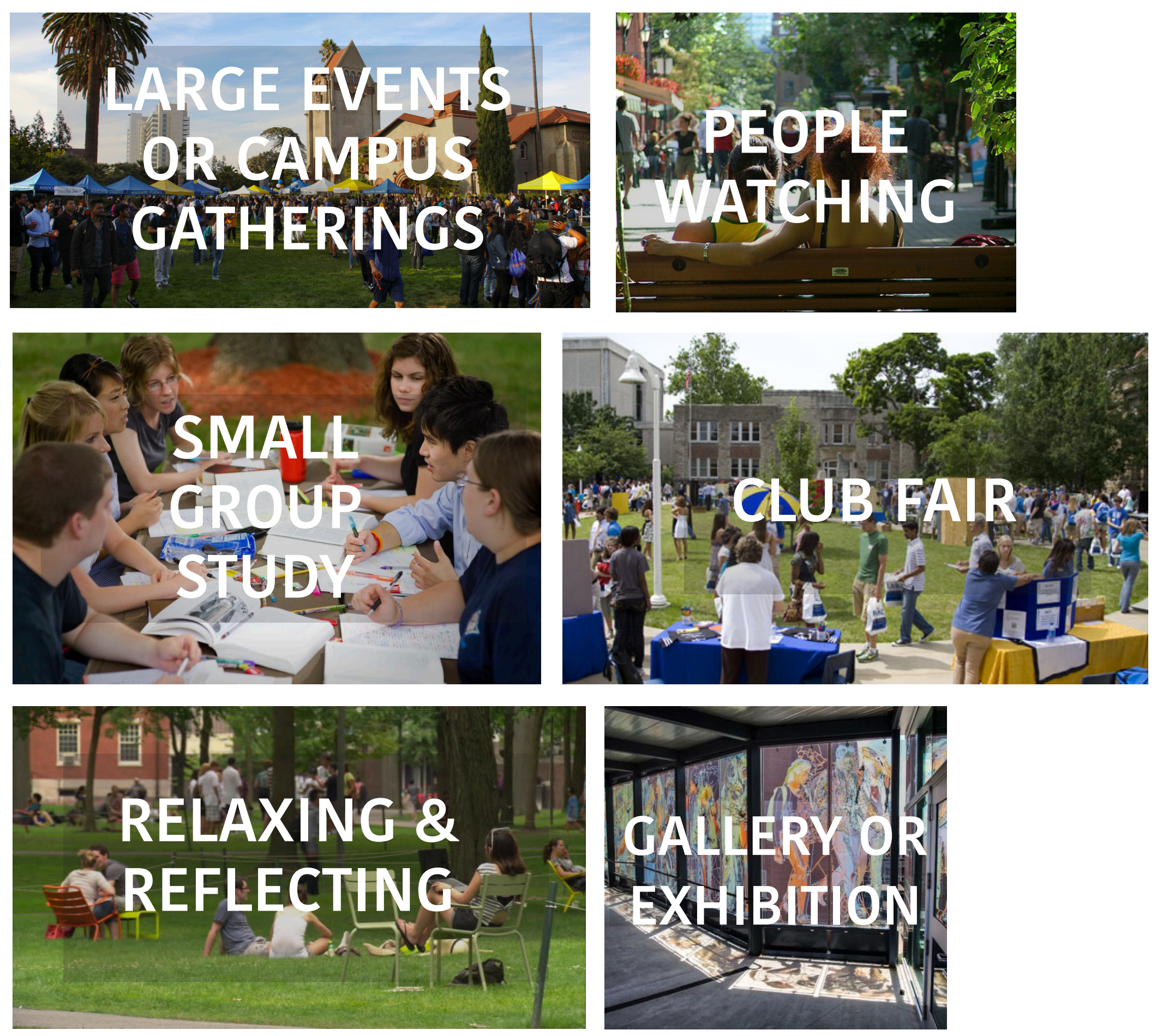
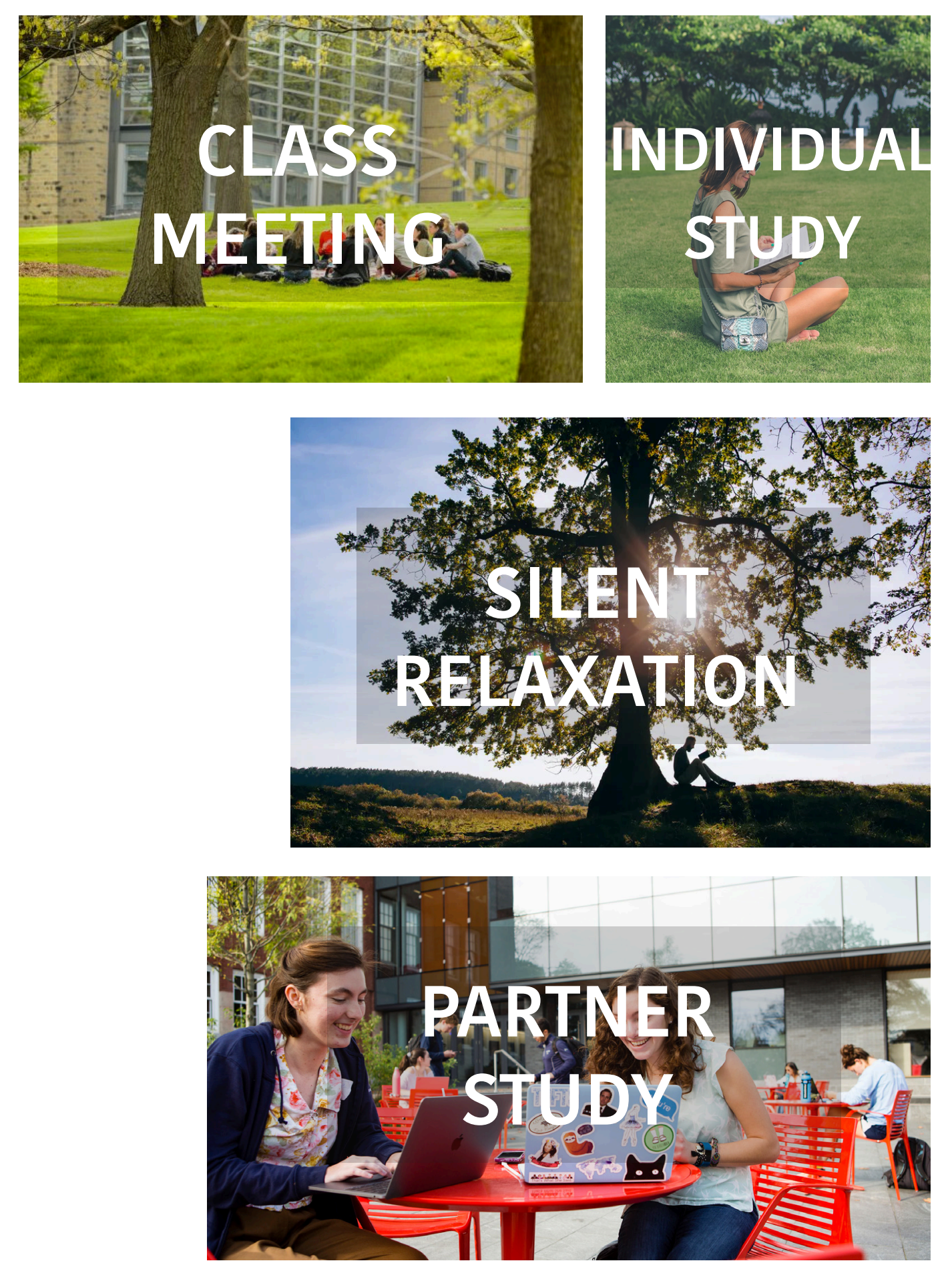
Design Principles

1. SPACE IS ADAPTABLE TO BOTH LARGE AND SMALL ACTIVITIES AND EVENTS.

2. SPACE IS FLEXIBLE TO ACCOMMODATE WIDE RANGE OF ACTIVITIES INCLUDING SOCIALIZING, RELAXING, AND LEARNING.

3. SPACE IS THE FACE OF CAMPUS, AND SHOULD BE SEEN AS A MARKETING TOOL AND ENHANCE THE CAMPUS IDENTITY. THEREFORE, ITS IMAGEABILITY IS CRITICAL.

4. SPACE IS INCLUSIVE AND IS WELCOMING TO A DIVERSE GROUP OF STUDENTS.

5. SPACE IS LOCATED IN THE CENTRAL PORTION OF CAMPUS AND ALONG FREQUENTLY TRAVELED PATHWAYS.

6. SPACE INTEGRATES CIRCULATION AND WALKWAYS INTO THE DESIGN.

7. ALTHOUGH LARGER, THE SPACE IS DIVIDED INTO SMALLER, MORE MANAGEABLE SECTIONS. THEREFORE, SERVING VARIOUS USES.

8. SECTIONS ARE PROPERLY INTEGRATED AND UNITED AS PART OF ONE LARGER SPACE.
7. SPACE IS AN EXEMPLARY MODEL FOR SUSTAINABLE DEVEL OPMENT AND SUSTAINABLE CAMPUS LIFE.

8. SPACE UTILIZES A VARIETY OF NATURAL ELEMENTS FOR REC REATION AND COMFORT.

9. SPACE FOSTERS SOCIAL CONNECTION AND ACTIVE LEARNING. 


\section{Design Recommendations}

\begin{tabular}{|c|c|c|c|c|c|c|c|c|}
\hline \# & LARGE ACTIVE & 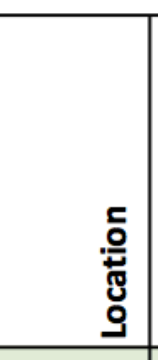 & 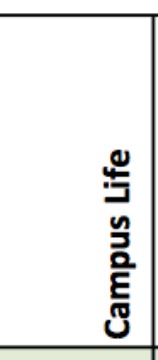 & 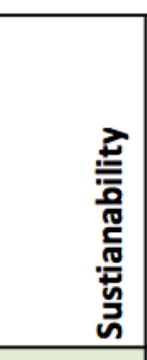 & 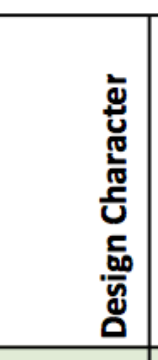 & 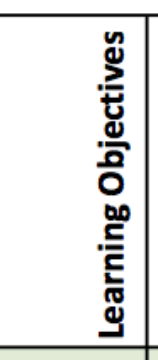 & 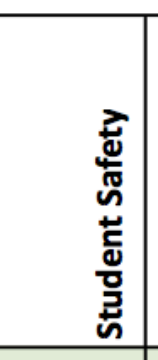 & 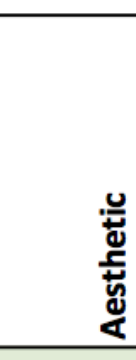 \\
\hline 1 & $\begin{array}{l}\text { Located in the central campus core and along a main pathway or fourcourt. Should be placed } \\
\text { next to this main pathway route, allowing for proper pedestrian circulation along the main } \\
\text { pathway. }\end{array}$ & $\mathbf{x}$ & & & & & & \\
\hline 2 & $\begin{array}{l}\text { Mix of paved areas, with lawn and green spaces. The percentage of paved areas ranged from } \\
15 \text { to } 85 \text { percent. Predominately hardscaped spaces should have pervious paving. Pervious } \\
\text { paving is recommended to promote infiltration of stormwater. }\end{array}$ & & & $\mathbf{x}$ & $x$ & & & \\
\hline 3 & $\begin{array}{l}\text { To accommodate large events, trees are better to be arranged around the peripheries rather } \\
\text { than to be scattered. While designing the space, consider a larger, more open section that can } \\
\text { accommodate these event spaces. }\end{array}$ & & $\mathbf{x}$ & & $\mathbf{x}$ & & & \\
\hline 4 & $\begin{array}{l}\text { A small or large lawn space should be considered to accommodate large events and active } \\
\text { recreational activities. To reach sustainability goals, consider a smaller sized lawn space with } \\
\text { alternating concrete or tiles mixed in. }\end{array}$ & & & $\mathbf{x}$ & $x$ & & & \\
\hline 5 & $\begin{array}{l}\text { Shade must be provided with either trees or shade structures. Therefore, consider trees that } \\
\text { provide shade, while not blocking the views. }\end{array}$ & & & & $x$ & $x$ & & $x$ \\
\hline 6 & $\begin{array}{l}\text { Seating must be provided by either seating walls, non-movable benches, or movable chairs. } \\
\text { Consider creative seating options such as swinging or hanging chairs, innovative ground } \\
\text { seating, or using steps as seating. These creative seating options should be placed throughout } \\
\text { the design for a cohesive space. }\end{array}$ & & & & & $\mathbf{x}$ & & $\mathbf{x}$ \\
\hline 7 & $\begin{array}{l}\text { Shade structures not only offer sun protection, but in some cases a bit of privacy. Therefore, } \\
\text { different types of shade structures should be considered based on the desired level of visibility } \\
\text { and the number of people that are covered. For example, a gazebo or a pavilion both provide a } \\
\text { relative privacy for group work and group study. On the other hand, pergolas can cover a wide- } \\
\text { open outdoor areas and offer partial shade without increasing privacy. Adding vines or sheer } \\
\text { curtain can increase privacy and shade, if needed. Water proof and retractable shade sails and } \\
\text { canopies can be designed for large outdoor areas as well. }\end{array}$ & & & & $\mathbf{x}$ & & & \\
\hline 8 & $\begin{array}{l}\text { Lighting should be added in and around seating areas and walkways. Consider the addition of } \\
\text { under seat wall or bench lighting as well as overhead lighting. Additionally, university-wide blue } \\
\text { light, help stations can be used to increase safety within and around these outdoor learning } \\
\text { environments. }\end{array}$ & & $\mathbf{x}$ & & & $\mathbf{x}$ & $\mathbf{x}$ & \\
\hline
\end{tabular}




\begin{tabular}{|c|c|c|c|c|c|c|c|c|}
\hline$\#$ & LARGE ACTIVE & 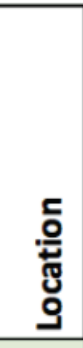 & 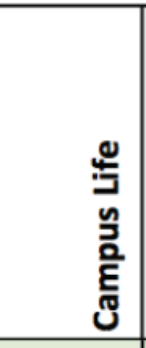 & 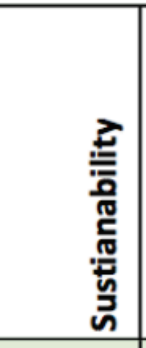 & 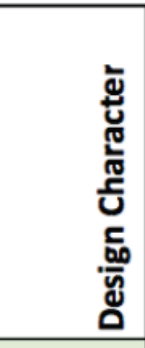 & 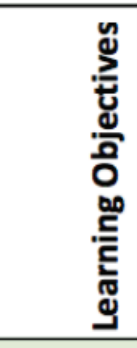 & 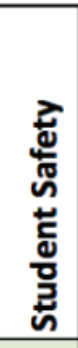 & 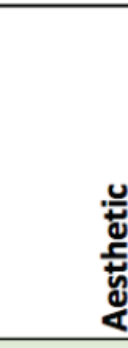 \\
\hline 9 & $\begin{array}{l}\text { Heavily traveled walkways are at least } 8 \text { feet wide to accommodate wheel chairs and groups of } \\
\text { people walking in either direction. This pathway measurement should be increased if the } \\
\text { overall population of the University is large and the location of this outdoor learning space is } \\
\text { near a heavily traveled walkway. }\end{array}$ & & $\mathbf{X}$ & & & & & \\
\hline 10 & $\begin{array}{l}\text { When considering planting and irrigation design, consider using native and drought tolerant } \\
\text { plants, curb cuts for runoff, planting a small garden, and using sustainable materials within the } \\
\text { design. }\end{array}$ & & & $X$ & & & & $\mathbf{X}$ \\
\hline 11 & $\begin{array}{l}\text { The overall design aesthetic should match or reflect the current structures and buildings } \\
\text { surrounding the site. Consider adopting a similar style or character of the established buildings. }\end{array}$ & & & & $\mathbf{X}$ & & & $\mathbf{x}$ \\
\hline 12 & $\begin{array}{l}\text { Landmarks and place-making elements should be highlighted though capturing the views from } \\
\text { the outdoor learning environment site. Consider various sidelines from each seating and } \\
\text { recreational area in order to create a space that enhances student's learning abilities as well as } \\
\text { attraction from future students and their visiting parents. }\end{array}$ & & $\mathbf{X}$ & & & & & \\
\hline 13 & $\begin{array}{l}\text { The addition of power outlets should be considered when designing a space that is intended for } \\
\text { students to spend long periods of time. Collaborating with the University technical support and } \\
\text { administration will determine if the addition of power outlets is feasible for an active outdoor } \\
\text { learning environment. }\end{array}$ & & & & & $\mathbf{X}$ & & \\
\hline
\end{tabular}




\section{LARGE DISCOVERED}

The Holyrood North - University of Edinburgh

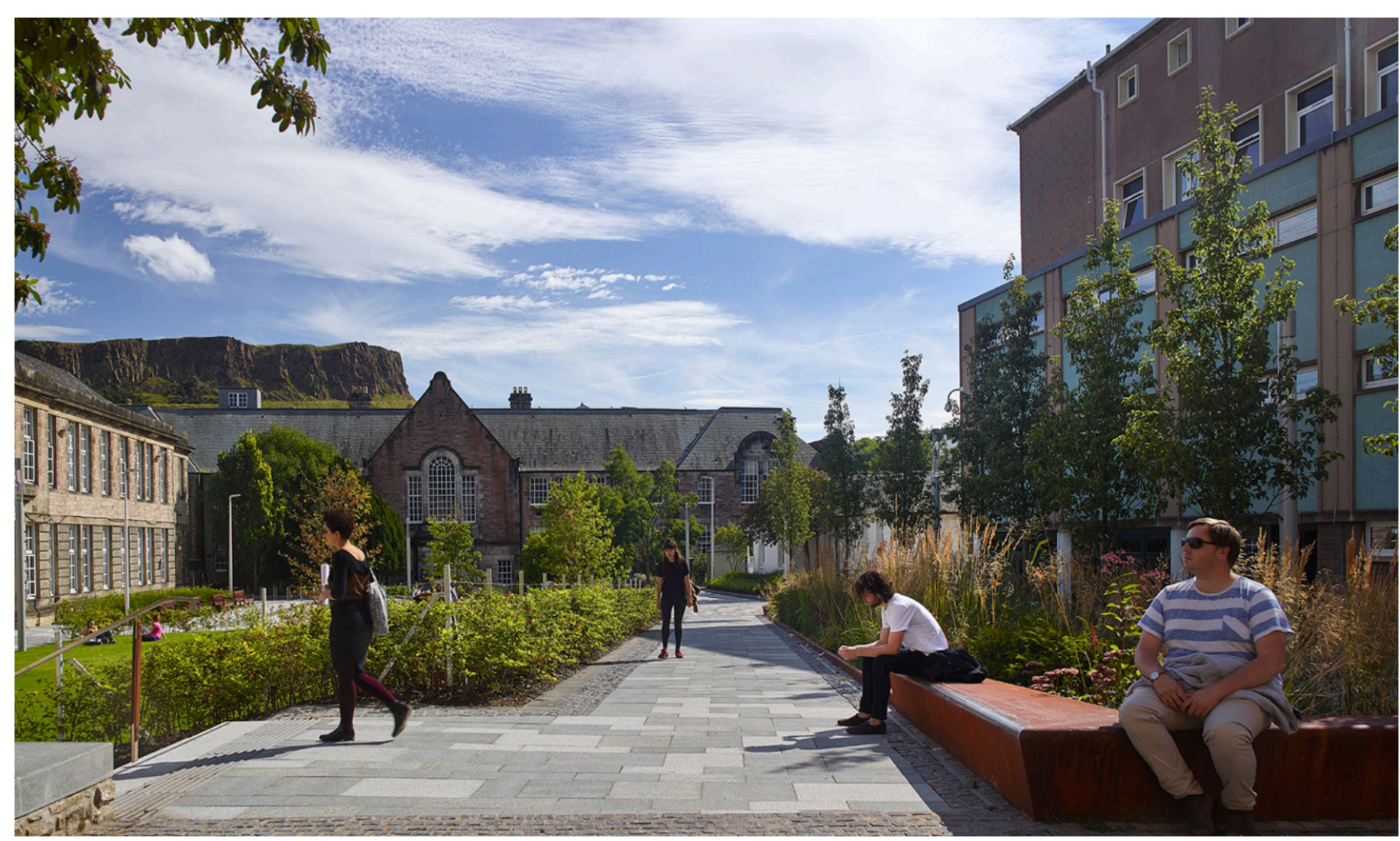

Figure 3.7: Pedestrian view showing students using the Holyrood North complex.

The Holyrood North landscape project is located on the North portion of the University of Edinburgh's campus, near both residential and academic buildings. This project won the Landscape Institute Award in 2017 for its high-quality detailing, thoughtful design, and its connection to the local context. The designers at Harrison-Stevens wanted to utilize the natural light within this denser urban environment and enhance the relationship between light and dark through both confined and open spaces. Natural lighting enhances the sense of anticipation, allowing people to be drawn into and discover the space.
The Holyrood North portion of campus is not the hub or social center of campus and sees far less pedestrian traffic than the south and west side of campus. The terraced learning and socializing spaces are located within a secluded courtyard, making this a discovered space. At first glance, the user or pedestrian doesn't notice the space and must fully enter into the area in order to discover this large space. As they discover this natural learning environment through entering the protected courtyard, they stumble upon additional personal study or relaxing spaces that are embedded within the larger area.

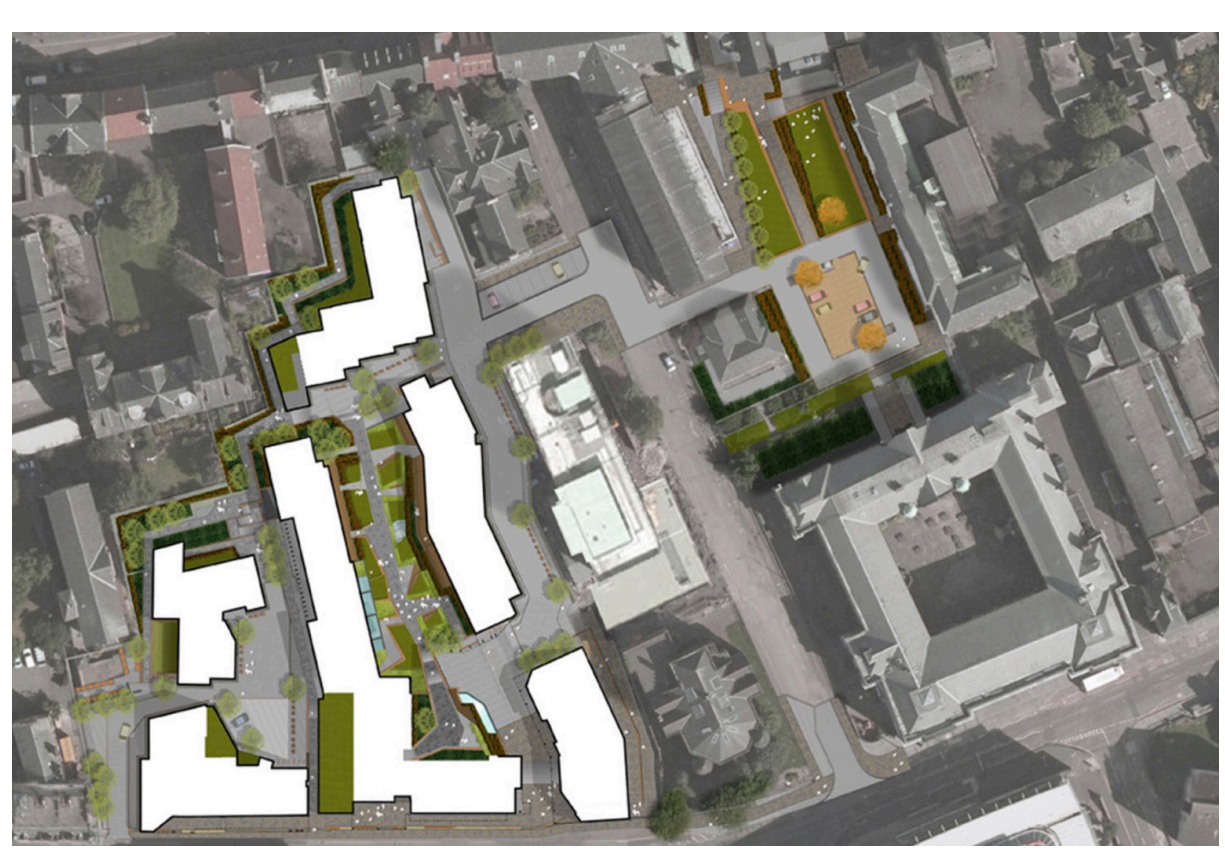

Figure 3.8: Site plan of The Holyrood North, located adjacent from the social hub of campus.

The Holyrood North landscape project connects the academic and residential sections of campus through unique landscape design features. Each section seamlessly flows into the next. The space properly enhances the topography though large sets of steps and sloping walkways dropping 2 stories across the city block. These spaces are integrated into the landscape design 
using natural colors and a variety of planting. The use of natural materials and colors create a comfortable, inviting, and warm space to either relax or learn. Seating walls both provide seating for students as well as creates a planting box for shrubs, flowers, or grass. This space has main pathways that are roughly 8 feet wide and adjusts pathway width as needed. Although furniture is kept to a minimum, trash cans and recycling bins are integrated into the design. This project aims to re-use materials, include native and bio-diverse plants, and integrate the extensive green rood system in order to reach their sustainability goals. With various types of seating as well as both large and small 'off the path' meeting areas, this space is used for both quiet, individualized learning as well as various types of group or class learning.

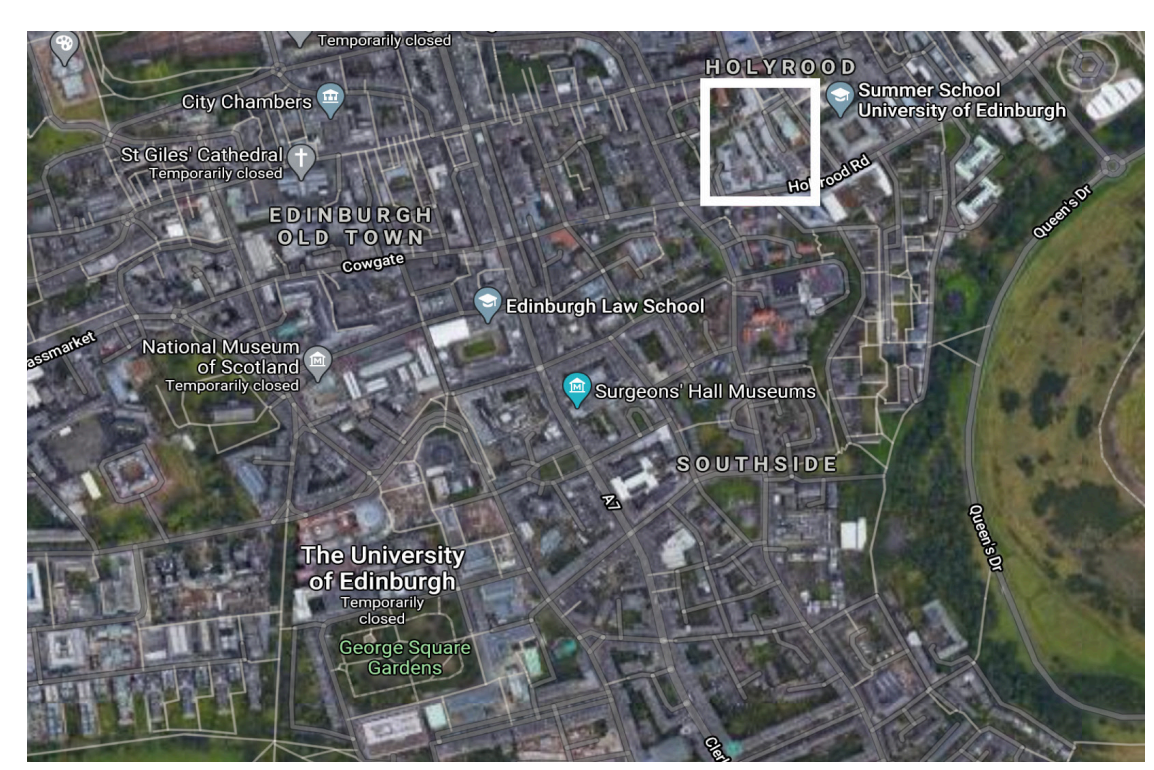

Figure 3.9: Map of University of Edinburg showing the location of Holyrood North complex.

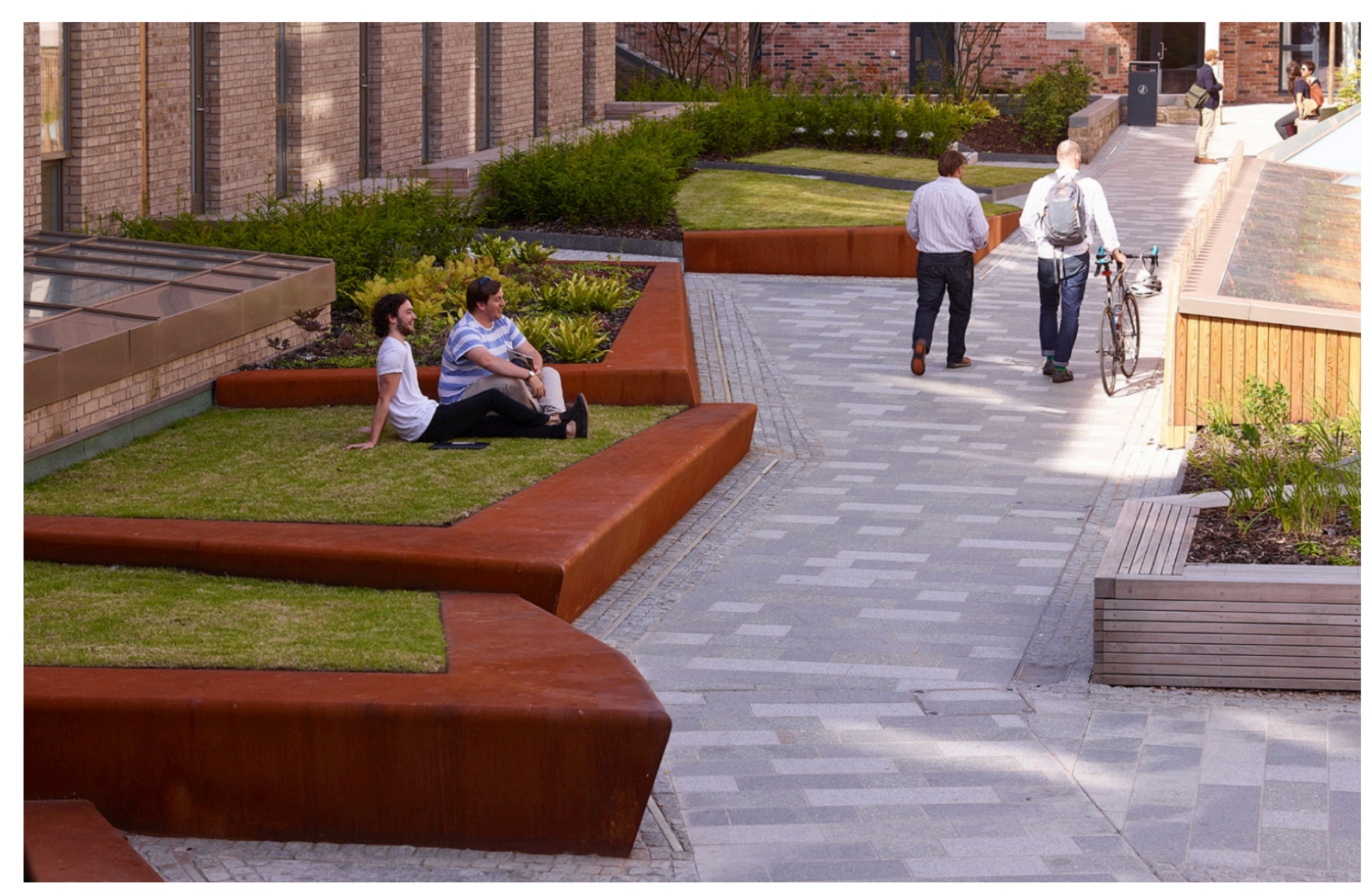

Figure 4.1: Students in groups of two enjoying various seating options at the Holyrood North complex. 


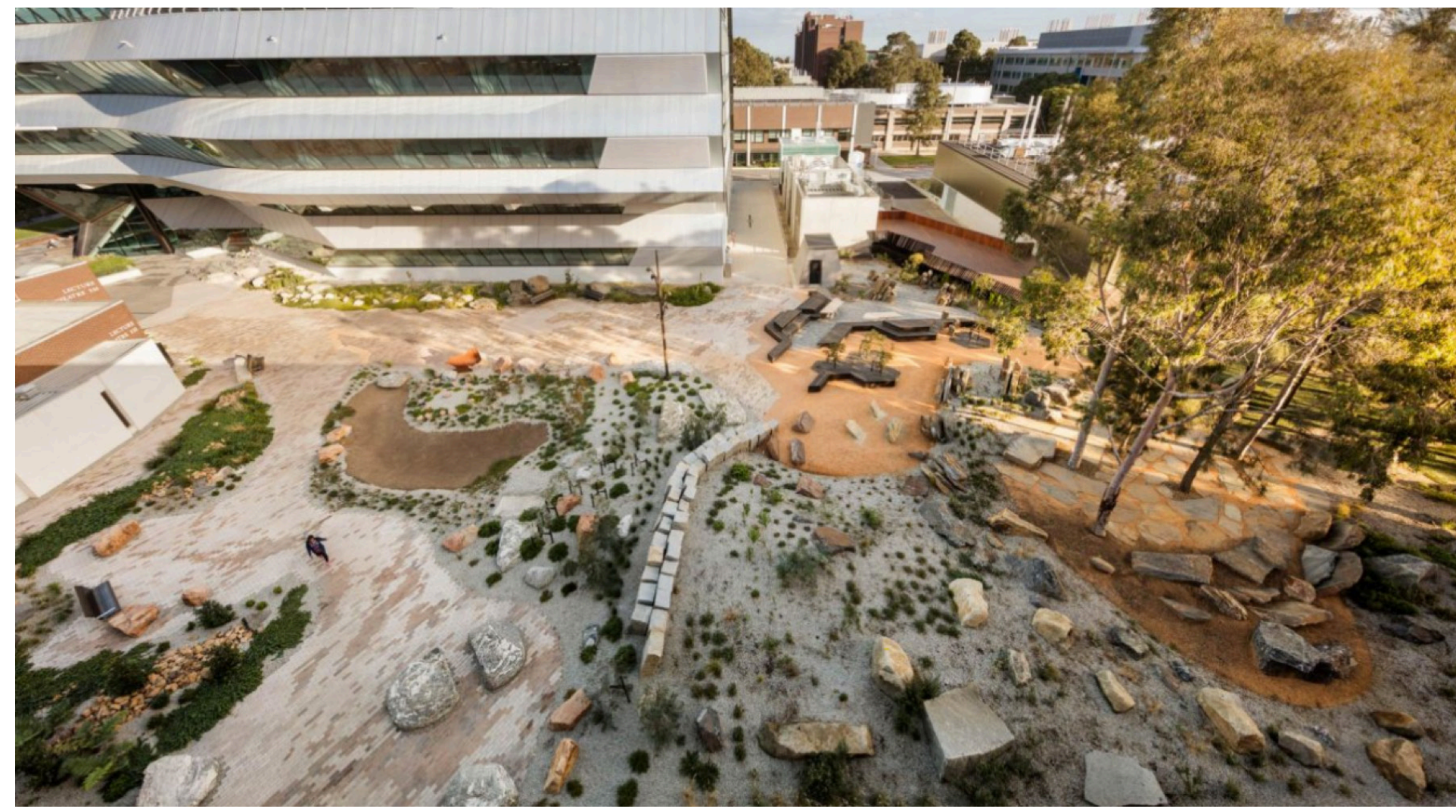

Figure 4.2: The Earth Sciences Garden top view, showing both an open and secluded section.

The Earth Sciences Garden located on the North West section of Monash University's Clayton campus. The space is designed by Rush Wright Associates as an outdoor teaching laboratory and integrates "key features of geology and geomorphology within the design of the space" (Landezine, 2017, p. 1). This space was immediately recognized in scientific community and used as an innovative teaching environment. This project is internationally recognized and established a new benchmark for outdoor learning landscapes. With a budget of \$2 million Rush Wright Associates designed a 32,400 square foot space $(360 \mathrm{ft} \times 90 \mathrm{ft}$ ). This project received awards from the 2018 AILA National Landscape Architecture Awards - Civic Landscape and 2016 Association for Learning Environments: Landscape/Outdoor Learning Area.

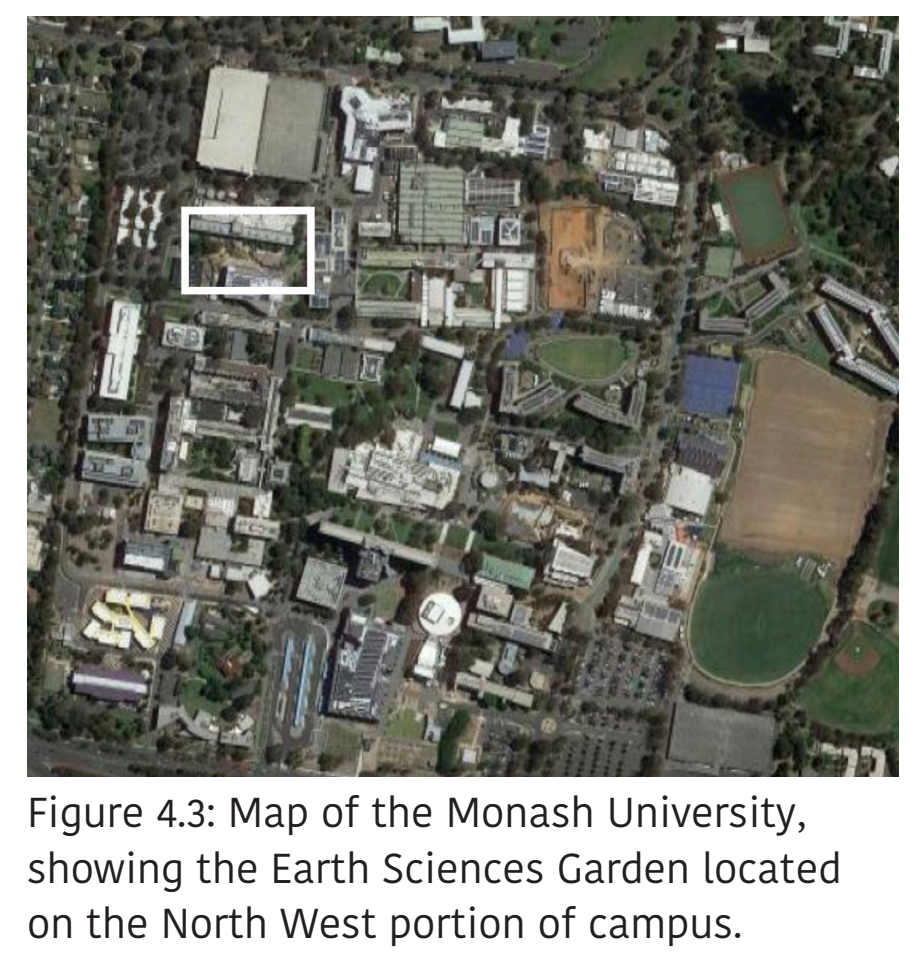

The use and placement of rocks and vegetation is very specific to the design, reflecting certain geographic regions. A collection of rocks is arranged around walkways to "mimic specific regions of Victoria" (Landezine, 2017, p. 1). 20 different types of rock are used in the design as well as handmade sculptures and art pieces and vegetation that reflect the unique flora of each region (Landezine, 2017). Rush Wright Associates wanted to focus on creating an environment that acts and looks more like a national park, rather than a curated display garden.

The Earth Sciences Garden comes to life with the placement of the rocks and vegetation but the design features allow the space to be used as a comfortable outdoor learning environment. Neutral colored brick walkways meander 
through the space and are about 4 to 10 feet wide. Benches, both organic and park-like line the walkways. Using rock formations as benches and backrests creates an organic and creative environment for the user to experience. A small pond or water feature considers the designers goal of resembling a nation park. The addition of walkways, benches, lighting, and shade trees makes this space feel comfortable and allows a group or class to enjoy and learn in this space for longer periods of time.

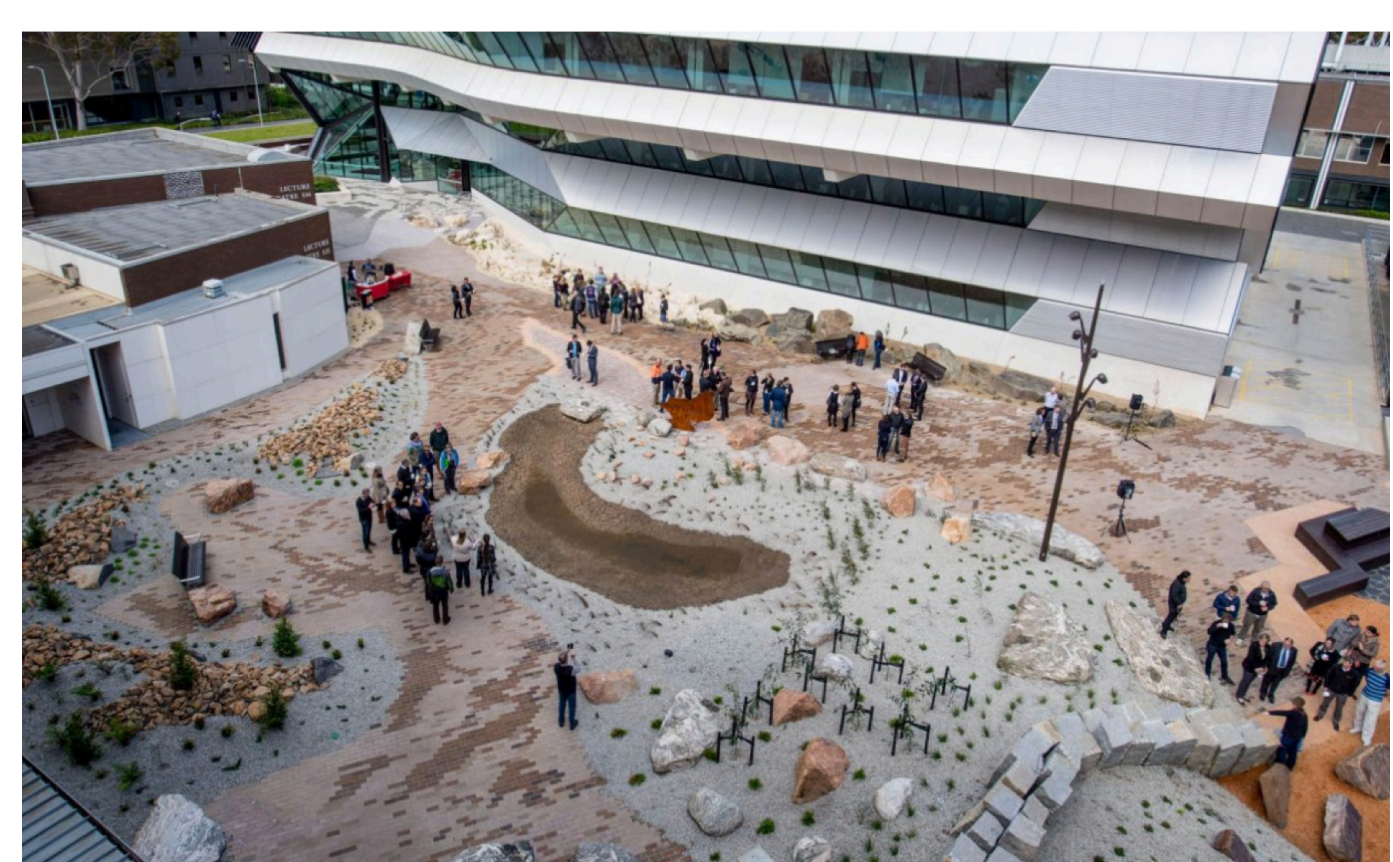

Figure 4.4: Groups of students, both in classes and small study groups gathering in the Earth Science Garden.

Located off the main axis and large campus walkways, the Earth Sciences Garden must be discovered or found by the user. Once surrounded in this unique garden, the user can visit each section to learn something new, and maybe discover their new favorite study spot. The Earth Sciences Garden is truly a space for students in the sciences or a related field to learn and grow without physically being in a walled classroom.

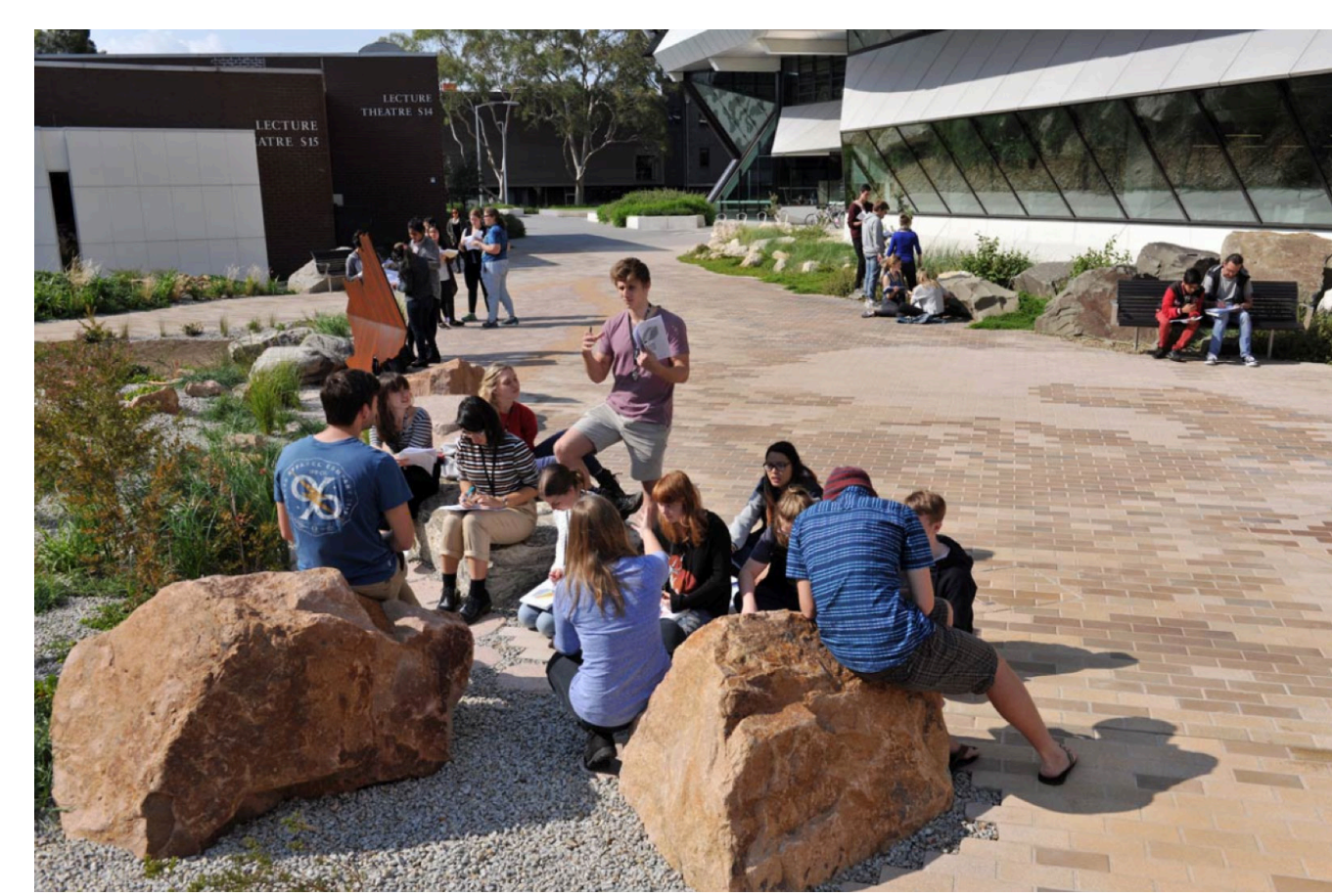

Figure 4.5 (left): Groups of students actively learning in the Earth Science Garden at Monash University.

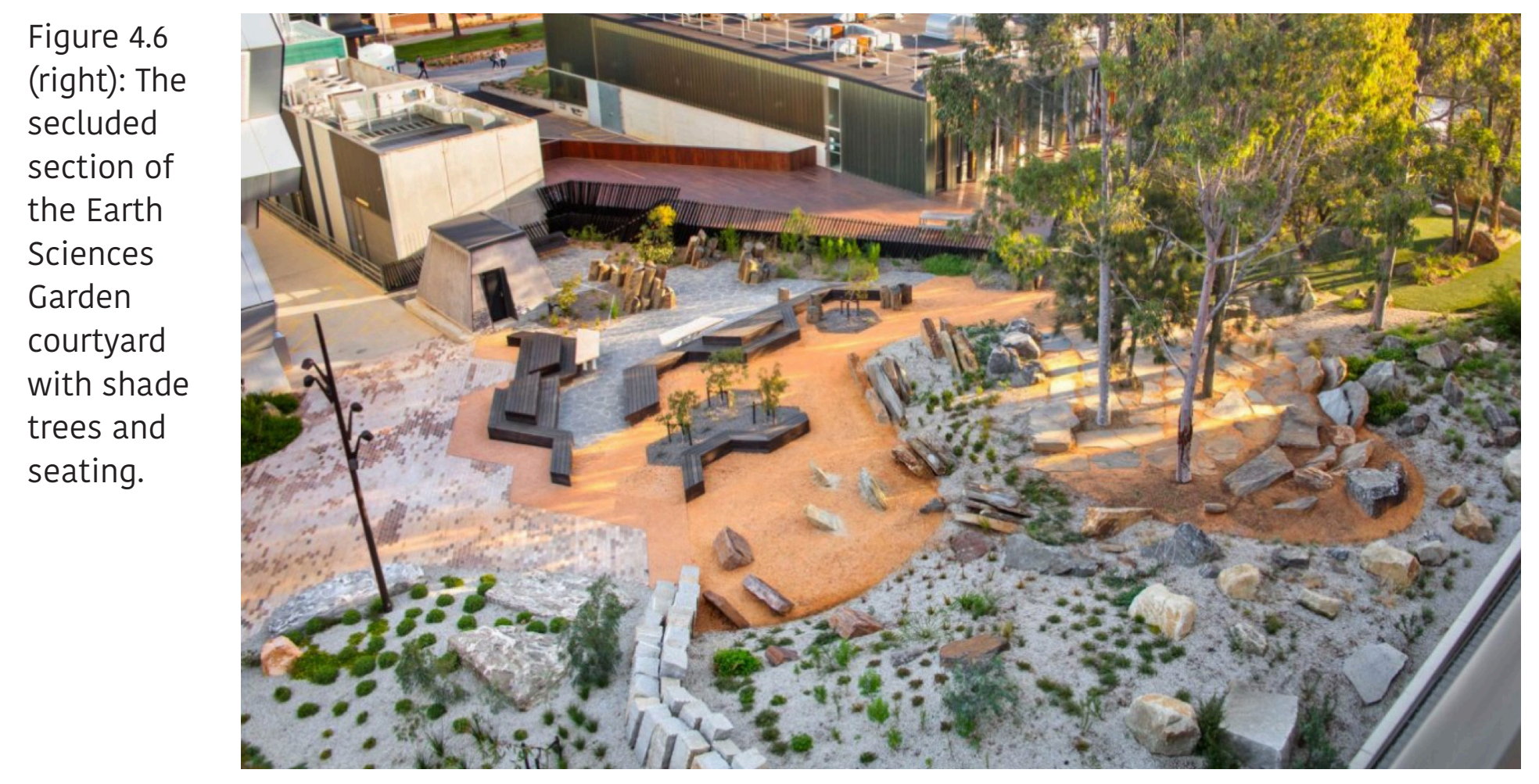



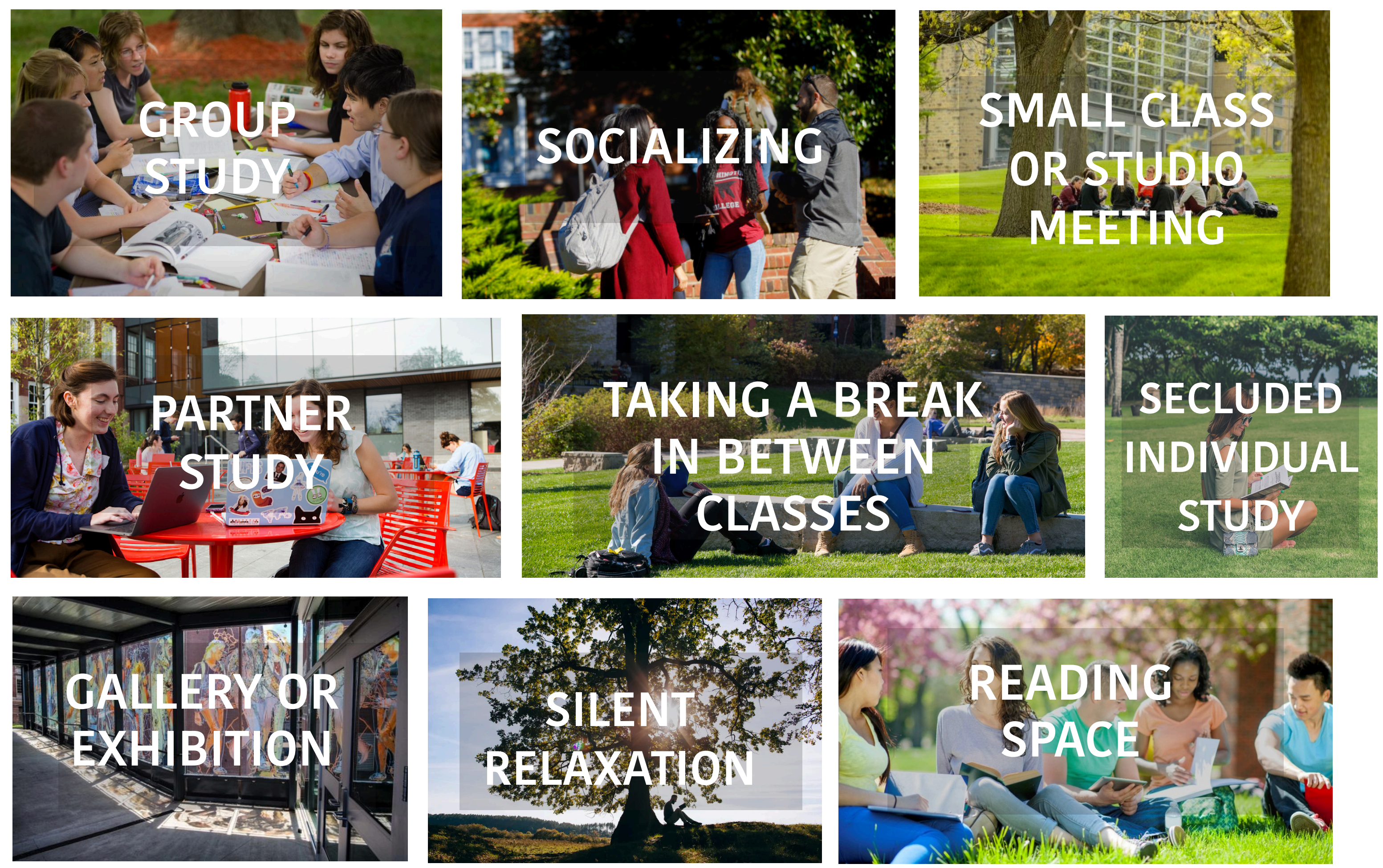
Design Principles

1. SPACE FEELS OPEN BUT IS SECLUDED AND PROTECTED BY BUILDINGS, TREES, OR STRUCTURES.

2. SPACE INCLUDES MANY SEATING AND GATHERING OPTIONS. THEREFORE, ALLOWING FOR A WIDE VARIETY OF USES AND ACTIVITIES.

3. SEATING IS ADAPTABLE AND INCLUDES CREATIVE SEATING OPTIONS. CONSIDER CREATIVE SEATING OPTIONS SUCH AS SWINGING OR HANGING CHAIRS, INNOVATIVE GROUND SEATING, OR USING STEPS AS SEATING. FOR EXAMPLE, A LARGE ROCK IN A GRASS PATCH WHICH HAS THE OPPORTUNITY TC SERVE AS A BACKREST.

4. SPACE IS AN EXEMPLARY MODEL FOR SUSTAINABLE DEVELOPMENT AND SUSTAINABLE CAMPUS LIFE.

5. SPACE INCLUDES BOTH SMALLER GARDEN SECTIONS THAT ARE TUCKED AWAY AND SPACES THAT ARE OPEN AND ARE SPECIFICALLY USED FOR LARGE GROUP OR CLASS SPACE.

6. SPACE USES A VARIETY OF PLANTS AND NATURAL COLORS. CONSIDER LIMITING THE USE OF LARGE LAWNS AND ADDING SOME SHADE TREES NEAR SEATING. THEREFORE, CREATING A SPACE THAT IS WELCOMING BUT STILL PROTECTED.
7. SPACE INTEGRATES CIRCULATION AND WALKWAYS INTC THE DESIGN.

8. ALTHOUGH LARGER, THE SPACE IS DIVIDED INTO SMALLER, MORE MANAGEABLE SECTIONS. THEREFORE, SERVING VAR IOUS USES.

9. SECTIONS ARE PROPERLY INTEGRATED AND UNITED AS PART OF ONE LARGER SPACE.

10. SPACE INCLUDES SMALLER, QUIET STUDY OR REFLECTION SPACES.

11. SPACE HAS A TERRACED OR VARIED LANDSCAPE. USING STEPS, A SLOPED LAWN, OR A COMBINATION OF THE TWO.

12. SPACE IS INTERACTIVE. STUDENTS COULD LEARN FROM THE FEATURES (ROCKS, PLANTS, ECT.) OF THE SPACE AND THROUGH SPENDING TIME THE SPACE.

13. SPACE IS WELL LIT. 


\begin{tabular}{|c|c|c|c|c|c|c|c|c|}
\hline \# & LARGE DISCOVERED & 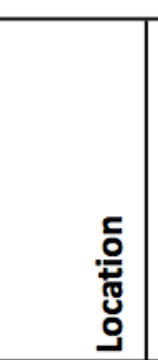 & 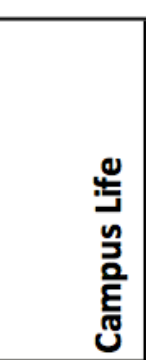 & 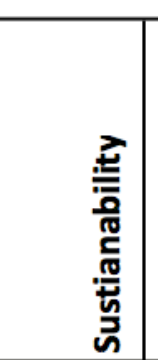 & 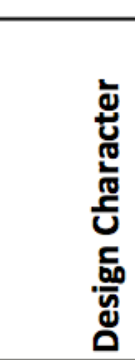 & 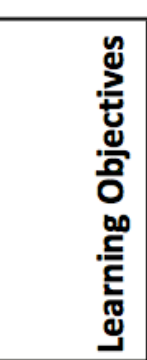 & 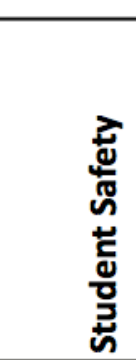 & 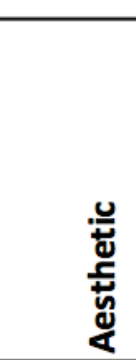 \\
\hline 1 & $\begin{array}{l}\text { When considering the location of the large discovered space, consider locating the space near } \\
\text { academic buildings, but not along main pathways. The space should be enhanced by the } \\
\text { neighboring academic buildings, but not be connected to or near a frequently traveled } \\
\text { pathway. }\end{array}$ & $\mathbf{x}$ & & & & & & \\
\hline 2 & $\begin{array}{l}\text { Mix of paved areas, with lawn and green spaces. The percentage of paved areas ranged from } \\
50 \text { to } 90 \text { percent. Predominately hardscaped spaces should have pervious paving. Pervious } \\
\text { paving is recommended to promote infiltration of stormwater. }\end{array}$ & & & $\mathbf{X}$ & $\mathbf{x}$ & & & \\
\hline 3 & $\begin{array}{l}\text { The design of the outdoor learning environment should recognize the importance of preserving } \\
\text { current open spaces. When designing in and around the space, consider the restorative and } \\
\text { natural impacts and consequences of altering that space. }\end{array}$ & $\mathbf{X}$ & & $\mathbf{X}$ & & & & \\
\hline 4 & $\begin{array}{l}\text { Landmarks and place-making elements should be highlighted though capturing the views from } \\
\text { the outdoor learning environment site. Consider various sidelines from each seating and } \\
\text { recreational area in order to create a space that enhances student's learning abilities as well as } \\
\text { attraction from future students and their visiting parents. }\end{array}$ & & $\mathbf{x}$ & & & & & \\
\hline 5 & $\begin{array}{l}\text { Lighting should be added in and around seating areas and walkways. Consider the addition of } \\
\text { under seat wall or bench lighting as well as overhead lighting. Additionally, university-wide blue } \\
\text { light, help stations can be used to increase safety within and around these outdoor learning } \\
\text { environments. }\end{array}$ & & $\mathbf{X}$ & & & & $\mathbf{x}$ & \\
\hline 6 & $\begin{array}{l}\text { Seating must be provided by either seating walls, non-movable benches, or movable chairs. } \\
\text { Consider creative seating options such as swinging or hanging chairs, innovative ground } \\
\text { seating, or using steps as seating. These creative seating options should be placed throughout } \\
\text { the design for a cohesive space. }\end{array}$ & & & & & $\mathbf{x}$ & & $\mathbf{x}$ \\
\hline 7 & $\begin{array}{l}\text { Shade must be provided by trees, small shade structures, or neighboring buildings. If located } \\
\text { near academic buildings that provide shade to the seating area, shade trees are not necessary, } \\
\text { but encouraged. Consider trees that provide shade, while not blocking the views. Shade } \\
\text { structures not only offer sun protection, but in some cases a bit of privacy. Therefore, different } \\
\text { types of shade structures should be considered based on the desired level of visibility and the } \\
\text { number of people that are covered. }\end{array}$ & & & & $\mathbf{X}$ & & & $\mathbf{X}$ \\
\hline
\end{tabular}




\begin{tabular}{|c|c|c|c|c|c|c|c|c|}
\hline$\#$ & LARGE DISCOVERED & 总 & 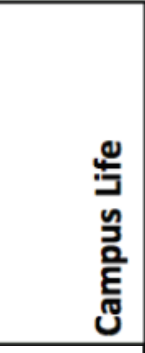 & 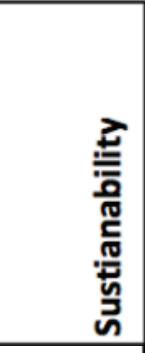 & 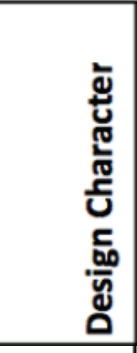 & 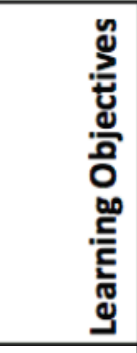 & 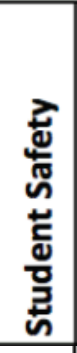 & 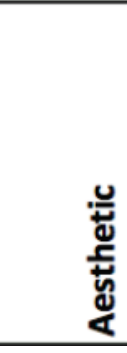 \\
\hline 8 & $\begin{array}{l}\text { The overall design aesthetic should match or reflect the current structures and buildings } \\
\text { surrounding the site. Consider adopting a similar style or character of the established buildings. }\end{array}$ & & $\mathbf{X}$ & & $X$ & & & $\mathbf{X}$ \\
\hline 9 & $\begin{array}{l}\text { Green vegetation such as vines, shrubs, planting boxes, fruit trees, or similar are used to } \\
\text { increase privacy or create shade, if needed. Consider using an additional amount of green } \\
\text { vegetation near sections that are designed for quiet studying and reflection. This will minimize } \\
\text { distractions and create a restorative learning environment. }\end{array}$ & & $X$ & $X$ & & $X$ & & $X$ \\
\hline 10 & $\begin{array}{l}\text { Majority of the colors used are neutrals with hints of color in planting or art pieces. The design } \\
\text { should flow and include visual connections to neighboring buildings. }\end{array}$ & & $x$ & & $\mathbf{X}$ & & & \\
\hline 11 & $\begin{array}{l}\text { Pathways should be sized appropriate to their expected purposes. Heavily traveled walkways } \\
\text { are at least } 6 \text { feet wide to accommodate wheel chairs and groups of people walking in either } \\
\text { direction. Less frequently traveled walkways are at least } 4 \text { feet wide. }\end{array}$ & & & & $X$ & $X$ & & \\
\hline 12 & $\begin{array}{l}\text { Landmarks and place-making elements should be highlighted though capturing the views from } \\
\text { the outdoor learning environment site. Consider various sidelines from each seating and } \\
\text { recreational area in order to create a space that enhances student's learning abilities as well as } \\
\text { attraction from future students and their visiting parents. }\end{array}$ & & $X$ & & & & & \\
\hline 13 & $\begin{array}{l}\text { When designing planting and irrigation, consider using native and drought tolerant plants, curb } \\
\text { cuts for runoff, planting a small garden, and using sustainable materials within the design. }\end{array}$ & & & $X$ & $X$ & & & $X$ \\
\hline 14 & $\begin{array}{l}\text { Interactive learning features are incorporated into the space. These features both inform and } \\
\text { inspire students and visitors. For example, plaques sharing the University's history or plaques } \\
\text { describing the species of plant. }\end{array}$ & & $X$ & $\mathbf{X}$ & $X$ & & & \\
\hline
\end{tabular}




\section{SMALL DISCOVERED}

Campus Park - Lund University of Technology (LTH), Sweden

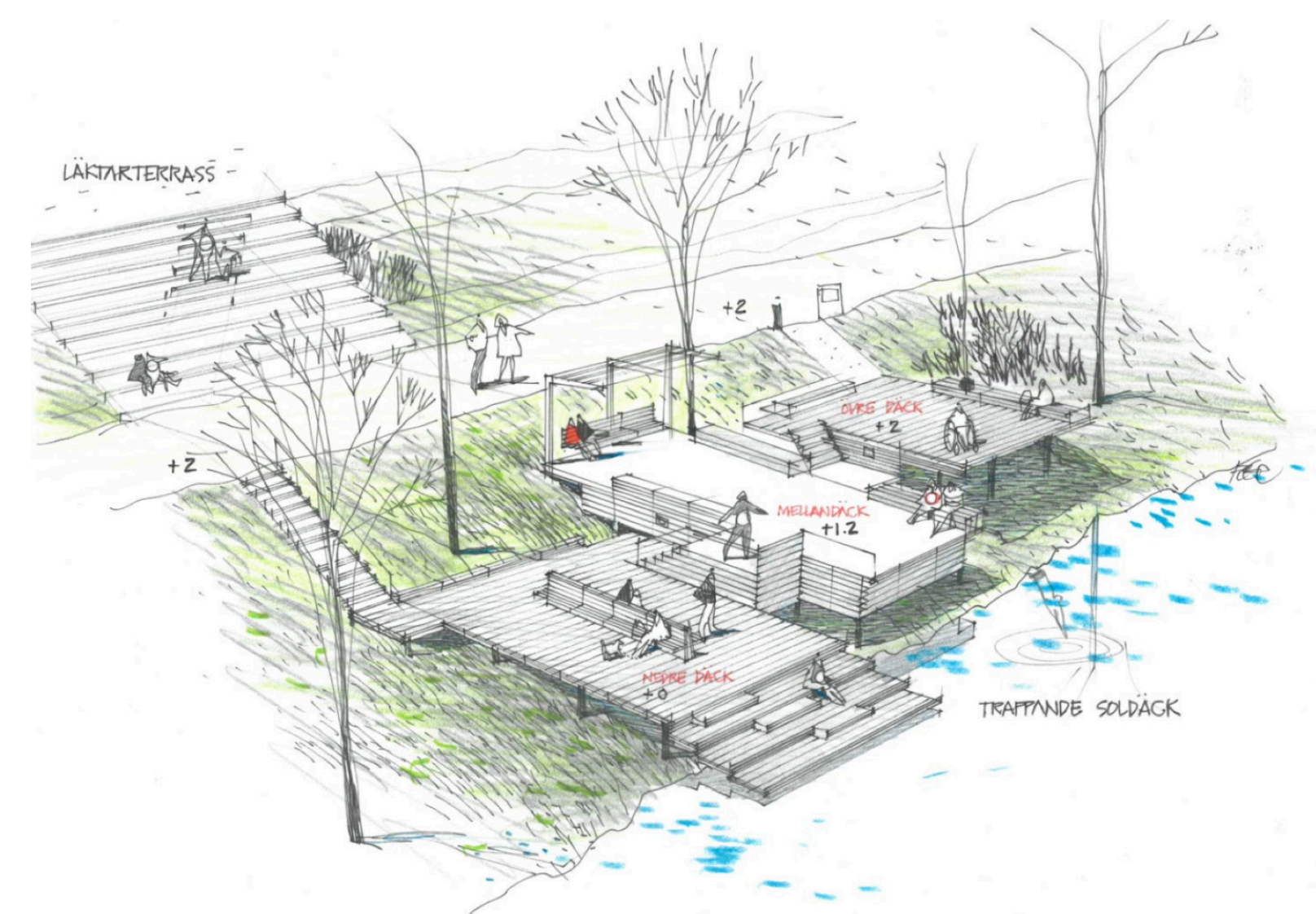

Figure 4.7: Sketch of the three terraces floating over the water designed for the Campus Park project, located at the Lund Institute of Technology, Sweden.

The Campus Park at the Lund Institute of Technology (LTH), in the southern portion of Sweden. The architects, Thorbjorn Andersson and PeGe Hillinge, aimed to transform this once unused and underdeveloped natural area into three sloping platforms or terraces that emerge from the terrain and are surrounded by nature. These three tiered platforms are roughly 30 feet by 40 feet and include steps and ramps to access each terrace. While the designers re-imagined the entire 51,000 square foot river space, this tiered section stands out (Landezine, 2017). Since the opening of this redevelop- ment project in 2016, the University has seen an increase in the overall foot traffic and use of this area.

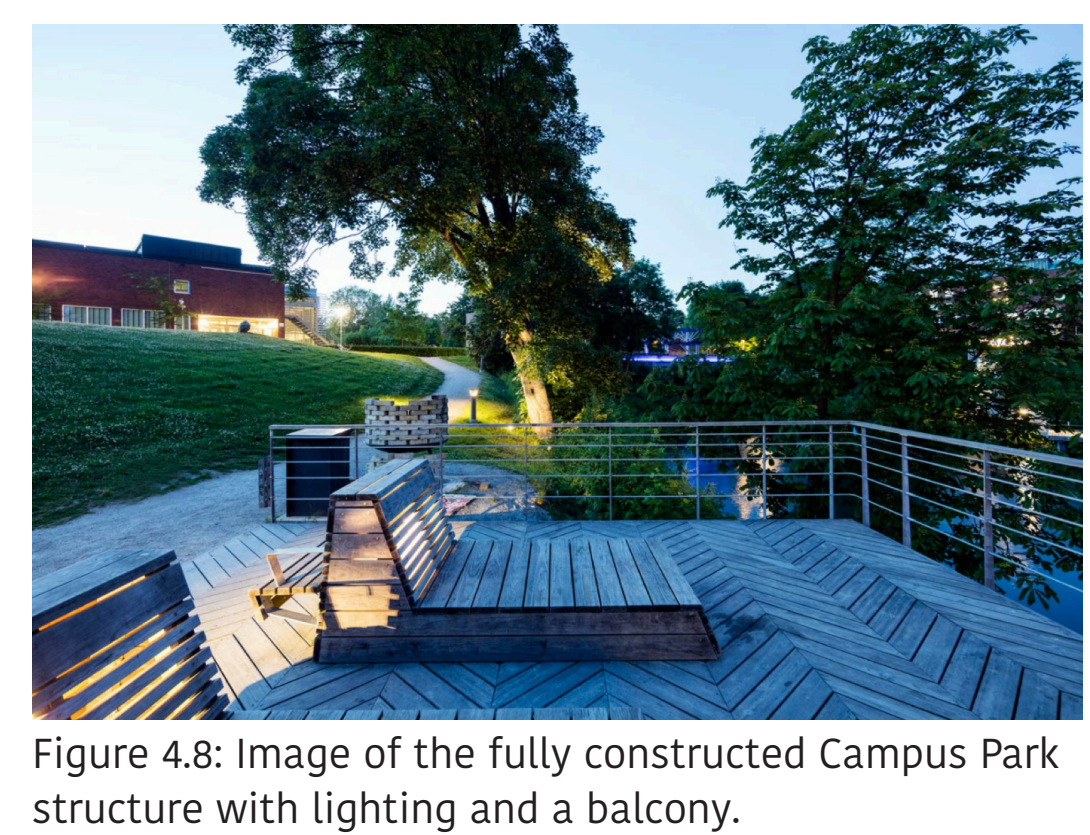

The Campus Park's design features relate to and connect the user to nature. The natural pond and dense vegetation protects the space from wind and creates a small, secluded social hub at the edge of the campus. Using natural colored features allow the terraces to blend into the forest-like area, creating the illusion that you are located in a remote, natural area. Visitors discover this space among the trees and find three terraces that are named 'the lounge', 'the pergola', and 'the ballroom' (Landezine, 2017). Shade trees and small shade structures provide added shade and protection. Railings are added on sides facing the water for safety, without blocking the view of the water. Lighting is added along the walkways as well as throughout each platform. The space includes a variety of seating options, from swing seating to bench seating. All of the design features make the Campus Park feel livable and comfortable. 
The Campus Park project increases the user's accessibility to the lake as well as enhanced the both the walkway and existing natural area. The series of platforms creates additional personal spaces that can be adapted based on the use. Collaborative activities or individualized learning can occur in this space, while being surrounded and inspired by nature. Located near, but not right next to, a series of academic buildings this space has the opportunity to enhance interdisciplinary learning. Designed as a relaxing space, away from the bustling campus core, this space is a restorative space for reflection and quiet studying as well as a place to meet with a partner or small group. Visitors feel comfortable using this space and spending long periods of time here because the natural elements unify the space and create a welcoming environment.

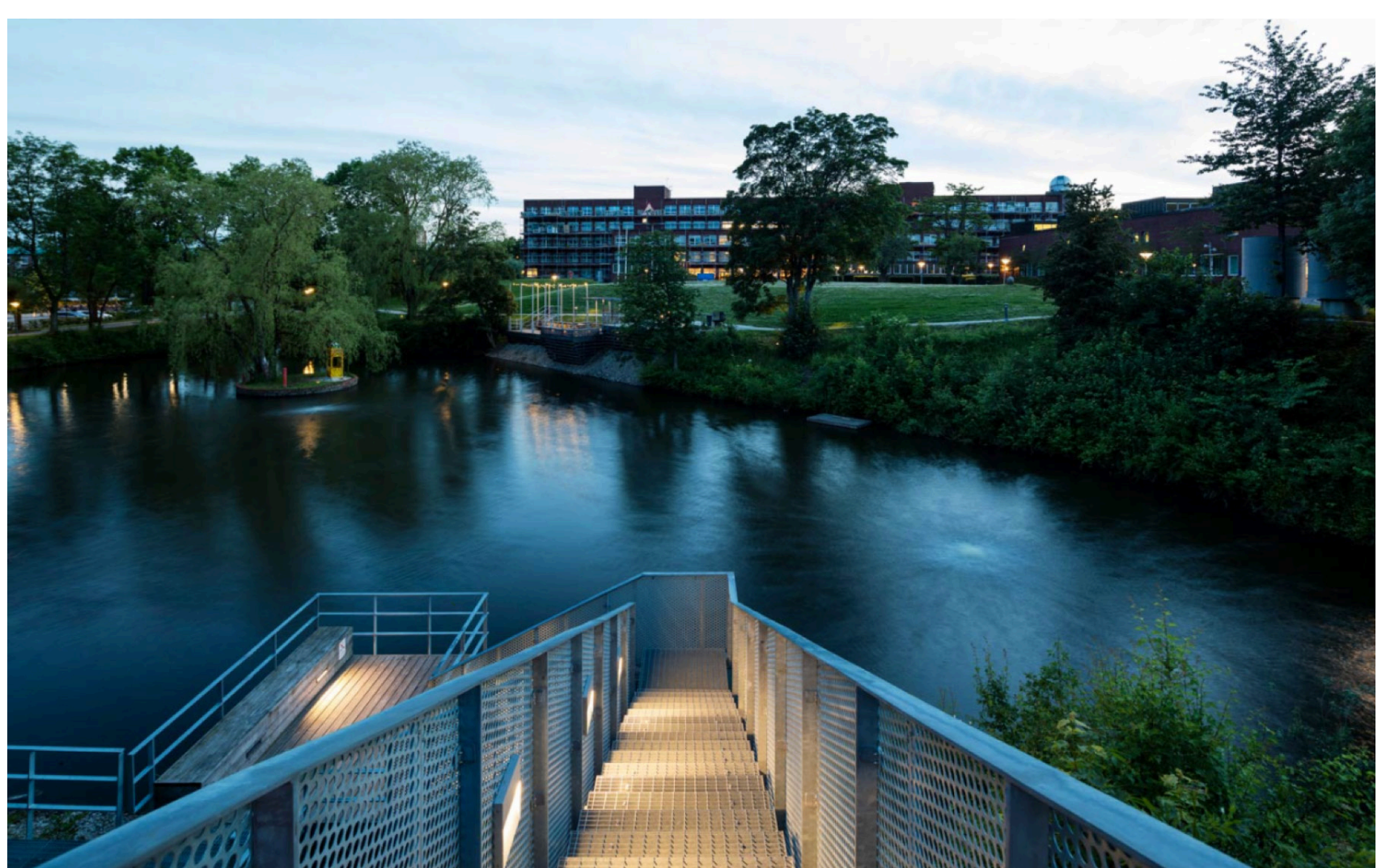

Figure 4.9: Pathway lighting on a walkway of the Campus Park project, looking over a pond and campus.

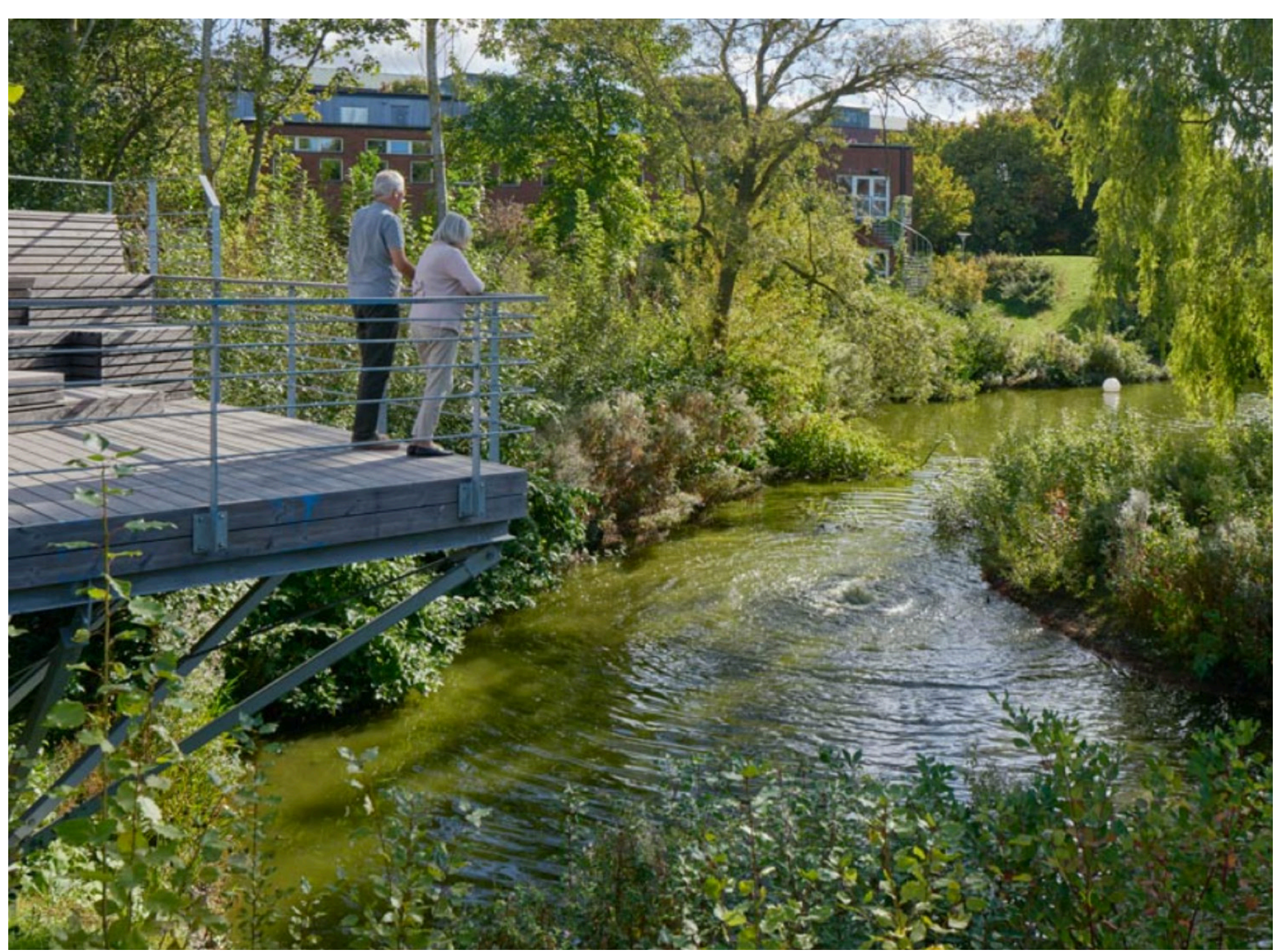

Figure 5.0: Visitors explore one of the terraces at Campus Park that looks over nature and a small creek. 


\section{Rega Leuven - University of Louvain}

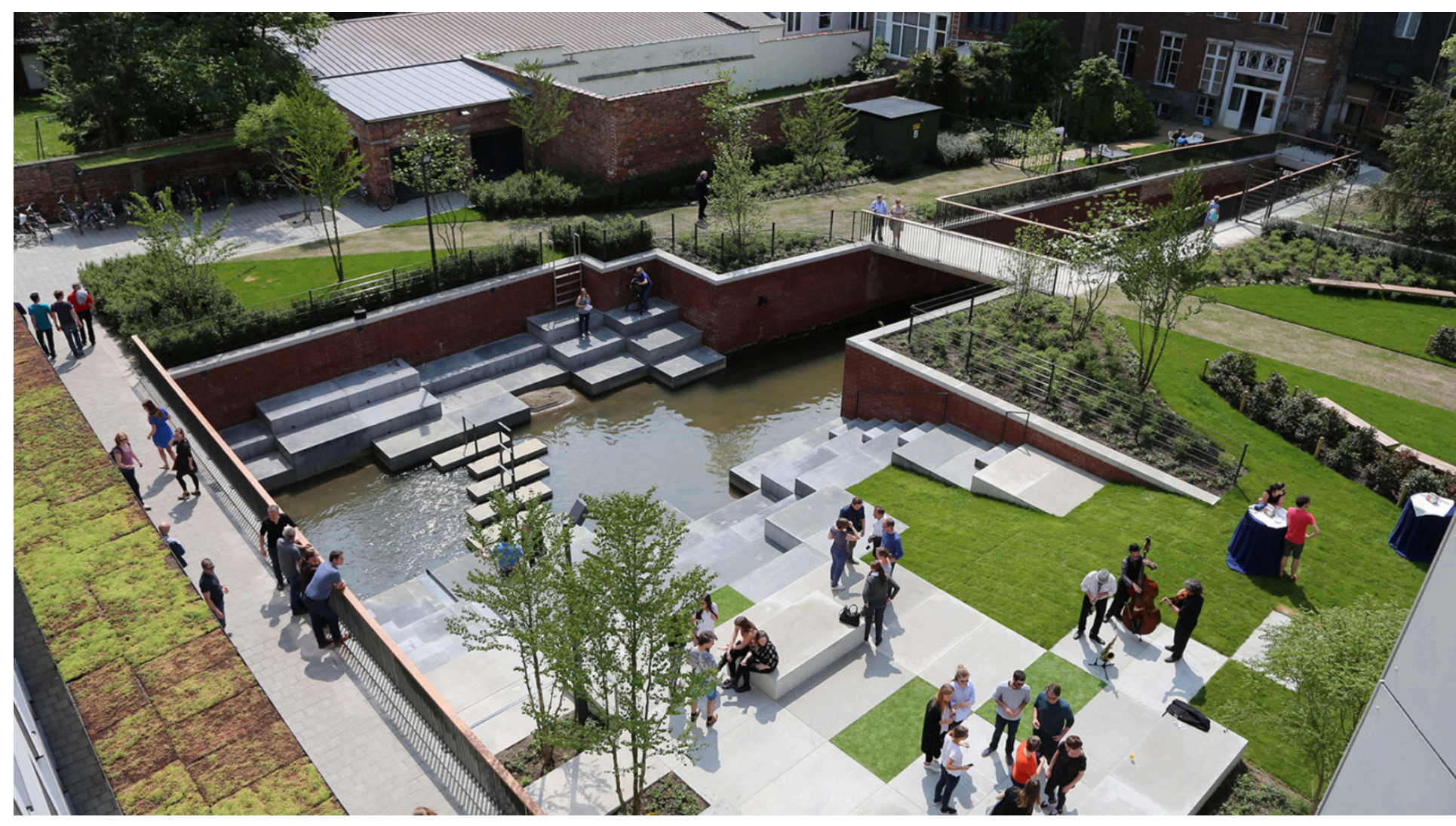

Figure 5.1: Students in groups socializing and studying at the Rega Leuven plaza.

The Rega Leuven plaza is located at the University of Louvain, near both resident halls and academic buildings. The designer, Ontwerpbureau Pauwels BVBA (Michel Pauwels), was called to examine the possible restoration of the damage of the hidden river and develop a solution to transform the hidden water into a water related experience (Landezine, 2018). When opening in 2016, this project both solved the damage of the river and crated an outdoor learning environment for students to both study and relax.

As the riverbed was opened up, the designers needed to install quay walls to support the river. As a result, the garden area acts as an entrance that “folds open" the landscape (Landezine, 2018, p. 1). The quay walls allow the seating area to protected by wind and distractions. The space combines natural elements with man-made features, such as the stepping stones in the river. These stepping stones allow visitors to cross the water or go "through the water" (Landezine, 2018, p. 1). Small patches of grass surround the space. 8 to 10 shade trees are places around the space as well as 3 or 4 near the platform steps. Natural elements are very important to the design of the Rega Leuven plaza, as they both enhance the quality of the river and increase the student's interaction with nature.

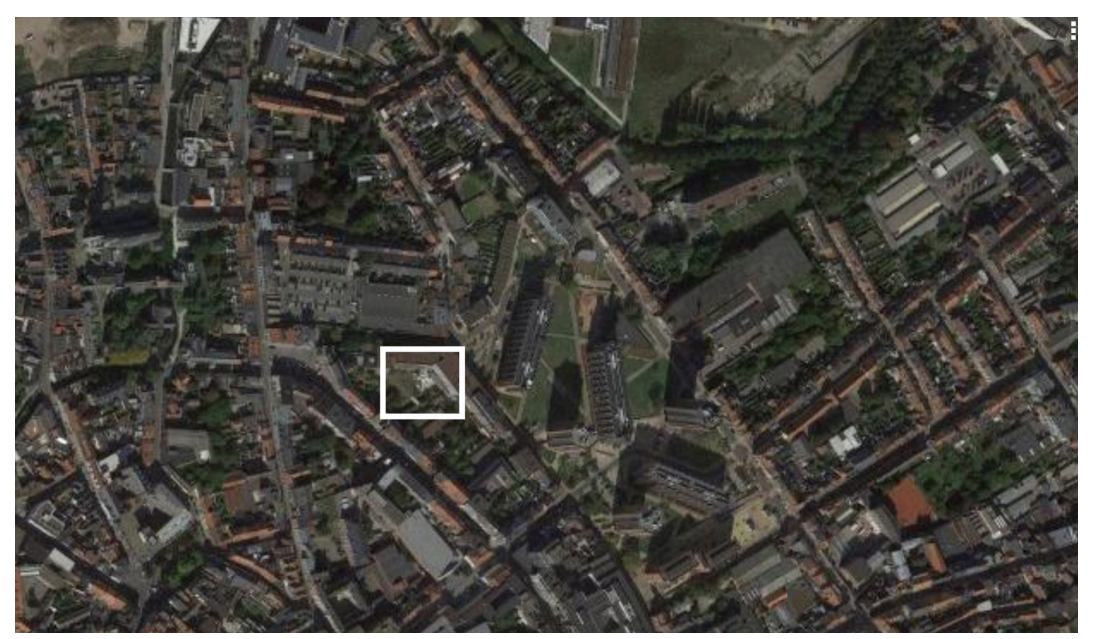

Figure 5.2: Map of the University of Louvain, showing the Rega Leuven plaza.

The topography is altered to create large platforms that act as steps going down to the water. These steps, both grassy and stone, provide seating and a more personal nook within the larger area. As a result, students are able to study and socialize by the water or soak up the sun on one of the many staggering and stepped platforms. Students can also meet in small groups in one of the larger sections. The addition of natural vegetation, shade trees, and water elements makes the space feel comfortable and relaxing. 
Visitors discover this space when walking along a less frequently traveled path and are able to stop for a few minutes or a few hours to study or socialize. The Rega Leuven plaza and student learning space is unique solution to the once damaged hidden river. The natural elements are enhanced while creating a quaint social and academic hub.

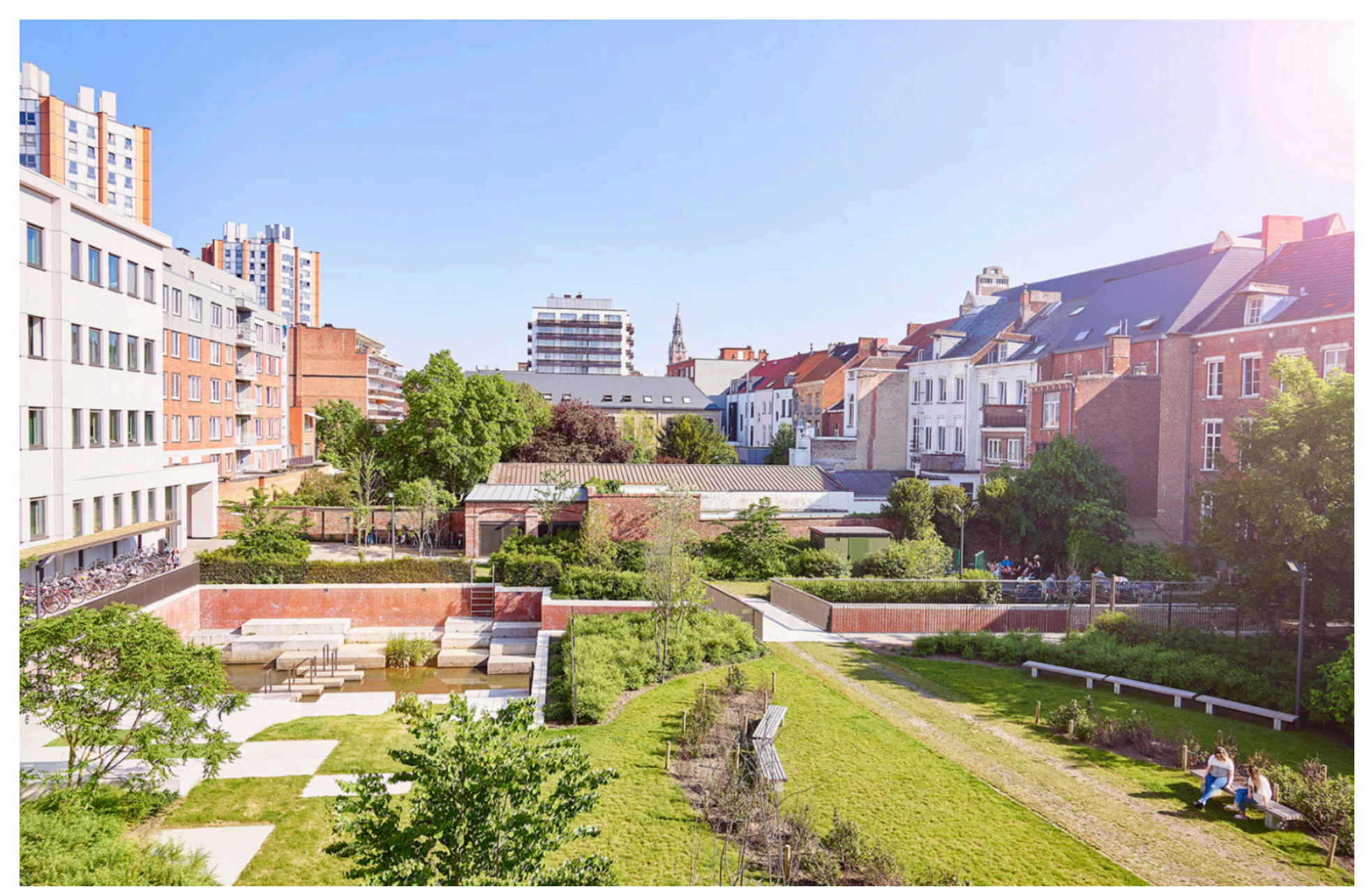

Figure 5.3: Image showing Rega Leuven plaza with the University of Louvain campus in the background.

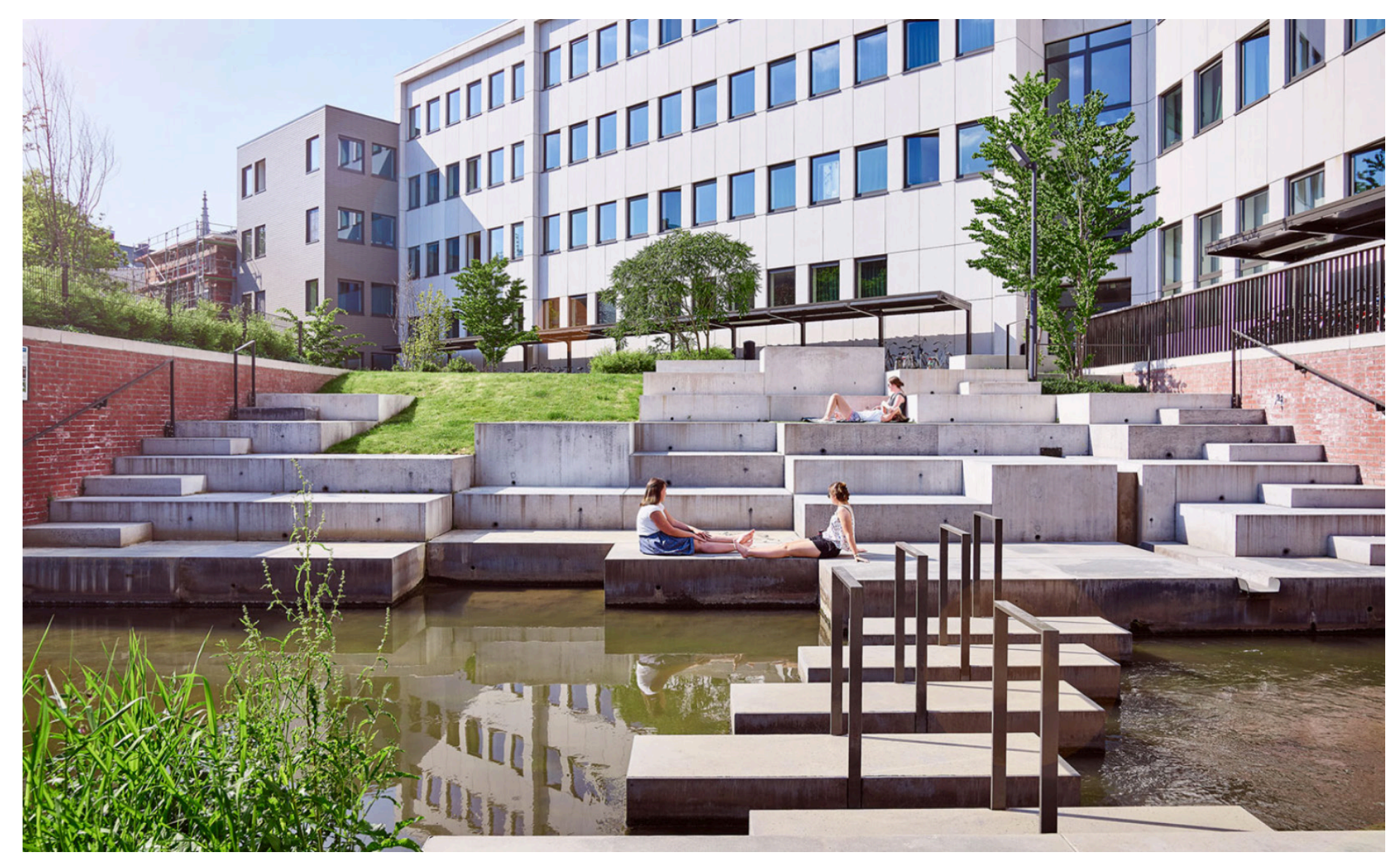

Figure 5.4: Students studying on large staggered steps in the Rega Leuven plaza. 

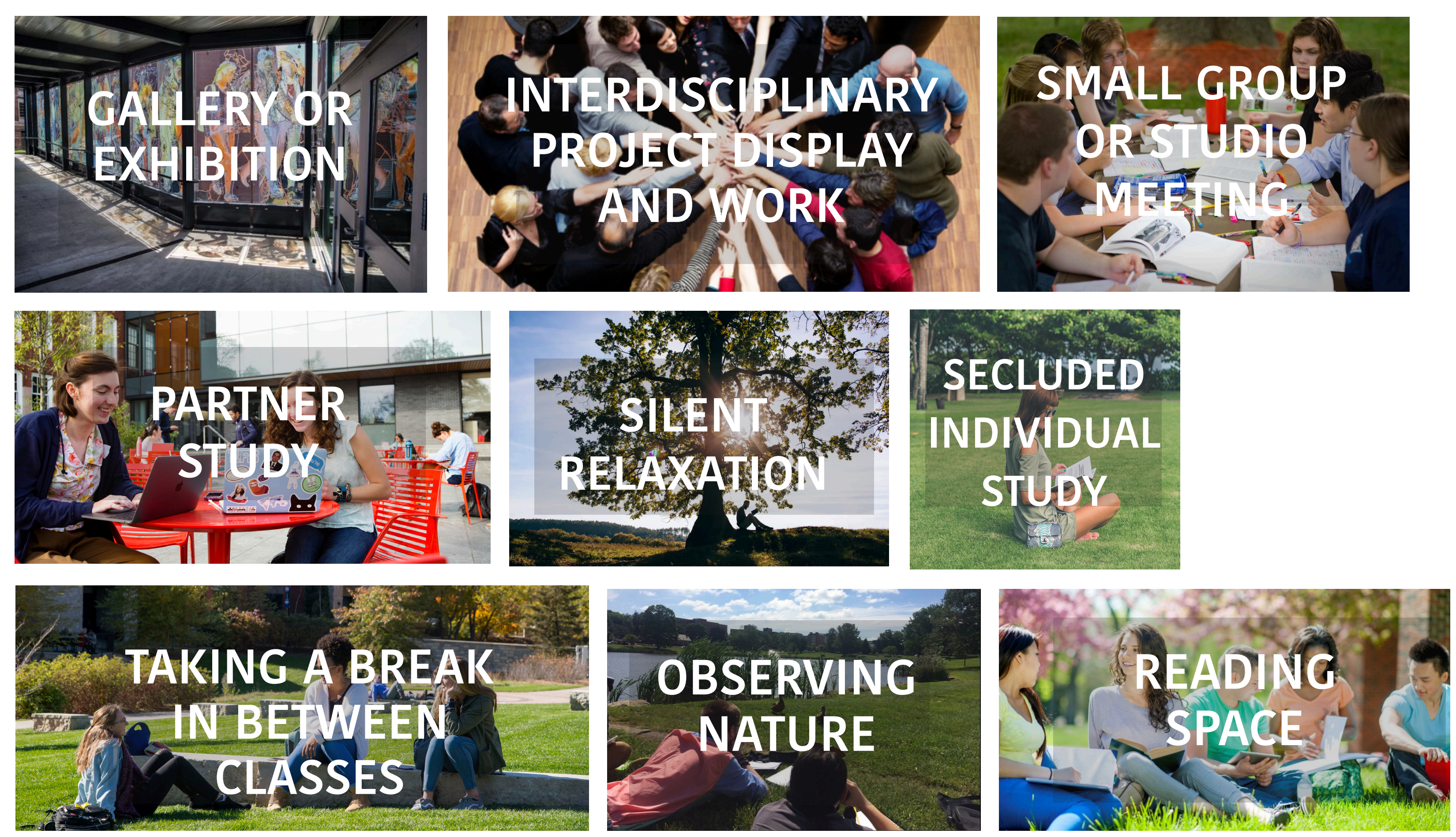
Design Principles

1. SPACE CONNECTS PEOPLE TO NATURE. THEREFORE, ALLOWING THEM TO RELAX AND REFLECT.

2. SPACE ADAPTS TO BOTH INTERDISCIPLINARY LEARNING AND INDIVIDUALIZED LEARNING ACTIVITIES. THEREFORE, CREATING A DIVERSE AND UNIFIED SPACE.

3. SPACE IS AN EXEMPLARY MODEL FOR SUSTAINABLE DEVELOPMENT AND SUSTAINABLE CAMPUS LIFE.

4. SPACE INCORPORATED NATURAL ELEMENTS INTO THE DESIGN, ALLOWING THE USER TO FEEL SECLUDED AND SAFE.

5. SPACE APPEARS INVITING AND COMFORTABLE. THE USER IS ABLE TO DISCOVER THE SPACE AS A PLACE TO STUDY AND RELAX IN A NEW, UNIQUE ENVIRONMENT

\section{SPACE INCLUDES A VARIETY OF SEATING AND LEARNING} NOOKS.

7. SEATING IS ADAPTABLE AND INCLUDES CREATIVE SEATING OPTIONS. CONSIDER CREATIVE SEATING OPTIONS SUCH AS SWINGING OR HANGING CHAIRS, INNOVATIVE GROUND SEATING, OR USING STEPS AS SEATING. FOR EXAMPLE, A LARGE ROCK IN A GRASS PATCH WHICH HAS THE OPPORTUNITY TO SERVE AS A BACKREST.
8. SPACE HAS A TERRACED OR VARIED LANDSCAPE. USING STEPS, A SLOPED LAWN, OR A COMBINATION OF THE TWO.

9. SPACE IS WELL LIT AND INCLUDES LIGHTING BOTH ON SMALLER PATHWAYS AND AROUND SEATING AREAS OR LEARNING NOOKS. 


\begin{tabular}{|c|c|c|c|c|c|c|c|c|}
\hline$\#$ & SMALL DISCOVERED & 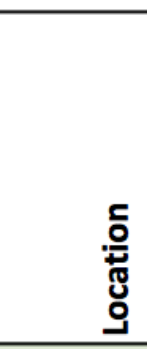 & 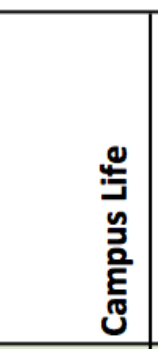 & 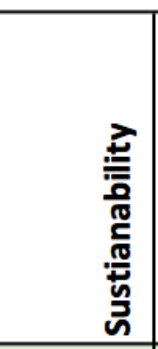 & 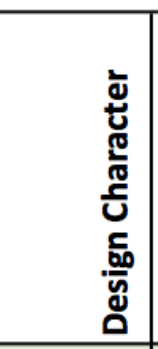 & 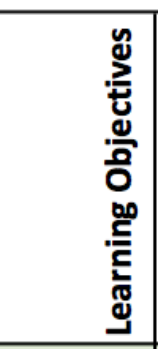 & 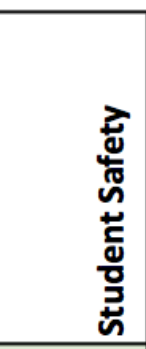 & \\
\hline 1 & $\begin{array}{l}\text { When considering the location of the small discovered space, consider locating off the main } \\
\text { pathway and are protected. The space should be enhanced by the neighboring academic } \\
\text { buildings, but not be connected to or near a frequently traveled pathway. }\end{array}$ & $\mathbf{x}$ & & & & & & \\
\hline 2 & $\begin{array}{l}\text { Mix of paved areas, with lawn and green spaces. The percentage of paved areas ranged from } \\
15 \text { to } 85 \text { percent. Predominately hardscaped spaces should have pervious paving. Pervious } \\
\text { paving is recommended to promote infiltration of stormwater. }\end{array}$ & & & $\mathbf{x}$ & $x$ & & & \\
\hline 3 & $\begin{array}{l}\text { The design of the outdoor learning environment should recognize the importance of preserving } \\
\text { current, small open spaces. When designing in and around the space, consider the restorative } \\
\text { and natural impacts and consequences of altering that space. When designing, enhance the } \\
\text { underutilized area, while preserving the qualitites and features of the open space. }\end{array}$ & & $\mathbf{x}$ & $x$ & & & & $\mathbf{x}$ \\
\hline 4 & $\begin{array}{l}\text { Green vegetation such as vines, shrubs, planting boxes, fruit trees, or similar are used to } \\
\text { increase privacy or create shade, if needed. Consider using an additional amount of green } \\
\text { vegetation near sections that are designed for quiet studying and reflection. }\end{array}$ & & & $x$ & & $X$ & & $\mathbf{x}$ \\
\hline 5 & $\begin{array}{l}\text { Shade must be provided by trees, small shade structures, or neighboring buildings. If located } \\
\text { near academic buildings that provide shade to the seating area, shade trees are not necessary, } \\
\text { but encouraged. Consider trees that provide shade, while not blocking the views. }\end{array}$ & & $\mathbf{x}$ & & $\mathbf{X}$ & 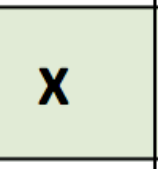 & & \\
\hline 6 & $\begin{array}{l}\text { Seating must be provided by either seating walls, non-movable benches, or movable chairs. } \\
\text { Consider creative seating options such as swinging or hanging chairs, innovative ground } \\
\text { seating, or using steps as seating. These creative seating options should be placed throughout } \\
\text { the design for a cohesive space. }\end{array}$ & & $\mathbf{x}$ & & & $\mathbf{x}$ & & $\mathbf{x}$ \\
\hline 7 & $\begin{array}{l}\text { Shade structures not only offer sun protection, but in some cases a bit of privacy. Therefore, } \\
\text { different types of shade structures should be considered based on the desired level of visibility } \\
\text { and the number of people that are covered. }\end{array}$ & & & & $x$ & $\mathbf{X}$ & & \\
\hline 8 & $\begin{array}{l}\text { Lighting should be added in and around seating areas and walkways. Consider the addition of } \\
\text { under seat wall or bench lighting as well as overhead lighting. }\end{array}$ & & & & $\mathbf{x}$ & $\mathbf{x}$ & $\mathbf{x}$ & \\
\hline 9 & $\begin{array}{l}\text { Majority of the colors used are neutrals with hints of color in planting or art pieces. The design } \\
\text { should flow and include visual connections to neighboring buildings. }\end{array}$ & & $\mathbf{x}$ & & $\mathbf{x}$ & & & $\mathbf{x}$ \\
\hline
\end{tabular}




\begin{tabular}{|c|c|c|c|c|c|c|c|c|}
\hline \# & SMALL DISCOVERED & $\begin{array}{l}\overline{0} \\
\overline{\tilde{g}} \\
\end{array}$ & 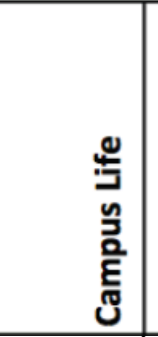 & 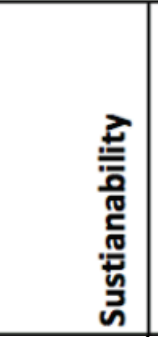 & 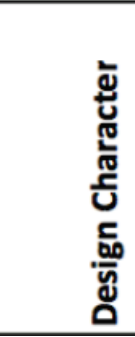 & 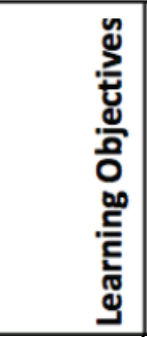 & 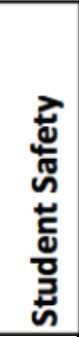 & 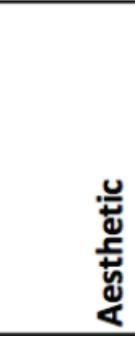 \\
\hline 10 & $\begin{array}{l}\text { When considering planting and irrigation design, consider using native and drought tolerant } \\
\text { plants, curb cuts for runoff, planting a small garden, and using sustainable materials within the } \\
\text { design. }\end{array}$ & & & $\mathbf{x}$ & $\mathbf{x}$ & $\mathbf{x}$ & & \\
\hline 11 & $\begin{array}{l}\text { Additions and features should be added to enhance the learning capability and overall student } \\
\text { comfort. For example, table-like additions are encouraged in some of the learning nook spaces. }\end{array}$ & & $\mathbf{x}$ & & & $\mathbf{x}$ & & $\mathbf{x}$ \\
\hline 12 & $\begin{array}{l}\text { Landmarks and place-making elements should be highlighted though capturing the views from } \\
\text { the outdoor learning environment site. Consider various sidelines from each seating and } \\
\text { recreational area in order to create a space that enhances student's learning abilities as well as } \\
\text { attraction from future students and their visiting parents. }\end{array}$ & & $\mathbf{x}$ & & & & & \\
\hline 13 & $\begin{array}{l}\text { When designing planting and irrigation, consider using native and drought tolerant plants, curb } \\
\text { cuts for runoff, planting a small garden, and using sustainable materials within the design. }\end{array}$ & & & $\mathbf{x}$ & $\mathbf{x}$ & & & $\mathbf{x}$ \\
\hline 14 & $\begin{array}{l}\text { The overall design aesthetic should match or reflect the current structures and buildings } \\
\text { surrounding the site. Consider adopting a similar style or character of the established buildings. }\end{array}$ & & $\mathbf{x}$ & & $\mathbf{x}$ & & & $\mathbf{x}$ \\
\hline 15 & $\begin{array}{l}\text { Pathways should be sized appropriate to their expected purposes. Less frequently traveled } \\
\text { walkways are at least } 4 \text { feet wide. }\end{array}$ & & $\mathbf{x}$ & & $\mathbf{x}$ & & & $\mathbf{x}$ \\
\hline
\end{tabular}




\section{SMALL ACTIVE}

The Central Plaza - James Cook University

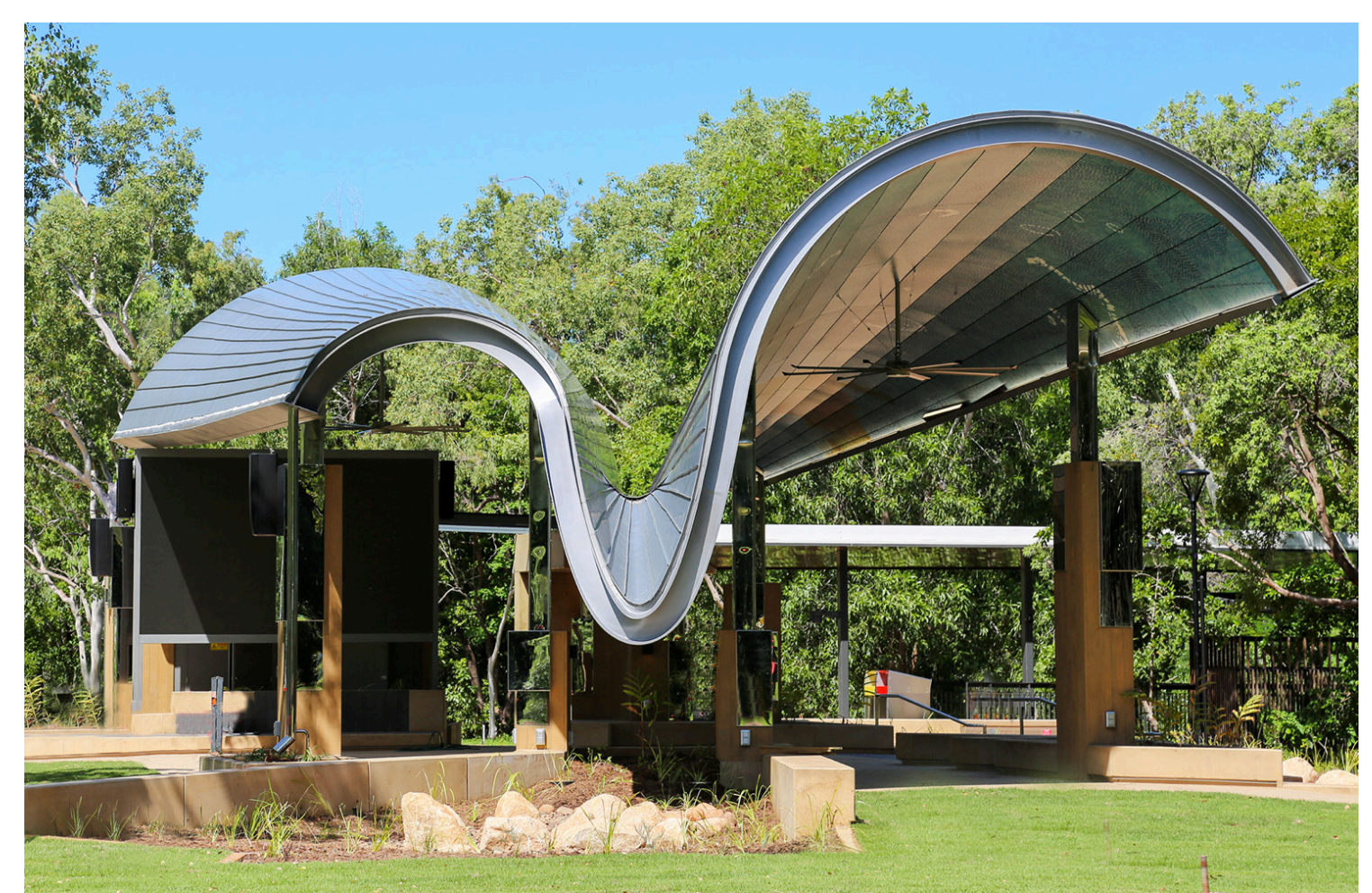

Figure 5.5: Side view of the Central Plaza at James Cook University.

The Central Plaza at James Cook University recently opened at the start of 2020. The Plaza's ribbon cutting began the opening O-week 2020 ceremony. The dramatic canopy structure sits at the very center of the University and is "adjacent to Wadda Moilli Creek, a large event lawn, a water feature, and connecting pathways (COX, 2020, p. 1). COX, architecture firm and designer of the plaza, designed this roof canopy as an elegant, fluid, and spatially complex structure (COX, 2020). While this is a relatively small project, it captures the University's ambitions for engagement in the tropics (COX, 2020, p. 1). Located along a frequently traveled axis that runs through the center of campus. This axis links key components of the campus and serves as a placemaker and meeting place for students and faculty.

The eye-catching structure is constructed by 479 individual printed perforated panels, working to integrate the curved rood form and is about 50 feet long (COX, 2020). The artwork under the panels is titled 'After the Flood' and is part of the Cope's flooded landscape series. Additionally, lighting and a large fan is added to increasing the amount of time spend at the space as well as increase air flow through the structure. The structure itself represents and reflects the "science, medicine, and engineering subjects with its organic qualities representing the humanities" (COX, 2020, p. 1). This

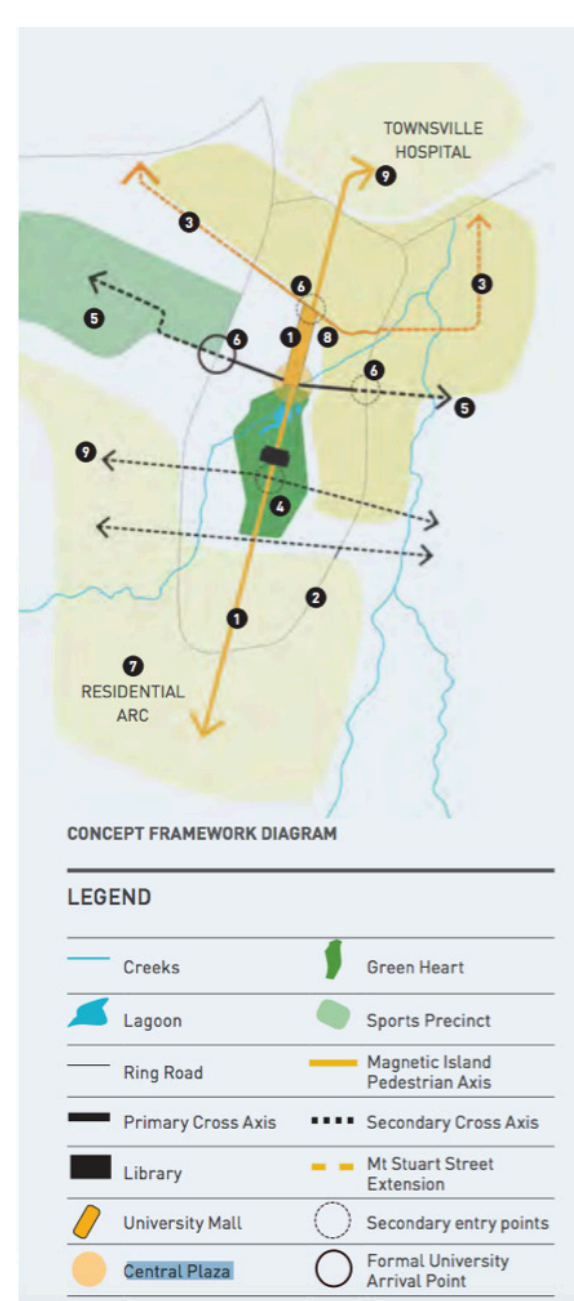

Figure 5.6: Site map showing the location of the new James Cook University Central Plaza. innovative and dramatic design attracts prospective students and visitors, increasing enrollment.

The structure is enhanced by the design of the base as well as the surrounding landscaped areas. The Central Plaza incorporates campus walkways or an axis into the design of the structure and base landscaping. Water features, small gardens, stone work, and shade trees are scattered beside the pathway leading up to the structure, building suspense. Lawn space surrounds 


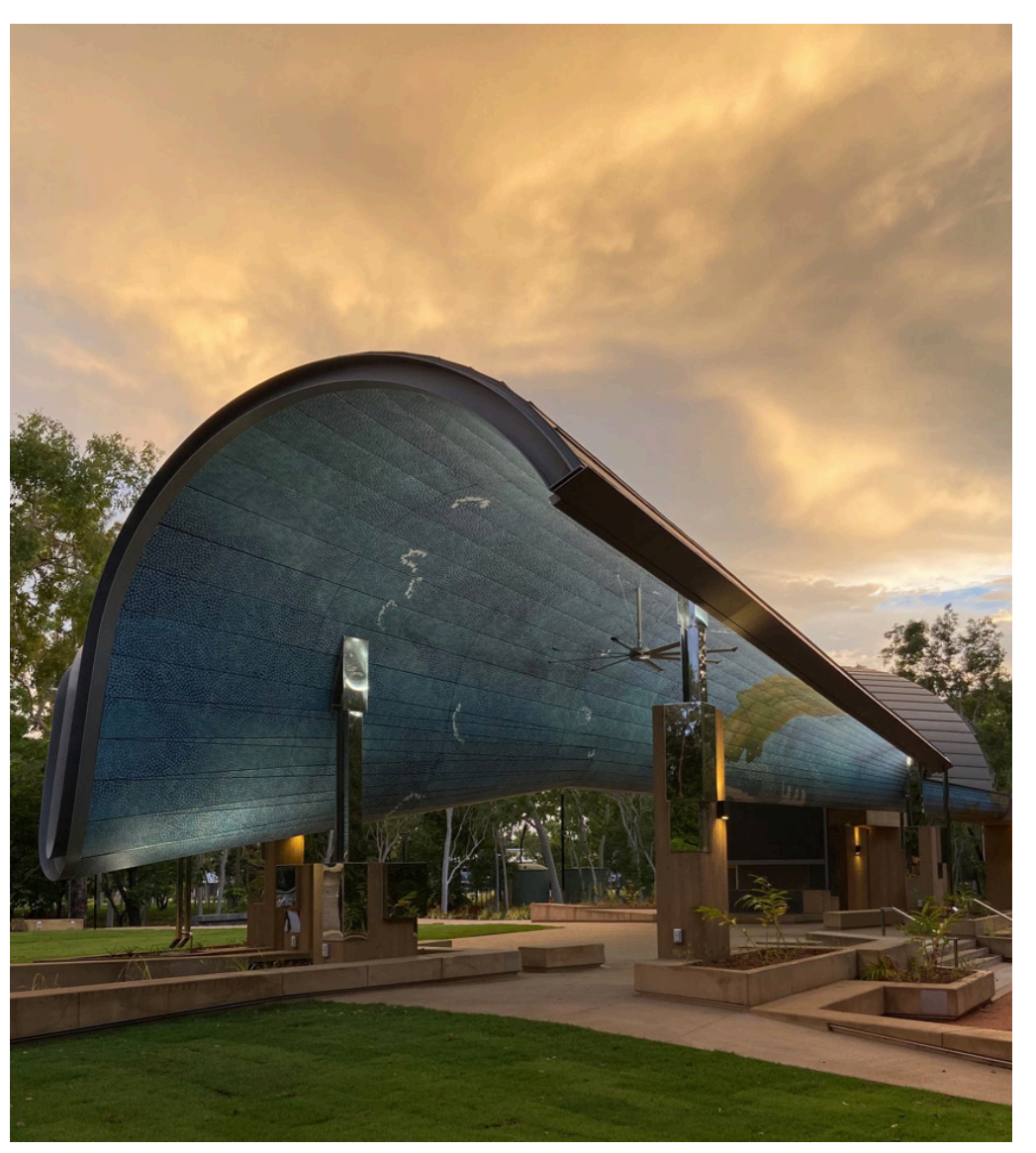

Figure 5.7: Image showing built in lighting under the structure of the Central Plaza. the base of the structure. Seating walls are incorporated into the design and reflect the surrounding topography. The Central Plaza at James Cook University’s (JCU) Townson campus is an academic and social hub. It's a place to relax, learn, or host a group gathering or class. With a goal of creating an urban identity while fostering the University's history, this space adapts to both teaching and learning. As the JCU Vice Chancellor Professor Sandra

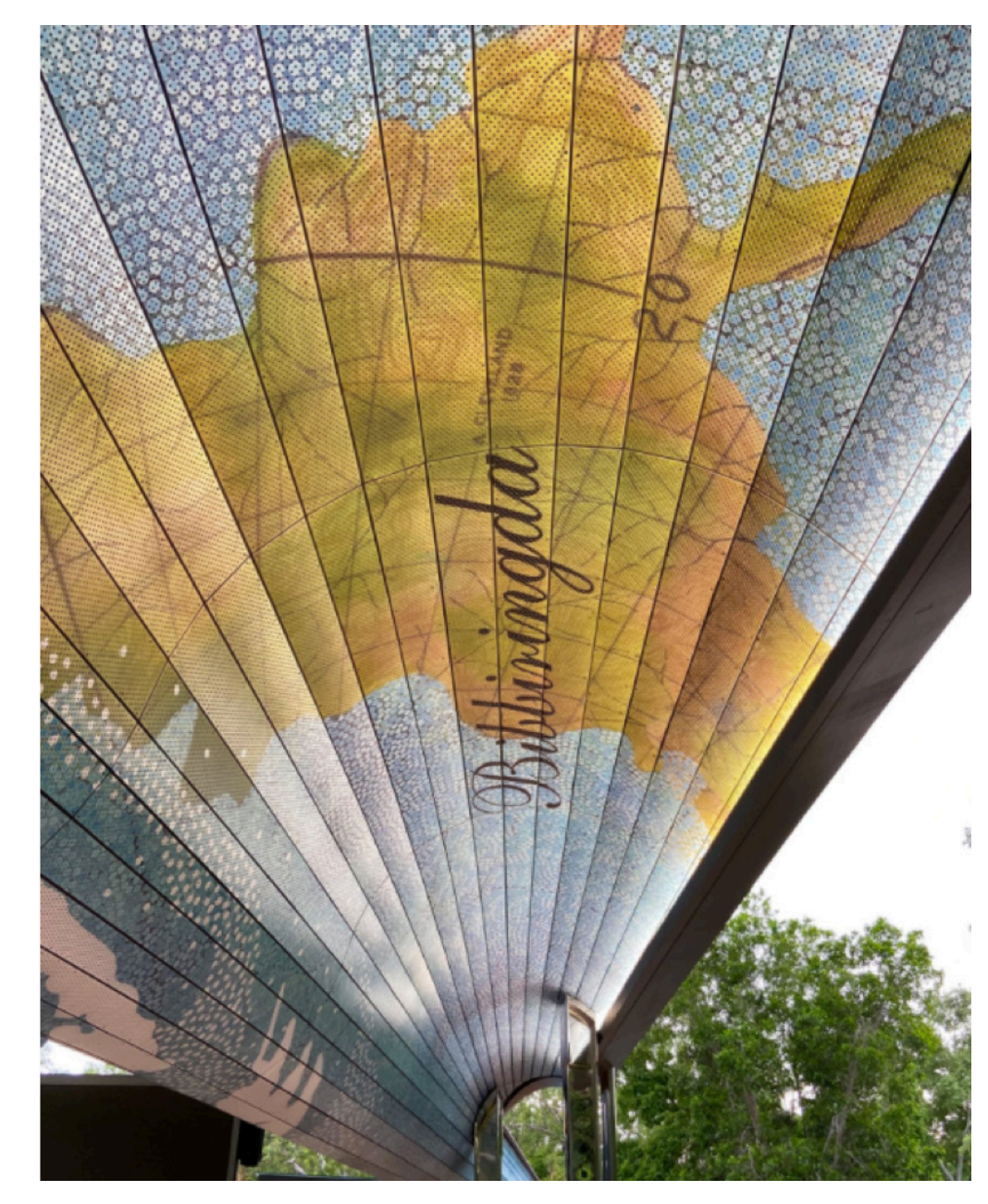

Figure 5.9 (left): Map of the world is printed on the underside of the shade structure at James Cook University's Central Plaza.

Harding says, "The Central Plaza will provide students with an enhanced campus experience".

Figure 5.8 (right): Water features on the walkway leading to the Central Plaza shade structure.

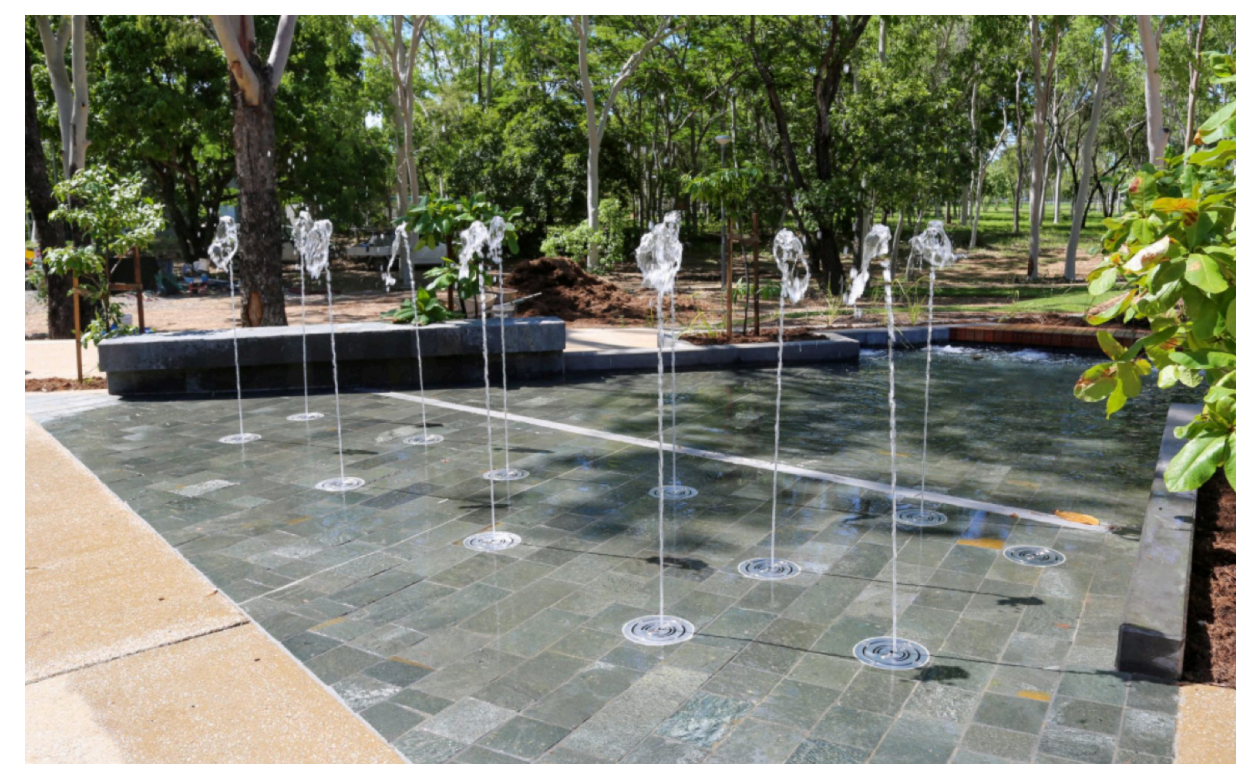


Therry Courtyard - St. Ignatius Riverview

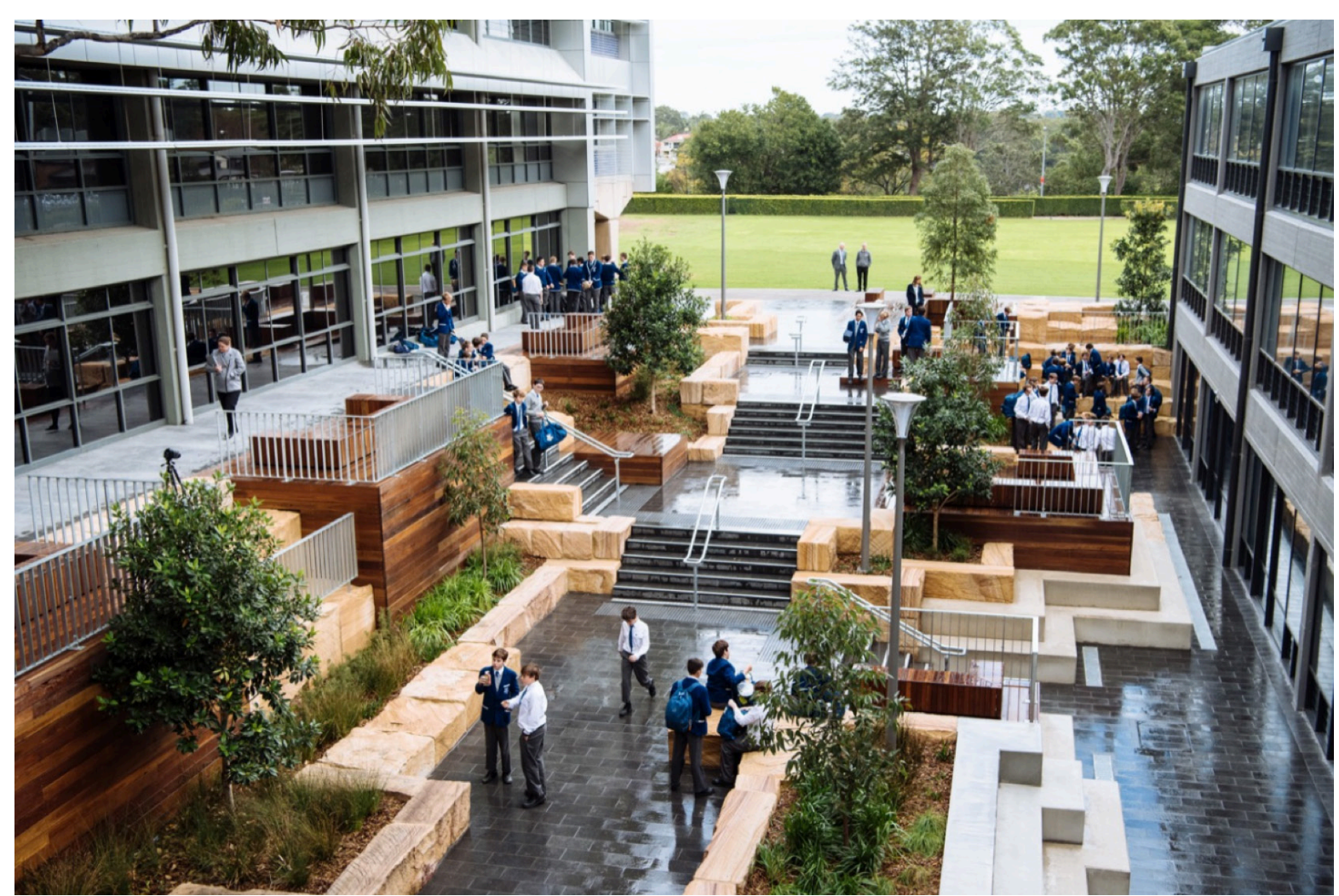

Figure 6.0: Groups and pairs of students using the Therry Courtyard, an urban active courtyard.

Therry Courtyard at St. Ignatius Riverview boys school is located at Lane Cove in Sydney, Australia. This redevelopment project was designed in 2015 and built in 2018 by Arcadia Landscape Architecture and PMDL. The active courtyard was designed to reflect and embody the school's motto of 'dare to do, as much as you can' (Landezine, 2019). The school encourages students to push their limits and strive their hardest and the design team saw this potential to create a space that brings this motto to life (Landezine, 2019). The designers focused on enhancing the new Therry Building, while increase the teaching potential of the courtyard. This outdoor learning space includes 14 to 24 teaching spaces as well as a comfortable collaborative environment for students to learn (Landezine, 2019). The overall goal of this courtyard redevelopment project is to provide a connection to the natural surroundings, while promoting creativity, focus, and wellbeing for the students.

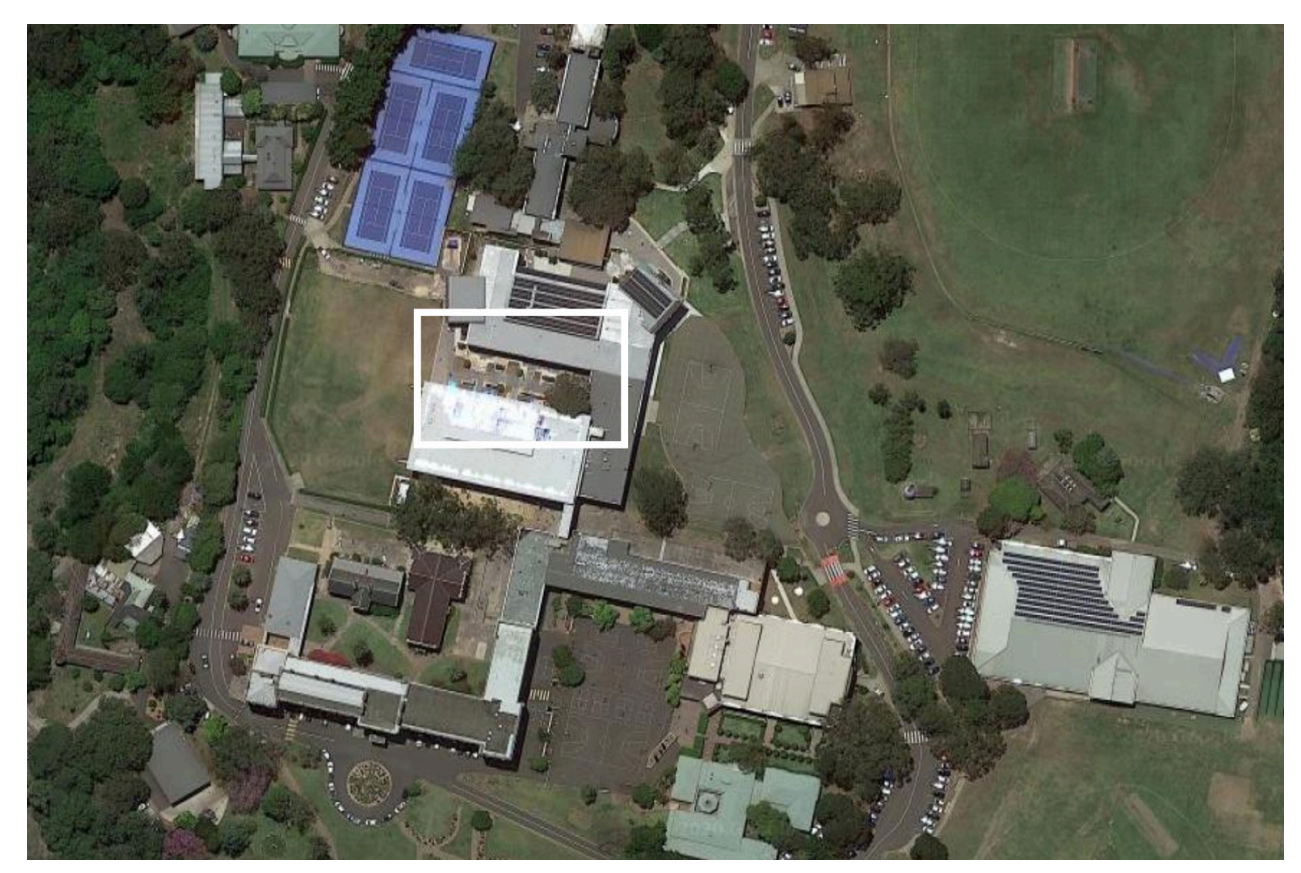
Therry Courtyard.
Figure 6.1: Map of St. Ignatius Riverview, showing the location of

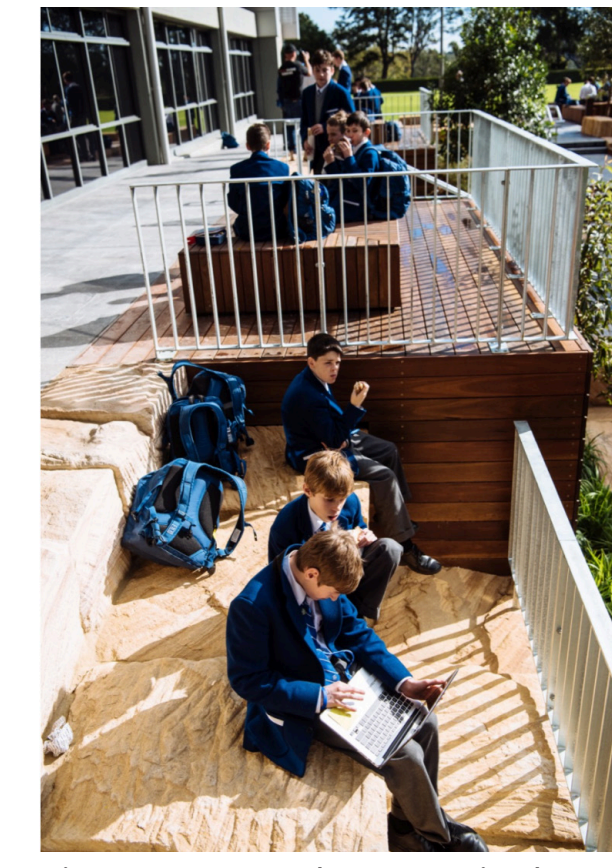

Figure 6.2: Students actively studying in the Therry Courtyard in between classes.
Biophilic design elements are used to prove a connect to the natural surroundings. Therefore, strengthening the capacity for creativity (Landezine, 2019). This space is protected by the Therry Building on three out of the four sides. This protected ally design both reflects similar elements of the classroom and also creates a more comfortable learning space. Located both near the Therry Building and adjacent to a green lawn, this space creates a meeting point or sense of place on campus. Modular stacking blocks are used across the sloping site, allowing a small pockets or learning nooks to be developed. Therefore, creating a more personal section 


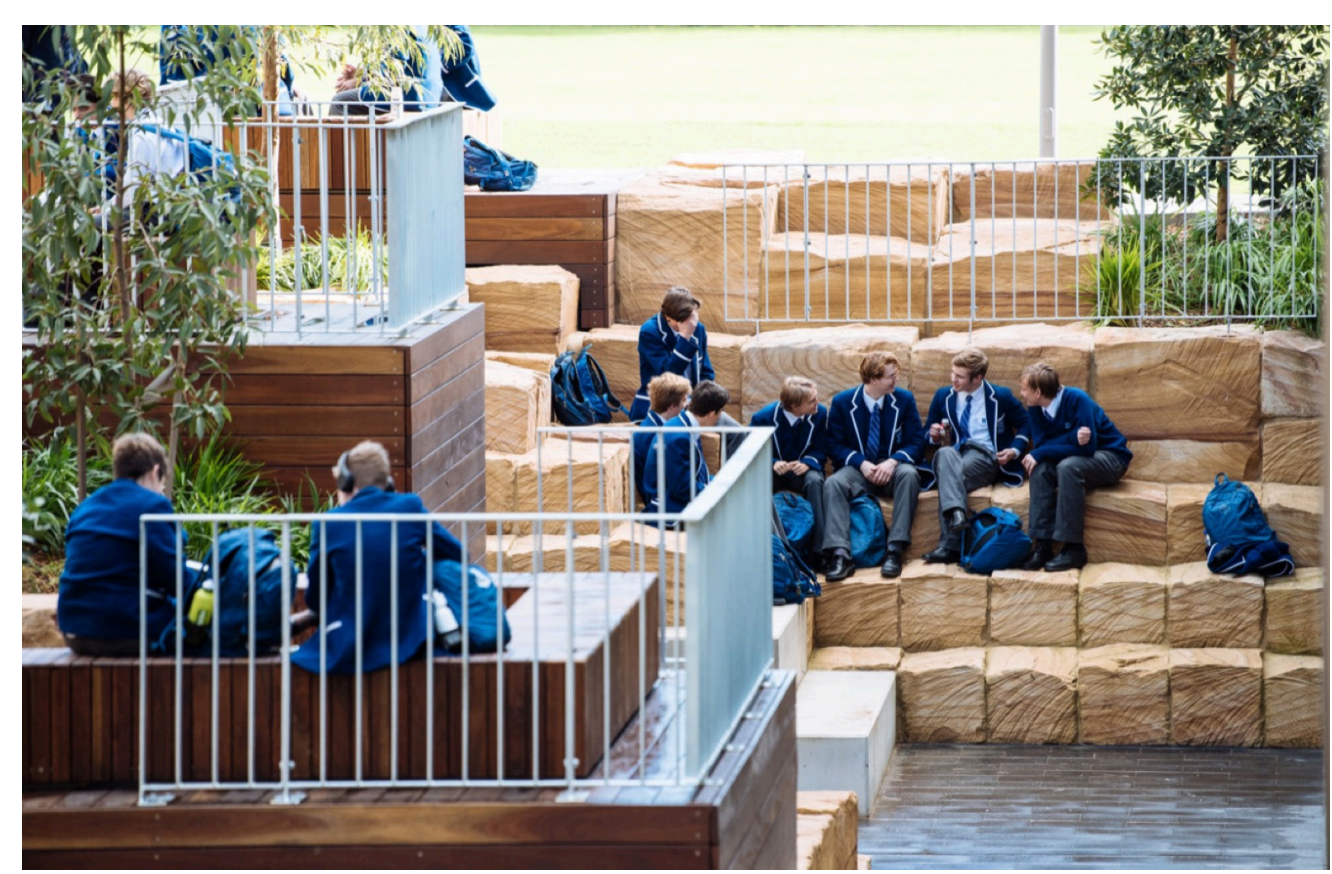

Figure 6.4: Groups of students studying on the large steps in Therry Courtyard. with minimal distractions that an individual or partner feels comfortable studying or working on a project. Concrete, hardwood timber, and natural stone is used throughout the design, especially to create seating walls.

Shade trees and small green shrubs create a more natural environment that students can relax and enjoy being outside. Additionally, this space creates a unique environment for the campus community to gather and socialize. Therefore, making this an active hub for learning and socializing.

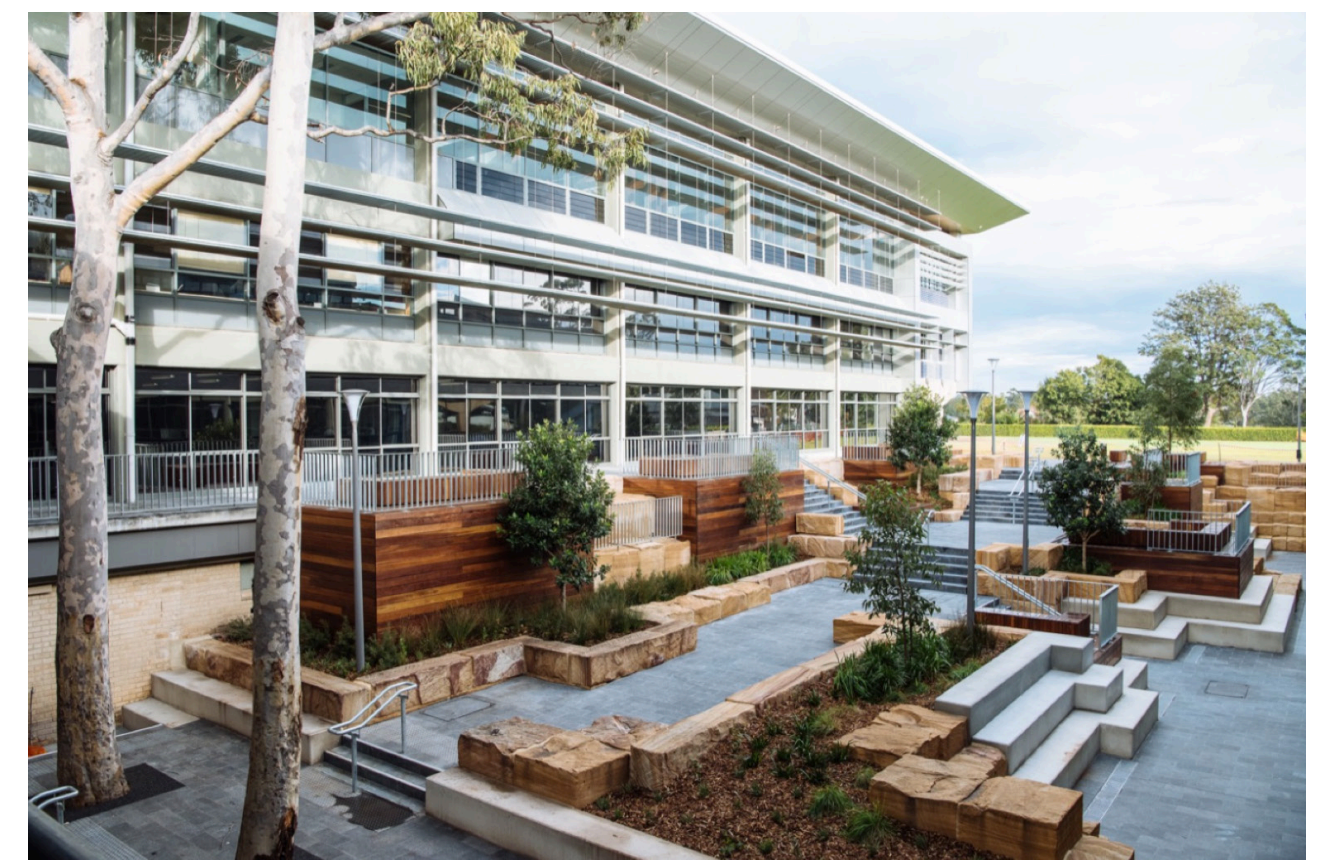

Figure 6.5 (left): Image highlighting the vegetation, lighting, and shade trees at Therry courtyard. 

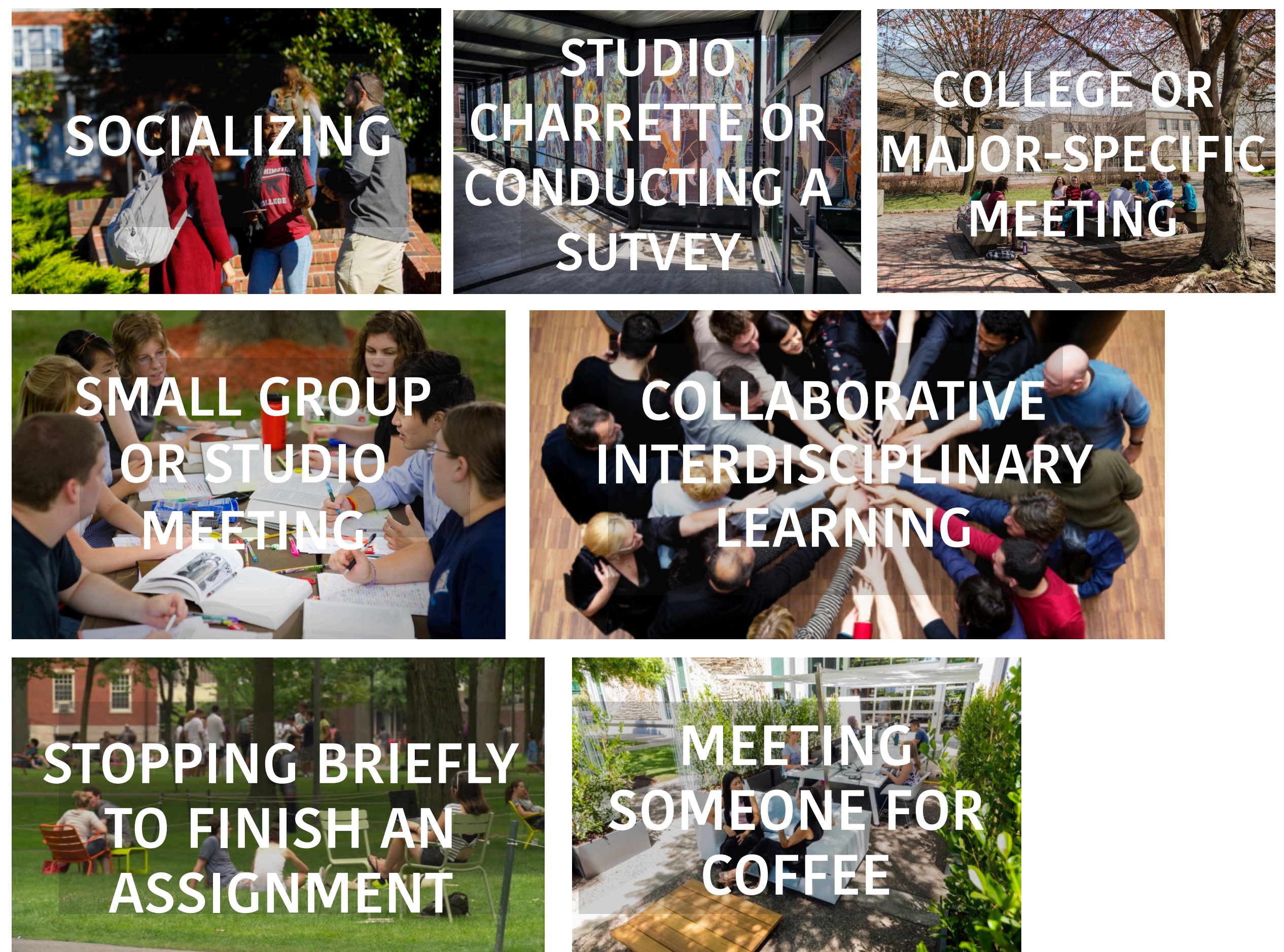

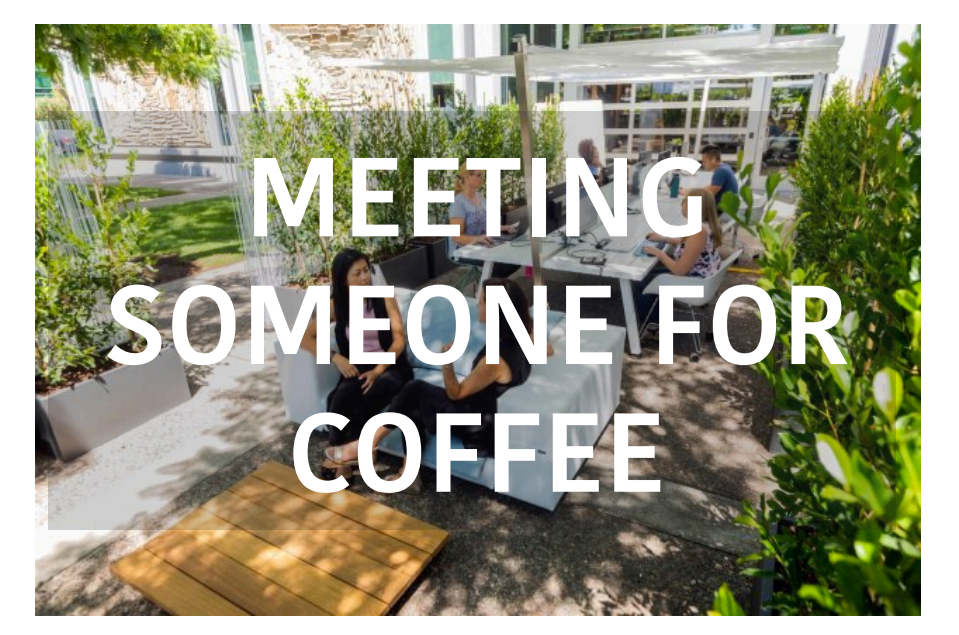

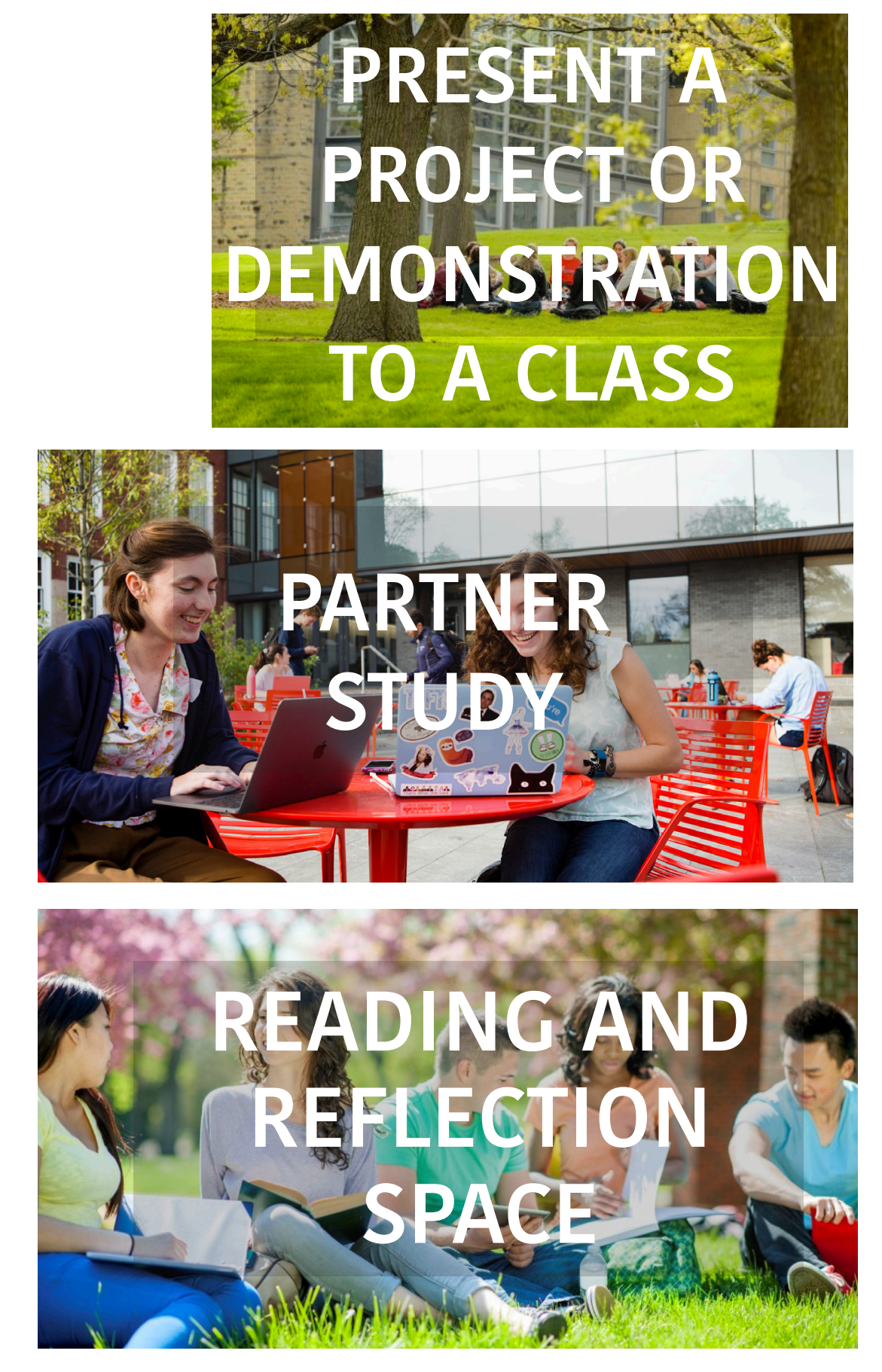


1. SPACE IS BOTH A SOCIAL AND ACADEMIC HUB.

2. SPACE IS FLEXIBLE TO ACCOMMODATE WIDE RANGE OF ACTIVITIES INCLUDING SOCIALIZING, RELAXING, AND LEARNING. CONSIDER THE ADDITION OF OPEN LEARNING NOOKS, OR SMALLER, MORE PERSONAL SPACES WITHIN THE LARGER AREA.

3. SPACE IS THE FACE OF CAMPUS, AND SHOULD BE SEEN AS A MARKETING TOOL AND ENHANCE THE CAMPUS IDENTITY. THEREFORE, ITS IMAGEABILITY IS CRITICAL.

4. SPACE IS INCLUSIVE AND IS WELCOMING TO A DIVERSE GROUP OF STUDENTS.

5. SPACE IS LOCATED IN THE CENTRAL PORTION OF CAMPUS AND ALONG FREQUENTLY TRAVELED PATHWAYS. IF POSSIBLE, ALONG OR JUST OFF OF A CIRCULATION AXIS. THE SPACE WILL BE ACTIVATED BUT STILL FEEL PERSONAL.

6. SHADE MUST BE PROVIDED WITH EITHER TREES OR SHADE STRUCTURES. THEREFORE, CONSIDER TREES THAT PROVIDE SHADE, WHILE NOT BLOCKING THE VIEWS.

7. SPACE REFLECTS THE UNIVERSITY'S HISTORY, TEACHING, AND LEARNING.
8. SPACE IS AN EXEMPLARY MODEL FOR SUSTAINABLE DEVELOP MENT AND SUSTAINABLE CAMPUS LIFE.

9. SPACE COULD HAVE A TERRACED OR VARIED LANDSCAPE. UING STEPS, A SLOPED LAWN, OR A COMBINATION OF THE TWO.

10. SPACE IS AN EXEMPLARY MODEL FOR SUSTAINABLE DEVELOP MENT AND SUSTAINABLE CAMPUS LIFE.

11. SPACE INCORPORATED NATURAL ELEMENTS INTO THE DESIGN, ALLOWING THE USER TO FEEL SECLUDED AND SAFE.

12. SPACE IS WELL LIT AND INCLUDES LIGHTING BOTH ON SMALLER PATHWAYS AND AROUND SEATING AREAS OR LEARNING NOOKS. 


\begin{tabular}{|c|c|c|c|c|c|c|c|c|}
\hline \# & SMALL ACTIVE & 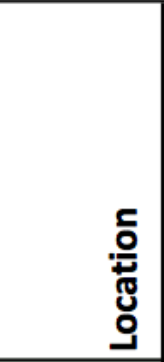 & 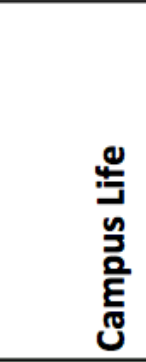 & 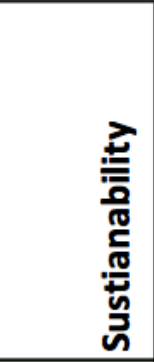 & 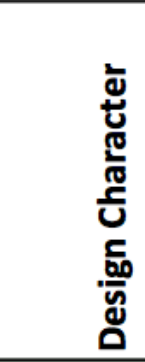 & 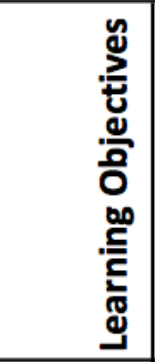 & 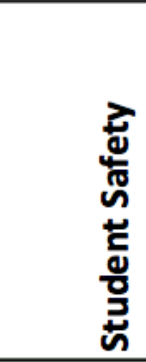 & 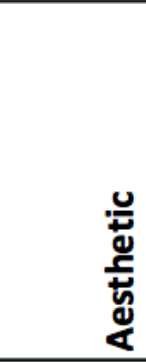 \\
\hline 1 & $\begin{array}{l}\text { When considering the location of the small active space, consider locating off the main } \\
\text { pathway, but within the central portion of campus. The space should be enhanced by the } \\
\text { neighboring academic buildings, but not be connected to or near a frequently traveled } \\
\text { pathway. }\end{array}$ & $x$ & & & & & & \\
\hline 2 & $\begin{array}{l}\text { Lighting should be added in and around seating areas and walkways. Consider the addition of } \\
\text { under seat wall or bench lighting as well as overhead lighting. Additionally, university-wide blue } \\
\text { light, help stations can be used to increase safety within and around these outdoor learning } \\
\text { environments. }\end{array}$ & & & & $X$ & $x$ & $X$ & \\
\hline 3 & $\begin{array}{l}\text { When designing planting and irrigation, consider using native and drought tolerant plants, curb } \\
\text { cuts for runoff, planting a small garden, and using sustainable materials within the design. }\end{array}$ & & $\mathbf{X}$ & $x$ & & & & $x$ \\
\hline 4 & $\begin{array}{l}\text { Additions and features should be added to enhance the learning capability and overall student } \\
\text { comfort. For example, table-like additions are encouraged in some of the learning nook spaces. }\end{array}$ & & $x$ & & $X$ & $X$ & & \\
\hline 5 & $\begin{array}{l}\text { Shade must be provided by trees, small shade structures, or neighboring buildings. If located } \\
\text { near academic buildings that provide shade to the seating area, shade trees are not necessary, } \\
\text { but encouraged. Consider trees that provide shade, while not blocking the views. }\end{array}$ & & $X$ & & $X$ & & & $x$ \\
\hline 6 & $\begin{array}{l}\text { Seating must be provided by either seating walls, non-movable benches, or movable chairs. } \\
\text { Consider creative seating options such as swinging or hanging chairs, innovative ground } \\
\text { seating, or using steps as seating. }\end{array}$ & & & & & $x$ & & \\
\hline 7 & $\begin{array}{l}\text { Shade structures not only offer sun protection, but in some cases a bit of privacy. Therefore, } \\
\text { different types of shade structures should be considered based on the desired level of visibility } \\
\text { and the number of people that are covered. For example, a gazebo or a pavilion both provide a } \\
\text { relative privacy for group work and group study. On the other hand, pergolas can cover a wide- } \\
\text { open outdoor areas and offer partial shade without increasing privacy. Adding vines or sheer } \\
\text { curtain can increase privacy and shade, if needed. Water proof and retractable shade sails and } \\
\text { canopies can be designed for large outdoor areas as well. }\end{array}$ & & & & $x$ & & & $x$ \\
\hline
\end{tabular}




\begin{tabular}{|c|c|c|c|c|c|c|c|c|}
\hline$\#$ & SMALL ACTIVE & 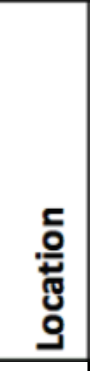 & 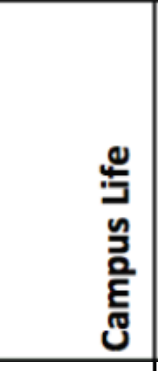 & 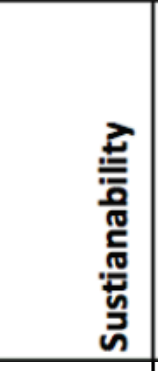 & 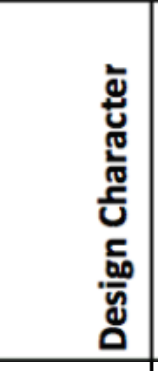 & 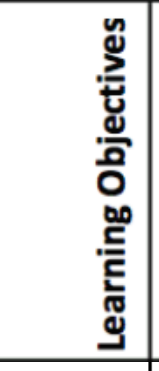 & 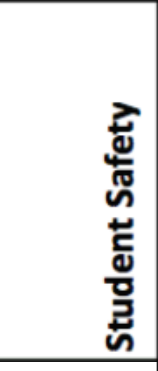 & 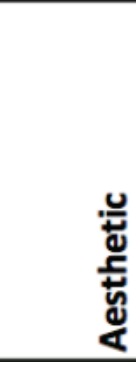 \\
\hline 8 & $\begin{array}{l}\text { Pathways should be sized appropriate to their expected purposes. Heavily traveled walkways } \\
\text { are at least } 8 \text { feet wide to accommodate wheel chairs and groups of people walking in either } \\
\text { direction. Lightly traveled walkways or walkways within seating area should be at least } 4 \text { feet } \\
\text { wide. }\end{array}$ & & $\mathbf{x}$ & & $\mathbf{x}$ & $\mathbf{x}$ & $x$ & \\
\hline 9 & $\begin{array}{l}\text { Green vegetation such as vines, shrubs, planting boxes, fruit trees, or similar are used to } \\
\text { increase privacy or create shade, if needed. }\end{array}$ & & $\mathbf{x}$ & $\mathbf{x}$ & & $\mathbf{x}$ & & \\
\hline 10 & $\begin{array}{l}\text { Seating is adaptable and includes creative seating options. Consider creative seating options } \\
\text { such as swinging or hanging chairs, innovative ground seating, or using steps as seating. For } \\
\text { example, a large rock in a grass patch which has the opportunity to serve as a backrest. }\end{array}$ & & & & $\mathbf{x}$ & $\mathbf{x}$ & & \\
\hline 11 & $\begin{array}{l}\text { The overall design aesthetic should match or reflect the current structures and buildings } \\
\text { surrounding the site. Consider adopting a similar style or character of the established buildings. }\end{array}$ & & $x$ & & $x$ & & & $x$ \\
\hline 12 & $\begin{array}{l}\text { Landmarks and place-making elements should be highlighted though capturing the views from } \\
\text { the outdoor learning environment site. Consider various sidelines from each seating and } \\
\text { recreational area in order to create a space that enhances student's learning abilities as well as } \\
\text { attraction from future students and their visiting parents. }\end{array}$ & & $\mathbf{X}$ & & & & & \\
\hline 13 & $\begin{array}{l}\text { The addition of power outlets should be considered when designing a space that is intended for } \\
\text { students to spend long periods of time. Collaborating with the University technical support and } \\
\text { administration will determine if the addition of power outlets is feasible for an active outdoor } \\
\text { learning environment. }\end{array}$ & & & & $\mathbf{x}$ & $\mathbf{x}$ & & \\
\hline
\end{tabular}




\section{DESIGN CASES}

3D VISUALIZATION, SITE PLANS, \& SECTIONS
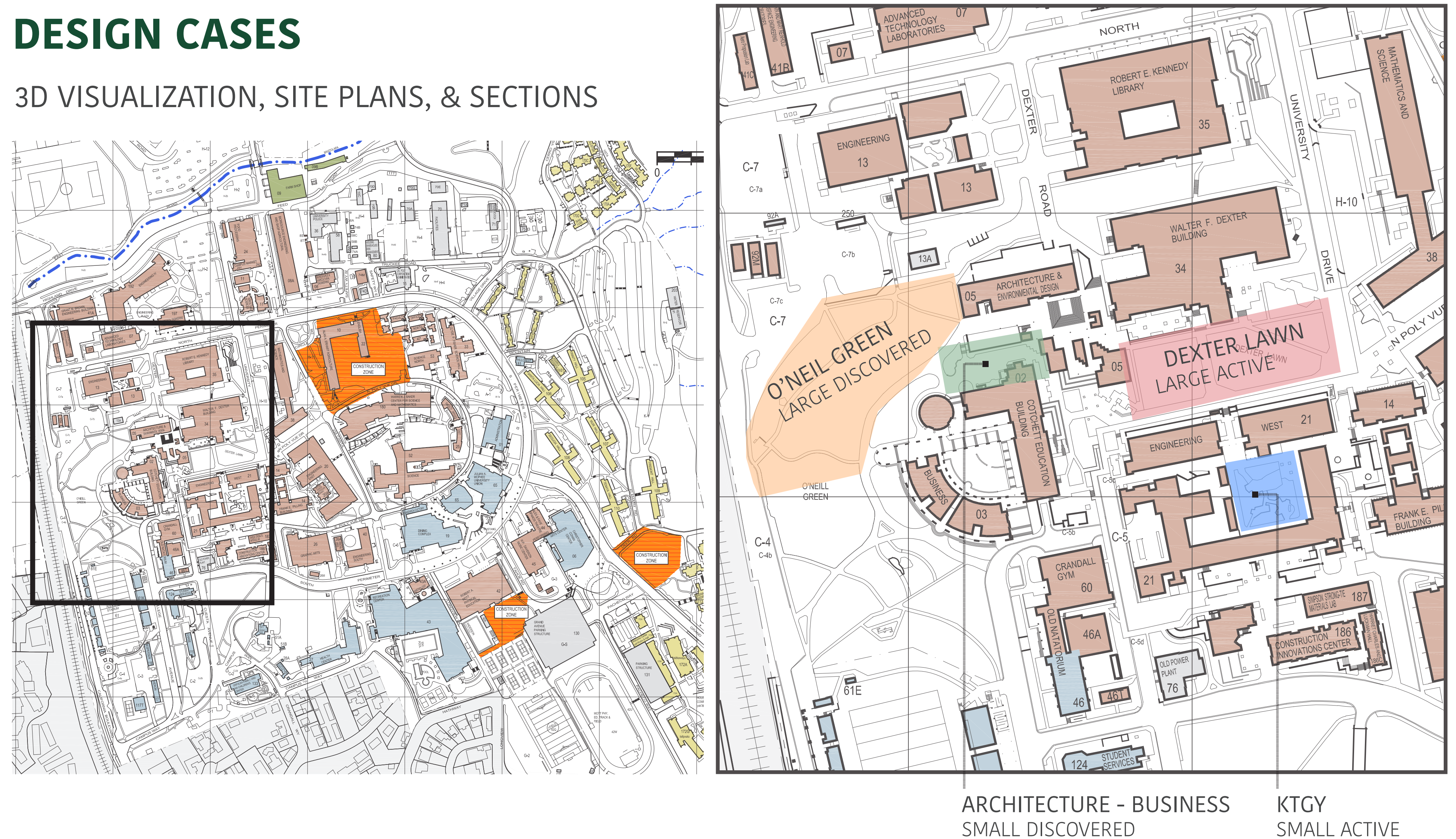

Outdoor Learning Environments 2020 


\section{LARGE ACTIVE}

Dexter Lawn - Cal Poly

Introduction

The large active, Dexter Lawn space is split into three distinct scenarios.

Each scenario has a similar base and includes shade structures. Although

not every scenario recomends the shade structures to be open.

1. Relaxation and socialization

2. Teaching and class presentations

3. University-wide concert and event space 


\section{SITE PLAN}

DEXTER 1

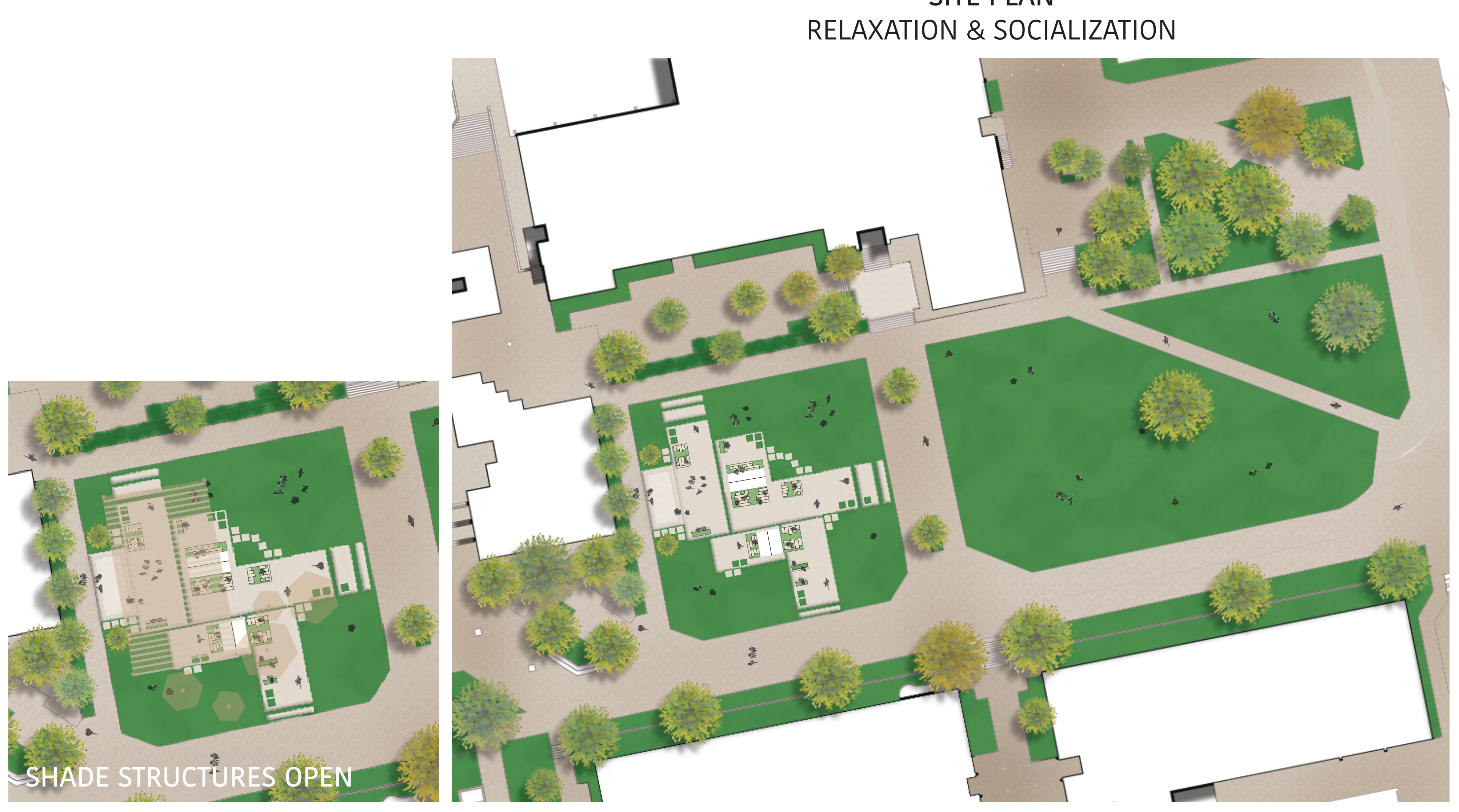


FEATURES

\section{RELAXATION \& SOCIALIZATION}

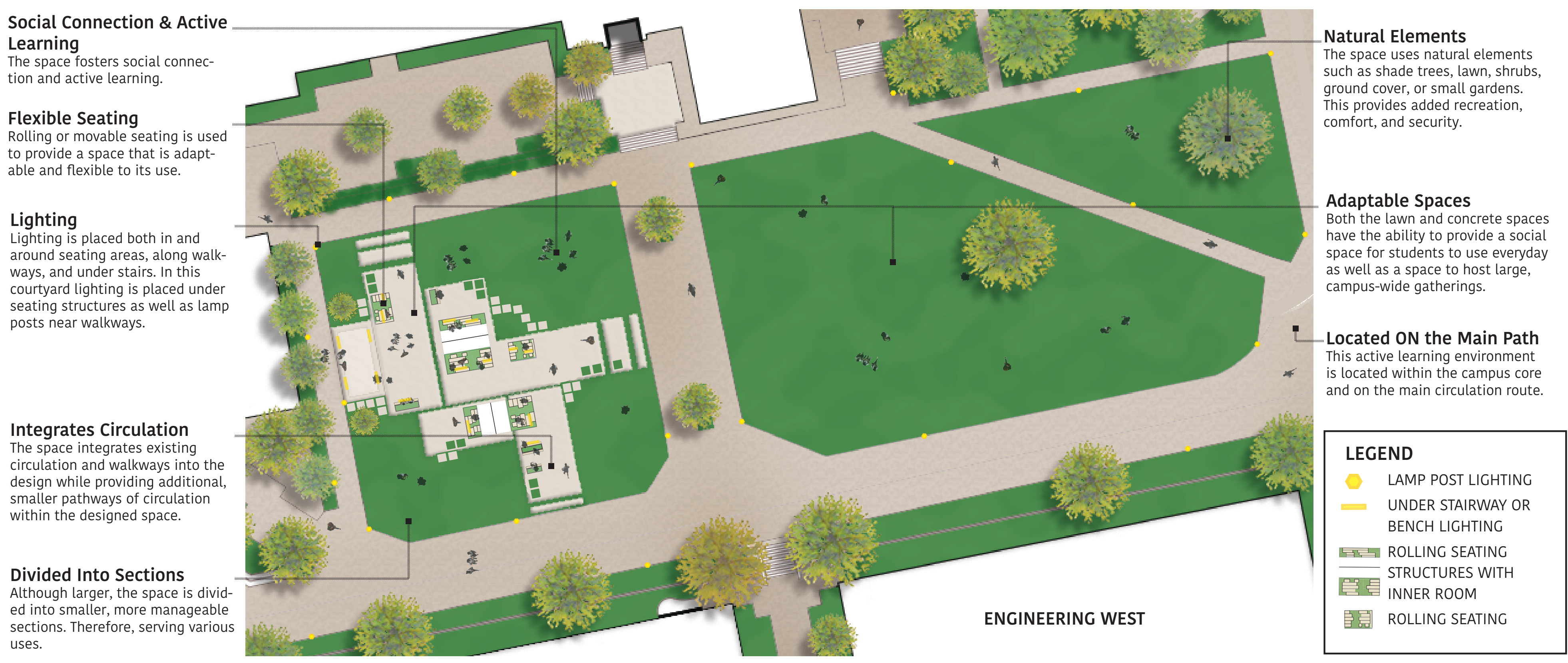



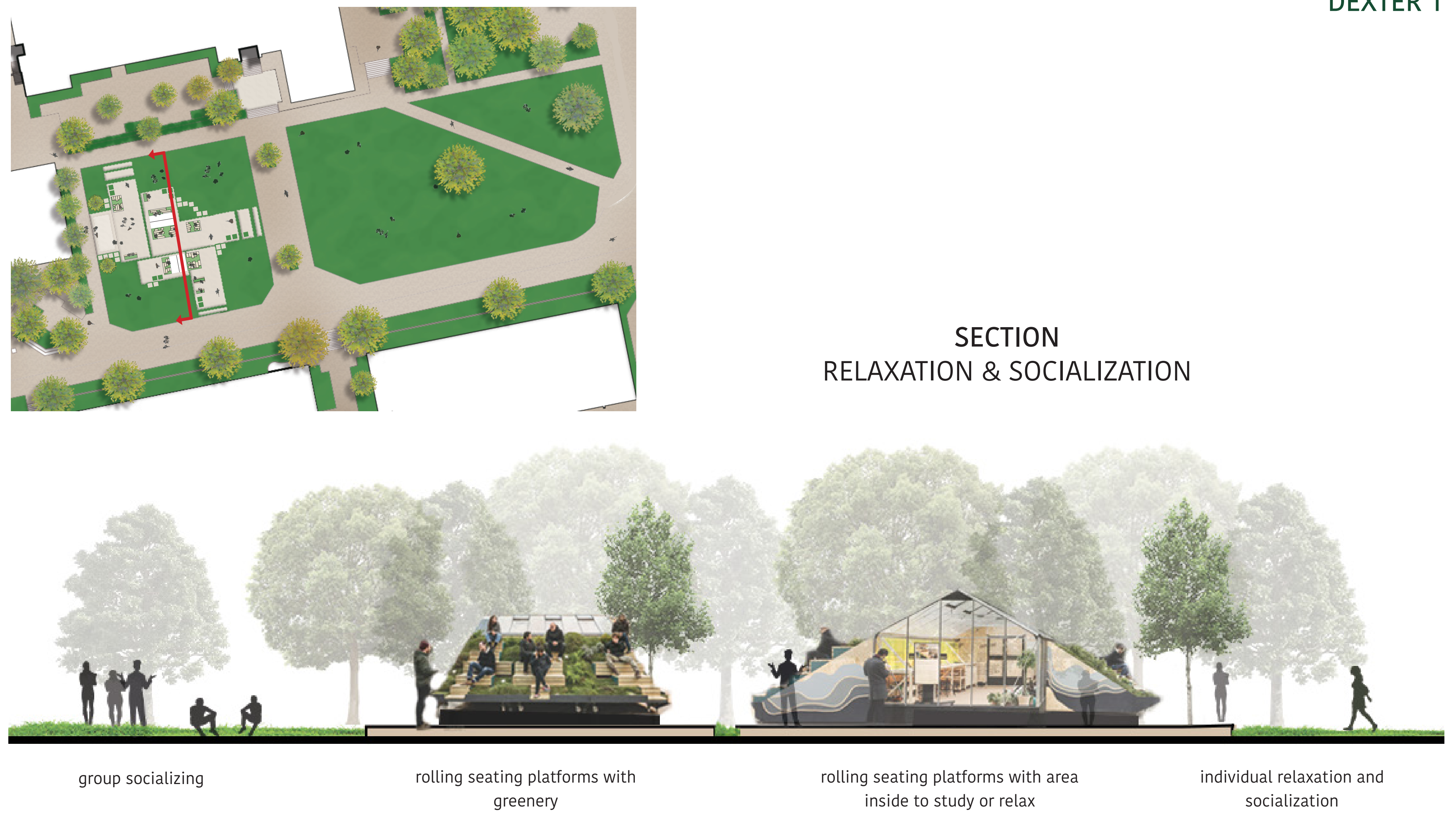
TEACHING \& CLASS PRESENTATIONS
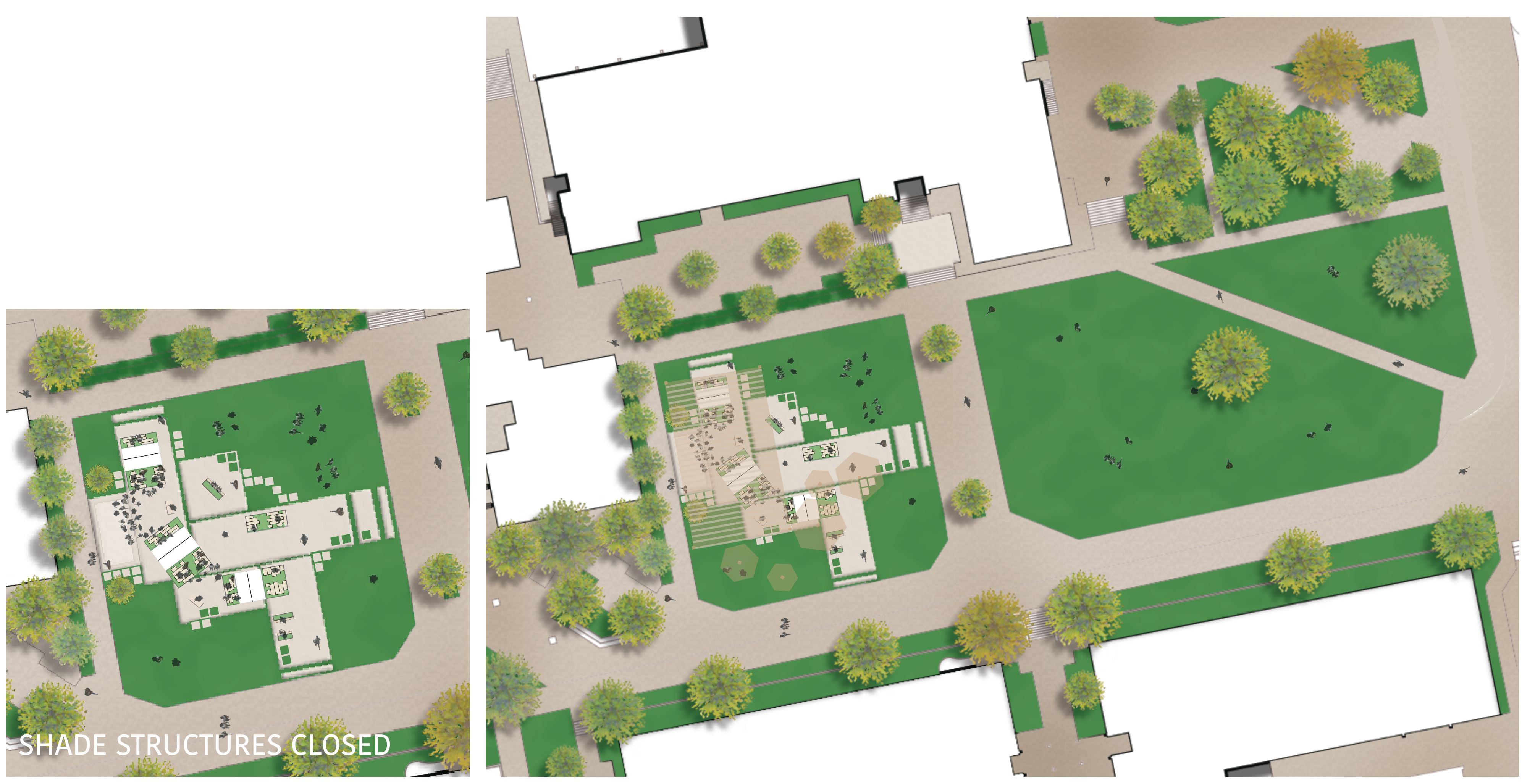


\section{FEATURES}

\section{TEACHING \& CLASS PRESENTATIONS}

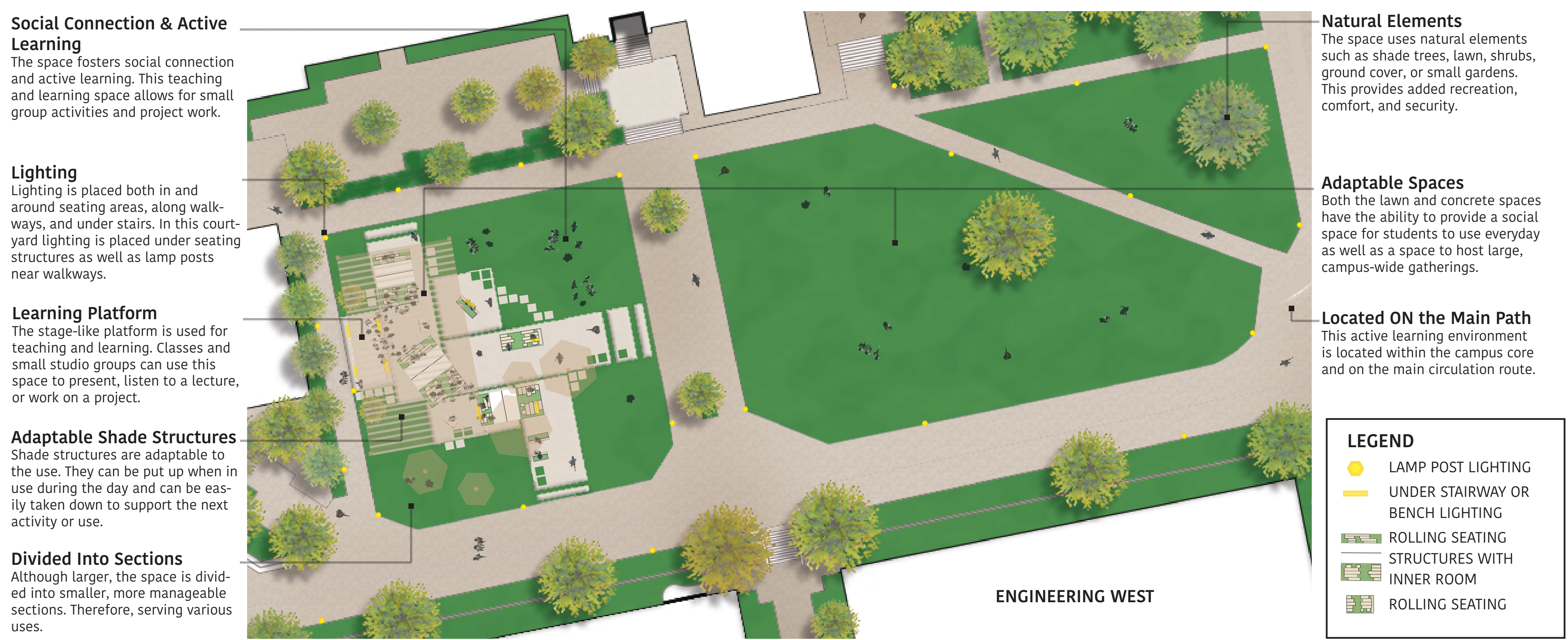



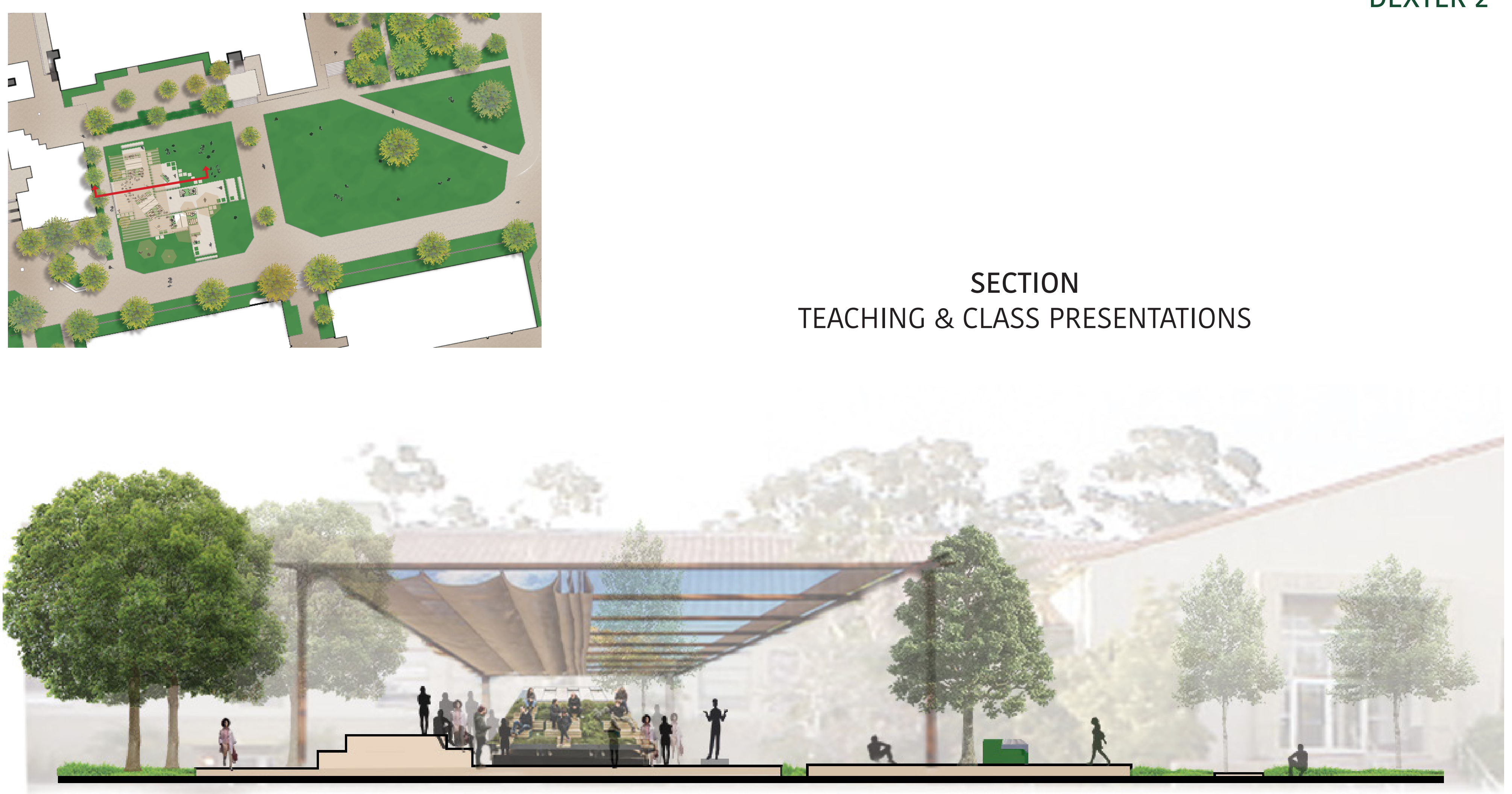

stage-like teaching or rolling seating platforms with greenery with student seating platform area inside to hold teaching supplies

planter with seating

\section{TEACHING \& CLASS PRESENTATIONS}




\section{SITE PLAN}

DEXTER 3

\section{CONCERT \& UNIVERSITY EVENT}
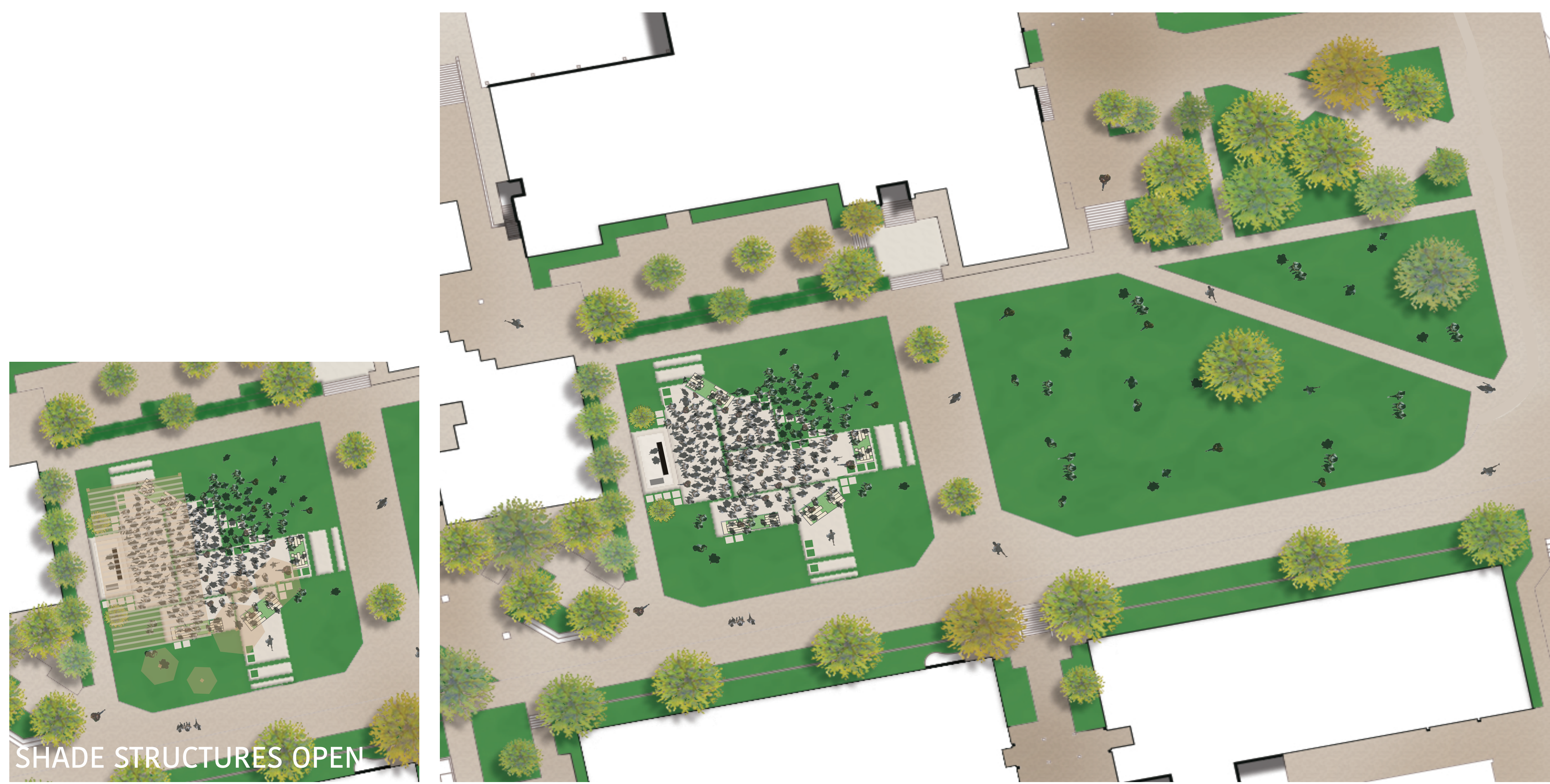


\section{FEATURES}

DEXTER 3

\section{CONCERT \& UNIVERSITY EVENT}

Social Connection \& Active Learning

The space fosters social connection and active learning. This teaching and learning space allows for small group activities and project work.

\section{Lighting}

Lighting is placed both in and

around seating areas, along walk-

ways, and under stairs. In this court-

yard lighting is placed under seating

near walkways.

\section{Presentation Platform}

The stage-like platform is used for presentations or gatherings. The University can host a concert, event, graduation, athletic ceremony, and more.

\section{Flexible Seating}

Rolling or movable seating is used to provide a space that is adaptable and flexible to its use. In this scenario, they are uses as bleacher-like seating.

\section{Divided Into Sections}

Although larger, the space is divided into smaller, more manageable sections. Therefore, serving various uses.

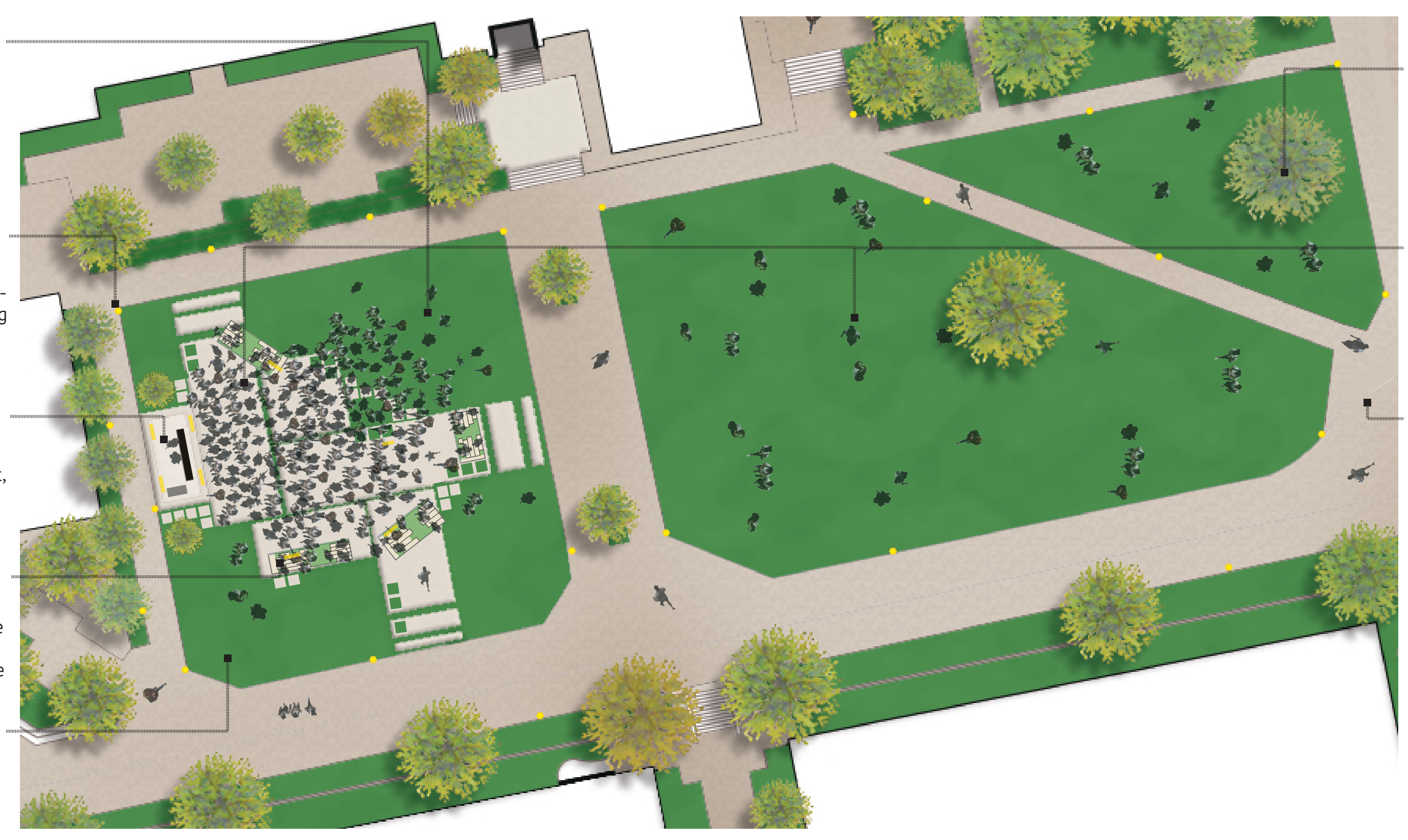

Natural Elements

The space uses natural elements

The space uses natural elements

ground cover, or small gardens.

This provides added recreation,

comfort, and security.

Adaptable Spaces

Both the lawn and concrete spaces have the ability to provide a socia

space for students to use everyday

as well as a space to host large, campus-wide gatherings or, in this scenario, a concert.

Located ON the Main Path This active learning environment is located within the campus core and on the main circulation route.

\section{LEGEND}

LAMP POST LIGHTING

- UNDER STAIRWAY OR BENCH LIGHTING

대를 ROLLING SEATING

STRUCTURES WITH

Eᄅ

官罟 ROLLING SEATINC 


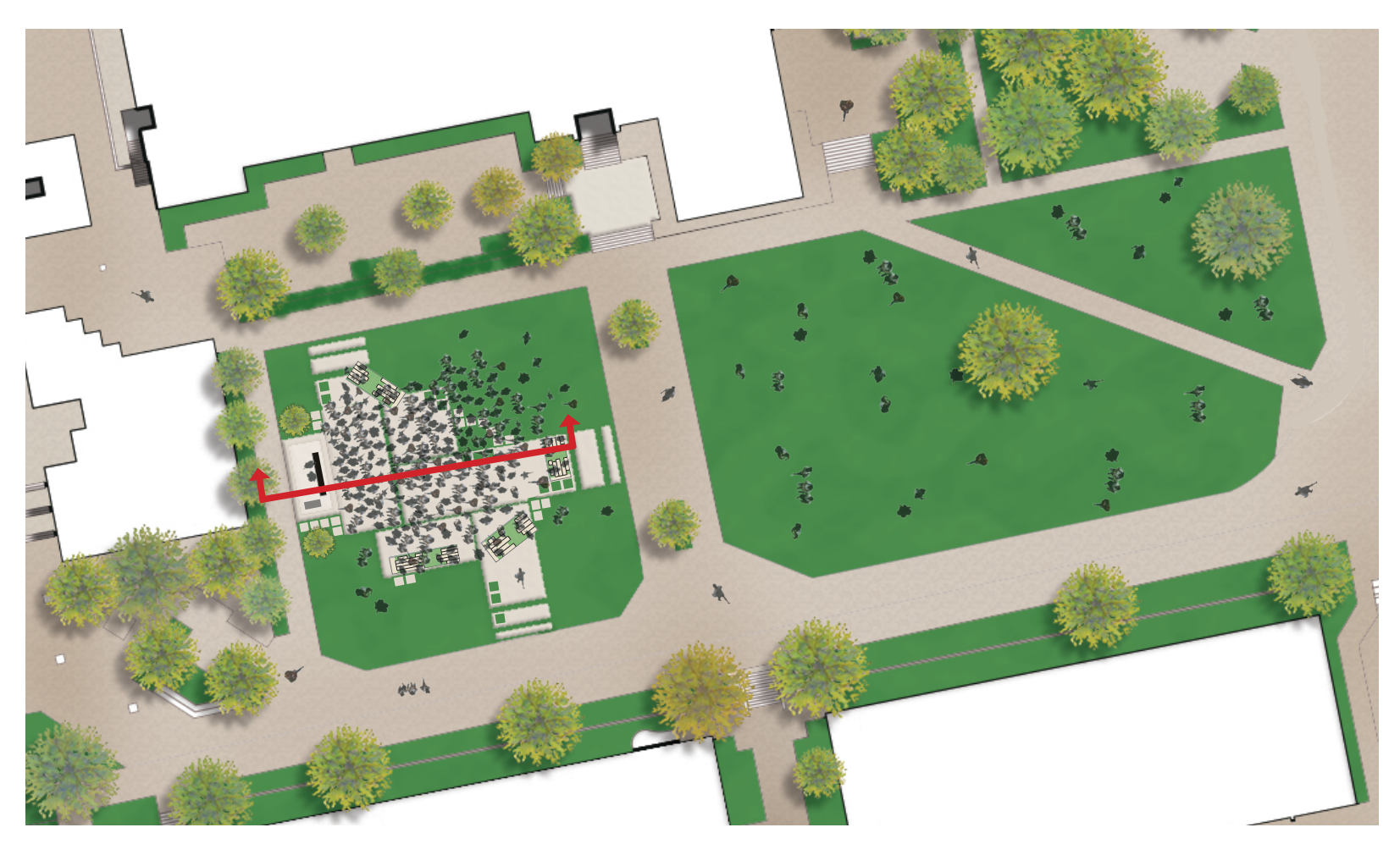

DEXTER 3

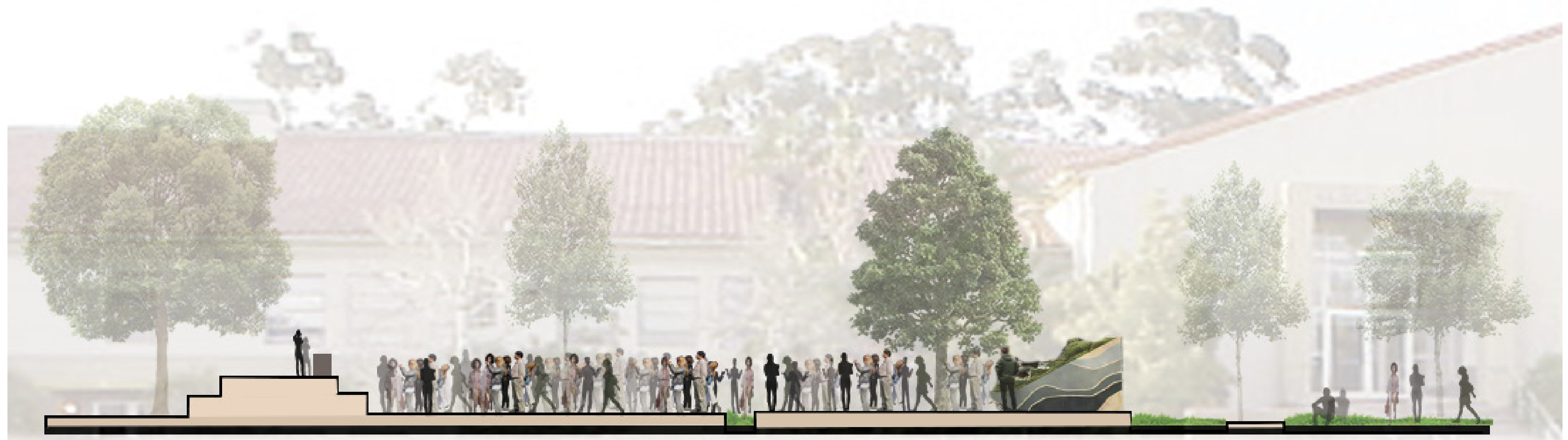

rolling seating platforms with greenery, used as bleacher-like seating
SECTION

\section{CONCERT \& UNIVERSITY EVENT}

lawn seating or viewing 


\section{SITE PLAN}

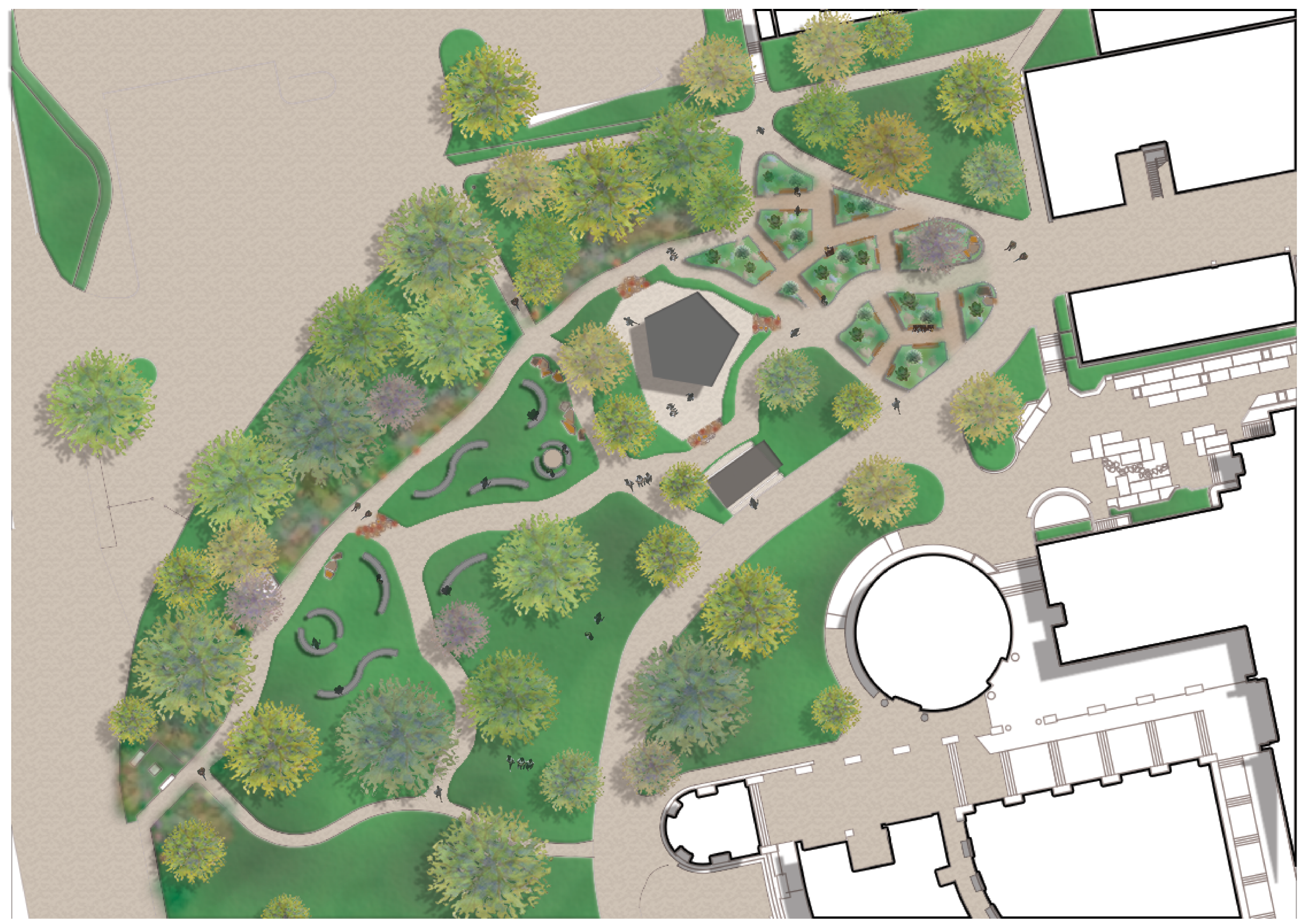



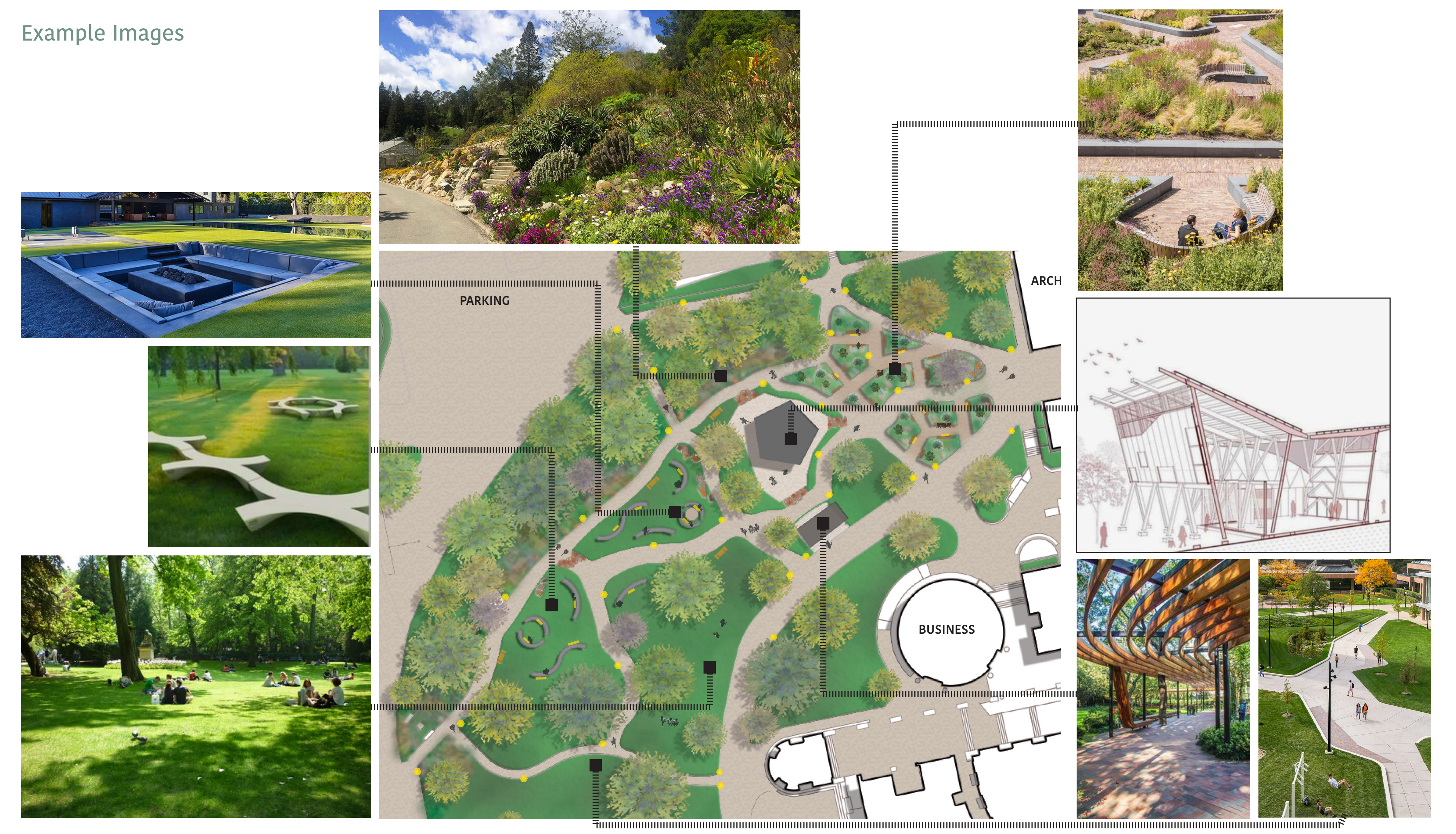


\section{DIMENSIONS}

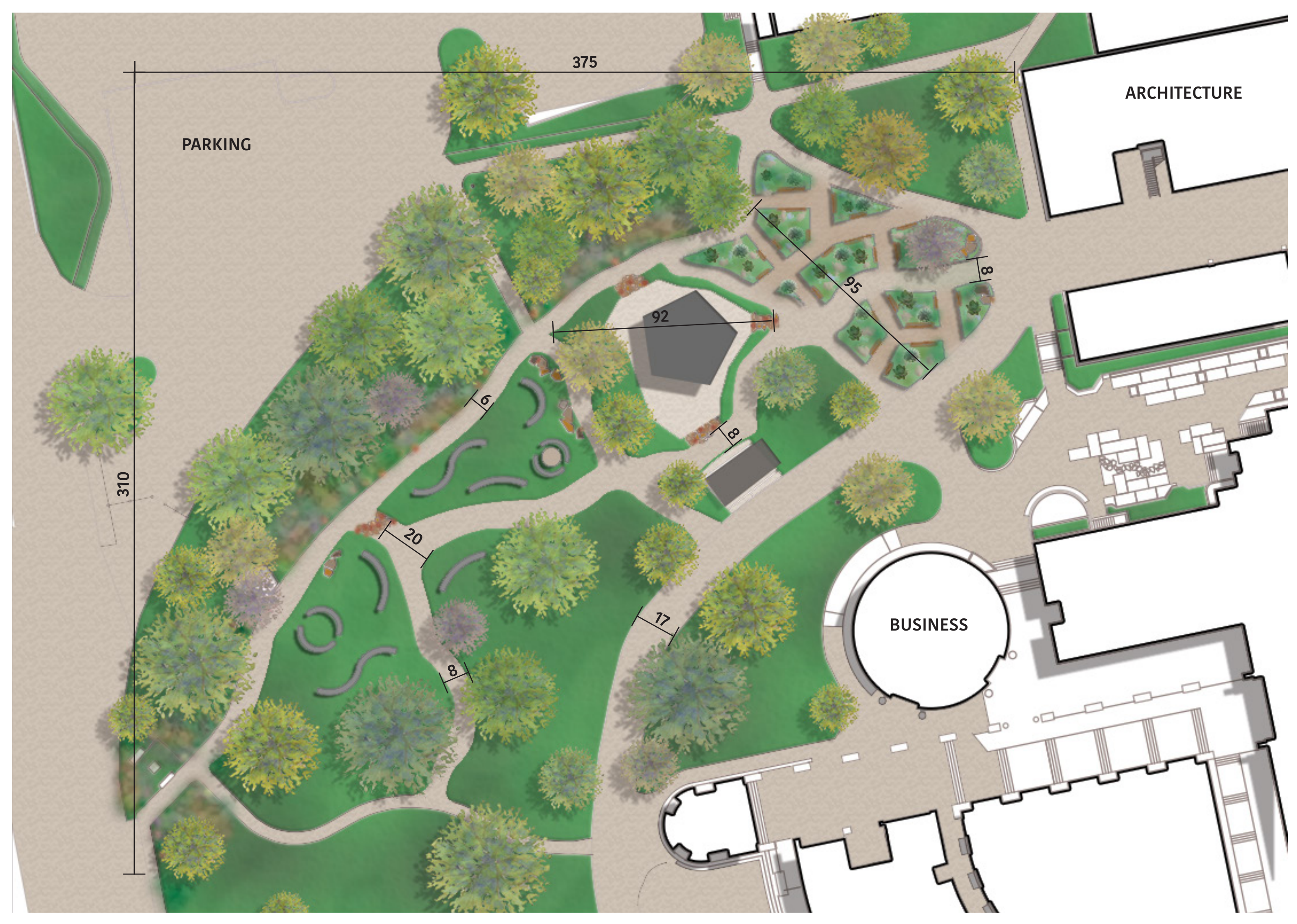




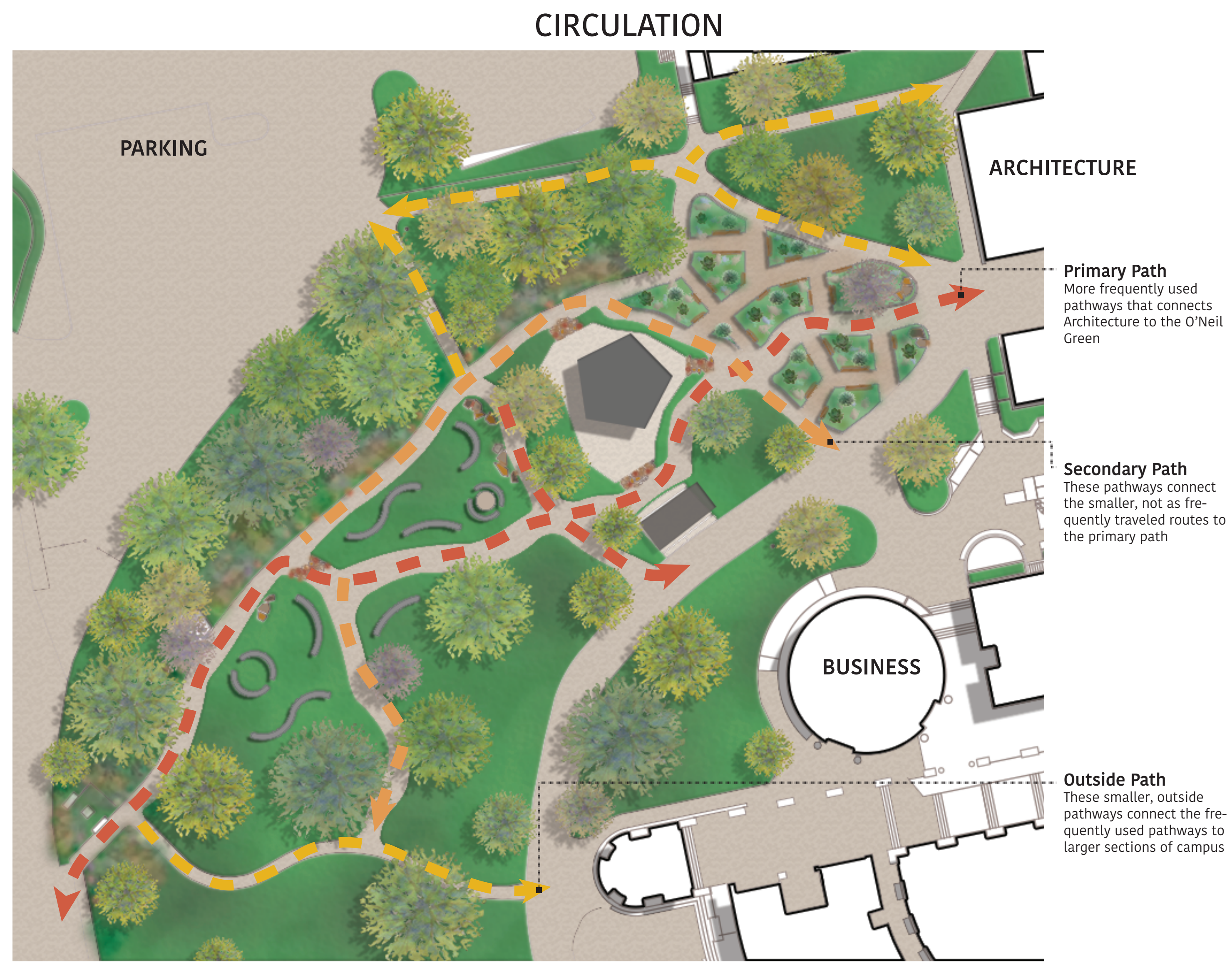




\section{ACTIVES}

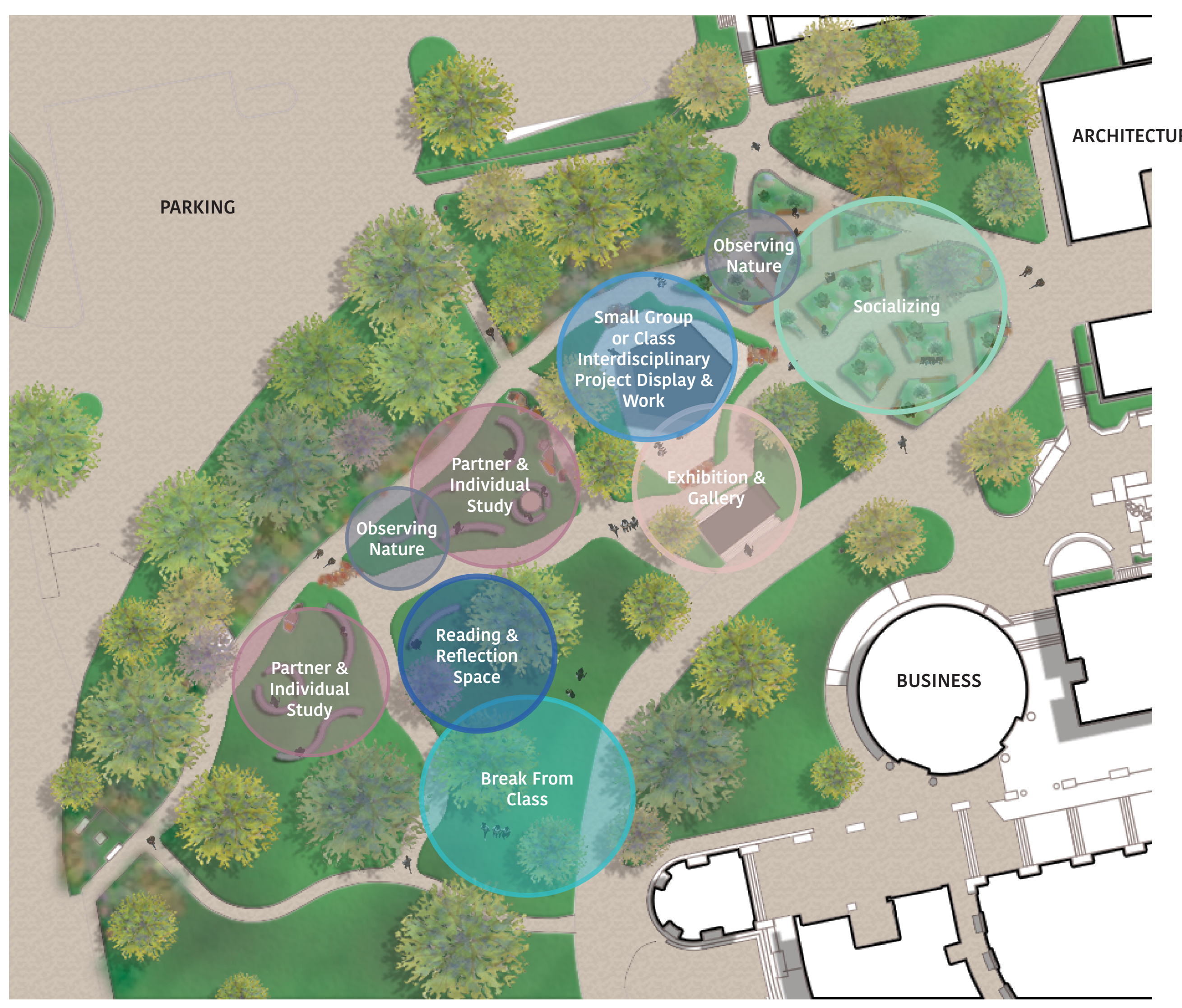




\section{FEATURES}

Shade Trees

Shade tree and shade struc-

tures are places near seating

for comfort without blocking

the views.

Connection to Nature

Dense tree planting, a wind-

ing garden, and a variety of

plants are added to the space

reflect students will feel safe and secluded.

\section{Variety of Seating}

Seating is provided through seating walls (brown; around social plaza, North-East), swing seating (brown), and seating walls (gray, in grass). Designed for individual or partner learning or socializing.

\section{Pathway Width}

Lesser traveled walkways are at least 5 feet wide. Wider
walkways are allocated on main pathways and near entrances.

\section{Refection Space}

More quiet areas or garden

sections are designed near

natural areas to provide a

space for resting or relaxation.

\section{Lighting}

Lighting is placed both in and

around seating areas, along

walkways, and under stairs.

In this courtyard lighting is

placed under seating bench-

es as well as lamp posts near walkways.

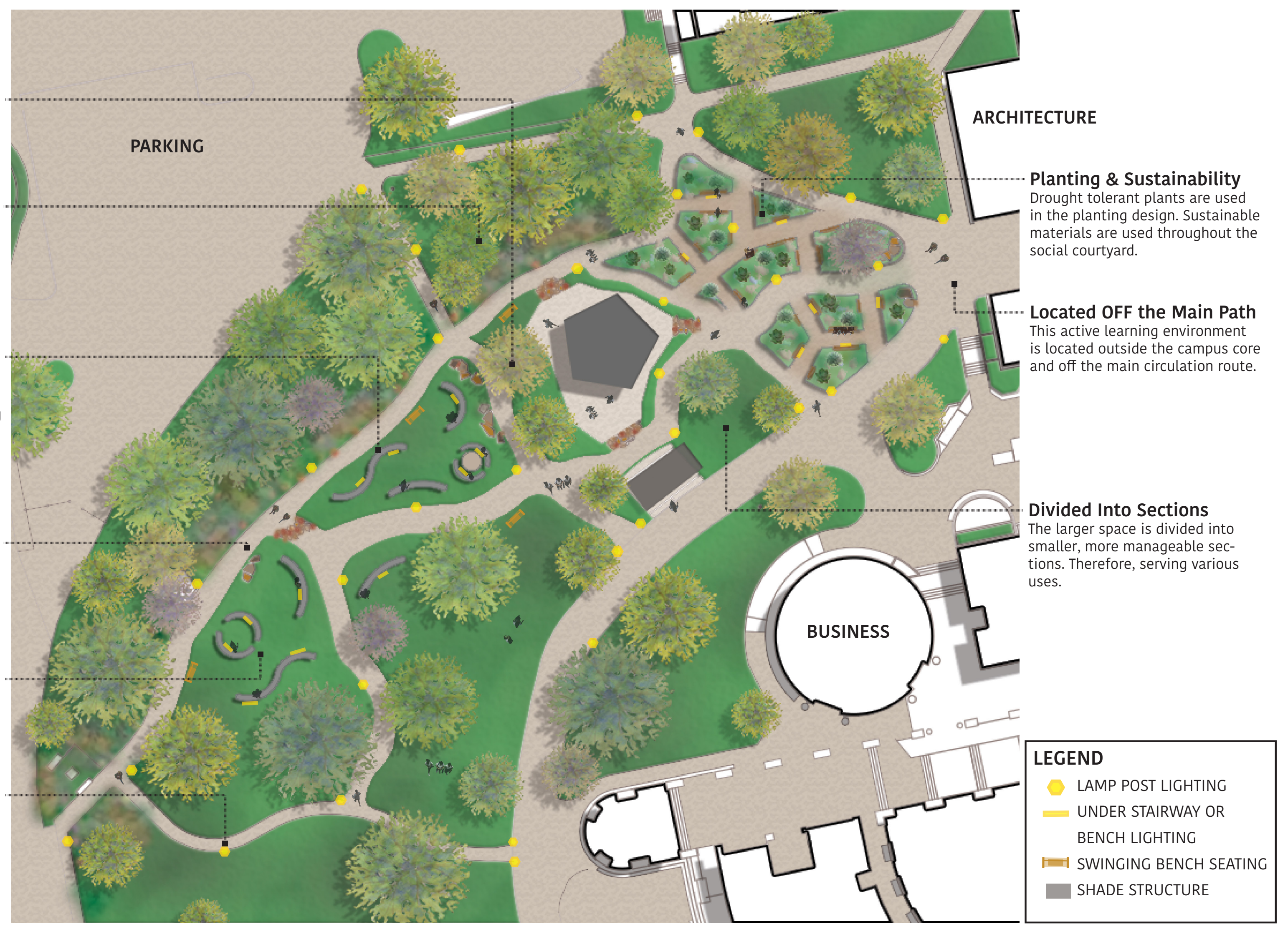




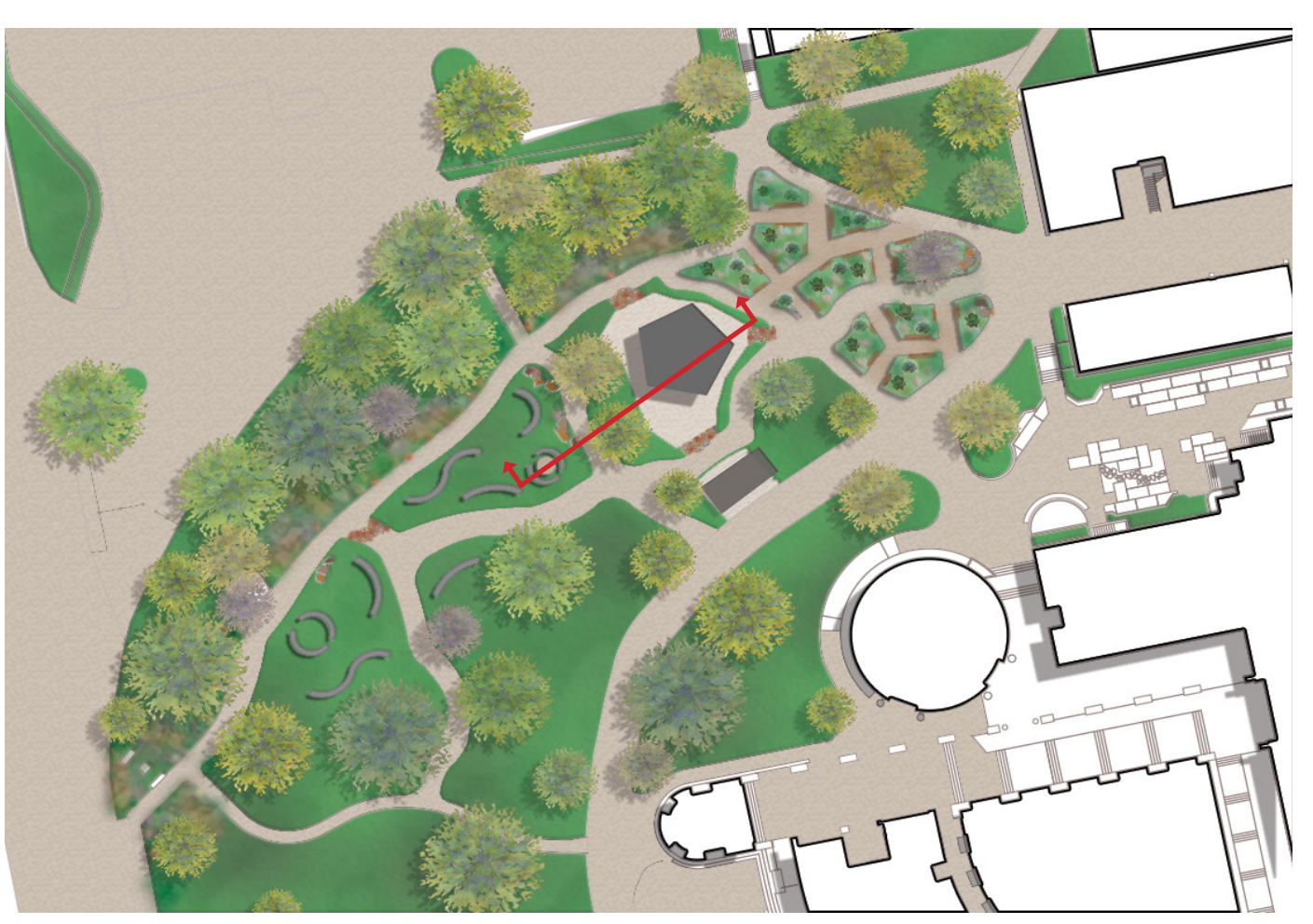

SECTION

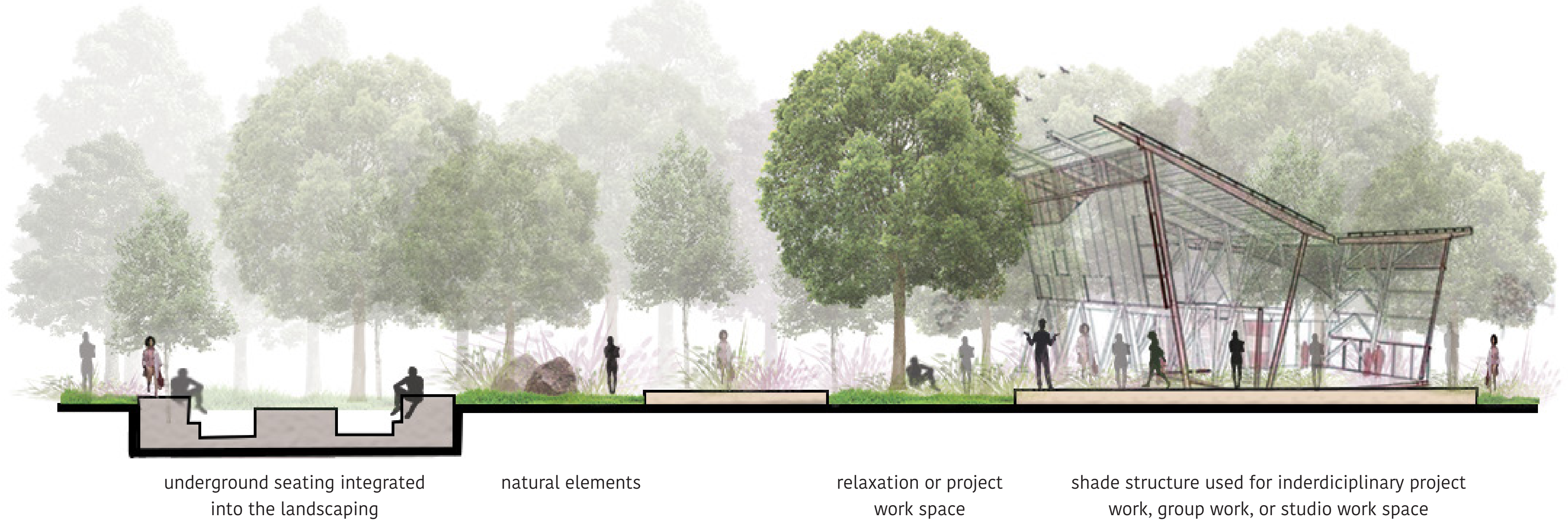


SMALL DISCOVERED

Architecture - Business - Cal Poly

SITE PLAN

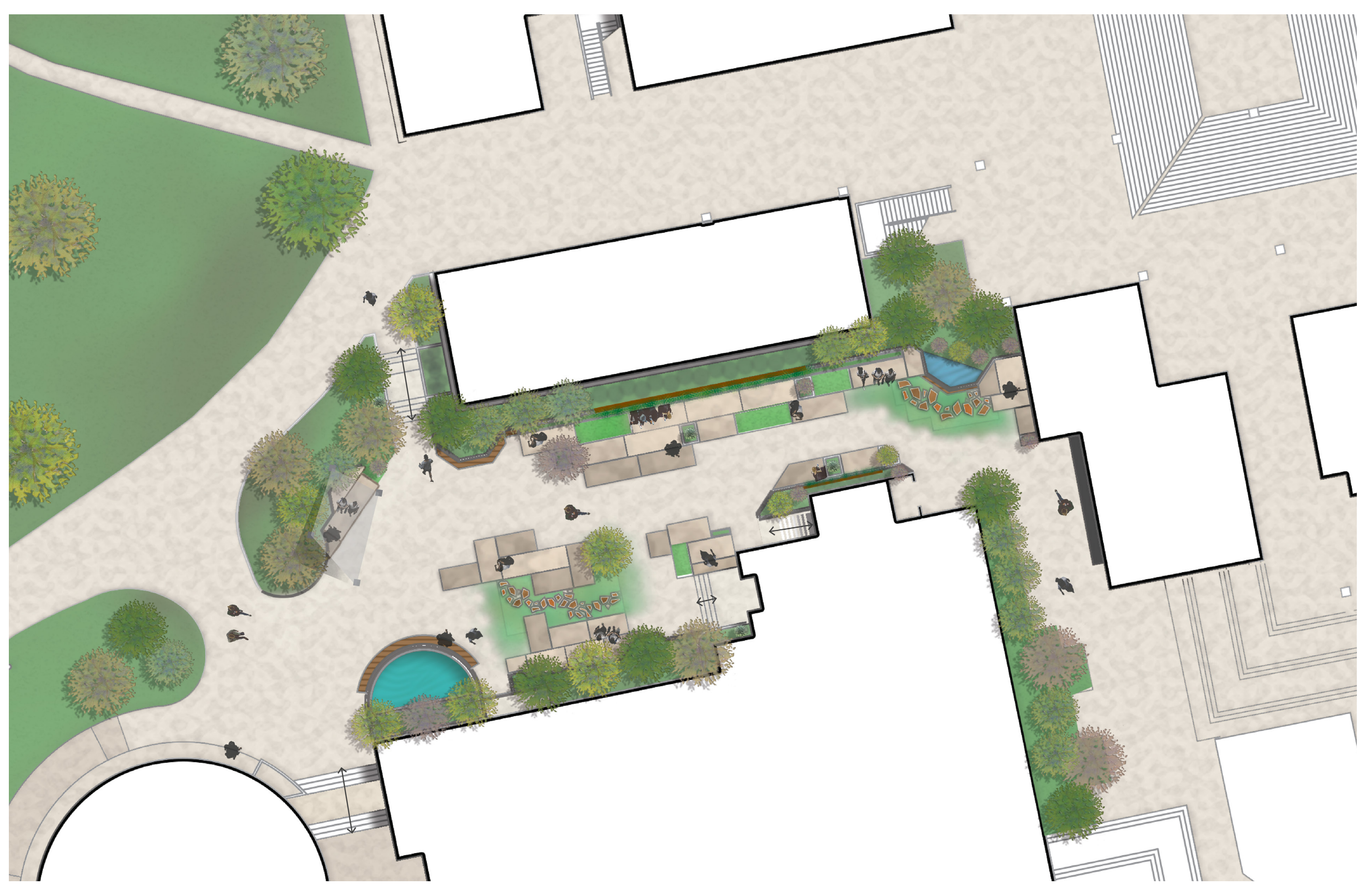

Outdoor Learning Environments 2020

75 

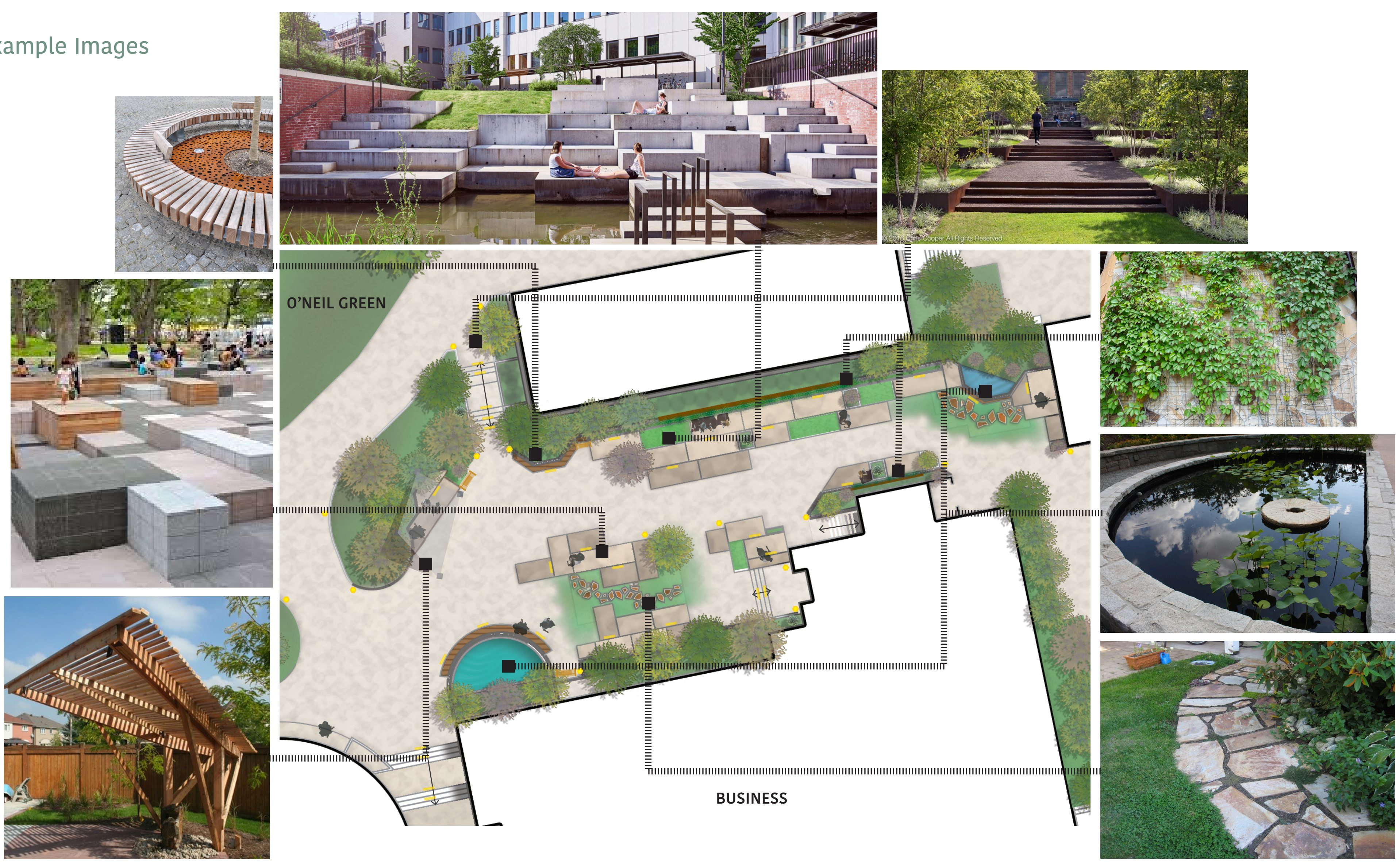


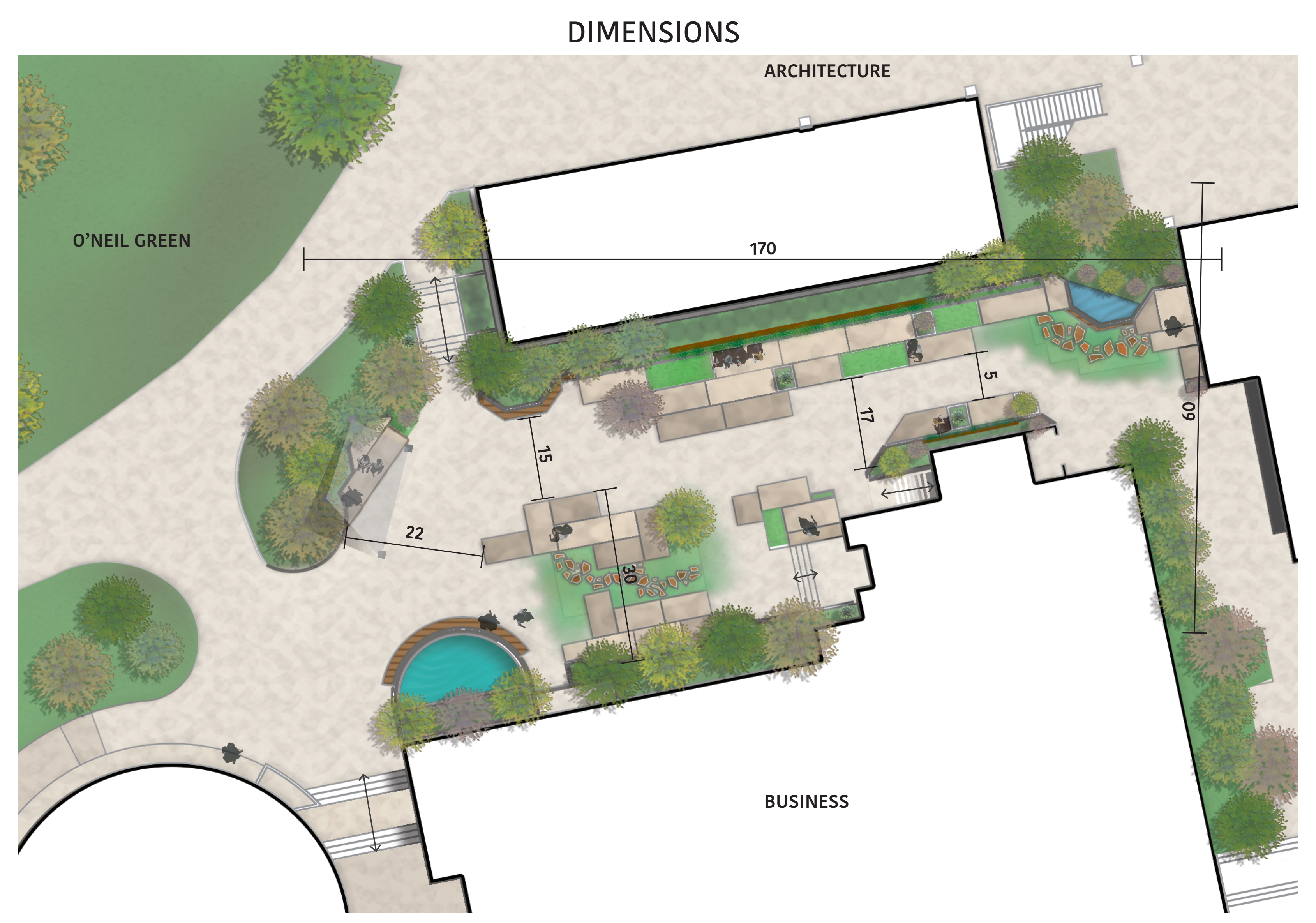




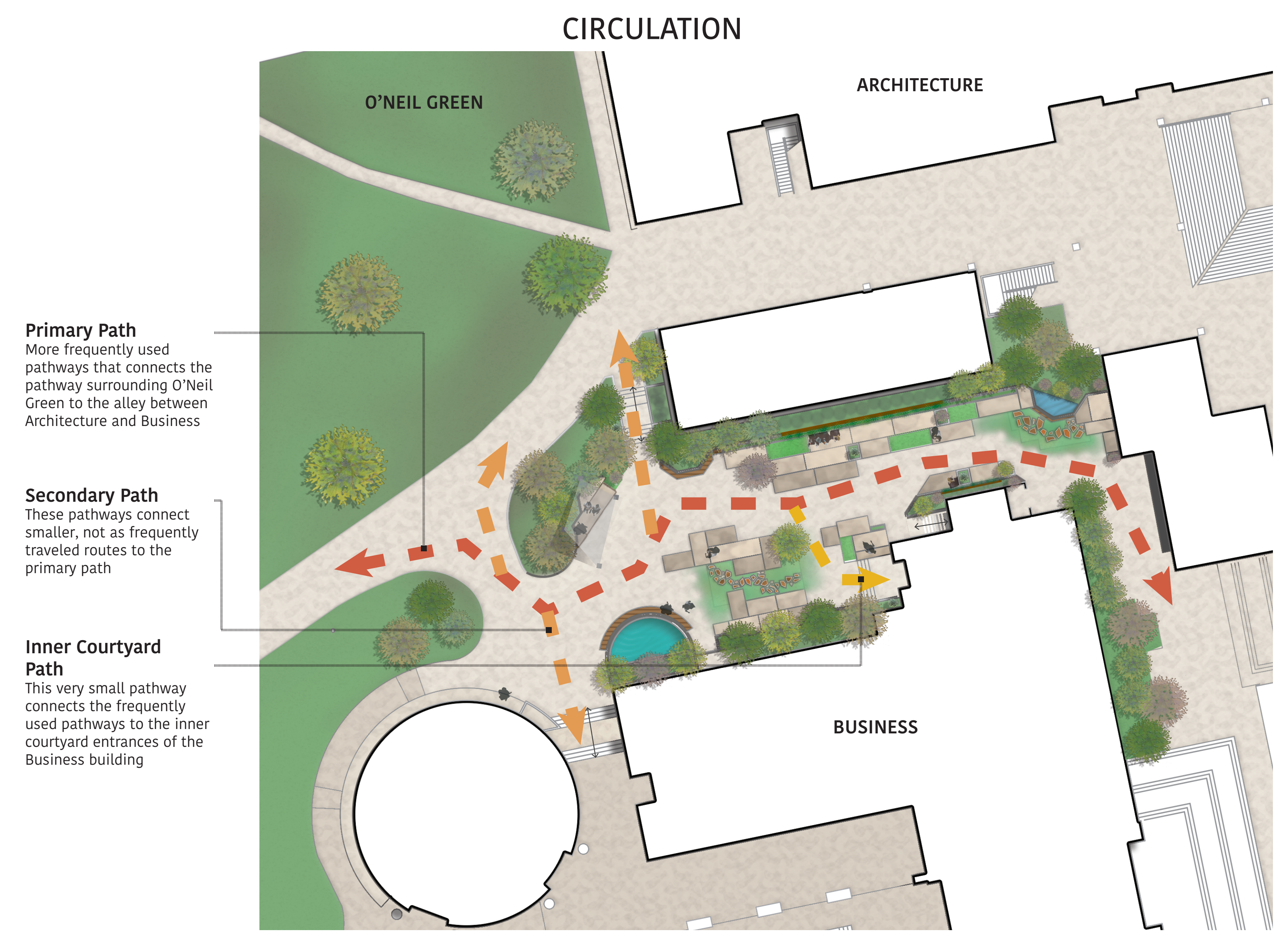




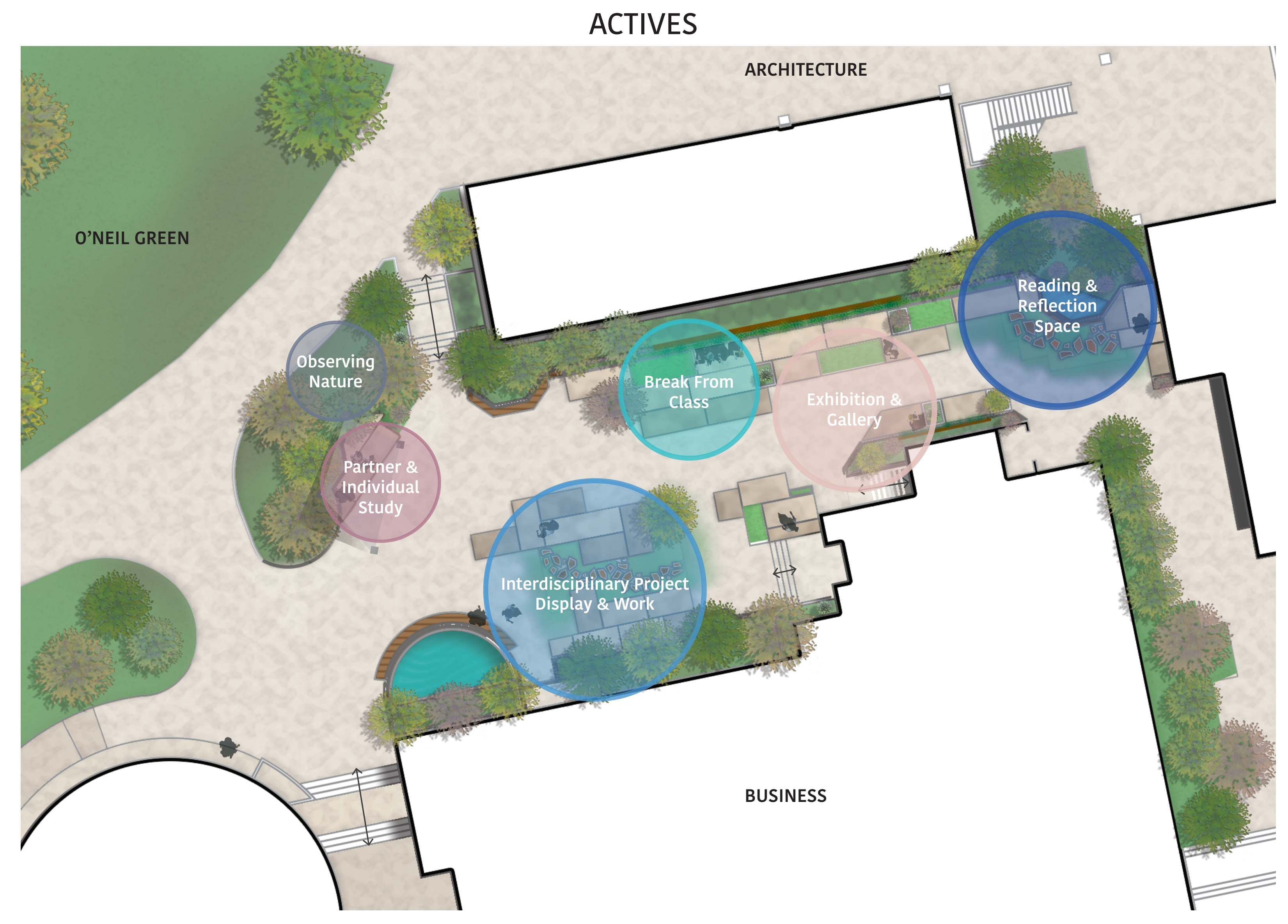




\section{FEATURES}

\section{Lighting}

Lighting is placed both in and around seating areas, along walkways, and under stairs. In this courtyard lighting is placed under seating benches as well as lamp posts near walkways.

\section{Shade Trees}

Shade tree and shade structures are places near seating for

comfort, without blocking the

\section{Pathway Width}

Lesser traveled walkways are at least 4 feet wide. Wider walkways are allocated near entrances.

\section{Located OFF the Main Path} This active learning environment is located outside the campus core and off the main circulation route.
ARCHITECTURE

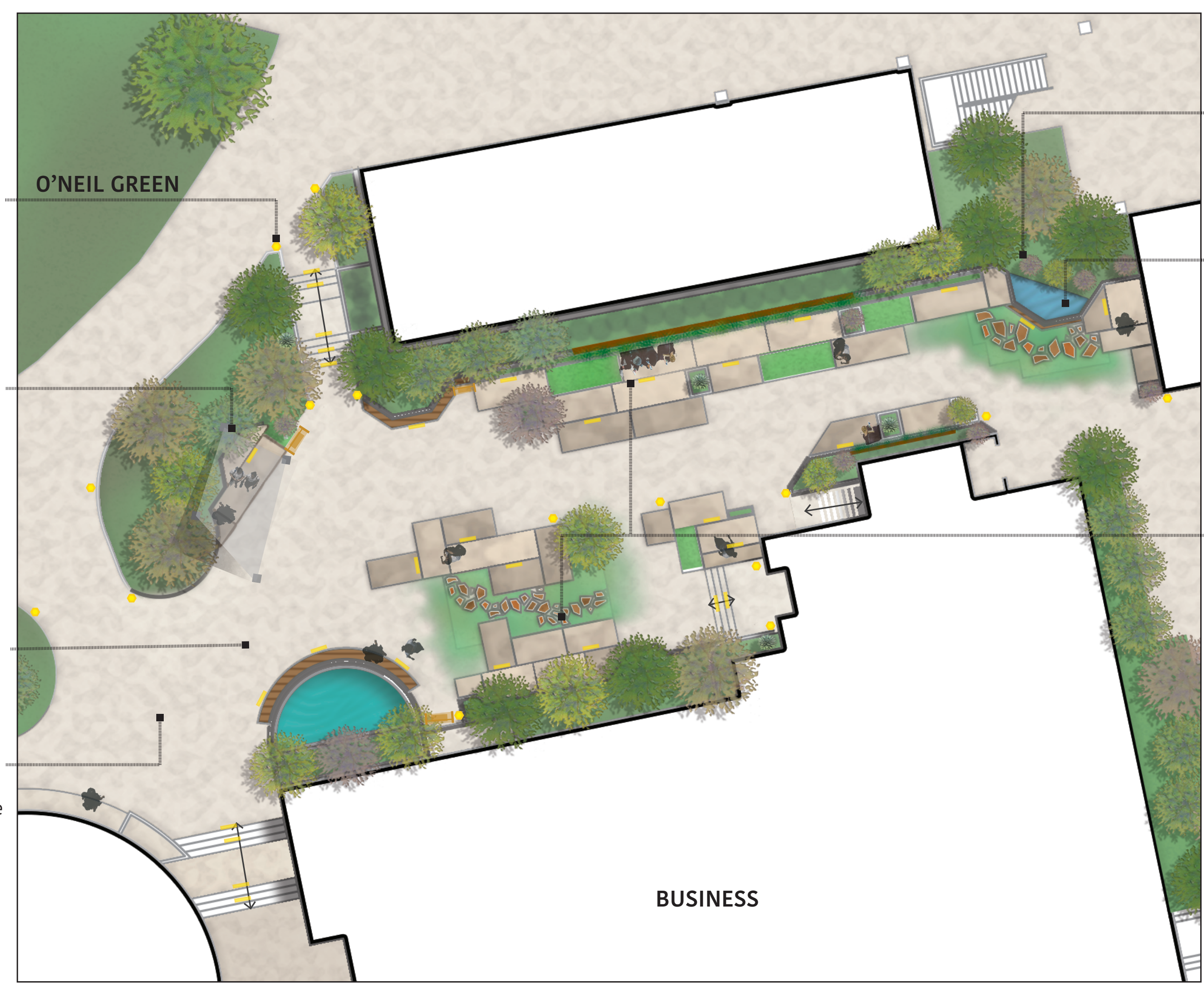

Planting \& Sustainability Drought tolerant plants are used in the planting design. Sustainable materials are used throughout the courtyard.

\section{Connection to Nature}

Fountains and a variety of plants added to the space to provide a space to relax and reflect. Students will feel safe and secluded.

Seating \& Learning Nooks Seating is provided through seating walls (brown striped) and steps (gray and brownish) as well ss swing seating, Learning nools as swing seating. Learning nooks can provide a space for groups of students to study or for interdisciplinary project work to take place.

\section{LEGEND}

C LAMP POST LIGHTINC

- UNDER STAIRWAY OR BENCH LIGHTING

SWINGING BENCH SEATING

1. SHADE STRUCTURE 


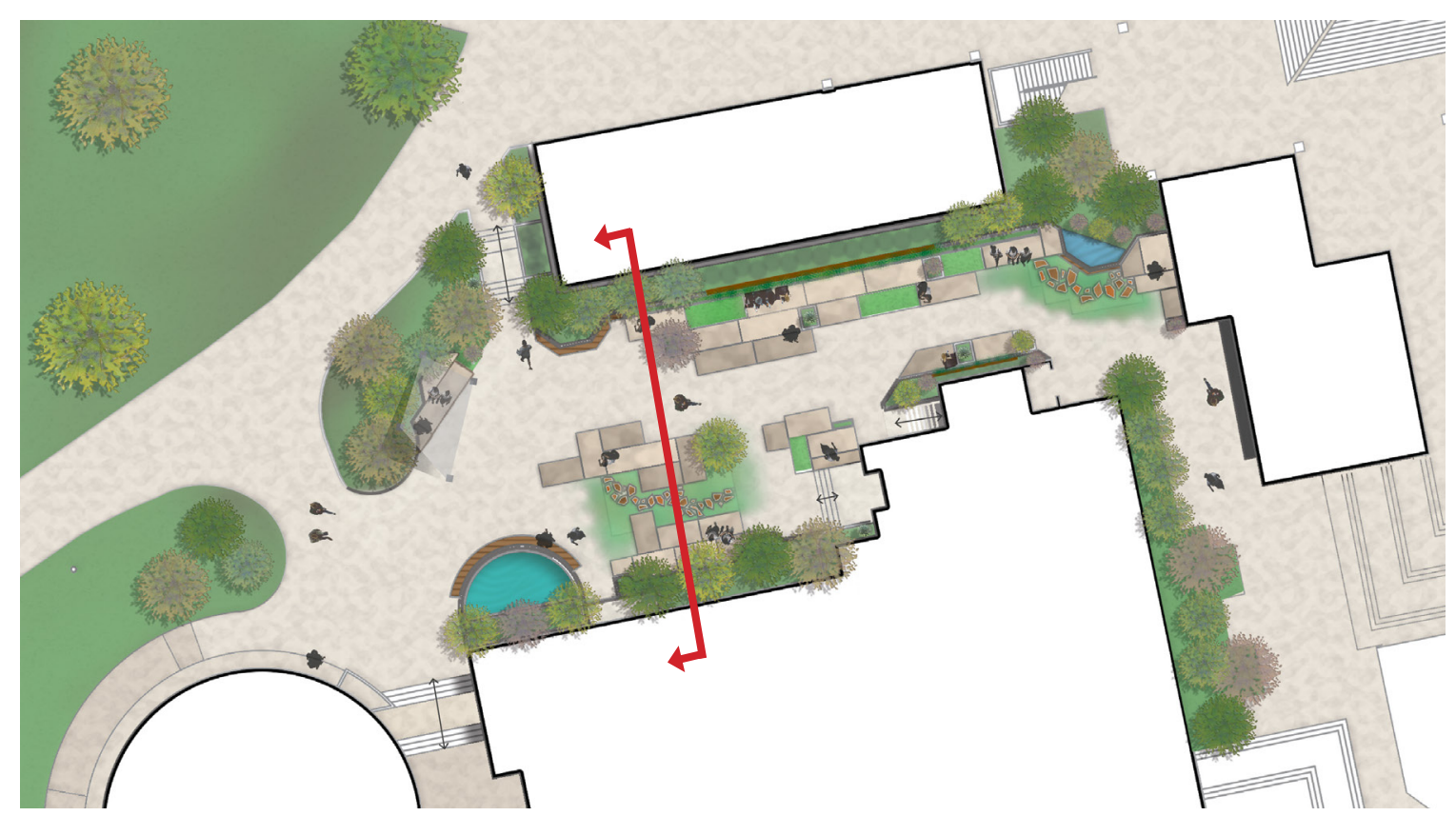

\section{SECTION}

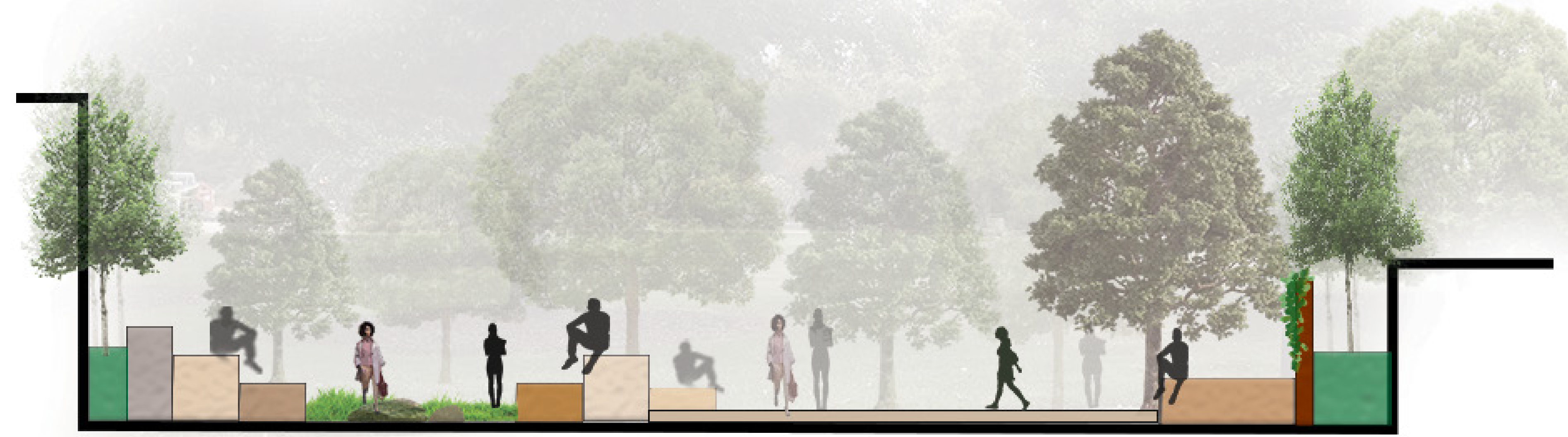

seating blocks arranged to support group work or a small group discussion walkway inbetween seating areas

more quiet seating area used for individual or partner work 


\section{SMALL ACTIVE}

\section{SITE PLAN}

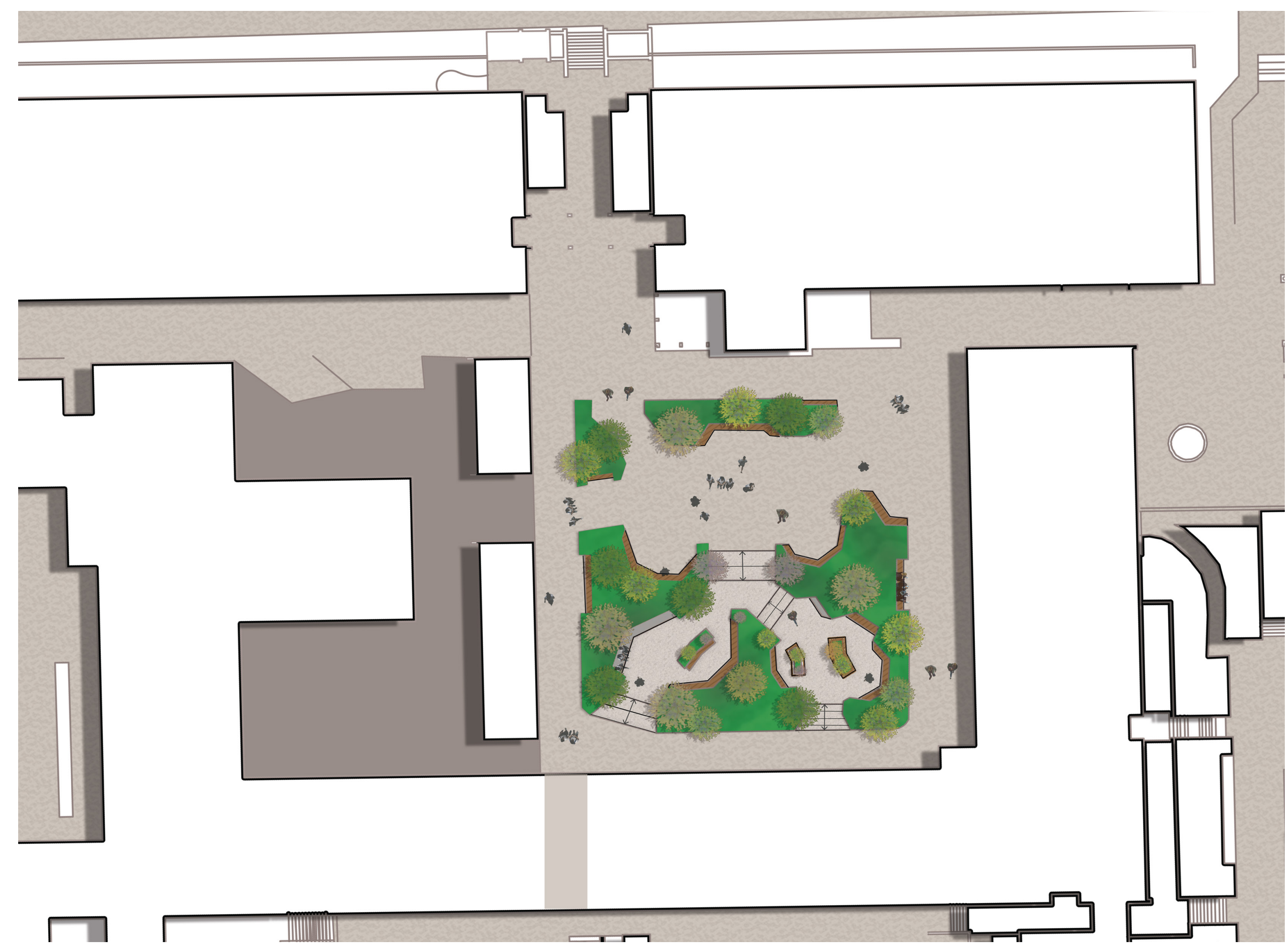


Example Images
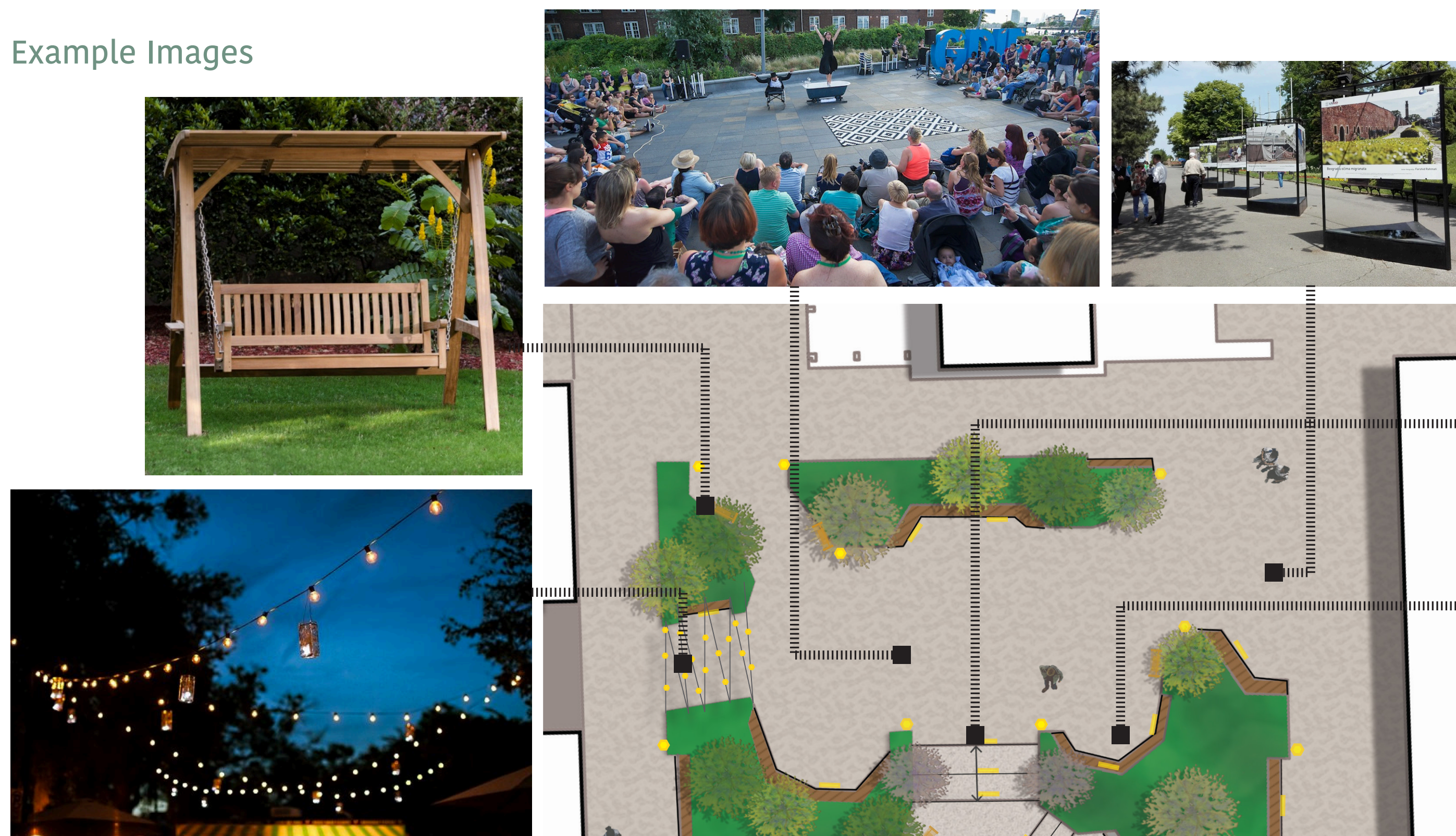

4.

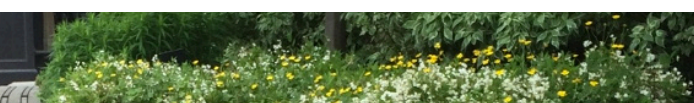

$\left.\left(-x^{2} x^{2}\right) y^{5}\right)^{2}$
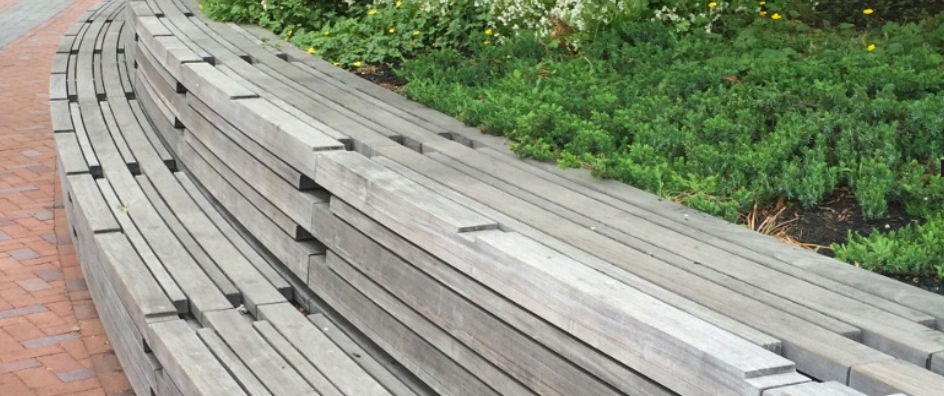

$+2$
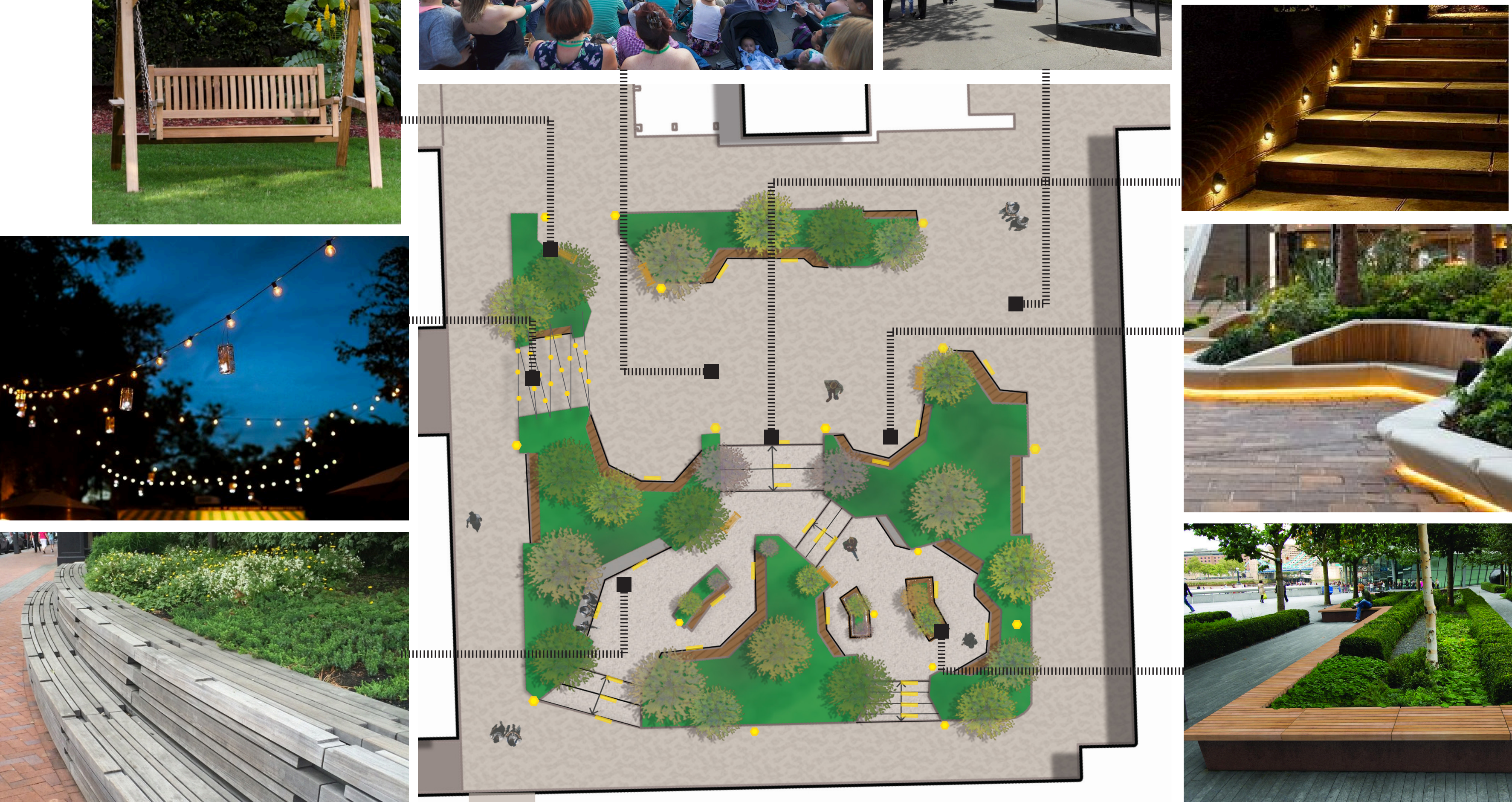

9
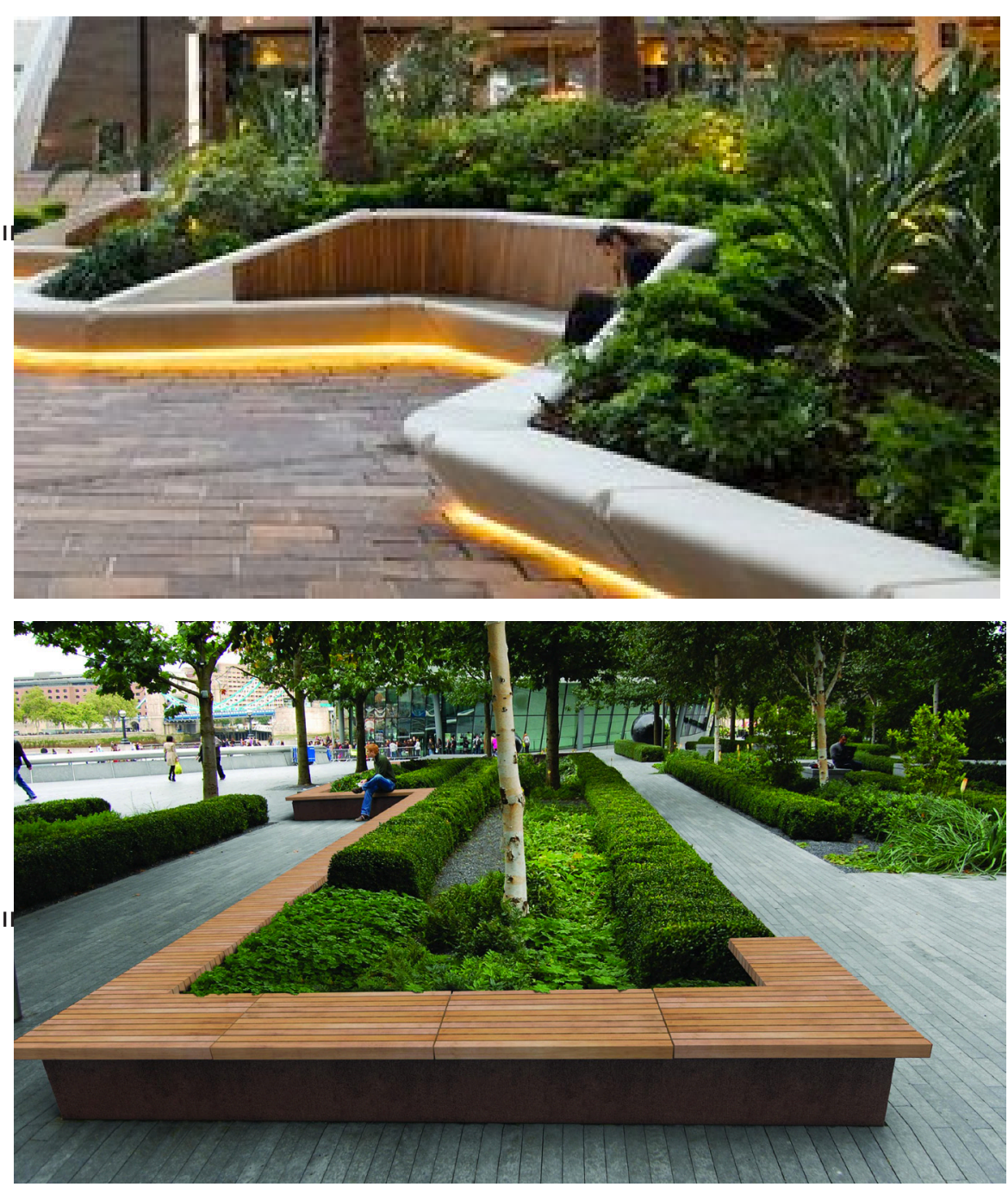


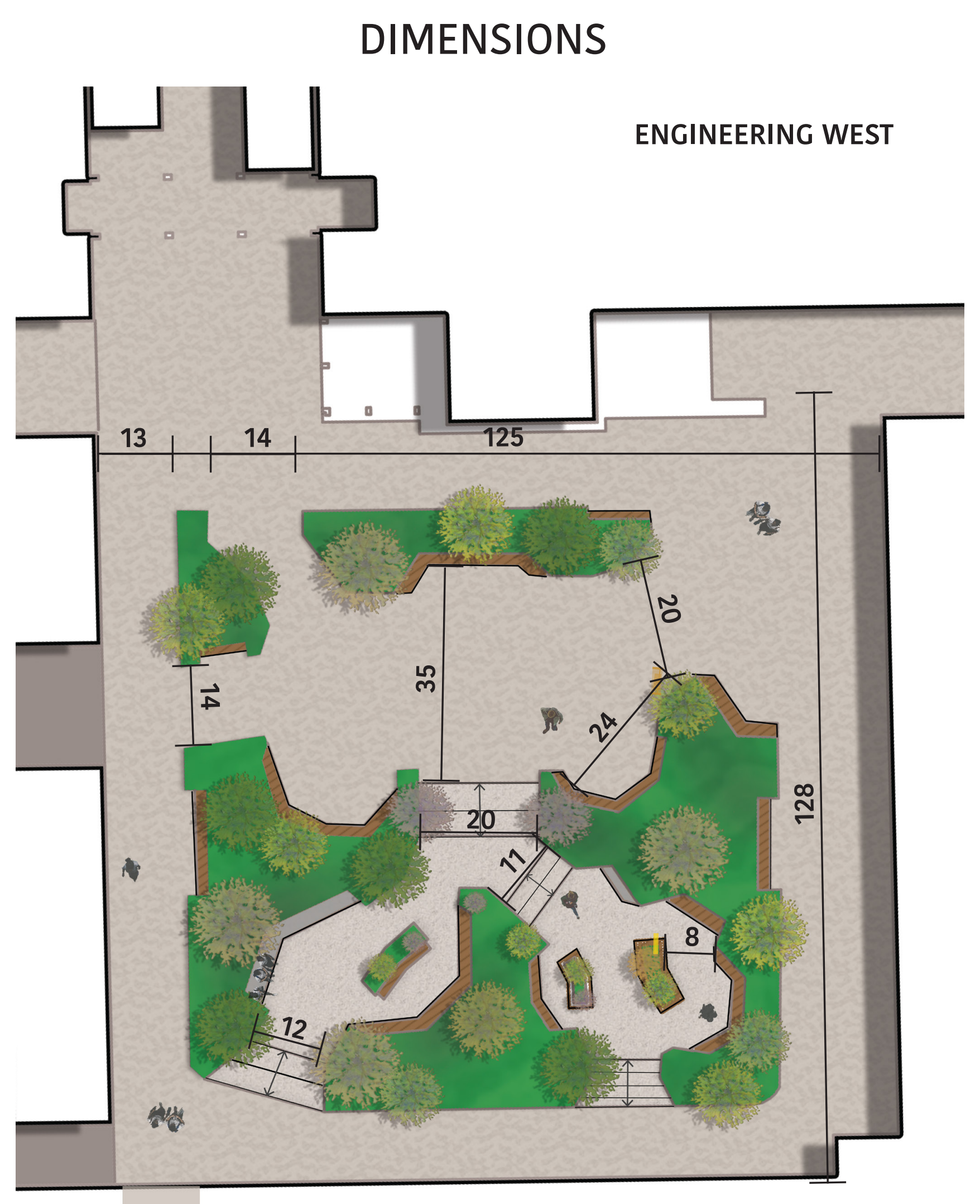

ENGINEERING WEST 


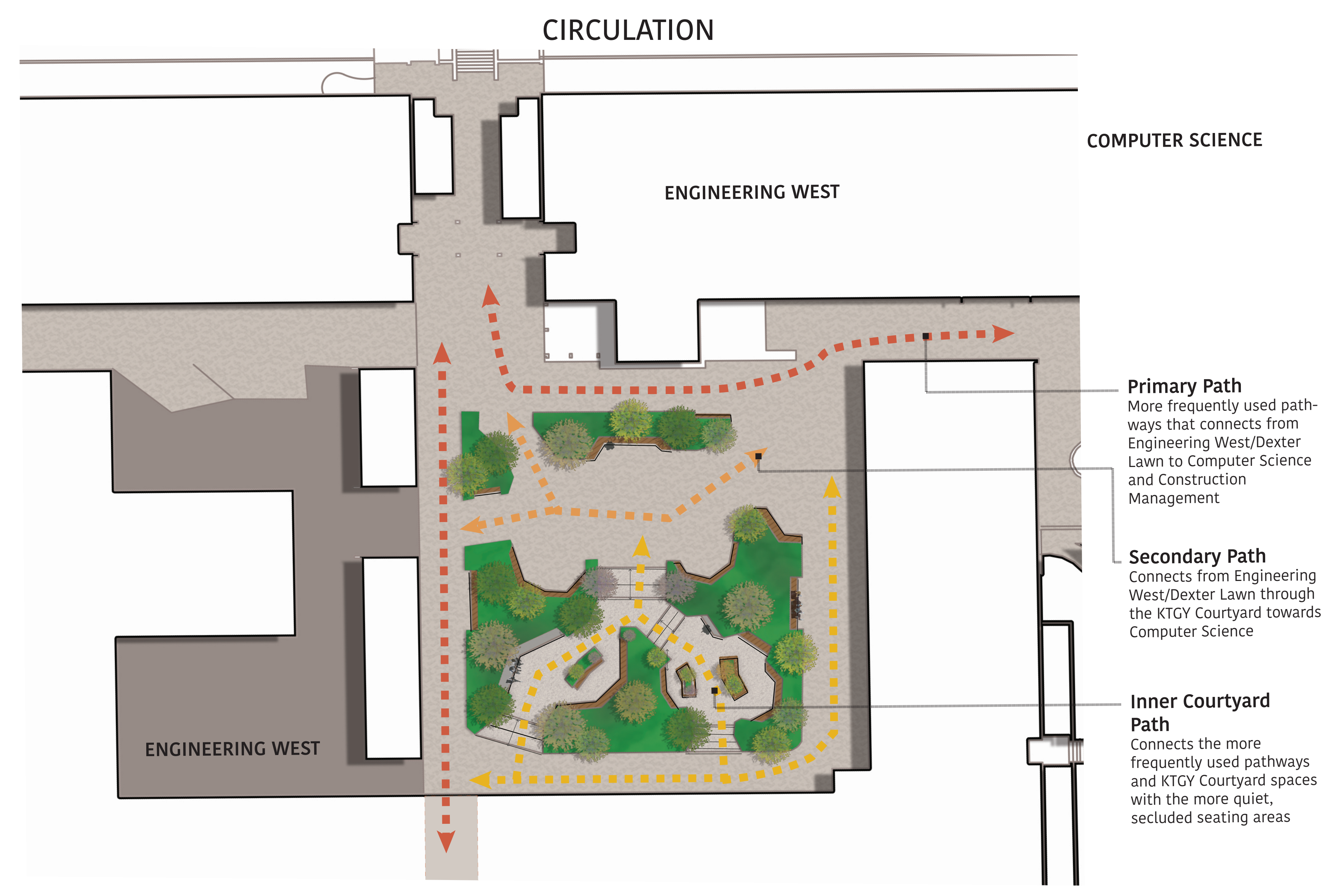




\section{ACTIVITIES}

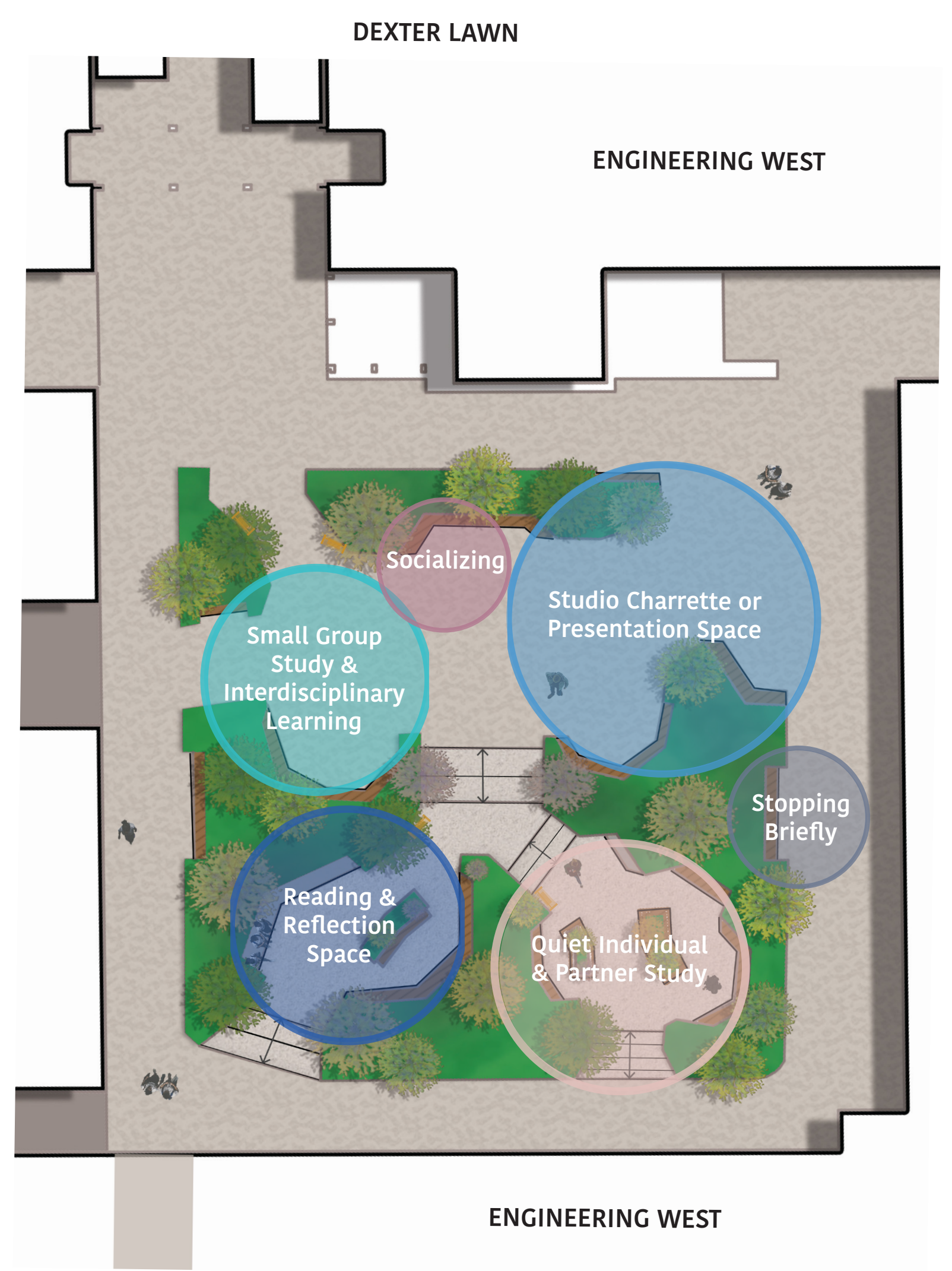

CONSTRUCTION MANAGEMENT 


\section{FEATURES}

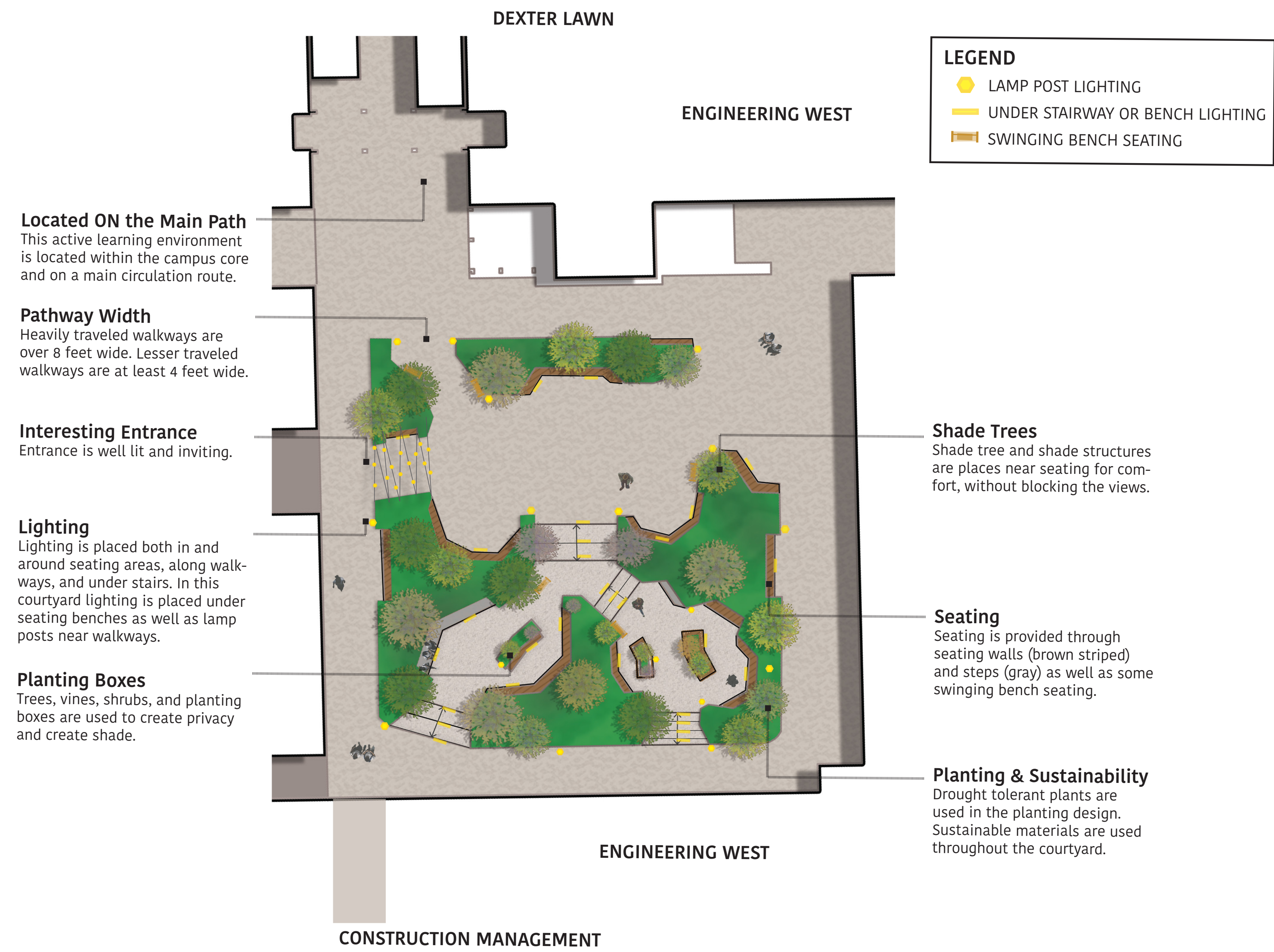




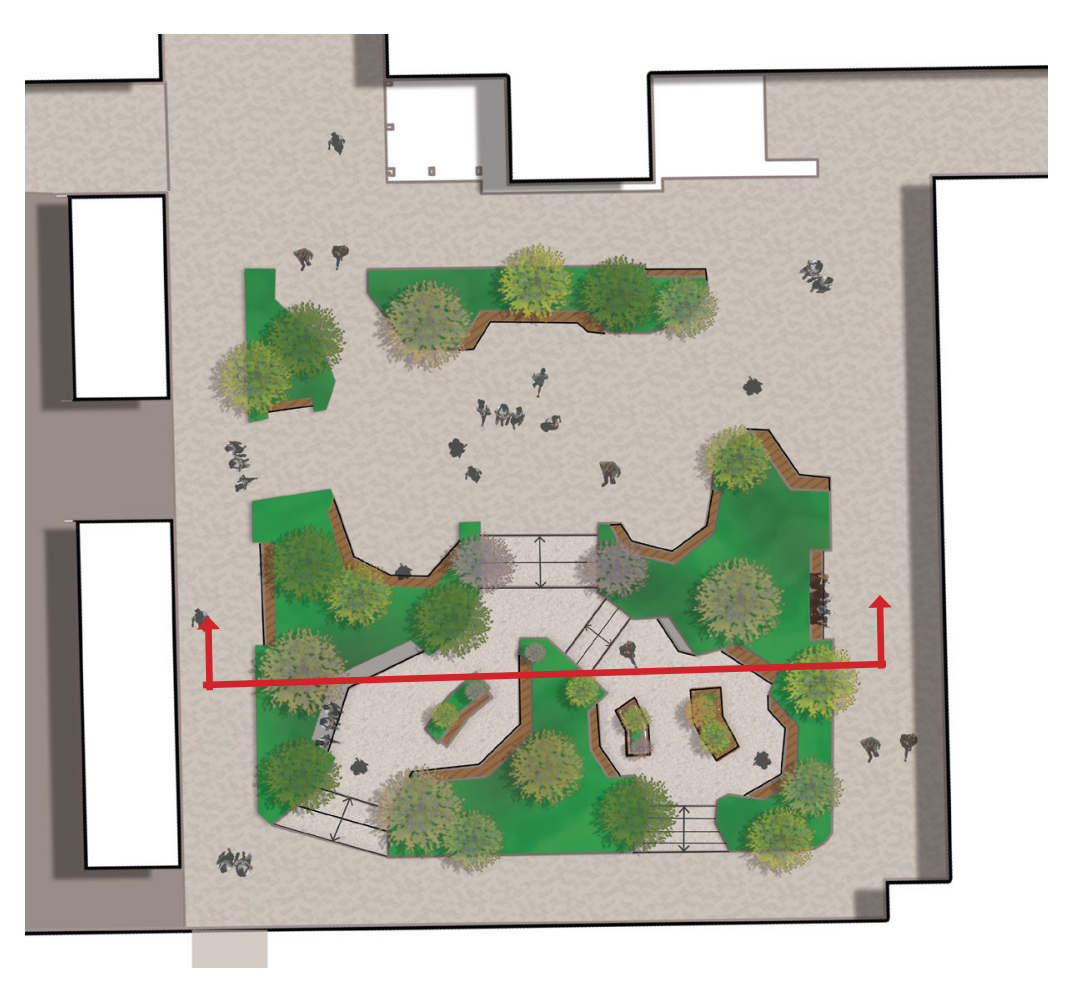

\section{SECTION}

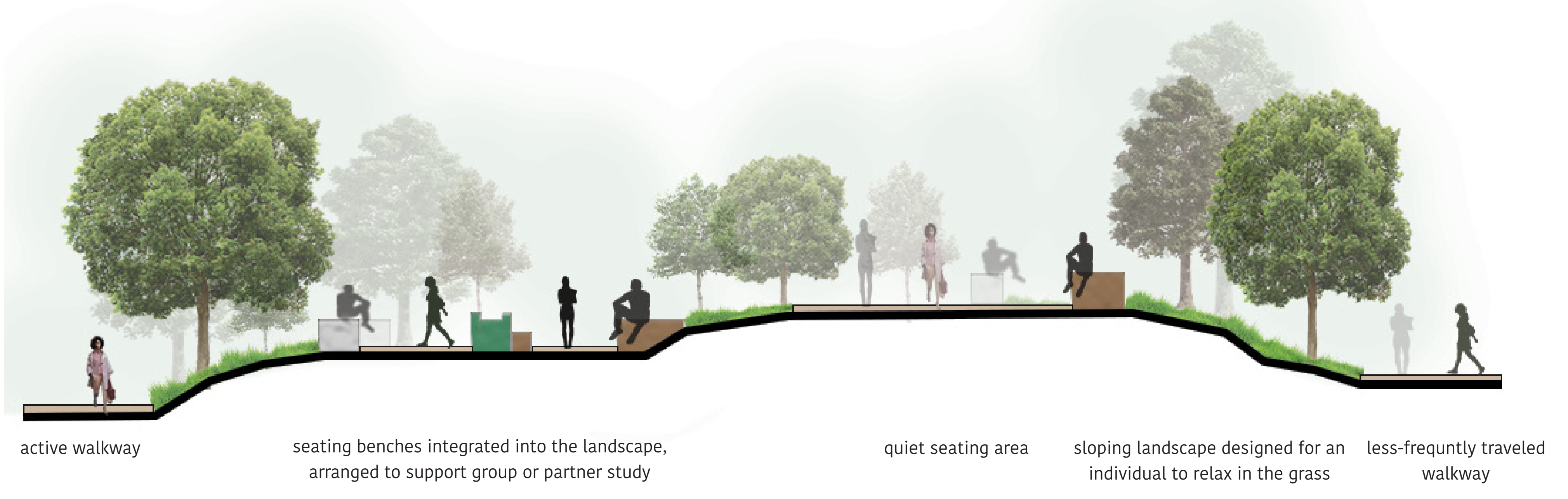




\section{CONCLUSION}

\section{Final Remarks}

The overall goal of this project was to expand upon the research conducted by designers of both university campuses and effective outdoor learning spaces to fully understand the principles of an outdoor learning space on a university campus. By presenting research and dialogue about the importance of outdoor learning spaces, categorizing and creating typologies for higher education campus outdoor learning spaces, and creating design principles and design examples of these learning environments, this project will pave the way for the design of future Outdoor Learning Environments.

Listening to and observing how the students interact with current outdoor environments should be considered when designing future Outdoor Learning Environments. The design of the space should support the uses or activities of the particular outdoor environment. Additionally, it is important to collaborate with campus planning and university administration to discover what events or activities the university as a whole would like to host in each specific location. Identifying and partnering with various university stakeholders throughout the research and design process will not only result in an Outdoor Learning Environment that is frequently used but will also be enjoyed by all members of the campus community. 


\section{REFERENCES}

\section{Bibliography}

Cattell, V., Dines, N., Gesler, W., \& Curtis, S. (2007). Mingling, observing, and lingering: Everyday public spaces and their implications for well-being and social relations. Health \& Place. Retrieved from http://illinois-online.org/krassa/ps450/Readings/Cattell Mingling in public spaces and well being (smaller).pdf

APA. (2018). Great Public Spaces. Retrieved from https://www.planning.org/ greatplaces/Bell, P. (2009). Learning science in informal environments: people, places, and pursuits. Washington: National academies Press.

Gaines, T. A. (1998). The Campus as a Work of Art (1st ed.). New York: Praeger.

Goertz, P. (2015, April 20). What Does a 21st Century Classroom Look Like: Creativity. Retrieved from https://www.edutopia.org/discussion/ what-does-21st-century-classroom-look-creativity

Good Practice. (2020). Retrieved from https://www.outdoor-learning.org/ Good-Practice/Research-Resources/About-Outdoor-Learning
Kelly-Salo, J., \& Mellard, J. (2018, February 1). Outdoor Learning Environments. Retrieved from https://spaces4learning.com/articles/2018/02/01/outdoor-learning.aspx

Kennedy, M. (2011, August 1). The Great Outdoor Learning Environment. Retrieved from https://www.asumag.com/planning-design/facility-planning/article/20850529/the-great-outdoor-learning-environment

Kollie, E. (2015, January 1). How to Design Outdoor Learning Environments. Retrieved from https://spaces4learning.com/articles/2015/01/01/ outdoor-learning-environments.aspx

MINI hub installation in madrid rethinks the future of cities. (2018, March 1). Retrieved from https://www.designboom.com/architecture/minihub-madrid-creative-space-installation-enorme-studio-02-28-2018/ 
Rouse, H. N. (2011, May 6). College Struggles With Social Space: News: The Harvard Crimson. Retrieved from https://www.thecrimson.com/article/2011/5/6/space-social-students-harvard/

Scholl, K. G., \& Gulwadi, G. B. (2015). Learning Spaces, 4(1).

Speake, J., Edmondson, S., \& Nawaz, H. (2013). EVERYDAY ENCOUNTERS WITH NATURE: STUDENTS' PERCEPTIONS AND USE OF UNIVERSITY CAMPUS GREEN SPACES. Retrieved from https://www.semanticscholar.org/paper/EVERYDAY-ENCOUNTERS-WITH-NATURE:-STUDENTS'-AND-USE-Speake-Edmondson/9184eaebdf313665a6ae97dgf3adefa92f829d7a

Strange, C. C., \& Banning, J. H. (n.d.). Designing for Learning: Creating Campus Environments for Student Success (2nd ed.).

Strange, C. C., \& Banning, J. H. (2001). Educating by design: creating campus learning environments that work. San Francisco: Jossey-Bass.
Think Outside the Building. (2010, April 30). Retrieved from https://www.asumag.com/bonus-content/article/20850535/think-outside-the-building

University of Denver. (2007). Open Space Typologies, 1-14. Retrieved from https://www.du.edu/architect/media/documents/Appendix_G.pdf

Whyte, W. H. (2018). The Social Life of Small Urban Spaces. New York: Project for Public Spaces.

Worpole, K., \& Knox, K. (2008). The Social Value of Public Spaces. York: Joseph Rowntree Foundation. 